\title{
Technology investment in pollution control in sub- Saharan Africa : the case of the Nigerian manufacturing industry
}

Citation for published version (APA):

Adeoti, J. (2001). Technology investment in pollution control in sub-Saharan Africa : the case of the Nigerian manufacturing industry. [Doctoral Thesis, Maastricht University]. Datawyse / Universitaire Pers Maastricht. https://doi.org/10.26481/dis.20010530ja

Document status and date:

Published: 01/01/2001

DOI:

10.26481/dis.20010530ja

Document Version:

Publisher's PDF, also known as Version of record

Please check the document version of this publication:

- A submitted manuscript is the version of the article upon submission and before peer-review. There can be important differences between the submitted version and the official published version of record.

People interested in the research are advised to contact the author for the final version of the publication, or visit the DOI to the publisher's website.

- The final author version and the galley proof are versions of the publication after peer review.

- The final published version features the final layout of the paper including the volume, issue and page numbers.

Link to publication

\footnotetext{
General rights rights.

- You may freely distribute the URL identifying the publication in the public portal. please follow below link for the End User Agreement:

www.umlib.nl/taverne-license

Take down policy

If you believe that this document breaches copyright please contact us at:

repository@maastrichtuniversity.nl

providing details and we will investigate your claim.
}

Copyright and moral rights for the publications made accessible in the public portal are retained by the authors and/or other copyright owners and it is a condition of accessing publications that users recognise and abide by the legal requirements associated with these

- Users may download and print one copy of any publication from the public portal for the purpose of private study or research.

- You may not further distribute the material or use it for any profit-making activity or commercial gain

If the publication is distributed under the terms of Article 25fa of the Dutch Copyright Act, indicated by the "Taverne" license above, 


\section{Technology Investment in Pollution Control in Sub-Saharan Africa: The Case of the Nigerian Manufacturing Industry}

\section{PROEFSCHRIFT}

ter verkrijging van de graad van doctor aan de Universiteit Maastricht,

op gezag van de Rector Magnificus, Prof. dr. A.C. Nieuwenhuijzen Kruseman volgens het besluit van het College van Decanen, in het openbaar te verdedigen op woensdag 30 mei 2001 om 16.00 uur

John Olatunji Adeoti 
Promotors:

Prof. Dr. R. Cowan

Prof. Dr. L.K. Mytelka

Co-promotor:

Dr. R. Kemp

Beoordelingscommissie:

Prof. dr. L.L.G. Soete (voorzitter)

Prof. dr. A. Nentjes (Rijksuniversiteit Groningen)

Dr. Th. Ziesemer

The following institutions sponsored this $\mathrm{PhD}$ thesis research:

United Nations University Institute for New Technologies, Maastricht, The Netherlands

African Economic Research Consortium, Nairobi, Kenya 


\section{Dedicated to}

\section{JESUS, \\ my Life and Inspiration;}

\section{Detola,}

for her friendship and untiring support;

and our children, Tomi, Temi \& Tolu, for the many months they missed my company. 



\section{TABLE OF CONTENTS}

List of Illustrations

Acknowledgements

\section{INTRODUCTION}

1.1. Background and Problem Statement

1.2. Research Questions and Objectives

1.3. Outline of the Thesis

2. TECHNOLOGY DIFFUSION AND ADOPTION CAUSALITIES

2.1. Introduction

2.2. Technology Diffusion: Outcome of Adoption Decisions

2.3. An Overview of the Scope of Diffusion

2.4. Models Based on Implicit Tradition of Old versus New Technologies

2.5. Adoption of Technology and the Supply-side Factors

2.6. Diffusion and Competitive Selection

2.7. Conclusion

\section{ADOPTION OF ENVIRONMENTALLY BENIGN TECHNOLOGIES: A CONCEPTUAL VIEWPOINT}

3.1. Introduction

3.2. Firm Level Adoption Behaviour: a Model of Adoption Causalities for Environmentally Benign Technologies

3.2.1. Technology response for pollution abatement or prevention

3.2.2. Adoption causalities in perspective

3.3. A Trajectory of Firms' Technology Responses to Environmental Policy

3.3.1. Stage 1: Weak regulation, limited technology responses

3.3.2. Stage 2: Appreciable regulation, notable technology responses

3.3.3. Stage 3: Strong regulation, prominent technology responses

\section{ADOPTION OF ENVIRONMENTALLY BENIGN TECHNOLOGIES IN} NIGERIAN MANUFACTURING

4.1. Introduction

4.2. Environmental Regulation in Nigeria $\quad 60$

4.2.1. The institutional framework 
4.3. A Framework for the Analysis of the Adoption of Environmentally Benign

Technologies in Nigerian manufacturing

4.3.1. Environmental policy as a major driver of adoption

4.3.2. Auxiliary drivers of adoption

\section{RESEARCH METHODOLOGY}

5.1. Introduction

5.2. Sampling and Data Collection

5.3. Research Questionnaires

5.4. Econometric Analysis

\section{TRENDS IN TECHNOLOGY RESPONSES FOR WATER POLLUTION CONTROL IN NIGERIAN MANUFACTURING}

6.1. Introduction

6.2. Characteristics of Nigerian Manufacturing

6.2.1. Firm size distribution

6.2.2. Affiliation to multinational enterprises

6.2.3. Distribution of age in production

6.2.4. Human and physical capital

6.2.5. Sources of technological knowledge

6.2.6. Environmental management

6.3. Trends in Technology Responses for Industrial Water Pollution Control

6.3.1. Technology responses for pollution abatement (TPA)

6.3.2. Technology responses for pollution prevention (TPP)

6.3.3. Sources of technical solutions to TPA/TPP problems

6.4. Obstacles to Technology Responses for Water Pollution Control

\section{TECHNOLOGY RESPONSES FOR WATER POLLUTION CONTROL IN NIGERIAN MANUFACTURING: AN ANALYSIS OF ADOPTION CAUSALITIES}

7.1. Introduction

7.2. The Empirical Model

7.3. Adoption Causalities for Environmentally Benign Technologies (EBTs)

7.3.1. Environmental policy as a major driver of EBT adoption

7.3.2. Auxiliary drivers of EBT adoption

7.4. Adoption Causalities for Technology Responses for Water Pollution Abatement (TPA)

7.4.1. Environmental policy as a major driver of TPA adoption 
7.5. Adoption Causalities for Technology Responses for Water Pollution Prevention (TPP)

7.5.1. Environmental policy as a major driver of TPP adoption

7.5.2. Auxiliary drivers of TPP adoption

7.6. Conclusion: A Synthesis of Adoption Causalities

\section{CASE STUDY ILLUSTRATIONS OF FIRMS' TECHNOLOGY} RESPONSES FOR WATER POLLUTION CONTROL IN NIGERIAN MANUFACTURING

8.1. Introduction

8.2. The Case Studies: Firms in the Food and Beverages Sector

8.3. The Case Studies: Firms in the Textiles Sector

\section{SUMMARY AND CONCLUSIONS}

9.1. Introduction

9.2. Major versus Auxiliary Driver Hypothesis

9.3. The Empirical Results in Brief

9.4. Policy Implications

9.5. Directions for Further Research

REFERENCES

\section{APPENDICES}

1. Instruments of Environmental Regulation in Nigeria

2. Effluent Limitation Guidelines in Nigeria

3. Additional Effluent Limitation for Wastewater Discharge for Food \& Beverages and Textile Sectors in Nigeria

4. Glossary of Wastewater Treatment Plants 


\section{List of Illustrations}

\section{Tables}

1.1. Manufacturing value added of food \& beverages and textile sectors of selected sub-Saharan African countries in 1995 (US\$ million)

1.2. Industry shares of emissions of organic water pollutants, 1993

1.3. Growth rates of the Nigerian economy

3.1. Incentives for innovation under various pollution control arrangements

3.2. Stages in environmental regulation and technology responses by industrial firms

4.1. FEPA research and linkage centres

4.2. Regulators' perception of obstacles to firms' compliance monitoring and enforcement in Nigerian industry

4.3. Threshold values of allowable concentrations of certain pollutants in effluents into surface waters in Hungary, Nigeria, and Germany

4.4. Classification of auxiliary drivers of adoption of environmentally benign technologies in developing countries

4.5. Number and sources of foreign technology agreement registered in Nigeria between 1990 and 1992

5.1. Distribution of firms in Nigerian food \& beverages and textile sectors in 1992 (according to number of persons employed)

6.1. Distribution of sample firms according to size

6.2. Multinational companies' involvement in Nigerian manufacturing

6.3. Age distribution of sample firms

6.4. Age distribution of MNE affiliates vs. Local firms

6.5. Local and foreign skill intensity ratios of the research sample firms

6.6. Mean proportion of workers according to their educational qualification

6.7. Source of main production equipment

6.8. Sources of technological knowledge or innovation

6.9. Adoption of industrial wastewater treatment plant in Nigerian manufacturing

6.10. Number of TPA adoption according to time and sectoral distribution of adoption

6.11. TPA adoption by affiliates of multinational enterprises (MNE)

6.12. Number of TPP adoption according to time and sectoral distribution of adoption

6.13. TPP adoption by affiliates of multinational enterprises

6.14. Sources of technical solution to TPA/TPP problems

6.15. Obstacles to the adoption of environmentally benign technologies (EBTs)

6.16. Regulators' perception of obstacles to firms' compliance with Nigerian effluent limitation regulation (S.I.8/S.I.9 law)

6.17. Sectoral distribution of most important obstacles to the adoption of environmentally benign technologies (EBTs)

7.1. Distribution of types of water pollution control technologies adopted by the sample firms 
7.2. Summary of the logistic regression for technology responses for water pollution control (i.e. EBT adoption)

7.3. Correlation matrix of the logistic regression estimated coefficients for EBT adoption

7.4. Final model for the logistic regression for technology responses for water pollution control (i.e. EBT adoption)

7.5. Summary of the logistic regression for technology responses for water pollution abatement (i.e. TPA adoption)

7.6. Correlation matrix of the logistic regression estimated coefficients for TPA adoption

7.7. Final model for the logistic regression for technology responses for water pollution abatement (i.e. TPA adoption)

7.8. Summary of the logistic regression for technology responses for water pollution prevention (i.e. TPP adoption)

7.9. Correlation matrix of the logistic regression estimated coefficients for TPP adoption

7.10. Final model for the logistic regression for technology responses for water pollution prevention (i.e. TPP adoption)

8.5. Summary of reasons for TPA adoption by case study firms

\section{Figures}

1.1. Structure of Nigerian manufacturing value added, 1980-1994.

1.2. Industry shares of emissions of organic water pollutants, 1993.

2.1. A graphical illustration of 'diffusion jumps' 20

2.2. Relationship between technology adoption, profitability and firm size 27

2.3. The distribution of firm characteristics in a probit framework

2.4. Technology diffusion as an outcome of the interactions between the forces of 'technology push' and 'demand pull'

3.1. A framework for the analysis of the adoption of environmentally benign technologies

3.2. A trajectory of technology responses to environmental policy in industry as national development progresses 
7.1. A histogram of predicted probabilities of EBT adoption based on model presented in table 7.4

7.2. A histogram of predicted probabilities of TPA adoption based on model presented in table 7.7.

7.3. A histogram of predicted probabilities of TPP adoption based on model presented in table 7.10.

\section{Boxes}

8.1. FB1 environmental strategy

8.2. Water hyacinth aided biological wastewater treatment at FB1 156

8.3. Discovery of 'Oso biodegrader plus' (OBD $\left.{ }^{+}\right)$

8.4. Main features of the statement of environmental responsibility by FB3's parent company

8.5. A centralised industrial wastewater treatment plant

8.6. Summary of FB5's statement of environmental policy

8.7. Main features of FB6's environmental policy statement 


\section{Acknowledgements}

"I will extol Thee, O LORD; for Thou hast lifted me up" - Psalm 30:Ia.

So many people have contributed in positive ways to make this dissertation an evidence of my little contribution to the definition and strengthening of the technological path to environmentally sustainable industrial development in developing countries. First, I would like to specially thank my promoters, Lynn Mytelka and Robin Cowan, and my supervisor, René Kemp. I am profoundly grateful for their intellectual guidance and support. I also wish to thank members of the PhD examining committee (Luc Soete, Andries Nentjes and Thomas Ziesemer) for their efforts in examining my thesis.

I am grateful to Luc Soete for his encouraging and very useful comments on my work in the course of the $\mathrm{PhD}$ research. I thank Anthony Arundel for his help during the preparation of the research questionnaires and data analysis. Corien Gijsbers deserves many thanks for her outstanding administrative support. I thank Sunil Mani for his guidance as UNU/INTECH's dean of students and his suggestions for the thesis. I am sincerely grateful to Charles Cooper, Anthony Bartzokas, Joonghae Suh, Swasti Mitter, Bart Verspagen, Sam Wangwe, and Shulin Gu from whose comments I have benefited at various stages of this research work. Particular mention should be made of Charles for his support as my director at the UNU/INTECH before his retirement in March 2000. To many other colleagues (former \& present) and friends at MERIT and UNU/INTECH who offered helpful comments/criticisms especially during my seminars at the UNU/INTECH and CERES PhD workshops, I say "thank you!"

I wish to express my gratitude to the United Nations University Institute for New Technologies (UNU/INTECH) not only for the two year fellowship award granted me at the beginning of the doctoral programme, but also for the continuous institutional support all through the duration of the $\mathrm{PhD}$ project. I also gratefully acknowledge the financial support of the African Economic Research Consortium, Nairobi, Kenya through the $\mathrm{PhD}$ thesis research grant. I am sincerely thankful to the United Nations University Institute of Advanced Studies (UNU/IAS), Tokyo, Japan for the fellowship award that aided my smooth completion of the dissertation.

I thank the UNU/INTECH librarian, Ad Notten for his untiring support for my many requisitions. Jane Williams was of much help, and gave the warmth needed to enjoy a research stay in the cool and calm environment of UNU/INTECH. I must thank my colleague UNU/INTECH PhD fellows (Noi Kwanjai, Ali Syed, Norman Dytianquin, Djono Subagjo) for their pleasant and respectable company. I am sincerely grateful to Enzo Ciarnella (Chief of Administrative \& Programme Services), Arnold Vermeer (computer assistant) and all UNU/INTECH support staff for their cooperation during my research at UNU/INTECH. In the same vein, I wish to thank Wilma Coenegrachts and Silvana de Sanctis of MERIT for their support. 
I am grateful to Olu Ajakaiye, the Director General of Nigerian Institute of Social and Economic Research (NISER), Ibadan, for granting me the opportunity to carry out my fieldwork at NISER. I also thank his predecessor, Dotun Phillips, who earlier granted the approval. I sincerely thank the staff of Business and Technology Development department of NISER, especially G.O.A. Laditan (director) and Banji Oyeyinka for their support, which facilitated the speedy completion of my fieldwork. I also thank Femi Olokesusi for his support during my stay at NISER.

The fieldwork was in no small measure facilitated by the cooperation of the Nigerian environmental regulators. I wish to thank the officers and staff of the compliance monitoring and enforcement (CME) department and zonal offices of the Federal Ministry of Environment (former Federal Environmental Protection Agency), and the various State Environmental Protection Agencies (SEPAs) that participated in this research. At the Federal Ministry of Environment, I am grateful to Dr. I.U. Onyekwelu (HOD, CME), Dr. Idris Goji (AD, CME), Mr. Akin Awobamise (zonal director, Ibadan), Mr. A.A. Akinsanya, Mr. Femi Adegbite, Mr. Omoniyi, Mrs. A.V. Enemali, Dr. O.A. Adefemi (zonal director, Portharcourt) and Mr. Sani Mamman Katsina (CES, zonal office, Kaduna). At the Ogun SEPA, I especially thank Dr. Koya Adedoyin $(\mathrm{GM})$, Mr. Muyiwa Adetimilehin (AD) and Mr. Akinola (AD). At the Oyo SEPA, my special thanks to Mr. F.S. Adeyemo (GM). At the Lagos SEPA, I thank Dr. Olatokunbo Adedeji (GM), Dr. (Mrs.) Titi Anibaba (DGM \& HOD pollution control), Mrs. Abimbola Jijoho-ogun and Mrs. Onisarotu. I wish to express my profound gratitude to Mrs. Jijoho-ogun, Mr. Adetimilehin and Mr. Akinsanya for their outstanding support during our several company visits.

I thank the company chief executives, plant managers, officers and staff in the various manufacturing firms that provided the empirical information for this research. Without their cooperation this project would have been a mission in the impossible.

I wish to thank my brothers and sisters in the Gospel Group, Oritamefa, Ibadan and Express Road Baptist Church, Ibadan, Nigeria for their prayers. In particular, I thank Solomon Adeleke for his brotherly love. Finally, I am deeply grateful to my bosom friend and sweetheart for being my 'help meet' in deed. Detola, we have fought together, and thank God, we have won together. To our good and great God be all the glory! 


\section{Chapter One}

\section{INTRODUCTION}

\subsection{Background and Problem Statement}

While issues relating to the topic of "technology and the environment" have been widely studied in developed countries, there remains a paucity of understanding of how environmental issues could be integrated into the industrial and technological development process in developing countries, particularly in Africa. In this respect, the environmental performance of manufacturing enterprises is one of the major concerns. Environmental performance of firms is largely determined by the technologies employed for production activities, and the organisation of these activities to minimise or prevent their undesirable impacts on the natural environment, either through the use of pollution abatement technologies or technological innovation that reduce pollution at the source. The crucial role that technology thus plays, has underscored the importance of the study of technology adoption behaviour of firms as a key to understanding the economic and social implications of measures designed to promote environmentally friendly behaviour of industrial firms.

The external diseconomy of industrial production activities could appear in the form of water, land or air pollution. While all the three aspects of pollution are important, in order to make the study herein reported manageable within available resources, we have streamlined the investigation to firms' technology responses that are aimed at curbing the undesirable effects of water pollution. Besides, industrial wastewater pollution has traditionally been the focus of regulation in developing countries (see Dasgupta et al, 1998, p.3; Hettige et al, 2000, p.455). It is therefore not unlikely that industrial water pollution control policies may present a good opportunity to study technology responses to the imperatives of environmentally sustainable industrialisation in developing countries.

The need to conserve fresh water resources has been very crucial to human development, and thus features prominently in the sustainability debate. The main source of the world fresh water is surface waters, particularly the rivers and streams, which form the natural source of water that are suitable for treatment for both domestic and commercial uses. Added to this is water in underground aquifers which are not always accessible, and where accessible may not always be suitable for human or industrial consumption. Apart from the constraint of population growth, it is widely acknowledged that economic activities, particularly manufacturing activities, have introduced further stress on world fresh water resources through pollution (World Bank, 1992, RIVM/UNEP, 1997; Rosegrant, 1999). 
Furthermore, water pollution is an environmental problem that could cut across national regions and boundaries,' and it has been noted as a major concern among the adverse effects of industrial activities on the natural environment. Like other negative impacts of industrialisation, the effects are more pronounced in developed countries and abatement/preventive measures are accordingly more advanced. However, while the consequences of water pollution are equally alarming in developing countries, the measures for alleviating or preventing the social costs of these externalities are generally acknowledged as not yet well developed (Reed, 1992; O'Connor, 1994). In fact, the current reality is that, whereas rivers in rich countries have become steadily cleaner in recent decades; rivers in the poorest developing countries, by contrast, have become more polluted. An estimated $90 \%$ of sewage (from various sources) in developing countries are discharged into surface waters without treatment. In addition, supplies of fresh water that may dilute the sewage are dwindling in many areas (The Economist, March 21st, 1998; Rosegrant, 1999). With respect to manufacturing industry, technology investment in pollution control is an important means of mitigating this trend of water pollution. Consequently, this study investigates industrial firms' technology responses that are aimed at solving water pollution problems with a focus on Nigerian manufacturing industry. From evidence presented by Ohagi (1988) and Chokor (1988), industrial wastewater pollution is perceived as a serious environmental problem in Nigeria. ${ }^{2}$

The challenge of industrialisation remains daunting in many developing countries, especially in Africa. Though the experiences of some newly industrialising countries of Southeast Asia have demonstrated that windows of opportunities could exist for catching-up that may not take the conventional path of traditional industry (see Perez and Soete, 1988), development essentially remains a process that has the industry, particularly traditional manufacturing enterprises at its core. Accordingly, for countries of sub-Saharan Africa, traditional manufacturing remains a major focus in the development strategy. Moreover, the apparent relatively low level of physical and human capital makes the leap into advanced manufacturing activities and production of high technology goods difficult. Thus, evidence abound showing that the manufacturing industry in these countries focuses on relatively low technology industrial production activities (Stewart et al, 1992; Jalilian et al, 2000). Among the

\footnotetext{
' The Rhine River is a good illustration of this phenomenon. It flows through the Ruhr industrial region in Germany, and entered the sea at the Dutch coastal line. Over the years, the protection of the Rhine has been a major concern among the countries (France, Germany, Luxembourg, Netherlands, and Switzerland) that share the use of the Rhine resources. This led to the formation of the International Commission for the Protection of the Rhine in 1976 (Kraemer and Jager, 1997). Similar organisations have emerged for the protection of waters in developing countries. In Africa, examples include the Mano River Union (involving Guinea, Liberia and Sierra Leone); Organisation for the development of Senegal River (involving Gambia, Mali, Mauritania and Senegal); and the Lake Chad River Basin Commission (involving Cameroon, Chad, Niger and Nigeria). (Olokesusi, 1990).

${ }^{2}$ Ohagi (1988) and Chokor (1988)'s empirical evidence are respectively from studies on the impact of industrial wastewater effluents on receiving waters and public opinion surveys in one of Nigeria's urban industrial centres of Benin. Nigeria is also recently reported to be among the 48 developing countries that may run out of fresh water supplies in 30 years time; industrial wastewater pollution being one of the identified causes ('The Guardian', Nigeria, 02.11.1998).
} 
manufacturing sectors in this category, the food \& beverages and textile sectors are prominent. Illustrating this for some selected sub-Saharan African countries for which data are available, except for South Africa, the two sectors generally accounted for more than $40 \%$ of manufacturing value-added in 1995 (see table 1.1). Thus, while it is arguable that sub-Saharan Africa has experienced 'de-industrialisation' in recent decades (Lall, 1999a; Jalilian and Weiss, 2000), the contribution of these two sectors to environmentally unsustainable industrialisation may be quite significant if appropriate technical change to mitigate or prevent pollution is not adequately encouraged.

Table 1.1 : Manufacturing Value-added of Food \& Beverages and Textile Sectors of Selected sub-Saharan African Countries in 1995 (million US Dollars)

\begin{tabular}{|c|c|c|c|c|c|c|c|}
\hline \multirow[t]{2}{*}{ Country } & \multicolumn{3}{|c|}{ Manufacturing VA } & \multirow{2}{*}{$\begin{array}{l}\text { Total } \\
\text { MVA }\end{array}$} & \multicolumn{3}{|c|}{ Share of VA in Total MVA (\%) } \\
\hline & $F / B^{*}$ & Textile & $F / B+$ Textile & & $F / B$ & Textile & $F / B+$ Textile \\
\hline Cameroon & 159 & 90 & 249 & 539 & 29.5 & 16.7 & 46.2 \\
\hline Cote D'Ivoire & 306 & 152 & 458 & 1395 & 21.9 & 10.9 & 32.8 \\
\hline Kenya & 336 & 47 & 383 & 814 & 41.3 & 5.8 & 47.1 \\
\hline Nigeria & 2595 & 823 & 3418 & 7884 & 32.9 & 10.4 & 43.4 \\
\hline South Africa & 4688 & 923 & 5611 & 29071 & 16.1 & 3.2 & 19.3 \\
\hline Zambia & 163 & 44 & 207 & 450 & 36.2 & 9.8 & 46.0 \\
\hline Zimbabwe & 589 & 136 & 725 & 1670 & 35.3 & 8.1 & 43.4 \\
\hline
\end{tabular}

* Food \& Beverages sector

Source: Extracted from data in UNIDO (1997).

In addition to the relative importance of the food \& beverages and textile sectors in sub-Saharan African manufacturing, the two sectors are also generally acknowledged as remarkable water pollution intensive sectors, especially in developing countries. Accordingly, the Nigerian case study presented in this dissertation focuses on the two sectors. Figure 1.1 depicts the relative importance of the two sectors in Nigerian manufacturing. The two sectors are among the four sectors that dominate Nigerian manufacturing. 


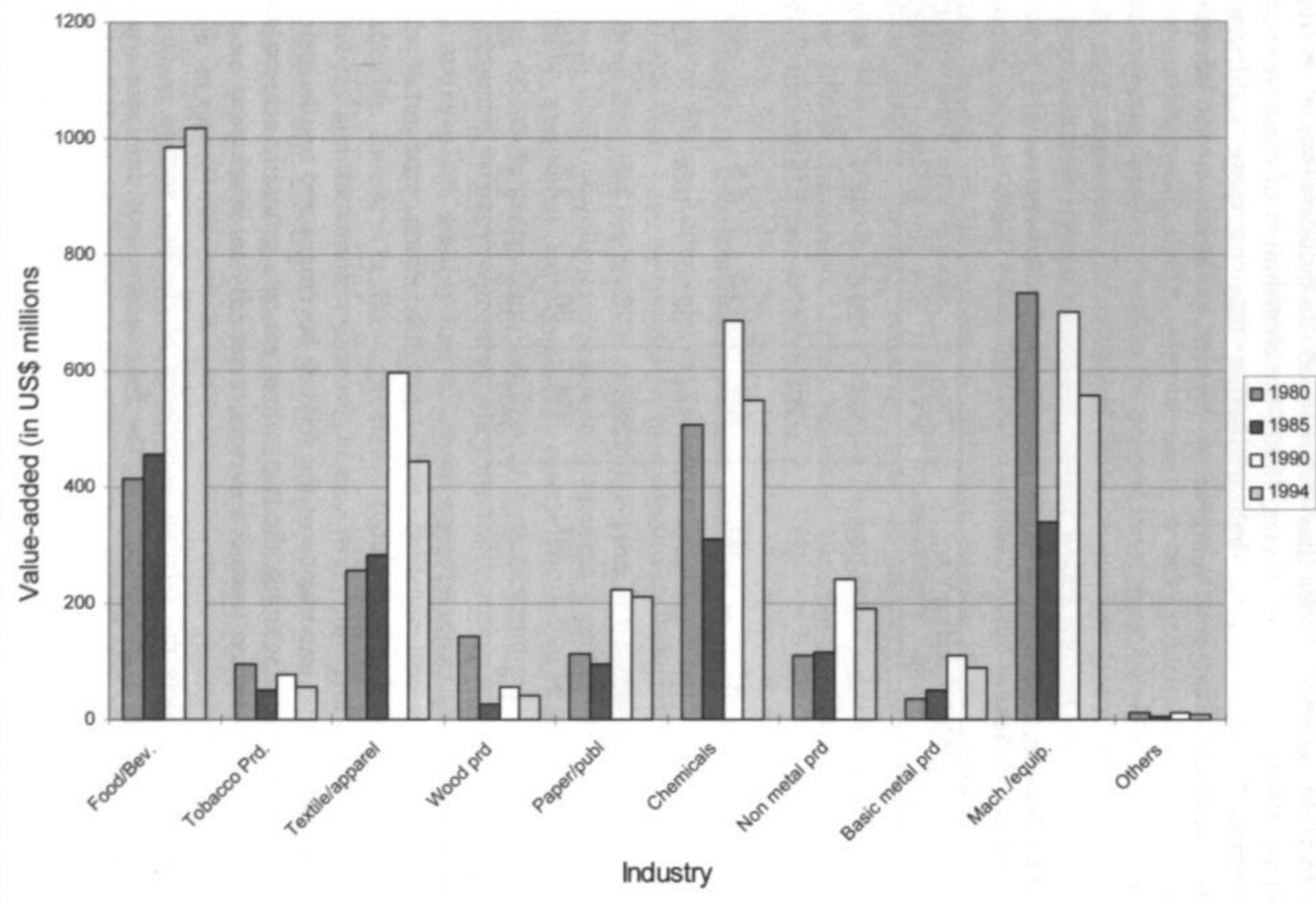

Fig. 1.1: Structure of Nigerian Manufacturing Value Added, 1980-1994.

Source: Based on data in UNIDO (1996). 
Table 1.2 presents statistics on the major water pollution intensive manufacturing sectors. ${ }^{3}$ The food \& beverages sector contributes an average of about one-third $(32.4 \%)$ of the emissions of organic ${ }^{4}$ pollutants in the group of seven most industrialised countries. In all these countries, with the exception of the United States, ${ }^{5}$ the food \& beverages sector is remarkably the most important water polluter. In developing countries as represented by the African countries on which data are available in table 1.2, the food \& beverages sector accounts for more than half $(55.4 \%)$ of the industrial wastewater pollution. Other selected developing countries show similar trends, though not as pronounced as in Africa. Thus, this sector is one of the most important industrial water polluter in both developed and developing countries. This notwithstanding, it is important to stress that table 1.2 indicates that the relative importance of the food processing ${ }^{6}$ industry for water pollution in developing countries is more serious when compared with developed countries. While pollution contribution from the food processing industry is less than $40 \%$ in each of the G-7 countries, it is generally well over $40 \%$ in each of the African countries shown. This could be explained from the transition from the agrarian economy to industrial economy, which has to do with processing of agricultural commodities. Moreover, the need to meet the food demand of developing countries necessitates a bias of industrial investments in favour of the sector. The sector is one of the most actively promoted industrial sectors in developing economies, particularly the less developed countries. According to Shaaeldin (1992), the food and beverages industry constitutes the largest industrial sector in Africa. ${ }^{7}$ The growing demand for food due to population growth

\footnotetext{
${ }^{3}$ Though the statistics presented in table 1.2 show only sectoral shares of emissions of organic water pollutants, it nevertheless gives a reasonable measure of the relative contribution of industrial sectors to water pollution problems. If the statistics are weighted or standardised to reflect the sectoral importance of each sector to the national economy, the relative importance of the sectoral contributions might be different from those shown. We however consider weighting unnecessary since the absolute emission from each sector is of much importance to the quality of receiving water system.
}

${ }^{4}$ When we speak of water pollution in general terms, the focus is usually on the impact of organic pollution, for which the food processing and textiles industries are regarded as major culprits. Organic pollutant, usually measured in terms of BOD or COD (respectively biochemical oxygen demand or chemical oxygen demand), is a generally accepted indicator of water pollution (Cropper and Oates, 1992, p.716; UNIDO, 1998; Hettige et al, 2000 , pp.448\&455). We however recognise that organic pollutants are not the only unwanted industrial emissions into water streams. There are more dangerous and toxic wastes, which may constitute worse threats to the environment. Where such exists (for example, in the chemical industry), they are closely monitored and treated peculiarly. It is nevertheless noteworthy that technologies that control BOD discharges tend to reduce the levels of other pollutants in wastewater (Megat and Viscusi, 1990, p.335).

${ }^{5}$ The exception of the United States only arises because USA dominates the world pulp and paper industry (see Tables 1 and 2 of Lundan, 1996, pp.46-47). Otherwise the food and beverages industry is also the most important water polluter as in other industrial economies.

${ }^{6}$ For definitional purposes, in this study the food processing industry refers to the food and beverages sector, and we will thus use the two terms interchangeably.

${ }^{7}$ For Nigeria, while there has generally been apparent decline or stagnation in value added of other manufacturing industries (see table 1.3), there have nevertheless been increases in the absolute values and relative shares of the manufacturing value added (MVA) in the food and beverages industry. The MVA for food and beverages industry increased from US\$416 million (17.2\% share of total MVA) in 1980 to US\$1019 million 
points to increasing activities of the food processing industry, and by implication, increasing need to control the attending impacts on the environment.

Like the food \& beverages sector, the textiles sector is also portrayed by table 1.2 as one of the most important water polluters especially in developing countries. Understandably, the sector contributes an average of only $8.3 \%$ of organic water pollutants in the G7-group apparently because textile manufacturing is regarded as a sunset industry in most highly industrialised countries. However, the textiles sector ranked second only to the food \& beverages industry as a water pollution intensive sector in developing countries, contributing $12.1 \%$ of the organic water pollutants in 1993. For the African countries reported, the contribution is $13.1 \%$, indicating that the textiles sector is a worse water polluter in Africa when compared to other developing countries. Figure 1.2 presents a graphical illustration of the relative importance of the water pollution intensive manufacturing sectors. 
Table 1.2 : Industry shares of emissions of organic water pollutants, 1993.

\begin{tabular}{|c|c|c|c|c|c|c|c|c|}
\hline \multirow[b]{2}{*}{ Country } & \multicolumn{8}{|c|}{ Industry shares of emissions of organic water pollutants (in \%) } \\
\hline & $\begin{array}{l}\text { primary } \\
\text { metals }\end{array}$ & $\begin{array}{l}\text { paper } \\
\& \text { pulp }\end{array}$ & chemicals & $\begin{array}{l}\text { food \& } \\
\text { beverages }\end{array}$ & $\begin{array}{l}\text { stone, } \\
\text { ceramics, } \\
\text { and glass }\end{array}$ & textiles & wood & others \\
\hline Cameroon & 3.1 & 5.5 & 17.8 & 67.9 & 0.0 & 3.0 & 2.5 & 0.3 \\
\hline Egypt & 11.7 & 7.1 & 9.1 & 50.5 & 0.3 & 17.5 & 0.5 & 3.5 \\
\hline Ethiopia & 2.1 & 9.5 & 2.4 & 59.0 & 0.1 & 24.9 & 1.5 & 0.4 \\
\hline Kenya & 4.3 & 11.8 & 5.6 & 64.2 & 0.1 & 9.3 & 1.9 & 2.7 \\
\hline Nigeria* & 12.1 & 9.3 & 10.4 & 57.0 & 0.2 & 7.3 & 2.2 & 1.6 \\
\hline South Africa & 12.7 & 16.7 & 9.5 & 41.3 & 0.2 & 11.0 & 2.7 & 5.9 \\
\hline Tunisia & 15.8 & 8.0 & 7.0 & 46.6 & 0.3 & 17.0 & 0.7 & 4.5 \\
\hline Zambia & 3.5 & 9.4 & 7.5 & 63.4 & 0.2 & 12.4 & 1.6 & 2.1 \\
\hline Zimbabwe & 13.5 & 12.5 & 4.7 & 48.7 & 0.1 & 15.8 & 1.9 & 2.8 \\
\hline $\begin{array}{l}\text { Average for } \\
\text { selected African } \\
\text { countries }\end{array}$ & 8.8 & 10.0 & 8.2 & 55.4 & 0.2 & 13.1 & 1.7 & 2.6 \\
\hline Argentina & 7.7 & 11.8 & 7.7 & 57.4 & 0.3 & 8.6 & 1.5 & 5.1 \\
\hline Brazil & 10.4 & 13.5 & 9.1 & 45.8 & 0.3 & 11.5 & 3.0 & 6.4 \\
\hline Chile & 6.6 & 10.1 & 6.4 & 65.0 & 0.1 & 7.4 & 1.9 & 2.5 \\
\hline China & 22.0 & 10.0 & 14.0 & 33.3 & 0.4 & 11.5 & 0.4 & 8.3 \\
\hline India & 15.6 & 8.1 & 7.3 & 50.9 & 0.2 & 12.9 & 0.3 & 4.8 \\
\hline Indonesia & 2.4 & 2.3 & 8.3 & 51.8 & 0.2 & 7.7 & 22.0 & 5.4 \\
\hline Malaysia & 6.8 & 14.3 & 15.2 & 31.8 & 0.2 & 11.1 & 7.6 & 13.1 \\
\hline Mexico & 11.0 & 9.8 & 12.6 & 51.9 & 0.3 & 7.6 & 0.5 & 6.4 \\
\hline South Korea & 12.8 & 15.4 & 11.2 & 25.8 & 0.3 & 20.8 & 1.5 & 12.2 \\
\hline $\begin{array}{l}\text { Average for } \\
\text { selected } \\
\text { developing } \\
\text { countries }\end{array}$ & 9.7 & 10.3 & 9.2 & 50.7 & 0.2 & 12.1 & 3.0 & 4.9 \\
\hline Canada & 10.1 & 30.1 & 8.7 & 34.5 & 0.1 & 5.9 & 3.3 & 7.3 \\
\hline France & 11.9 & 20.7 & 11.0 & 37.0 & 0.2 & 6.7 & 1.8 & 10.8 \\
\hline Germany & 15.6 & 15.3 & 15.1 & 27.9 & 0.2 & 6.4 & 2.0 & 17.6 \\
\hline Italy & 17.0 & 16.1 & 10.5 & 25.8 & 0.3 & 16.1 & 2.1 & 12.1 \\
\hline Japan & 9.9 & 22.0 & 8.8 & 36.5 & 0.2 & 7.9 & 1.9 & 12.8 \\
\hline UK & 8.9 & 24.7 & 10.1 & 37.1 & 0.2 & 7.2 & 1.7 & 10.0 \\
\hline USA & 8.3 & 32.7 & 9.5 & 28.2 & 0.1 & 7.8 & 2.4 & 10.8 \\
\hline $\begin{array}{l}\text { Average for } \\
\text { G-7 countries }\end{array}$ & 11.7 & 23.1 & 10.5 & 32.4 & 0.2 & 8.3 & 2.2 & 11.6 \\
\hline
\end{tabular}

Note: * Nigeria's data are for 1992.

Source: Compiled from data in World Bank (1998a; 2000). 'Development Indicators - CD Rom'. 
Table 1.3 : Growth Rates of the Nigerian Economy

\begin{tabular}{lcccc}
\hline SECTOR & \multicolumn{5}{c}{ Average Annual Growth Rate (\%) } \\
& $1960-70$ & $1970-80$ & $1980-90$ & $1990-99$ \\
\hline Agriculture VA & -0.4 & -0.1 & 3.3 & 2.9 \\
$\begin{array}{l}\text { Industry' VA } \\
\text { Manufacturing VA }\end{array}$ & 14.7 & 7.3 & -1.1 & 1.7 \\
$\begin{array}{l}\text { Services VA } \\
\text { Total Product } \\
\text { (GDP) }\end{array}$ & 9.1 & 5.2 & -1.0 & n.a. \\
\hline
\end{tabular}

+ The figure for industry includes manufacturing. n.a. implies not available.

$\mathrm{VA}=$ value added.

Source: Compiled from Data in World Development Report (1978, 1992, 1995, 1997, 1998b, 2001). 


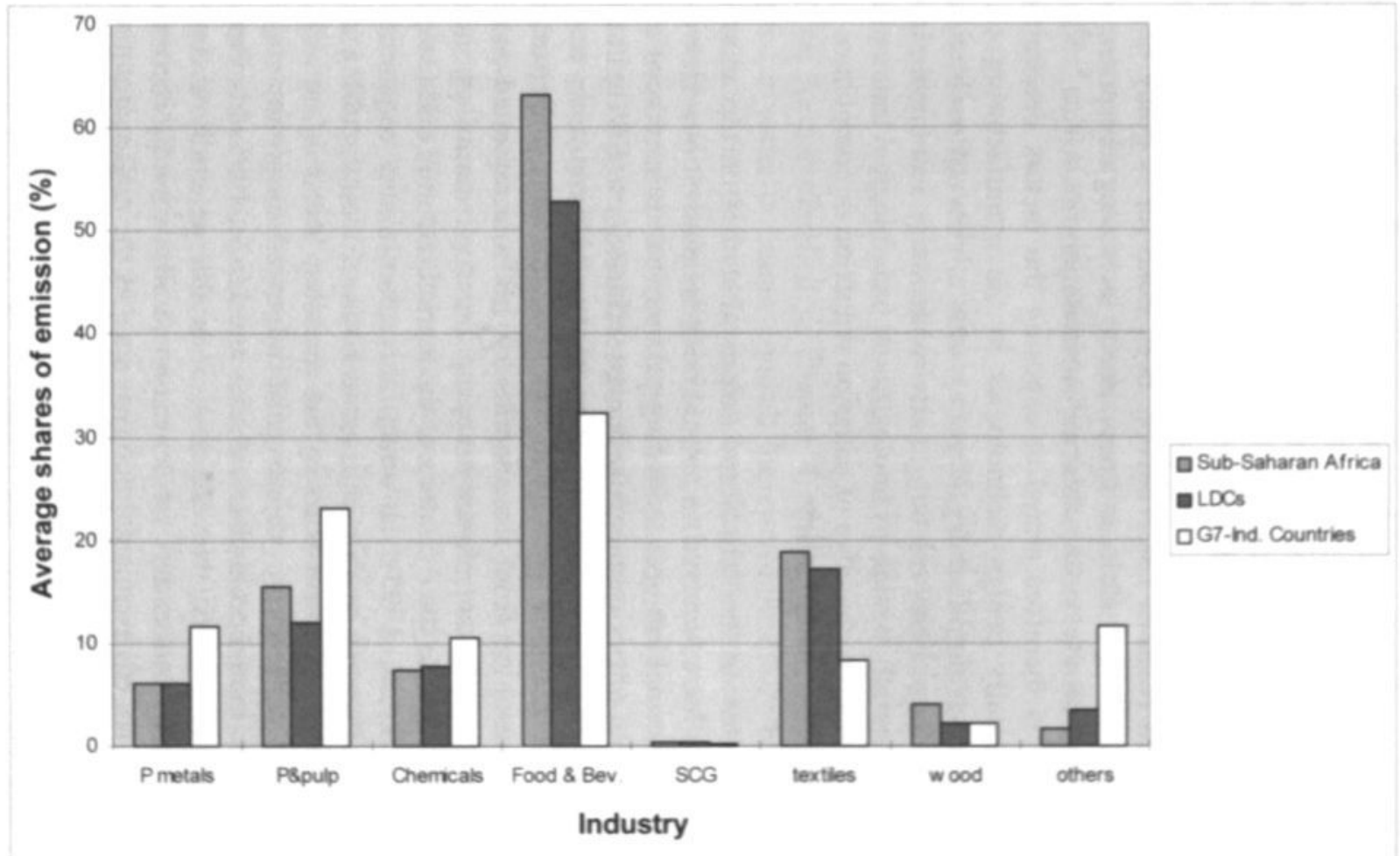

Fig. 1.2: Industry shares of emissions of organic water pollutants, 1993.

Source: Based on data from Word Bank (1998a) 


\subsection{Research Questions and Objectives}

Technology diffusion studies have concentrated on investigations into the socioeconomic determinants of the spread of normal business technological innovations, and their policy implications for the achievement of economic development objectives. However, not all technical innovations have business or economic development as the direct or main objective. Particularly, the challenge of environmentally sustainable behaviour of economic agents has made the aspect of environmentally benign technological change an emerging area of profound importance. While much research has relatively been done (or is going on) in this respect in industrial countries, ${ }^{8}$ little is know about technology responses to the imperatives of environmentally sustainable industrialisation in Africa. ${ }^{9}$ The main objective of this study is therefore aimed at exposing the factors determining the adoption of environmentally benign technologies in the manufacturing sector of developing countries as exemplified by Nigeria, with a view of ascertaining the implications they have for policies relating to environmentally sustainable industrial development. Environmentally benign technologies are technological innovations that firms employ for achieving the objective of emission reduction or compliance with the prevailing regime of environmental policy.

As already indicated, previous theoretical and empirical studies on the adoption and diffusion of technologies have focussed on normal business innovations. However, the adoption rationales for normal business technological innovations have been incapable of explaining the adoption of environmentally benign technologies (EBTs) in industry. This is because EBTs are traditionally viewed to imply additional costs to the firm without a corresponding value added to the output. The improvement in environmental quality resulting from the adoption of EBTs is regarded as a public good, such that the firm cannot directly appropriate the returns on additional investment in EBT when left to the dynamics of the market (Baumol and Oates, 1988; Siebert, 1987; Palmer et al, 1995). However, this mainstream economic theory perception of trade-off between private and social costs of manufacturing activities has been largely challenged in recent years by the so-called 'win-win' notions, which stress that firms could achieve the objective of improved environmental quality without a loss or decline in competitiveness (Porter and Linde, 1995a\&b; Bonifant et $a l$, 1995; Hart and Ahuja, 1996). Nevertheless, it is still generally accepted that regulatory intervention is necessary for environmentally friendly behaviour of industrial firms; and hence environmental policy is seen as the major causative factor that compel or induce firms to adopt environmentally friendly technologies (Howes et

\footnotetext{
"Examples of this include Kemp and Soete (1992), Ashford (1993), Kemp (1997, 1998), Hemmelskamp (1999), and Rennings (1999).

'In the case of Nigeria, the only known study that has some technology considerations in analysing the socioeconomic impact of policies aimed at industrial pollution control is Olokesusi et al (1997). The study was more of a general nature investigating the technological, social, and economic impacts of the then relatively new 'national effluent standards and limitation' that was made mandatory for industry at the beginning of 1995 .
} 
al, 1997; Jaffe et al, 1995; Repetto, 1995). In essence, this has resulted in the dominance of the 'stimulus-response' notions of environmental regulation as the compelling reason for the adoption of environment conserving technologies by economic agents. We however question this view particularly with respect to developing countries where environmental regulation is generally regarded as being comparatively weak. Accordingly, while making the impact of environmental policy on the adoption of EBTs an important focus of this study, we have attempted to disentangle the influence of other factors determining adoption from that of the environmental policy. This is expected to enable us ascertain the significance of other factors in stimulating the adoption of EBTs. The research questions for this inquiry can thus be summed up in two questions:

i) What causes the adoption of environmentally benign technologies in developing countries' manufacturing with a particular reference to Nigerian manufacturing industry?

ii) What implications do the factors affecting the adoption of environmentally benign technologies have for policies relating to environmentally sustainable industrial development, especially the aspect of water pollution control?

As will be further clarified in chapter 4 , since our focus is on firms' technology responses for water pollution control, the environmentally benign technologies that are investigated in this study include industrial wastewater treatment plants, and process integrated techniques/methods that reduce water pollution at the source. It is necessary to point out that the scope of this study does not include the downstream eco-impact of industrial wastewater. Our focus is on the technology adoption that takes place within the firm as a strategy to mitigate the external diseconomies arising from industrial wastewater effluent. Technology adoption in this context will be limited to evident introduction of EBTs as part of a firm's strategy to control industrial wastewater pollution. By implication, an adopter firm has made actual technology investment in EBT(s). Furthermore, our analysis shall not include the examination of phases or stages of technology adoption such as in Rogers (1983, pp.163-209), Biemans (1992, pp.41-45), and Preece (1995). These limitations notwithstanding, the study addresses pertinent questions such as: Is the adoption of environmentally benign technologies in Nigerian manufacturing industry governed by regulatory policy or by normal economic considerations of cost reduction initiatives? Could evidence in support of 'Porter's hypothesis' about the compatibility of firms' environmental performance with economic development be found in Nigeria? Has the regime of environmental policy in Nigeria been strong enough to significantly stimulate technology adoption for the abatement and prevention of industrial wastewater pollution in the Nigerian manufacturing? If yes, what type of technical change can be identified: is the direction towards abatement or prevention? Apart from environmental policy, what other reasons could be ascribed for environmentally friendly innovations in Nigerian manufacturing; and what implications do they have for industrial wastewater control and technology policies? If $\boldsymbol{n o}$, besides weak regulatory policy, what are the other obstacles to adoption, and what can be done to 
remove them? What opportunities exist for strengthening the institutional framework for environmental policy so that it can enhance the adoption of environmentally benign technologies in Nigerian manufacturing? What is the environmental code of the multinational industrial firms in Nigeria: do they adopt technology in response to the Nigerian environmental regulatory law or in compliance with the international norm of their parent companies? Will economic incentive instrument (e.g. effluent charges) be relevant for environmental policy in Nigeria?

As the foregoing indicates, the specific objectives of this study can be enunciated as follows:

i) To elucidate and analyse the links between factors determining the adoption of environmentally benign technologies in a developing country context as exemplified by Nigeria.

ii) To analyse the technological impact of environmental policy on Nigerian manufacturing industry, and determine whether or not the existing policy instrument has been effective in stimulating technology adoption for water pollution control.

iii) To ascertain the relative importance of other factors, apart from environmental policy, that may be responsible for technology adoption for water pollution control in Nigerian manufacturing.

iv) To present a view on policy directions that may encourage environmentally sustainable industrialisation in sub-Saharan Africa, especially with respect to industrial wastewater pollution control in Nigeria.

Our approach to this study is essentially empirical, and we have employed firm level survey method, backed up by detailed questionnaire guided firm-level case study interviews to give deeper insights into the underlying rationales for the survey findings. The theoretical underpinnings for the research draw largely from three streams of literature. The first is represented by the mainstream environmental economics perspectives on the trade-off between private and social costs of firm's environmental performance (e.g. Siebert, 1987; Baumol and Oates, 1988; Palmer et al, 1995). The second is signified by the reflections of business economic school on the so-called 'win-win' notions that relax the traditional 'trade-off' while stressing that environmental regulation can induce innovations that offset private costs of compliance (e.g. Porter and van der Linde, 1995a\&b; Bonifant et al, 1995; Hart and Ahuja, 1996). The third stream of literature are those relating to economics of technological innovation, especially the evolutionary perspectives (e.g. Nelson and Winter, 1982; Rosenberg, 1982; Dosi et al, 1988; Lall, 1992; Freeman and Soete, 1997). 


\subsection{Outline of the Thesis}

This dissertation is organised into nine chapters comprising an introductory chapter, three theoretical chapters, three empirical chapters, one chapter describing the research methodology, and a concluding chapter reflecting on the findings and policy implications.

Chapter one describes the research background, states the main problems and questions to be tackled, and gives the objectives of the study. The research methods to be employed are mentioned, and the main theoretical thoughts that would guide the empirical study are highlighted.

Chapter two begins the theoretical aspect of the dissertation with a detailed review of literature on the adoption and diffusion of technologies with the objective of exposing the adoption causalities for normal business technological innovations. Environmentally benign technologies are in themselves technologies that are adopted by firms. Hence, reasons why firms would normally adopt technologies are expected to give important background to understanding the determinants of technology adoption aimed at ameliorating external diseconomies of industrial production activities.

Chapter three presents our theoretical viewpoint on the links between types of firms' technology responses for pollution control and the factors responsible for firms' technology adoption decisions. The chapter develops an analytical framework that can be used to analyse the adoption of environmentally benign technologies (EBTs) irrespective of the level of development of the country or region where the firms are operating. Since our focus is on developing countries, a trajectory linking firms' EBT adoption to the level of national economic development is also presented. The trajectory gives indication on the nature and type of technology responses that may arise from the imperatives of environmentally sustainable industrialisation as a country develops.

Considering the important role of environmental policy in the analytical framework developed in chapter three, chapter four provides insight into the environmental regulatory framework in Nigeria. The institutional framework and policy instruments are described based on secondary information and our field research data. In addition, our analytical framework is applied to the case of Nigerian manufacturing. Consequently, the model resulted in two main hypotheses termed the major driver hypothesis and auxiliary driver hypothesis.

Chapter five gives a detailed description of the research methodology we employed for the study. The chapter describes the sampling and data collection procedures, the research questionnaires, and the econometric model applied for our empirical analysis.

The presentation of the empirical results of the study begins in chapter six. Before proceeding to analyse the adoption causalities in chapter seven, this chapter is 
intended to give an overview of the trends in technology responses for water pollution control in Nigerian manufacturing industry. The chapter has five sections, first introduction, and last conclusion. Based on our sample data, section two attempts to expose the characteristics of the two selected Nigerian water pollution intensive sectors. The characteristics described include firm size distribution, affiliation to multinational enterprises, distribution of age in production, human and physical capital, sources of technological knowledge, and environmental management. Section three of the chapter identifies the nature and types of technology firms in the two sectors have employed to abate or prevent industrial wastewater pollution, while section four highlights the obstacles to EBT adoption.

In chapter seven, we present the result of the analysis of the adoption causalities for technology responses for water pollution control in Nigerian manufacturing industry. After describing the necessary adaptations required in the empirical model employed, the technology adoption causalities were analysed in three stages. The first treated environmental benign technologies as a 'bundle' to find what reasons firms have for adoption if the type of EBT is not signified. The second and third stages respectively decouple EBTs according to our classification in the analytical framework in chapter three, viz., technology responses for water pollution abatement (TPA), and technology responses for water pollution prevention (TPP). This disaggregation of EBTs is done in order to isolate specific reasons why firms adopt TPA or TPP. The chapter is concluded with a synthesis of our findings on the adoption causalities for environmentally benign technologies with respect to industrial wastewater pollution control in Nigerian manufacturing.

Chapter eight presents twelve firm-level case study illustrations of technology responses for water pollution control in Nigerian manufacturing industry. The illustrations are drawn from ten food \& beverages firms and two textile firms. Each firm is discussed with close attention paid to the firm's background and basic characteristics, production technology and innovation, environmental problems and management, and technology adoption for industrial wastewater pollution control. The detailed case studies are intended to shed more light on the factors determining EBT adoption as presented by the survey results. Expectedly, while some factors earlier identified in chapters six and seven were reinforced, some caveats were thrown on others.

The final chapter concludes the thesis by giving a summary of the findings, and policy implications with respect to environmentally sustainable industrial development in developing countries, especially Nigeria. Some guides are also presented on directions for further research emanating from this dissertation. 


\section{Chapter Two}

\section{TECHNOLOGY DIFFUSION AND ADOPTION CAUSALITIES}

\subsection{Introduction}

At the centre of the general framework for this thesis is the subject of the adoption of environmentally benign technologies by manufacturing enterprises. As already indicated in chapter one (section 1.2), environmentally benign technologies (EBTs) are a peculiar category of technological innovation that enables firms' compliance with the prevailing regime of environmental policy. With a focus on developing countries, one of the important questions that this thesis is set to answer is: after the EBTs have been produced or developed, ' what factors determine their adoption? Before we could gain a comprehensive insight into this question it is necessary to first consider the adoption of normal business technological innovations in industry with the aim of identifying the factors that guide their adoption. We expect that the basic reasons why firms employ technological innovations will provide a basis for ascertaining the peculiarities of the adoption causalities for EBTs. This is because EBTs are technological innovations in their own right before being adapted for achieving the objective of environmental sustainability of industrial production activities. The purpose of this chapter therefore is to explore literature in order to expose what they have to say on the rationales for the adoption of technological innovations.

We will set out to argue that technology diffusion is the outcome of adoption decisions in industry or conversely, adoption decisions are the building blocks for diffusion. Thus, we will first establish in the following section that in order to understand the underlying reasons for the adoption of technological innovations, our search should make the economic literature on the diffusion of technological innovations a major focus. Thereafter, in section 2.3 we will give an overview of the scope or level at which technological diffusion are usually analysed with the aim of locating the aspects that are of particular relevance to this study. The search for the reasons for technology adoption begins in section 2.4 with the examination of the mainstream economic theories and empirical analyses of the adoption and spread of technological innovations. Because studies in this tradition have largely being carried out from the perspective of diffusion as a demand-side phenomenon, section 2.5 serves as a complement to section 2.4 by exploring adoption causalities from the interactions between diffusion and supply-side factors. Section 2.6 extends our search with the examination of the theoretical underpinnings of diffusion and competitive market

\footnotetext{
' EBTs are usually produced by the environmental goods and services (EGS) sector. In this respect, the EGS sector is regarded as a capital goods industry, the product innovations of which are required for the greening of the processes of industrial production. However, this does not preclude the fact that industries themselves innovate technically to comply with environmental policy or improve their environmental image.
} 
selection. The concluding section presents our findings as a checklist of adoption causalities for normal business technological innovation.

\subsection{Technology Diffusion: Outcome of Adoption Decisions}

A fisherman itching for a large haul will not proceed to the desert in search for an oasis to fish, but rather to an ebullient stream, or better still, to the deep sea. In the same light, it seems appropriate that a search for the reasons for the adoption of technological innovation should be directed towards exploring the circumstances of the adoption decisions. Inasmuch as firms do not exist in isolation, an adoption decision is bound to be a product of a firm's internal or endogenous accumulated knowledge and learning processes, and the external influences ranging from those of its competitors to factors that are even external to its sphere of operation. These endoand exogenous influences create the stimulus needed for a firm to adopt a given technological innovation. However, it is not enough that a technology appears and its use is restricted to the first adopter or the innovator. A nation or society can achieve the desirable impact of technological innovation in improvement of socio-economic welfare only when its diffusion has taken effect. In this sense, diffusion signifies the spread of the adoption of the new, and presumably superior technological innovation. Considering the expected benefits from such innovations, the economic and societal influences that stimulate diffusion are focused on broadening or increasing the adoption decisions spatially. As firms adopt a technology over a spectrum of time, the observed pattern of diffusion is generated. Thinking along this line in a more general sense, Rosegger (1989, p.178) conceptualise diffusion as the acceptance, over time, of an item, idea or practice, by individuals, groups or other adopting units, linked to specific channels of communication, to a social structure, and to a given system of values or culture (emphasis added). Within the context of our own conceptualisation, apparently the adopting unit is the firm, while the item, idea or practice is the technology. Furthermore, in relating the adoption decisions to the diffusion process, Ray (1974) also concluded that the adoptions at micro-level add up to diffusion at macro-level. From the foregoing, our view suggests that what actually lead to diffusion is the adoption decisions; and in order to gain a comprehensive understanding of the underlying reasons for adoption, we should examine what diffusion literature have to say.

Diffusion has been a very important focus of theoretical and empirical analyses in the study of the economics of technical change apparently because of the economic implication of diffusion. Although the adoption and diffusion literatures are distinguishable, the line of demarcation is often blurred. The close link between adoption and diffusion of technologies is amply reflected in the close integration of the subjects in theoretical and empirical studies. However, the relationship is such that adoption is subsumed under diffusion, perhaps, because diffusion appears to be a function of adoption. For example, Stoneman and Kwon (1996) presented 'an encompassing model of diffusion' to discuss the subject of technology adoption and 
profitability, and stated clearly that their paper was built on the theory of diffusion. Also Nabseth (1974, p.299) when concluding the report on an analysis of the diffusion of ten process innovations in six countries remarked that, "it is primarily the adoption stage that has been analysed in this study' (emphasis added). Thus, a search for the reasons for the adoption of technological innovations that is targeted at the economic literature on the diffusion would not only present a broad-base for identifying adoption causalities; but also enable us avoid sieving out adoption out of the larger pool of diffusion literature, an exercise which we consider may limit the chance of an in-depth examination of the rationale for adoption of technologies. In this respect, we will first give an overview of the scope of the diffusion of technologies in general, and identify the areas that will command our concentration.

\subsection{An Overview of the Scope of Diffusion}

As earlier indicated, the contribution of the diffusion of technologies to economic development has been immensely explored in research over the years. The literature on this subject ranges from those that treat diffusion ${ }^{2}$ as a microeconomic phenomenon (intra-firm) impacting on firm structure of production to those that relate to sectorwide cum inter-sector diffusion, in which case diffusion not only affects the form and direction of structural change in the industry concerned, but also, viewed from the perspective of the aggregate impact on the macro-economy, dictates the direction and path of growth and overall economic development. Diffusion from a literal sense means 'spread', and signifies the locational shift of certain quantities from their originally perceived quantitative state or level of existence. Diffusion is thus a quantitative phenomenon which is highly amenable to the tools of formal mathematical formulations, albeit, as typical in modelling economic phenomena, with assumptions that are in no way immune to criticisms.

The scope of the diffusion of new technologies can generally be approached from the perspective of the economic level at which the diffusion takes place. From the literature that give cognisance to this approach, taking a comprehensive view, it is possible to identify four levels of diffusion; viz., intra-firm, inter-firm, inter-industry, and inter-economy. The first two levels are central concerns of studies on the economics of technical change. One of the early studies that distinguish these two levels is Mansfield (1968), which demonstrated what would be a later trend by

\footnotetext{
This thesis is about the adoption of environmentally benign technologies that are essentially process technologies. Hence our discussion should be interpreted, except where otherwise stated, to address only issues relating to the adoption and diffusion of technological innovations applied for production processes. We should however say that, as Stomenan (1983) observed, the general principles for the analysis of process and product innovations are very similar; the major difference being that the analysis of the diffusion of new process technologies defines the economic decision makers as firms, whereas in the analysis of the diffusion of product innovations, the economic decision makers are labelled as consumers. Thus, the economy-wide study of the spread of the use of a new process embodied in a new capital good could be treated as an equivalent of the diffusion study from the viewpoint of consumer.
} 
focusing more on inter-firm diffusion. In his discussion on the determinants of intrafirm diffusion, Stoneman (1981) also acknowledged that research has been concentrated on the aspect of inter-firm diffusion. Stoneman noted that though the spread of the usage of a technology within a firm may be as important as the spread of its use across firms, inter-firm diffusion has attracted more attention especially in a world of large and 'global' firms. The reason for this, according to Stoneman, lies in the fact that majority of the empirical evidence for diffusion of technologies are obtainable at the inter-firm level. Added to this, Mansfield (1968) observed that since intra-firm rate of diffusion measures how quickly a firm substitutes a new technique for an old one once it has begun to use the new technique, some innovations can only be introduced on such a large scale that the intra-firm rate of diffusion is of little relevance. The firm either adopts the innovation or it does not. In addition to these two reasons, we suggest that an equally important reason apparently emanate from the central role of competition in firm behaviour. The urge to improve the competitive advantage of firms propels the spread of technologies across firms. The overall economic concern is usually focused on the rate at which the innovation diffuses and the plight of non-adopters. Under such an atmosphere, which is typical of contemporary capitalist economies, inter-firm diffusion will obviously attract more attention. This is because it is at the firm level that the adoption or non-adoption of a technology influences important economic factors such as labour and capital productivities, which in turn have significant implications for the macro-economy.

The third level, inter-industry diffusion, identified in Stoneman (1983), and earlier in Davies (1979), involves inter-sectoral spread of technologies. In this respect, the diffusion of one or more innovations in a number of sectors is studied. This is usually done by empirically explaining the variance of the speed of diffusion in terms of differences in the attributes of the industries and innovations concerned in the analysis. Taking a universal view of technology, we would like to state at this juncture that, the analysis of diffusion might however not split into three levels ${ }^{3}$ as neatly described above. Technologies usually find application beyond the bound of the industry of their source; and when this happens, diffusion analysis only recognise the fact that the quantitative value of the potential extent of the spread ( $a$ la, saturation level) of the technology has increased. Under such a situation, especially when the focus is the technology, the border of industries may melt down. Nevertheless, in view of the often observed diversities in the nature and mode of application of a technology when used across sectors and the resulting heterogeneity of products, the distinction between intra and inter-industry diffusion appears wholesome and relevant.

The fourth level, inter-economy diffusion addresses the issue of the spread of innovations across the borders of nations and regions. ${ }^{4}$ It is usually not considered in

\footnotetext{
${ }^{3}$ See Stoneman (1983, p.67) for further clarification on the three levels of diffusion.
}

4 Stoneman (1983 p.117) also recognises the inter-economy diffusion, however, not only as the final level of diffusion that represents the transmission of technologies between countries, but also as a comparison of national diffusion across countries. 
the regular bunch of diffusion literature. We perceive that the reason for this is the fact that this aspect traditionally falls into the realm of international economics, and the often so-called technology transfer aspect of development economics; ${ }^{5}$ and in more recent discourse, it is embedded in the large pool of literature on the 'globalisation' of production and the strategic behaviour of firms. ${ }^{6}$ These literatures, especially the latter category, closely link the concept of diffusion of technologies to that of international diffusion of knowledge. Diffusion at this level is no longer merely seen as a phenomenon of spread from firm level to industry, and from industry to economy wide, and then across the national border. Rather, there could be a 'jump' from firmlevel right across the border with the diffusion process taking a new form or pattern in the new diffusion environment. In this respect multinational enterprises have been found to play an important role. ${ }^{7}$ Figure 2.1 is an illustration of this possibility of 'diffusion jumps'. This trend has been greatly enhanced by the increasing opportunity for multinational firms to internalise knowledge as a result of the immense advances in the information and communication technologies.

While the international diffusion of technologies has a salient meaning for this thesis because of the underlying assumption of possible transfer of environmentally benign technologies to developing countries, it is however not our focus. Our reference is more at the firm level, and to a limited extent, at the industry level. We are more concerned with identifying factors that determine adoption of technologies so that we can relate such factors to the peculiarities of environmentally benign technologies in the next chapter. Therefore, more important for us in this treatise is the diffusion of technologies at the first three levels. Restricting ourselves to these three levels of diffusion, in the next section we will proceed to the more specific issues of theoretical models and empirical studies of the diffusion phenomenon in order to identify the causalities for the adoption of technological innovations.

\footnotetext{
${ }^{5}$ Examples of literature in this category include Ethier and Markusen (1991); Brezis et al (1993); and Chamarik and Goonatilake (1994).

${ }^{6}$ Examples of literature in this category include Dunning (1995): Globalisation of Business; and Lall (1997) in Dunning and Hamdani (eds.) : The New Globalism and Developing Countries.

${ }^{7}$ For example, Kim (1997) reported that the manufacture of microchips in South Korea was started by subsidiaries of multinational enterprises. He pointed out that when the local firms (notably the 'chaebols') adopted the technology for chips production, the pattern and rate of diffusion were unprecedented as they rapidly caught up with the American and Japanese innovators that introduced the technology to Korea.
} 


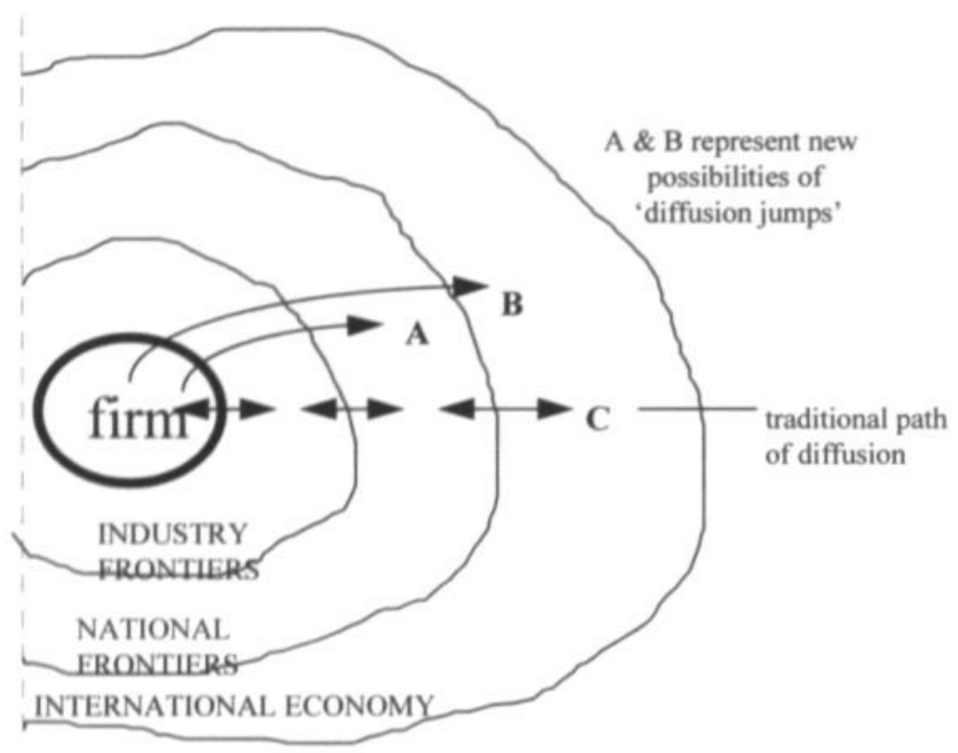

Fig.2.1. A graphical illustration of 'diffusion jumps'

\subsection{Models Based on Implicit Tradition of Old versus New Technologies}

The traditional approach to modelling the diffusion of new technologies are based on the understanding that, when a new technology appears, because of the perceived improved returns to investment accruing as a result of the better performance of the new technology, there is a systematic displacement of the old technology in order to give room for the new. The consideration is focused on the interplay of economic and technological imperatives that deter the withdrawing and subsequent exit of the old technology on the one hand, and those that favour the advent and subsequent entrenchment of the new technology on the other. A firm, industry or economy experiencing such interplay of forces is a system at the throes of change, the speed of which is determined by the rate at which the new technology diffuses. Davies (1979) recognised this as a transition from one potential state of equilibrium in which all firms employ the 'old technology' machinery, to another state in which all output is produced by the 'new process'. Metcalfe (1981) described the diffusion of technological innovations as the process by which new technologies displace, or substitute for, existing (i.e. 'old') technologies. Reacting to Dixon (1980)'s criticism 
of his pioneering study of the diffusion of the hybrid corn, Griliches (1980, p.1463) also pointed out that his earlier approach to diffusion research emphasises the role of time and information in the transition from one technology of production to another (emphasis added). This notion of old versus new technology, which is usually not clearly acknowledged in diffusion analysis forms an important underlying basis for the diffusion process, especially when process innovation is concerned. Product innovation may be completely or absolutely new (e.g. the television set, airplane, etc.) and having no precedent; however, it is not so with process technologies. Except we go back in economic history to very primitive and earliest times, it is difficult to find a process technology or capital good that has no preceding technology or technique it was meant to replace.

The models that are based on this perception of the diffusion process form the mainstream of models. These models implicitly presume that the firms are engaged in a struggle to gain competitive advantage over each other. Thus, when a new technology appears that would improve firm performance, after the innovator or first adopter has successfully implemented the use of the new technology, the competitors are assumed to follow the pioneering adopter in employing the innovation in a bid to close up the competitive gap so created by the first adopter. Generally speaking, these models have applied the epidemic theory from the natural sciences (epidemic models), the probability techniques (probit models), the vintage ${ }^{8}$ characteristics of the capital stock, and game theoretic ${ }^{9}$ approaches to explain the process of diffusion. However, the epidemic and probit approaches are more profoundly used in diffusion studies, perhaps, because they appear to be more adaptable for empirical research. Our review of the mainstream work on diffusion will focus on these two categories because they stand to provide the necessary and basic insights into the theoretical framework for analysing the diffusion of technologies. Moreover, the advantage of relatively wide spread empirical application of these models will give opportunity to identify what both theory and empirical findings have to say on the causalities for the adoption of new technologies. We would therefore discuss the two categories of models in detail, starting with the epidemic models.

\footnotetext{
'An obvious illustration of models based on 'old versus new' technology is the so-called vintage diffusion models, in which the economic characteristics of the old and new capital stock determine the diffusion of a new process technology. However, our theoretical review sidelines this group of models since they are not particularly relevant to the theme of the thesis. For a summary overview of the vintage models, see Meijers (1994, pp. 28-34).

'The game theoretic diffusion models (e.g. Reinganum, 1981, 1983) are models in which a firm's decision to adopt is an outcome of strategic behaviour of firms adopting the innovation. The adopting firms are assumed homogenous, all have perfect information about the technology, and declining profit is associated with increasing adoption. The driving force for adoption or non-adoption (which generates the diffusion path) depends on the level and sign of the difference between the benefit of (or profit gain from) adoption and the cost of non-adoption. These models would also be sidelined from our discussion because they do not fall into the mainstream of our focus.
} 


\section{The Epidemic Models}

The framework for the epidemic models is propelled by the contagion effect, in which the striving to maintain or attain 'appropriate' competitiveness through adoption of new or best practice technologies is likened to natural epidemic or infectiousness of a disease. Apart from the first adopter, every other user is regarded as an 'imitator' shifting from the old to the new technology. The major assumptions of the epidemic technological innovation diffusion models are:

- No 'cure and re-infection' is possible; i.e. when an innovation is adopted, the adopter cannot decide to change his decision, perhaps, by selling off the innovation, only to adopt it again at a later date when he has learnt more on how to profitably employ the innovation.

- The adopting population is homogenous and the characteristic features of the innovation do not change significantly over time.

- The maximum level of the adopting population is fixed.

- There is only one first adopter, sometimes regarded as the innovator.

- Imperfect information transmission processes: it is assumed that if there is perfect information for the adopting population, then every potential adopter will adopt at once, and hence the diffusion dynamics needed for the spread of the innovation would be non-existent.

In reality, these assumptions appear more appropriate if the conventional notion of epidemic spread derived from a 'solid-state contagion contact' after the first adopter, is replaced with that of a liquid or gaseous state physical dispersion or spread of a solute in a solvent or a gas released from a 'source' into a restricted atmosphere. In such a framework, all the assumptions, except that of information asymmetries, which introduce the human decision factor, will rightly describe the theoretical analogy of 'epidemic spread'. ${ }^{10}$

The importance of information in the endogenous learning processes of the firm emphasises the significance of the time at which a firm adopts an innovation. The diffusion process is thus driven by the spread of information; and the central concern of the analysis is the determinants of this spread and the time frame for the perceived spread to take place. Accordingly, Thirtle and Ruttan (1987) stressed that the determinants of adoption at any moment in time should intuitively be expected to be the independent variables for which time serves as a proxy. Since all variables describing each actor's behaviour and those affecting them are not observable, Griliches (1980) identified three important sets of forces for which time in brought in as a proxy in the analysis of diffusion:

\footnotetext{
${ }^{10}$ We do not intend to go into the wide criticisms of the epidemic theoretical framework for analysing the diffusion of technological innovation. We however add this somewhat critical remark as a contribution to, and as an acknowledgement of the existing reservations about the epidemic models. For an elaborate criticism of the epidemic models see Gold (1980, 1981), and for a cogent summary of the critiques see the introduction to Karshenas and Stoneman (1992) or Stoneman (1991, p. 173).
} 
i) The decline over time in the real cost of the new technology due to decreasing costs as the result of learning by doing and to cumulative improvements in the technology itself.

ii) The dying-off of old durable equipment, making room slowly for the new.

iii)The spread of information about the actual operating characteristics of the technology and the growth in the available evidence as to its workability and profitability.

Though the epidemic models essentially derived their emphasis from the third of these forces, the dynamics of all the three in varying measures, consistently introduce imbalances or disequilibrium between observed and potential attainable level of diffusion as long as the forces inducing adoption prevails in the adoption environment. It is important to note at this juncture that some of the prominent diffusion studies (e.g. Griliches, 1957; Mansfield, 1961; Nabseth and Ray, 1974; Davies, 1979; Stoneman, 1981) generally started their analyses as attempts to explain the observed pattern of diffusion before further theorising on the nature, path and direction of the diffusion process. The journey goes first from empirics to theory and not vice-versa. This points to the significance of the fact that each technological innovation is unique, and attempts to forge a generalised theory or model of diffusion are bound to encounter many pit-falls. Nevertheless, it is possible to identify the epidemic model as playing the role of a basic or primary model ${ }^{11}$ because other models seem to adopt some of its assumptions in varying degrees to develop 'better' models of diffusion, which could be more or less useful.

One of the important previous studies on diffusion that employed the epidemic framework is the study of Mansfield (1961) involving an empirical analysis of the diffusion of twelve technological innovations in four American industries ${ }^{12}$ between 1890 and 1958. Actually Mansfield was presenting a deterministic model ${ }^{13}$ to explain the results of observed pattern of diffusion of the twelve innovations without explicit reference to the epidemic diffusion model at the outset of the analysis. Besides, unlike the pioneering work of Griliches (1957) that focused on one innovation (hybrid corn) in a particular industry (agricultural sector), Mansfield's study provided the

\footnotetext{
"For example, Metcalfe (1981) described the epidemic model as the standard diffusion model, and Karshenas and Stoneman (1992, p.577) while presenting a 'flexible model of technological diffusion' incorporating economic factors referred to their new model as 'a new variant of the standard epidemic (or logistic) diffusion model' (emphasis added).

${ }^{12}$ The industries involved in Mansfield's analysis are bituminous coal, iron and steel, brewing, and railroad. The innovations were capital good or consumer durable in nature, and comprise: in bituminous coal - shuttle car, trackless mobile loader, and continuous mining machine; in iron and steel - continuous wide stripe mill, continuous annealing, and by-product coke oven; in brewing - tin container, pallet loading machine, and high speed bottle filler; in railroads -diesel locomotive, centralised traffic control, and car retarder.

${ }^{13}$ Mansfield (1961) also includes a stochastic version of the model. We however restrict our consideration to the deterministic version because as Karshenas and Stoneman (1992) rightly observed, the epidemic models are largely formulated in deterministic terms in economic literature.
} 
opportunity to understand the adoption of an innovation across industries. His approach enabled him to compare the rate of diffusion of an innovation applied in different industries, and to adduce reasons for the adoption of technologies from a broader perspective.

Mansfield introduced a model that says the proportion, $\lambda_{i j}$, of nonadopters of an innovation at the time of its introduction that would adopt it in the next opportune period as imitators, ${ }^{14}$ is a function of:

i) the proportion of firms that already introduced the innovation;

ii) the profitability of adopting the innovation;

iii) the size of investment required to adopt the innovation; and,

iv) other unspecified or unmeasurable variables.

$$
\lambda_{i j}=f\left(\frac{m_{i j}}{n_{i j}}, \pi_{i j}, s_{i j}, \ldots .\right)
$$

where

$m_{i j}=$ number of firms that have introduced the $i$ th innovation in the $j$ th industry at time $t$.

$n_{i j}=$ total number of firms that could adopt the $i$ th innovation in the $j$ th industry (i.e. potential level of adopters).

$\pi_{i j}=$ the profitability of a firm adopting the $i$ th innovation in the $j$ th industry.

$s_{i j}=$ the investment required by a firm to adopt the $i$ th innovation in the $j$ th industry as a share of the average total asset of firms in the industry.

Using the Taylor series expansion, Mansfield derived the celebrated logistic equation that has become almost a permanent imprint on diffusion theory. Following his presentation, the increase over time in the number of firms that have introduced an innovation should conform to the logistic function:

$$
m_{y}=\frac{n_{i j}}{1+e^{-\left(\alpha+\beta_{y}\right)}}
$$

and the rate of diffusion is governed by the parameter, $\beta_{i j}$ given by:

$$
\beta_{i j}=\mathbf{b}_{j}+\mathbf{c}_{j} \pi_{i j}+\mathrm{d}_{j} s_{i j}+\mathbf{z}_{i j}
$$

where

\footnotetext{
${ }^{14}$ In the thinking of Mansfield, adopters are imitators. However, we will avoid this notion as much as possible, because as Rosegger (1989) pointed out, the word 'imitation' tends to belittle the frequently substantial difficulties of adopting an innovation into an existing organisation and production system, no matter how successful it may have been elsewhere. Particularly when major innovations are involved, the adoption of the innovation require specific firm level adaptations that would be beyond the scope of merely imitating what another firm has done.
} 
$\alpha$ is a constant of integration;

$\mathrm{b}_{j}, \mathrm{c}_{j}$, and $\mathrm{d}_{j}$ are industry parameters; and

$\mathbf{z}_{i j}$ is a random variable with zero expected value.

Although the assumption of contagion effects which Mansfield called "bandwagon" effects was the first of his four basic propositions in specifying his model (Mansfield, 1961, pp.745-747), he was however silent on epidemic considerations in his discussion. The outcome of his derivations betrayed this silence because it located the model within the family of epidemic models. The conventional hypothesis of epidemic spread indicates that the change in the number of adopters over time is proportional to the probability of adoption (which could be safely represented by the proportion of firms that have already introduced the innovation) and the number of potential adopters that are yet to adopt the innovation.

Thus, if the time frame for the change in the number of adopters is assumed infinitesimally small,

$$
\frac{d m_{i j}}{d t}=\beta_{i j} \frac{m_{i j}}{n_{i j}}\left(n_{i j}-m_{i j}\right)
$$

where

$\boldsymbol{\beta}_{i j}$ is the proportionality parameter representing the rate of adoption or the diffusion speed.

Note that equation 2.2 can be derived by simply integrating equation 2.4 to derive its solution. We are however interested in Mansfield derivations because it leads to the expression of $\beta_{i j}$ in terms of $\pi_{i j}$ and $s_{i j}$. This gives credence to the hypothesis that the adoption or the rate of diffusion of a new process technology would depend on the economic characteristics of the innovation; in this case, the profitability of the technology and the value of the investment required to employ the technology in the production process (i.e. costs). Thus, in Mansfield's implicit application of the epidemic framework, it was possible to test the impact of profitability and cost of acquisition of the new technology on the rate of diffusion. Economic considerations, which are usually not given prominent considerations in epidemic models, are brought in as major determinants of the diffusion process. This is perhaps the reason why Mansfield was reluctant in making a straightforward specification of the epidemic model (e.g. as in Griliches, $1957^{15}$ and Bass, 1969).

As commonly done in the application of the epidemic model for empirical research, using least square regression (after weighting all the observations), Mansfield estimated a transformation of the logistic equation 2.2 : viz.,

\footnotetext{
${ }^{15}$ It is however necessary to state that Griliches also made significant reference to the economic role of profitability in determining when the farmers in the various American States in his study adopt the new 'technology' (hybrid corn).
} 


$$
\log \left(\frac{m_{i j}}{n_{y}-m_{i j}}\right)=\alpha+\beta_{i j} t
$$

The estimates of $\alpha$ and $\beta_{i j}$ were used to judge how well the logistic equation 2.2 represents the data by inserting them into equation 2.2 , and comparing the calculated increase in number of firms with the actual increase. The resulting growths provided reasonably good approximations to the actual observed growths; and hence Mansfield concluded that the logistic described well the observed growth curves from his data. In epidemic analysis, the growth curves are fitted, and if need be, they are used for predictions or forecasting. ${ }^{16}$ The slope of these curves, represented by $\boldsymbol{\beta}_{i}$, signifies the speed of diffusion, which is considered to be mainly determined by the intensity of the information flow or the propensity for non-adopters to learn about the new innovation through 'contagious contacts'.

The focus of Mansfield was however less on the growth curves and more on the estimates of equation 2.3. This is apparently a step ahead of the epidemic models. By assuming that the industry parameters $c_{j}$ and $d_{j}$ are constant among industries (i.e. making equation 2.3 linear), and that the errors in the estimates of $\beta_{i j}$ are uncorrelated with $\pi_{i}$ and $s_{i j}$, the least square regression was again used to obtain estimates for the industry parameters $b_{j}, c_{j}$ and $d_{j}$. It is interesting to note that, using equation 2.3 , Mansfield pointed to the import of industry parameters as determinants of the rate of diffusion; and by implication the rate of the adoption of technological innovation. The most important of such parameters in Mansfield's work are the size of the firms in the industry and profitability of the innovation. ${ }^{17}$ The empirical testing of Mansfield's model gave the expected positive correlation between diffusion speed $(\beta)$ and profitability; and negative correlation between diffusion speed and the cost of adopting the new technology. He also found that there was some apparent tendency for the rate of diffusion to be higher when the innovation did not replace very durable equipment, and when firms' (industry) output was growing rapidly. These are expected because firms with very durable machinery will be more reluctant to change to a new, especially if the old technology is still efficient and profitable. When industry output grows fast, the firms apparently become more competitive, and the more competitive firms would be more prone to adopting the best practice technology. A more recent study by Stoneman and Kwon (1996) on technology adoption and firm profitability has also shown that the profit gains to adopters of a new technology are related to firm

\footnotetext{
${ }^{16}$ In the same manner as the logistic curve is estimated and fitted, other epidemic models such as Bass and Gompertz could also be estimated and fitted. Bass (1969) illustrates this for the original Bass model, which was applied in studying the diffusion of eleven consumer durables, and Kemp (1997) presents a very good example in which three epidemic models (Bass, Gompertz, and Logistic) were fitted and compared.
}

${ }^{17}$ Other studies (e.g. Nabseth and Ray, 1974, and Karshenas and Stoneman, 1993) have also confirmed the positive correlation between firm size and profitability, and the rate of diffusion. 
and industry characteristics, with estimates depicting firm size as the most effective measure of firm characteristics. ${ }^{18}$ It should nevertheless be noted at this juncture that, as Stoneman and Kwon rightly pointed out in their study, firm size is not only important in itself, but could also serve as a proxy for unobservable differences across firms that may have impact on adoption or profitability. Another recent study that confirmed this notion is Mewilliams and Zilberman (1996), which in an empirical analysis of the diffusion of computer technology showed that firm size effects are responsible for early adoption of technology. Dynamic economies of scale due to learning by using played important role in the process. Consequently, firm size is a reflection of the extent of the existence of dynamic economies of scale. Thus, firm size may not be viewed as an explanatory variable in itself, but rather a proxy for unobservable variables. In fact, it is possible for firm size to have nothing to do per se with adoption or diffusion, but may simply be correlated with the availability of financial resources, management time \& attitudes, etc.

From the foregoing discussion on theory and empirical application of the epidemic models to technology diffusion analysis, it appears there is a triangle of linkages if we accept firm size as a variable, which in reality may represent some unobserved factors. Adoption depends on profitability and firm size; while profitability depends on firm size (see figure 2.2).

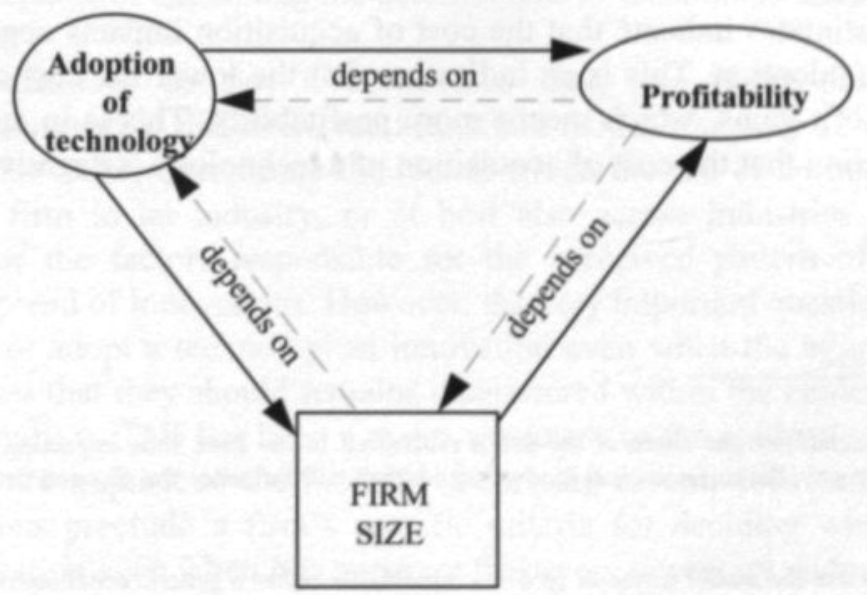

Fig.2.2. Relationship between technology adoption, profitability and firm size.

\footnotetext{
18 We do not intend to distinguish remarkably between firm and industry characteristics because in reality, the industry characteristic is a product of the aggregate firm characteristics. We are therefore compelled to cautiously use the two terms interchangeably.
} 
As shown in figure 2.2, the dependability links could however be reversed: that is, firm size (including its structure) could depend on technology adoption and profitability, ${ }^{19}$ while profitability could depend on technology adoption and firm size. Stoneman and Kwon introduced a wider scope of analysis that lead to some insight on the profitability aspect of this triangular relationship by developing and empirically testing a basic model ${ }^{20}$ expressing firm profitability as a function of the rank, stock, order, and epidemic effects. ${ }^{21}$ The data used was a panel data relating to a sample of firms in the United Kingdom engineering industry over the period 1983 to 1986 . Three main findings of the study are relevant to our discussion.

The first is that the estimates indicated that the profit gain of a non-adopter declines as other firms use the new technology. This is understandable because apart from the first adopter or the innovator who may enjoy some monopoly or near monopolistic gains, the late adopters will have to contend with more competitive prices that will affect their profit margins. The guiding principle may be stated as: the later the adoption, the lower the uncertainty $y^{22}$ associated with adoption, the lower the cost of acquisition, and the stiffer the price competition faced at the output market. ${ }^{23}$ It seems that the effect of price competition on the output market overrides the implicit impact of cheaper or more efficient technology. Thus, inasmuch as the cost of the technology may be important in determining profitability, the ferocity of competition in the output market may be the actual deciding factor as to whether or not adoption takes place. This will be discussed in detail in section 2.6.

Secondly, the estimates indicate that the cost of acquisition impacts negatively on the profit gain from adoption. This is an indication that the lower the cost of acquisition, the more the profit gains, which means more profitability. This is in agreement with Mansfield's finding that the cost of acquisition of a technology is negatively correlated with adoption.

${ }^{19}$ Profitability will determine the share of the profit reinvested in the firm, thus impacting on firm size and structure. In a similar way, the technological innovation adopted will influence the size and structural features of the firm.

${ }^{20}$ It should be noted that the model is not an epidemic model, but rather a general econometric model based on an application of diverse theoretical views of diffusion.

${ }^{21}$ Based on the work of Karshenas and Stoneman (1993), Stoneman and Kwon defined the rank, stock, order and epidemic effects respectively as the characteristics of the firm, the number of other adopters, the firm's position in the order of adoption, and information asymmetries.

22 The lower uncertainty will arise because as adoption increases with time, it leads to increased use, which in turn generates more knowledge about the innovation, and hence reduced uncertainty.

${ }^{23}$ This reasoning is based on the Schumpeterian notion that, as more firms use a new technology, industry average costs fall, which in turn results in lower prices (see Schumpeter, 1949; chapter IV). 
Thirdly, the findings of the study rejected the hypothesis that epidemic effects determine the profit gain from adoption. That the epidemic effects did not determine profit gains is not difficult to understand. It should be recognised that information asymmetries are difficult to quantify, and epidemic considerations focus more on the rate at which diffusion take place rather than the value of profit gains. Through epidemic effects, a firm may have information about an innovation. But having the information is not enough to make a profit. Profit loss or gain happens only when the epidemic effect leads to adoption. This points to the limitation of the epidemic effects in being unable to give the reason why some firms having information, but yet may not adopt an innovation. In Mansfield's model, this aspect was apparently absent but later addressed in a separate chapter of his 1968 book. $^{24}$

From the foregoing examination of the epidemic approach to diffusion analysis, we can draw the following conclusions with respect to technology adoption causalities:

a) Firm profitability is an important adoption causality.

b) Firm size as a measure of some unobservable variables plays an important role in determining adoption.

c) Cost of acquisition of a technology is negatively correlated with adoption.

d) The number of current users at any point in time could stimulate non-adopters to adopt especially if adoption has led to better performance of the current users.

e) As demonstrated by Stoneman and Kwon (1996), epidemic considerations may not always be capable of explaining the determinants of technology adoption.

From our discussions so far, it is obvious that, like many other analysis of technological innovation diffusion, the Mansfield model was only able to answer the question of what factors determine the rate at which the use of an innovation spread from firm to firm in an industry, or at best also across industries. It presents an explanation for the factors responsible for the perceived pattern of the aggregate phenomenal spread of innovations. However, the very important question of why some firms would not adopt a technological innovation even when the aggregate diffusion pattern indicates that they should remains unanswered within the epidemic framework of diffusion analysis. This has been a major weakness of the epidemic models and the reasons for it are implicit in the model's underlying assumptions earlier enunciated. The assumptions preclude a firm's specific criteria for deciding whether or not to adopt an innovation even when it is apparent that every necessary endogenous learning and assimilation of information relating to the innovation have taken place. Even the assumption of information asymmetries which is the driving force for the epidemic spread is inadequate to effectively represent the attendant uncertainties faced by firms in aggregate. Given a particular information on an innovation, the uncertainty faced by each firm is unique. Therefore for a model expressing the aggregate pattern of innovation diffusion, the assumption of information asymmetries only show that as more and better information are available, more firms adopt, and not necessarily less

\footnotetext{
${ }^{24}$ See chapter 8 of Mansfield (1968).
} 
uncertainty regarding the risk attached to adoption. In order to further explore the determinants of the adoption of technological innovations, our discussion in the next subsection will therefore focus on the probit models, which attempted to close some of the loopholes of the epidemic models.

\section{The Probit Models}

The probit models belong to what could be regarded as one part of a larger group of models generally referred to as rational choice ${ }^{25}$ models (as opposed to informationspreading models), which are characterised by the incorporation of economic factors in the analysis of the diffusion process. The other part is the game-theoretic type of diffusion models ${ }^{26}$ (e.g. Reinganum, 1983). While they emphasise the role of economic factors in facilitating the diffusion process, these models often play down or explicitly ignore the information spreading factors. The adoption of a technological innovation is considered to take place when an economic factor determining stimulus variate exceeds a critical value (Karshenas and Stoneman, 1992; Kemp, 1998). The probit analysis is based on the application of probability theory to the analysis of firms' adoption decisions within the transition time period during which the diffusion path is generated. Whereas the epidemic framework assumes a logistic distribution for the time path of the adoption decisions in a given population of firms, the probit model may assume a normal or any other suitable probability distribution. ${ }^{27}$ The models are models of decision under uncertainty based on the assumption of heterogeneous adopting population and non-declining benefit to adoption as adoption widens. The same level of information about the technology is assumed available to every potential adopter at every point on the diffusion path, and hence the 'contagion effects' are ruled out. As earlier indicated, each member of the heterogeneous adopting population is assumed to adopt only when a specified characteristic of the adopting member reach or exceed a specified level, usually, the critical level at which it makes economic sense to adopt. In Davies (1979), this characteristic feature is firm size as in David (1969), which was apparently the first attempt at using the probit model for diffusion analysis. To make this more explicit, we present the general framework for the probit models described by Stoneman (1991) as follows.

\footnotetext{
${ }^{25}$ While Karshenas and Stoneman (1992) referred to these models as 'discrete choice' models, we prefer to call them rational choice or threshold models as in Kemp (1998) because the term appears to more appropriately describe the underlying decision-theoretic rationale.

${ }^{26}$ As earlier mentioned in footnote 9, we are ignoring the game-theoretic type of models in this thesis.

${ }^{27}$ See Maddala (1992, pp.327-328) for a formal description of the basic probit and logit models. Note that the epidemic model is usually transformed into the logit form (refer to equation 2.5) for the purpose of estimation. In the restricted mathematical formulation of Maddala, the probit model is specified only for the normal distribution (in which case, it is considered more appropriately a 'normit' model). However, in the more flexible specification of Davies (1979), the probit model could assume any adopted appropriate probability distribution. Thus, based on past research findings on the empirical firm size distributions, which according to Davies, indicated the lognormal distribution as a fairly close approximation, the lognormal distribution was used to describe the probability distribution of firm size in Davies analysis.
} 
Given that the population adopting a technological innovation differ according to some specified characteristic, $z$, that is distributed across the population as $f(z)$ with a cumulative distribution $F(z)$. Assume that in time $t$, a potential adopter, $i$, will be a user of the technology if its characteristic level $z_{i} \geq z_{c}$, where $z_{\alpha}$ is some critical level of the characteristic at time $t$. Then the proportion of the population which have adopted by time $t$ is given as $1-F\left(z_{\alpha}\right)$. This is shown as the shaded area in figure 2.3. Either $f(z)$ is assumed to shift with time or the critical level $z_{c t}$ changes with time.

As such shift or changes happen, the proportion of the adopters and the number of adopters change, thus tracing out the diffusion path. In actual sense, this diffusion path would be the time path generated by the cumulative probability distribution of the specific characteristic feature of the adopters being used for the analysis. On a microlevel, the adoption decision is formulated with $z_{\alpha}$ as a yardstick that would determine adoption. For example, the Davies formulation in this respect can be presented as proposing that adoption would occur at a critical firm size, $z_{c}$, at which the expected present value of benefits from adoption is greater than or equal to the cost of adoption. ${ }^{28}$ Our discussion of the probit models will explore the findings of Davies $(1979)^{29}$ to suggest what such models may have to say on the rationale for adoption of new technologies.

Davies model set out to address two principal issues that had previously been treated separately: why within industries some firms adopt more quickly (a micro-level problem), and why shape of the diffusion growth curve (a macro-problem resulting from aggregation, and signifying rate of spread) would differ from one industry to the other. The theoretical propositions of Davies stipulate that adoption of innovation would depend on firm size and other unspecified characteristics of the firm. The unspecified characteristics which in actual sense are the potential determinants of a firm's profitability, are assessed to embrace technical attributes of the firm such as the nature of its product(s), and existing processes and inputs. Other identified unspecified attributes, which could be related to technological capabilities of the firm, are education of the managers and research intensity. Furthermore, Thirtle and Ruttan (1987, p.103) summed up unspecified attributes, notably, managerial attitudes, as "attitudinal" variables. For example, management's disposition to innovation and expansion could influence the decision to adopt a new technological innovation. Thus, from Davies theoretical propositions, it appears that a firm's propensity to adopt a technological innovation will mainly be determined by its size, perceived profitability of the innovation and the technological capability of the firm.

\footnotetext{
${ }^{28}$ Cost of adoption would include the cost of acquisition and all necessary firm adjustment costs for the profitable employment of the technology.

Davies (1979) is an in-depth study of the technological diffusion process with prominence given to the adoption decisions through the application of the probit model. The probit model used by Davies appears to be an advancement of David (1969) model.
} 


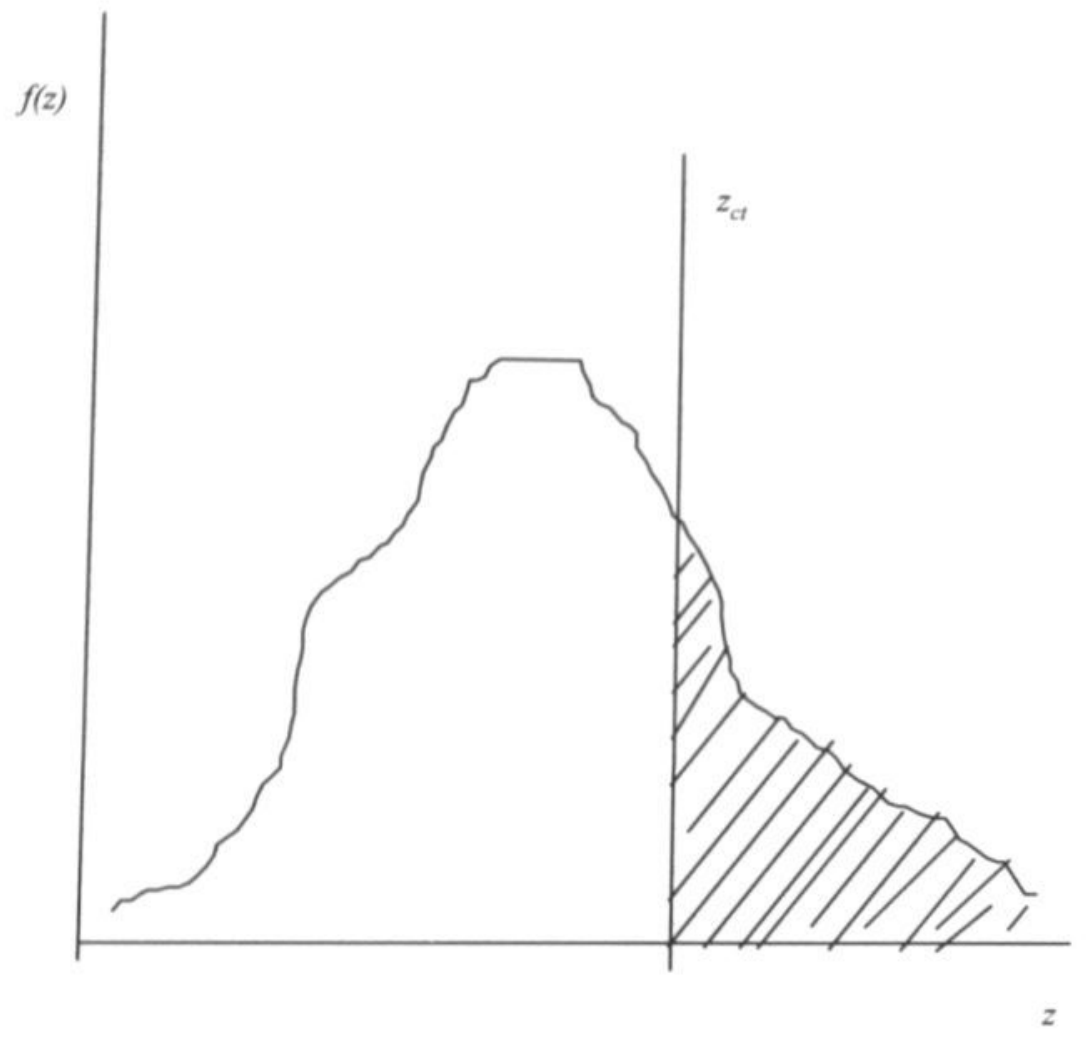

Fig.2.3. The distribution of firm characteristics in a probit framework

Source: Adapted from Stoneman (1991).

While most diffusion studies' empirical analyses have concentrated on one particular innovation, Davies, in a manner similar to Mansfield (1961), focused his analysis on a relatively broad based data of twenty-two technological process innovations in thirteen different British industries. Thus, though any conclusion from the analysis of such a wide array of innovations should be handled with caution to avoid undue generalisation, it is reasonable to expect that the findings of the study will give important indications of the adoption causalities for technological innovations, Particularly useful in this respect are the empirical questions that the study attempted to answer. These questions included the relationship between the nature of industry and the rate of technology adoption; the impact of the economic environment of the adopting firms on the speed of diffusion; and how the nature of the innovation (e.g. 
minor or major innovation ${ }^{30}$ ) affects adoption. To answer these questions, the diffusion curves for the twenty-two innovations were fitted, and the estimates of the various parameters of the estimated models were used in a cross-section analysis.

Besides, Davies theoretical considerations showed that diffusion curve (and by implication the rate of adoption) for minor and major innovations would be different due to learning effects (learning by using). The former would produce a positively skewed diffusion curve, akin to that resulting from the assumption of lognormal distribution for firm size, whereas the latter would generate a curve similar to the conventional sigmoid diffusion curve. The explanation for this is that minor innovations by nature are relatively simple, making learning to progress fast and quickly runs out as the adopters of such innovations soon find out that there is little or nothing again to learn about the innovation. In the case of major innovations, they are usually complex, and sometimes bulky. Learning proceeds gradually after many initial trials-and-errors in attempts to learn. After gaining initial experience of how to use the technology, the intricacy of the technology necessitates further learning, and perhaps learning may now proceed at a faster rate due to better knowledge of the technology. Learning continues and it takes a longer time before diminishing returns sets into the learning process. These propositions were empirically confirmed for all but four of the twenty-two innovations in Davies' sample. In a nouveau attempt of Mcwilliams and Zilberman (1996) in which they used the Tobit analysis to show how the static adoption time analysis could generate the dynamics of the diffusion curve for a computer technology, they also found that the learning capabilities of a firm is an important factor when making the decision to adopt a technology.

On the whole, Davies' results affirm that the rate of adoption (i.e. diffusion speed) will be faster:

- the more homogenous are firms in the adopting industry (i.e. the less the inter-firm differences);

- the stronger are the factors (e.g. firm size, profitability, etc.) that increase the chance of any one firm adopting over time (i.e. the dynamic influences on the adoption decision).

The hypothesis that the diffusion speed appears to be more rapid for more profitable innovations is confirmed by Davies' analysis. This is consistent with Mansfield findings on the fairly plausible hypothesis that profitable technological innovations

\footnotetext{
${ }^{10}$ Davies subjectively divided the twenty-two innovations into two groups, termed A and B. Group A are seemingly minor innovations, defined as technologically simple, probably relatively cheap and produced off-site from the location of use. Learning effects (as reflected by declining labour inputs), both in the production and use of the innovation might be quite initially large, but soon falling away drastically. Group B are more sophisticated, expensive innovations that are produced on a one-off basis, often requiring lengthy periods of installation on the adopter's site. Learning is much likely to be longer lived than for group A, and in the long run, more substantial. A third group also exists, called group $U$ comprising the innovations that are difficult to sort into either A or B. (Davies, 1979, pp.50-51). The main advantage of this distinction of the samples into groups as explained by Davies is that, since no single curve can satisfactorily describe the diffusion of all innovations, the divergence within each group would be considerably reduced. That is, only like is compared with like, and the representative diffusion curve would be closer to reality than otherwise.
} 
should presumably impose greater competitive pressure on non-adopters and perhaps arouse more interest and discussion (leading to better information on the technology) among the adopting population, and thus facilitating faster adoption decisions. Thus, innovation profitability is an important dynamic influence on adoption decision.

A negative finding which conflicts with Mansfield (1961)'s finding of inverse relationship between diffusion speed and cost of acquisition of the technology is that, within Davies' two groups (A\&B), there appears to be no tendency for the more expensive innovations to diffuse more slowly. According to Davies, the reason for this discrepancy may be due to the group A / group B break-down of his data, resulting in two sets of observations with neither set exhibiting substantial variance in the cost variable. Moreover, as earlier mentioned in the previous subsection, the more recent finding of Stoneman and Kwon (1996) confirmed that Mansfield was right.

The empirical analysis also confirm that at any point in time the probability that a firm will have adopted is larger, the bigger the firm. However, this does not establish that larger firms are more 'innovative' or 'better adopters' because when the in-built advantage of large scale (e.g. scale economies) was incorporated in Davies analysis, the reverse was seemly more convincing. In the same vein, there is little evidence to support the hypothesis that innovations will diffuse quicker in industries where demand and aggregate industry size are growing rapidly, though the model suggests a positive correlation because increasing size should make the innovation more profitable. The results also support the hypothesis that industries that are labour intensive are quicker to adopt technological innovations. We may infer from this that high wage rates may induce labour saving technical change that could promote the adoption of new technologies.

\subsection{Adoption of Technologies and the Supply-side Factors}

The adoption and subsequent diffusion of technologies that have been discussed in this chapter have attempted the exposition of the determinants of adoption by focusing on the demand-side analysis of the technology diffusion process. This is deliberate because the problem of diffusion is essentially a demand-side issue. The relative abundance of literature in this respect compared to the apparent paucity of literature that link diffusion to the supply side factors largely influence this bias. However, the importance of the supply-side factors to diffusion analysis cannot be overemphasised. Though his analysis was a major demand-side diffusion study, Davies (1979) could not ignore stressing that the invention and the development processes of the twentytwo innovations in his analysis were all attributed almost exclusively to firms or individuals outside the adopting industries; by implication, these innovative firms and individuals belong to the supply-side as producers of the process technologies. The main issue from this supply-side perspective is to identify how the production and development of technological innovations through research and development (R\&D) activities influence the adoption and spread of the innovations in the user industries. In 
this respect, the argument of Stoneman (1991, p.180) on the interactions of R\&D with diffusion is noteworthy. Stoneman stressed that:

"When one adds a supply side to the diffusion process, we know that the mumber of suppliers and their costs and the improvements in technology that they generate are important influences on the diffusion path. However, production costs, improvements in technology and entry to an industry are largely the result of $R \& D$ spending. The incentive to do $R \& D$ is expected profitability. This profitability is derived by the suppliers from sales during the diffusion process. Thus the diffision process generates the incentives to $R \& D$, and $R \& D$ brings forth the lower costs, improved technology, etc. that drive diffusion" (Stoneman, 1991, p.180).

This argument suggests that in a regime of dynamic evolution of technology, R\&D in the capital goods industry is potent in effecting reductions in the market price of technological process innovations. Since a major objective of a profit maximising firm would be to lower costs, then intensified R\&D in the capital goods sector that results in less expensive or more efficient process technologies would induce more wide spread adoption. Furthermore, in a similar manner, learning by doing in the capital goods industry and feedback from the innovation users could achieve similar results. The only difference is that, while R\&D could lead to radical changes, learning by doing and the assimilation of users' feedback mostly achieve evolutionary results.

It is however necessary to point out that R\&D could also impede diffusion. This would happen when R\&D results in radical changes that renders existing technologies obsolete, or when R\&D leads to delay/postponement of adoption in order to benefit from future improvements in the price-quality ratio. The recent experiences in the development of information technologies present a good example. ${ }^{31}$ However, we should quickly point out that this appears less likely for process technologies because such technologies are mostly by nature complex, and would more likely be advanced through a gradual development process based on R\&D, learning by doing and users' feedback.

From the foregoing we could propose that ceteris paribus, adoption of process technological innovations would be facilitated at the supply side:

i) if there is intensified R\&D in the capital goods sector;

ii) when learning by doing progresses well; and

iii) if the producer is able to assimilate innovation users' feedback.

Other supply side factors that would generally influence diffusion of technological innovation include:

i) availability of the innovation, quantities produced and distribution strategies;

\footnotetext{
${ }^{31}$ See chapter 7 of Kim (1997) for some empirical information in this respect about the semiconductor industry.
} 
ii) price strategy of the supplier, for example, market penetration through price skimming; and

iii) information by suppliers or intermediary agents.

\subsection{Diffusion and Competitive Selection}

In our discourse so far, we have largely considered the diffusion phenomenon exclusive of the diffusion environment, particularly, the impact of the market structure under which the firms are operating on the adoption of technology. Hitherto, it appears that we have focused on only one side of a balance; viz., factors determining the adoption of technological innovations based on the intrinsic nature of the technologies themselves, the behaviour of the firms using them, and the links with the supply-side factors. In this case, firms' behaviour is characterised by consumer behaviour as a user of capital good or a technological process. However, the other side of the balance, which is equally important, relates to the determinants of the adoption of new technologies based on the behaviour of firms with regard to how the technologies are employed to serve the output market in which the firms are operating. In this case, the firms' behaviour is largely influenced by producer's mentality, and the output market's functioning creates the necessary dynamics for adoption of technology and the observed path of diffusion. Diffusion in this respect is analysed as an induced diffusion based on the derived demands for the technologies being used for production. Figure 2.4 illustrates the two sides of the balance in diffusion analysis and depicts diffusion as an outcome of the interactions between the forces of 'technology push' and 'demand pull'. To the left of the balance is a kind of 'technology push' in which the technology supply conditions influences the adoption and diffusion of technology; while to the right side is a type of 'demand pull' ${ }^{32}$ whereby technology adoption and diffusion are determined by the firm's response to the imperatives of the output market. The 'pivot' on which this balance of forces stands would $a$ priori be the firm's own internal capability to adapt and absorb technological innovation. In this respect, the firm's internal processes of taking cognisance of technological possibilities and the obsolescence of existing techniques and technological artefacts will play an important role. In the foregoing we have apparently assumed that the firm's process technology is externally sourced. However, it doesn't seem that there would be much difference to the framework if the firm were the innovator of the process innovation.

\footnotetext{
${ }^{32}$ It should be noted that what we have described as 'demand pull' is actually an output market demand pull (analogous to Schmookler's 'demand pull') on the technology being used for production. See Chapter 2 of Kamien and Schwartz (1989).
} 


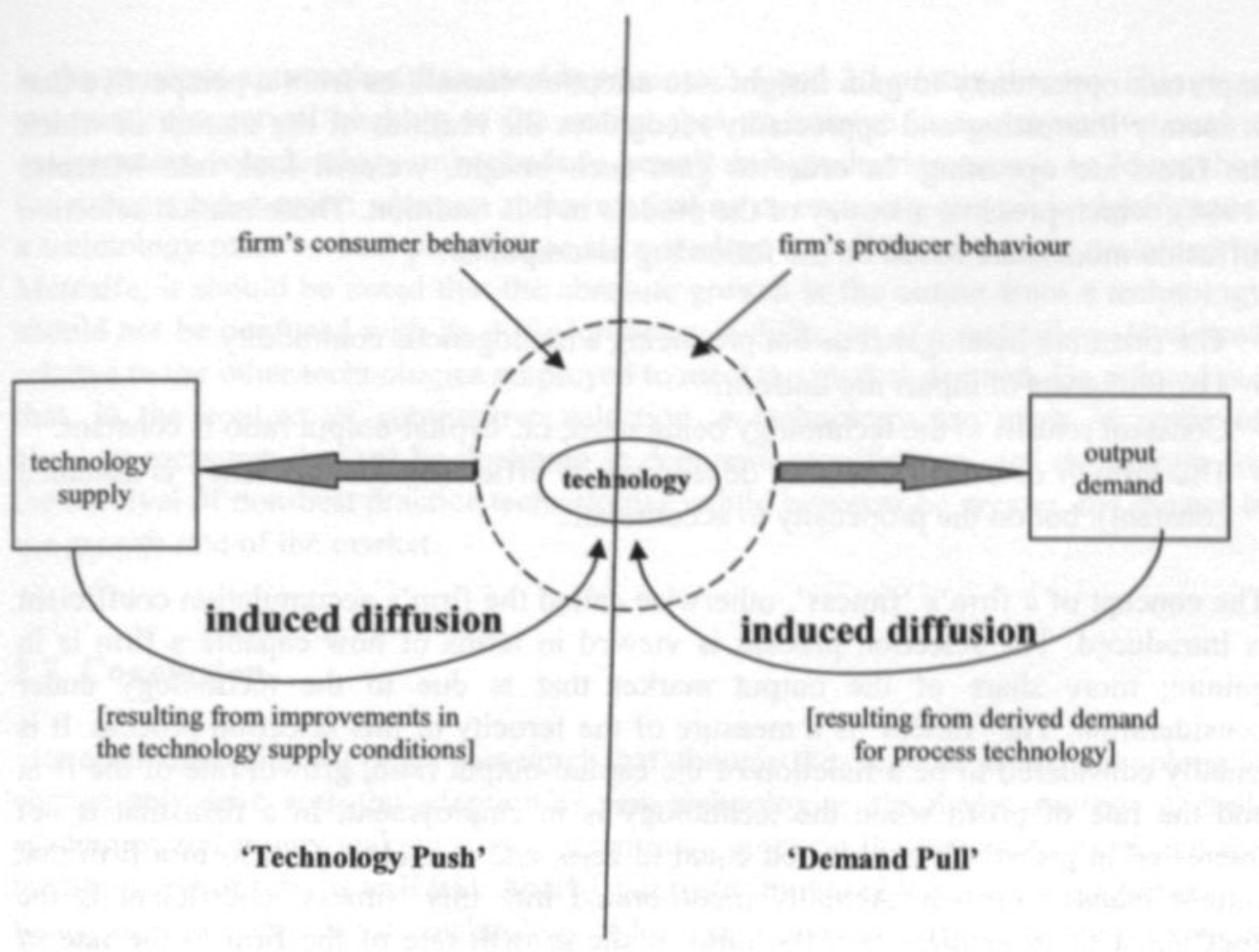

Fig. 2.4: Technology diffusion as an outcome of the interactions between the forces of 'technology push' and 'demand pull'.

While the analyses discussed in the previous subsections of this chapter have been primarily guided by the general neo-classical economic framework, the links between diffusion and the market competitive selection mechanism have been analysed using some of the tools of evolutionary economics, ${ }^{33}$ especially the acknowledgement of variety in a framework of competing technologies. The approach makes a remarkable break from the technology substitution notion implicit in the 'mainstream' diffusion analysis by adopting a multi-technology stance, in which the diffusion of a technology depends on the relative share of the market's output that is produced with the use of the technology. The varieties in the attributes of the firms and the attributes of the selection environment determine the differential rates of adoption of competing technologies. Though this multi-technology's approach appears pragmatic and addresses a major aspect of the previously unaddressed problem, it is however not yet amenable for empirical testing. The theoretical explanations, nevertheless present an

\footnotetext{
${ }^{33}$ For a comprehensive discourse of the evolutionary theory of economic change, see Nelson and Winter (1982), and Nelson (1995).
} 
important opportunity to gain insight into adoption causalities from a perspective that is seemly interesting and appreciably recognises the realities of the market in which the firms are operating. In order to gain such insight, we will look into Metcalfe (1988), which presents a survey of the models in this tradition. These market selection diffusion models are based on the following assumptions:

- The firms are heterogeneous but producing a homogenous commodity.

- The unit costs of inputs are uniform.

- Constant returns to the technology being used; i.e. capital-output ratio is constant.

- The growth of a firm does not depend on its efficiency (or efficiency is assumed constant), but on the propensity to accumulate.

The concept of a firm's 'fitness', otherwise called the firm's accumulation coefficient is introduced. The selection process is viewed in terms of how capable a firm is in gaining more share of the output market that is due to the technology under consideration. The 'fitness' is a measure of the ferocity of this selection process. It is usually considered to be a function of the capital-output ratio, growth rate of the firm and the rate of profit when the technology is in employment. In a firm that is not interested in growth, it is assumed equal to zero, and it is close to zero in a firm that cannot manage growth. Actually incorporated into this 'fitness' coefficient is the coefficient of investment (i.e. the ratio of the growth rate of the firm to the rate of profit). Thus, it is implicit in the definition of 'fitness' that faster growing firms increase the relative diffusion of the technologies that they employ through reinvestment of part of their profits, howbeit, at the expense of other firms because they gain more share of the output market. Based on this scenario, it became theoretically possible to group technologies into three: profitable technologies in which investment is occurring and output is growing (leading to more adoption of technologies); bankrupt technologies for which output is equal to zero (resulting in no further adoption of technologies); and marginal technologies on the borderline of survival, in which case output is positive but investment has ceased (also leading to no further adoption of technology).

Now, what implications does the theory on the market selection mechanism have with respect to the adoption of technologies? The theory highlights three important issues that expose reasons for adoption of technologies:

i) Growth in the market share of output due to a particular technology will elicit its adoption by some of the firms previously considered as non-adopters.

ii) The 'fitness', that is, the propensity to accumulate and re-invest is an important factor determining whether or not a firm decides to adopt a profitable technology. As earlier explained, 'fitness' is an indication of the ferocity of the selection market environment.

iii)A firm's desire for growth is an important rationale for technology adoption.

It is important to note that the theory of diffusion and competitive selection brought to the fore the significance of the evolution of the technology itself. This has not been so 
in the previous approaches discussed in sections 2.4 and 2.5 of this chapter. This gives necessary theoretical backing to the notion that, to survive in a competitive market environment, a technology only needs to permit unit production cost to be lower than the ruling market price; whereas, to have a lasting or enduring economic significance, a technology must be best practice, or at least close to it. ${ }^{34}$ However, as explained by Metcalfe, it should be noted that the absolute growth in the output from a technology should not be confused with its diffusion because diffusion of a technology is viewed relative to the other technologies employed to meet the market demand. He pointed out that, in the context of competitive selection, a technology can grow in terms of absolute measures, but yet be declining in economic significance; and the margin for the survival of non-best practice technologies would however be greater, the greater is the growth rate of the market.

\subsection{Conclusion}

Stoneman and Kwon (1996) lamented that though the benefits from technological change only arise with the adoption of new technologies, the major interests of both academics and policy makers have concentrated more on the determinants of and the measurement of returns to R\&D. Apart from fostering the objectives of this thesis, the focus of this chapter on technology adoption causalities therefore represents a contribution towards achieving a better balance in the study of the economics of technical change and the ensuing policy implications. We have gone through the main theoretical and empirical approaches to studying the adoption and diffusion of technological innovations in industry to elucidate the adoption causalities for new technologies. We have argued that technology diffusion is an outcome of the adoption decisions, and that in order to have a comprehensive view of the adoption rationales, it is necessary to examine the larger pool of diffusion literature. Among the diverse theoretical models for the diffusion of technologies, we have largely considered the findings of the epidemic and probit models because they have been comparatively more amenable to empirical analysis. However, this enabled us to ascertain the reasons for adoption of technologies only from the perspective of the firm as a user of technology. In order to gain a more comprehensive understanding of the adoption causalities, the discussion was extended to include the interactions of the supply-side factors, particularly the interaction of R\&D in the supply industry with the diffusion of new technologies.

\footnotetext{
${ }^{34}$ An important caveat to this is the divergence that technological expectations may introduce. A best practice technology may not last long or diffuse fastly if there exists an expectation of rapid technical progress that may lead to superior alternatives in the near future. This applies also if the adoption depends on a complementary technology. Expectations of improvements in the complement technology may delay the adoption of the best practice technology until the initial uncertainties are overcome to a reasonable degree. Rosenberg (1976) discusses the role of technological expectations with some interesting historical experiences.
} 
We also argued that the adoption and diffusion of a process technology and the interactions with the supply-side factors present only one side of the balance in the dynamics of the diffusion of new, and presumably superior technologies. The other side of the balance is to consider the firm's producer mentality and the competitive nature of the output market environment to be the determinants of the firm's adoption decision. In this respect, the firm's decision to adopt becomes a derived demand that depends on the requirements of the firm's output market. In order to expose and understand the adoption rationales from this perspective, we considered the findings of the theoretical diffusion models that are based on competitiveness and market selection. Though these are essentially models rooted in evolutionary theory of economic change, with no known significant empirical application, they fill an important vacuum that is difficult to ignore; and they present very plausible and complementary findings to the 'other side of the balance'. We also pointed out that the 'pivot' on which this balance stands is the firm's internal capability to adapt and absorb innovation.

The adoption causalities for technological innovations discovered in our search could be presented in six categories: profitability, other economic factors, technological capabilities, indirect influence of the supply-side, the output market, and institutional factors.

The first and perhaps most important is the profitability of the technology to be adopted. Without ruling out exceptions to the rule, all the theoretical and empirical studies we considered stressed that the main determinant of technology adoption is the perception of the firm on the possible profitability gain that may accrue to it on adoption. The profitability factor is however closely linked to other economic variables.

The most important of the other economic factors appear to be the firm size. In essence, there seems to be a triangular relationship between profitability, firm size, and the adoption of technologies; each factor influencing the other in a reversible manner (see figure 2.2). It is however important to note that firm size may not be an adoption motivating factor in itself because it is correlated with other factors. It may in fact be a reflection of other factors to which it is closely related.

The third set of factors embrace the technological capabilities for adoption. In this respect, such factors as the calibre and educational level of the workforce, R\&D capabilities and intensity, etc. are considered significant in determining the adoption of new technologies.

The fourth category of adoption causalities relates to the indirect influence of the supply-side factors on the adoption of new technologies. The variables involved include the level of R\&D and the progress of learning by doing in the capital goods sector, and the ability to assimilate the innovation users' feedback. 
The fifth category of factors signifies the impact of the output market on the adoption of technological innovations. Two important reasons for adoption are identifiable in this regard. Growth in the output share of a technology will induce more adoption of the technology by the previously non-adopters; and the growth of the entire market will discourage the adoption of new technologies.

The last set of factors consists of institutional variables such as the management attitudes (e.g. towards innovation, desire for growth, etc.). Though none of the models elaborately address the institutional factor, it obviously has significant influence on technology adoption in industry. Does the institutional setting of the environment in which the firm is located facilitate information flow? Are research and trade associations progressive? How about the national R\&D institutions - are they functionally linked with industry? Does the industrial policy regime encourage labour or capital intensive industries?

These findings are not assumed to be holistic. However, we believe that this checklist of adoption causalities represents a useful attempt to present a comprehensive view of the possible reasons for the adoption of process technological innovations in industry. With this at the background, the next chapter addresses the question: what causes the adoption of environmentally benign technologies in industry? 


\section{Chapter Three}

\section{ADOPTION CAUSALITIES FOR ENVIRONMENTALLY BENIGN TECHNOLOGIES: A CONCEPTUAL VIEWPOINT}

\subsection{Introduction}

The previous chapter has explored literature to identify the factors determining the adoption of normal business technological innovations. It appears plausible that the six categories of adoption causalities identified (viz., profitability, other economic factors, technological capabilities, indirect influence of the supply-side, the output market, and institutional factors) could in varying degrees influence the adoption of environmentally benign technologies (EBTs). In the context of normal business technological innovations, firm profitability and other economic related reasons ranked high as rationales for adoption. However, the trade-off between private and social costs of the adoption of EBTs may make direct justification of economic reasons for EBT adoption difficult. For EBT adoption, what role could be played by other reasons that have no direct bearing on economics? Of course, economic reasons cannot be precluded as reasons for EBT adoption; but to what extent, and what are the limits of economic related reasons of EBT adoption? In this chapter, we have attempted to answer these questions by presenting a conceptual viewpoint that could be used to analyse the underlying rationales for technology adoption decision of firms with respect to pollution control. Although the theoretical considerations draw largely from the experiences of industrialised countries, the focus of this thesis has made it imperative to tailor the theoretical framework developed such that it would be adaptable for addressing issues and problems of EBT adoption in developing countries. Consequently, while the next section presents the analytical framework for the adoption of environmental benign technologies, section 3.3 describes a trajectory of firms' technology responses to environmental regulation showing how EBT adoption could vary with levels of economic development. The central argument in this chapter is that, whereas environmental policy could be generally reckoned as the main driver of EBT adoption in developed countries, it is difficult to so conclude for developing countries' manufacturing. Other factors termed auxiliary drivers of adoption could play an equally important role as stimuli for EBT adoption. The auxiliary drivers proposed are factors generally identified with the firm characteristics, technological capability, and environmental policy implementation strategy.

\subsection{Firm Level Technology Adoption Behaviour: A Model of Adoption Causalities for Environmentally Benign Technologies}

The important role of technology as a solution to diverse environmental problems confronting economic actors has largely been subsumed in the general discourse of the 
costs of technological and economic development that contemporary environmental problems reflect. In the context of industrial development, internalisation of the social costs of production activities requires technical and organisational changes, which are largely accomplished at the firm level. As already indicated, the focus of this study is on the technical change aspect or the technology responses of industrial firms in their bid to improve the environmental performance of their activities. It is however important to point out that technological change is often accompanied by organisational adaptations or changes (Leonard-Barton, 1988; Tidd et al, 1997). While technical change is largely determined by man's handling or use of technological artefacts or knowledge, which can either result in incremental or radical innovation depending on the circumstances and scope of the underlying search activities; organisational change is largely a management issue. For example, referring to the experiences in organisational design in the Netherlands under the so-called STOD (socio-technical organisation design), de Sitter et al (1994) speaks about European approaches to organisational change, which seeks to transform 'complex organisations offering simple jobs' to 'simple organisations offering complex jobs'. Commenting in a similar vein, Kanter et al (1992) sees future organisations of the $21^{\text {st }}$ century as 'flexible organisations'. Flexibility as used in this context connotes not just technological adaptations or changes, but deeply rooted dynamics of adjustments in peoples' skills and positions in the emerging structure of new organisations. These new industrial structures have important implications for environmentally sustainable industrial production and development, especially with respect to firms' technology responses (see Fischer and Schot, 1993). This study could therefore be regarded as an investigation of the factors influencing the implementation of technical change that has environmental objective under a dynamic industrial structure.

Our theoretical approach in this study will draw from the traditional view of trade-off between social costs of economic activities and the private costs of compliance with environmental regulation (e.g. Baumol and Oates, 1988; Siebert, 1987; Palmer et al, 1995); and the new propositions on the possible relaxation of the trade-off as a result of regulation induced technical changes (e.g. Porter and Linde, 1995a\&b; Bonifant et al, 1995; Hart and Ahuja, 1996). To analyse the underlying rationales for firms' adoption of technologies that improve their environmental performance, we shall attempt to integrate into ideas derived from these apparently opposing concepts, contemporary (and perhaps new) insights based on the economic theory of technological innovation.

\subsubsection{Technology response for pollution abatement or prevention}

Viewed from the perspective that environmentally benign technologies are aimed at reducing the social costs of production and consumption activities, Stewart (1981, p.1261) has termed them 'social innovations'.' Stewart defines social innovation to

\footnotetext{
'In the same manner, Stewart (1981, p.1261) defines market innovation (the analogous of normal business innovation) to encompass development and adoption of new product and processes that will increase market
} 
include the development and adoption of new products and processes that are less polluting and safer or that otherwise deliver improved social performance, thereby facilitating the underlying goal of environmental, health and safety regulation. However, the notion of social innovation so defined may not necessarily connote technological innovation. It could also mean change in organisational processes that achieve better environmental performance of the firm. For clarity of expression, we will therefore avoid the use of the term 'social innovation' in this study. Our notion of environmentally benign technologies refers to those technological artefacts, measures or body of scientific knowledge, which facilitate the reduction or elimination of external diseconomies of firms. In this regard, a firm's technological response can be in the form of adopting technology for pollution abatement or adopting technology for pollution prevention. The former we have decided to term technology response for pollution abatement (TPA), while the latter is termed technology response for pollution prevention (TPP).

Drawing on Hartje (1984, p.10), we can succinctly articulate two main reasons or diversions why both TPA and TPP are traditionally thought to have negative impacts on a firm's costs schedule.

i) TPA/TPP diverts investment funds away from firm's normal business projects, including research and development that should promote innovations that could enhance the firm's standing in the market.

ii) TPA/TPP diverts firm's time and attention away from normal production activities and thus increase uncertainties thereby making the firm to face higher risks.

TPA falls into the traditional category of technologies usually referred to as end-ofpipe technologies (e.g. wastewater treatment plants, flue gas desulphurisation or scrubbers, catalytic converters, etc.). They are employed to ameliorate or remove the undesirable effects of production activities on the natural environment. They are usually 'add-ons' or 'retrofits' to the existing production facilities, and hence they engender additional production costs. They however often cost less for initial purchase and installation than extensive process changes, and they can be installed with less disruption to production schedules. They may not require the level of R\&D needed for making radical changes to products or processes (Geffen, 1995, p.314). They mostly result from demand pulls arising from environmental regulations rather than innovative attempts by firms to improve existing production processes. Even the market for end-of-pipe technologies favour their production and diffusion. The number of users tends to be higher than cleaner technologies because they can be used to treat wastes from a number of plants, processes and industries; they are only pollutant specific. In contrast, cleaner technologies are usually industry or process specific, and therefore, the number of users is bound by the number of process specific plants in the industry (Skea, 1995; OECD, 1985; Hartje and Lurie, 1984, 1985; Vernon and Johnson, 1984). Though end-of-pipe technologies are potent in achieving 
the objective of improving environmental quality; in many cases, they nevertheless end up in transferring pollution from one medium to another. ${ }^{2}$

In contrast to TPA, TPP represents a more desirable approach that portrays technology as a solution to environmental problems. TPP is in consonance with the concept of cleaner production (or technology) that requires that pollution be reduced at the source, and where possible eliminated. As one of the core issues relating to industry in Agenda 21 , the UNCED ${ }^{3}$ proposes a cleaner production programme which aims to improve the efficiency with which natural resources are used, by encouraging processes that generate less wastes and increasing the recycling and re-use of process wastes (Skea, 1994). The essential philosophy underpinning cleaner production is 'prevention is better than cure' (Vernon and Johnson, 1984, p.20). UNEP ${ }^{4}$ defines cleaner production as "the continuous improvement of industrial processes and products to reduce the use of resources and energy; to prevent the pollution of air, water, and land; to reduce wastes at source; and to minimise risks to the human population and the environment" (UNEP, 1997, p.134). Accordingly, a TPP can either be in the form of a process innovation that is directly a 'cleaner production', or a product innovation that induces cleaner production. However, it is increasingly acknowledged that cleaner technology has to be defined in broad terms as an approach or strategy, rather than a specific class of solutions (EC, 1997; Clift and Longley, 1995). A cleaner solution in one context might not be the best or most appropriate in another; and the concept may even be applied to relevant changes in management policies and practices as much as to technological innovations as earlier defined in this chapter. This limitation notwithstanding, the approach has the potential of introducing a new paradigm of environmentally sustainable production. Since the main focus of cleaner production is the reduction or elimination of pollution at the source, the strategy depends largely on firms' capability for innovation in pollution control.'

\subsubsection{Adoption causalities in perspective}

\section{Major driver of adoption}

Given the fact that TPA and TPP are apparently employed to solve the same problem (viz., reduce environmental burden), it is conceivable that the causative factors for their adoption would overlap. As we earlier indicated in chapter one, the most important of these factors appears to be the prevailing regime of environmental policy under which firms are operating. Environmental policy could therefore be regarded as

\footnotetext{
${ }^{2}$ For example, after a wastewater treatment plant has removed TSS (total suspended solids), BOD or COD, it leaves a sludge, which is 'digested and dewatered' before disposal into a land fill. Pollution is thus transferred from an aqueous medium to a solid medium.

${ }^{3}$ United Nations Conference on Environment and Development.

${ }^{4}$ United Nations Environment Programme.

In the context of our discussion, pollution control is not to be seen in the narrow sense of remediation activities, but also includes pollution prevention strategies.
} 
the major driver of the adoption of EBTs. A firm's technological response could vary between TPA and TPP depending on the forms and strategies of the prevailing regime of environmental policy. It has been largely demonstrated particularly from the theoretical viewpoint (e.g. Downing and White, 1986; Milliman and Prince, 1989; Jung et al, 1996) that different policy instruments will induce different levels of technical change in firms' compliance responses. As an illustration, Table 3.1 presents the summary of Downing and White's static analysis of the possible impact of various policy instruments on firms' incentive to carry out environmentally friendly innovation. In this respect, we consider innovation to include varying degrees of technical change ranging from the sometimes spontaneous adoption of abatement technologies (TPA) to a more innovative perspective that seeks to reduce pollution at source (TPP). Generally speaking, two broad categories of environmental policy are identifiable. The first is the traditional 'command-and-control' (CAC) effluent or practice standard prescription policies, which rely on the power of direct controls exercised by the regulatory authorities. The second comprises of economic incentive based policy approaches which rely on the power of the market to regulate the polluter after the regulator has set the optimal pollution level for social welfare (Irwin and Hooper, 1992). However, it may not always be possible to distinguish between firm's technology response borne out of the two kinds of policy measures because technology responses may be outcome of both economic and regulatory pressures working together. The technological responses to the German industrial wastewater control policies present a practical illustration of this (see Bongaerts and Kraemer, 1989; Kessler, 1998).

Table 3.1: Incentives for innovation under various pollution control arrangements

\begin{tabular}{|l|c|l|l|c|}
\hline & effluent fees & subsidies & $\begin{array}{l}\text { marketable } \\
\text { permits }\end{array}$ & $\begin{array}{l}\text { direct regulation } \\
\text { (CAC) }\end{array}$ \\
\hline $\begin{array}{l}\text { No change in marginal } \\
\text { conditions }\end{array}$ & optimal & optimal & optimal & deficient \\
\hline $\begin{array}{l}\text { Change in marginal } \\
\text { conditions, no racheting* }\end{array}$ & excessive & excessive & intermediate & deficient \\
\hline $\begin{array}{l}\text { Change in marginal } \\
\text { conditions, racheting }\end{array}$ & excessive & deficient & deficient & deficient \\
\hline
\end{tabular}

* 'racheting' is used to signify a situation in which a firm's innovation in pollution control has sufficient impact on the overall level of pollution such that the social marginal cost of pollution based on which the social regulator calculates his control measures changes, and he accordingly makes the necessary appropriate changes in the regulatory schedule.

Source: Downing and White (1986, p.28). 


\section{Auxiliary drivers of adoption}

Apart from environmental policy, other factors, which may be termed auxiliary drivers of adoption, could also be identified. The first of such factors is firms' capability for innovation in pollution control. Like normal business innovation capability, this capability has two broadly identifiable components. The first is the firm's internal capability for innovation; while the second is the firm's external network for innovation. This distinction is explored in a more detailed perspective by Rothwell (1994) which views the innovation process as comprising a series of internal learning on one hand, and a series of external learning on the other. Lall (1992, p.166) also makes similar dichotomy by specifying that firm level technological capability depends partly on past accumulation of skills and knowledge, and partly on external inputs from other economic agents with which the firm shares technical or market related characteristics. The learning process is widely accepted in economic theory of innovation as the means through which the capability for technological innovation is acquired (Arrow, 1962; Rosenberg, 1982; Nelson and Winter, 1982; Freeman and Soete, 1997; Kim, 1997).

The level of technological knowledge embodied in the firm's human resources and technological artefacts largely determines a firm's internal capability for innovation. This knowledge includes not only that required for R\&D but also the ability to adopt new technology, to evaluate a new technique, or to relate with parties external to the firm on finding solutions to technological problems (Mowery and Rosenberg, 1989, p.8; Tidd et al, 1997). The emphasis on knowledge has led to the general recognition of the level of skills and scientific knowledge embodied in a firm's personnel, and the sophistication of its technological artefacts as important indicators of the firm's internal capability for innovation. It is necessary to also point out that since technological knowledge is embodied in human resources and technological artefacts, the commitment of a firm to R\&D (and by implication, R\&D expenses) will also considerably affect the capability for innovation. Investment in R\&D implies the 'purchase' of skilled personnel, technological artefacts and/or 'blueprints' that would interact to generate innovation. Thus, either R\&D expenditure of the firm or perhaps, the number (and/or quality) of patents taken out of the firm's R\&D efforts would also be an indication of the firm's internal capability for innovation. The capability for innovation may however be constrained by technology specific factors. For example, with regard to EBTs, Hartje and Lurie (1985) gave relevant illustrations of how technology specific factors may limit the ability of firms to adopt TPP instead of TPA. Such technology specific reasons include the substitutability of inputs and the existence of dominant designs in certain industries or subsectors. ${ }^{6}$ Furthermore, the

\footnotetext{
${ }^{6}$ For example, TPA is likely to be more prevalent in industries such as power generation and metal smelting where central inputs like ores and other raw materials, cannot be easily substituted. On the other hand, TPP may be less difficult to achieve in industries such as painting. cleaning or metal-plating where input substitution is relatively less difficult. As for dominant design, many metal production processes, which usually involve the purification of an input to separate the metal from its natural impurities, have practically attained a theoretical optimal design. When a TPP is identified, it is very likely that such have been considered in the past but was considered less profitable. The processes being used by firms have become the standard or normal practice technologies because they reduce overall costs, not just pollution costs (Hartje and Lurie, 1985, pp. 2-6.).
} 
capability for innovation may be promoted by newness of firm (e.g. greenfield investments). Technical innovation that would have been relatively difficult to stimulate by regulatory action may be facilitated by opportunities for new firm entrants. The case of pulp and paper industry in Chile is a good illustration of this (see Herbert-Copley, 1998).

Firms' relationships with parties external to the firm on finding solutions to technological problems have underlined the crucial role of the type and number of external network relationships as important determinants of a firm's ability to innovate. In the theory of company networks, at least three kinds of network relationships with agents external to the firm have been identified. They include business network, knowledge (development) network, and regulatory networks. While Cramer et al (1990, p.20) gives a comprehensive list of actors involved in these networks, Dijken et al (1998) distinguishes between them as follows:

i) business network consists of the supply chain with regard to the products to be produced by the technology concerned and the supplier(s) of the technology (that may be either embodied in particular equipment or integrated in particular procedures or systems);

ii) knowledge network consists of research organisations, universities and consultancies which are actively engaged in the further development and application of a particular technology;

iii)regulatory network consists of government bodies engaged in the execution of certain policies, such as licensing or permit issuing authorities, enforcement authorities, and bodies executing certain financial support programmes.

While not denying the importance of the business and regulatory networks, the knowledge network apparently has more specific roles to play in a firm's capability for technological innovation. It could however be seen that the business network, as described above, has elements that could also contribute significantly to a firm's innovation capability. We therefore define a firm's external network for innovation to incorporate the knowledge network and the aspects of the business network that could potentially contribute to a firm's innovation capability. The external network for innovation may thus be viewed as consisting of the knowledge and business networks with a common distinguishing denominator of relationships that involve the exchange of technological information which could either be embodied in persons or equipment. With respect to the adoption of EBTs, it essentially includes the components of the knowledge network and the backward linkage with the environmental goods and services industry.

While the form and nature of environmental policy serve as the major driver of the adoption of EBTs, the national institutional capacity for environmental regulation could also be an important determinant of EBT adoption. The institutional capacity for environmental regulation may go a long way to determine the form and type of technological responses firms will adopt for compliance with environmental policy. In this respect, the answers to certain institutional related questions can unveil the 
strengths and weaknesses of a nation's capacity for environmental protection. Such questions include: Who formulates the policy, is the approach 'bottom-up' or 'topdown'? What is the scientific capability of the regulatory body? What links does it have with other agencies that are involved in environmental policy matters? Was technology content of firms' responses taken into consideration while formulating policy, while approving permits, and while monitoring compliance? Were policies based on scientific data or estimates, perhaps derived from other countries' experiences? In developed countries, there are ample evidence that reforms in the institutional framework for environmental regulation have been instruments for strengthening environmental policy and directing it towards more efficiency in inducing appropriate technical changes that have positive effect in improving environmental quality. For example, Andersen (1994) and Kraemer (1995) reported that an important reason why the German wastewater effluent charge scheme for water pollution control did not get support to carry the originally proposed strong economic incentives ${ }^{7}$ was because there was no specific full-fledged Federal Ministry charged with the responsibility of environmental protection. When the policy was adopted by the German Lower House (Bundestag) in the 1970s, environmental policy was still the responsibility of the Ministry of the Interior. The Federal Ministry of Environment, Nature Conservation and Nuclear Safety was not established until 1986. Thereafter, the wastewater effluent charges have undergone considerable upward reviews aimed at strengthening the economic incentive of the charges. Perhaps, the introduction of the Integrated Pollution Control ${ }^{8}$ (IPC) in the United Kingdom provides a more vivid illustration of the role of institutional regulatory capacity. The Environmental Protection Act of 1990 introduced the concept of IPC and a comprehensive reform of the regulatory system for pollution control. In 1987, several of the agencies responsible for pollution control were merged to form Her Majesty's Inspectorate of Pollution (HMIP), which together with the National Rivers Authority took over the responsibility of pollution control. These two agencies were later merged in 1995 to form the British Environment Agency to implement the IPC concept. These institutional reforms have been reported to result in better environmental performance of industrial firms in Britain (Howes et al, 1997; Smith, 1997).

Another factor that may determine the adoption of EBTs is the strategy for environmental policy implementation. In this sense, strategy is thought of in terms of whether it is an approach of co-operation between the regulator and industry or antagonism. For instance, it has been shown in Denmark, the United Kingdom and the Netherlands that when regulators use a strategy of co-operation and dialogue with

\footnotetext{
7 When the effluent charge scheme was proposed in 1974, it was to serve as a strong economic incentive instrument independent of direct regulation. The unit rate for effluent discharges was to be DM25 from 1976, and DM40 from 1980. However, the charge system was not only delayed until 1981, but was also reduced to a supplement to the direct regulation, with the effluent charge unit rate starting from as low as DM12 (Kraemer, 1995; Kraemer and Jăger, 1997).

"The IPC framework sets a holistic and integrated approach to reducing the overall environmental impact of industrial processes in the UK, and emphasises the need to minimise impacts across all media: air, water and soil (Howes et al, 1997).
} 
industry, the technological responses have tended towards TPP. In contrast to this, the approach of forced compliance has been noted to foster TPA (Murphy and Gouldson, 1997; Laudise and Graedel, 1998).

Closely related to the environmental policy implementation strategy is what may be termed firm's environmental disposition. A firm that is environmentally proactive most likely has comparatively better relations with the regulatory authorities. Furthermore, such firms may be a 'first mover' in environmental innovation, and have a better tendency towards TPP. Distinguishing feature of such firms would include whether or not the firm has internal environmental policy; or subscribes to some recognised standard environmental audit/assessment policy such as EU/EMAS, ${ }^{9}$ ISO 14001 , etc. The disposition of proactivity corresponds to what is described as 'innovative' industry's responses to environmental pressure by Roome (1994). For these firms, in spite of considerable environmental risks, they could still find opportunities for market growth. Roome also highlights other dispositions as 'defensive', 'indifferent', and 'offensive' depending on the firm's attitude to the risks that may attend the firm's overall responses to environmental policy. The firm is defensive in cases where risks are high. The organic chemicals sector where there is little opportunity for substantial product development through environmentally benign products and processes is an example of this. Firms are indifferent when they face low environmental risks either because the nature of their activities have comparatively less significant impact on the natural environment, or because they provide some other social benefit that make regulation not an optimal option. For example, one of the reasons why small-scale enterprises generally face less environmental risks is because they generate employment. 'Offensive' disposition is ascribed to firms that favour stringency in environmental regulation. Such include firms in the environmental goods and services sector because environmental policy enhances their opportunities for market growth, especially in the field of pollution control and monitoring equipment.

Other reasons why firms may adopt EBTs also include competitiveness and profitability as in the case of normal business technological innovation. Lall (1997) defines competitiveness at the company level to include growth, market share and profitability. However, with respect to technology responses to environmental policy, it is possible to isolate profitability from competitiveness at the firm level. Though the ultimate objective of competitiveness is profitability, the profitability reason may or may not be linked to that of competitiveness. It is recognised that competitiveness does not always imply more profit, especially in the contemporary world of imperfect competition and strategic behaviour of industrial firms. A firm's strategy to acquire market share in order to attain the optimal economies of scale may initially result in less profit (or even loss). Such a strategy may include eco-innovations that may boost consumer acceptance of products. Market share may be gained; but perhaps at less profits $^{10}$ to the firm. On the other hand, profitability could also be perceived as

\footnotetext{
'European Union's 'Eco-Management and Audit Scheme'.
}

${ }^{10}$ The strategic effect of less profit may in effect produce long-term profitability that recovers the initial losses. 
standing alone when firms are able to identify a process or product which though environmentally more benign, results in less costs to the firm.

The competitiveness reason could be tied to the 'first-mover' advantage argument. In this respect, Porter and Linde (1995a\&b) have argued that there has been sufficient evidence that should bring about a new thinking that environmental performance and competitiveness are not diametrically opposing. Rather, a firm could anticipate environmental regulation and thus innovate ahead, and in the process gain competitiveness while at the same time improving environmental performance. This notion has in recent years seriously challenged the traditional view of trade-off between competitiveness and environmental performance, " which is usually based on theoretical static analysis of the marginal pollution abatement levels that firms may decide to achieve in response to the regulator's perception of the required social welfare. Porter and Linde apparently suggest that competitiveness may depend on firm's ability to innovate in response to environmental regulation. We however propose that the reverse could also hold on two accounts. Firstly, since competitive firms are generally reckoned to be innovative firms (see Tidd $e t$ al, 1997; Clark and Staunton, 1989), the capability of a firm to adopt a peculiar technology such as EBT may depend on the intrinsic competitive nature of the firm. A very competitive firm may be more prone to recognise opportunities for eco-innovation than a less competitive one. The simplest of such innovative opportunities is akin to the so-called 'low lying fruits' or 'ten-dollar bill on the wayside'; or more profoundly, technical innovations ( $a$ la 'innovation offsets') that generate returns higher than the cost of environmental regulation (Porter and Linde, 1995b). Secondly, if it is truly possible to identify the 'innovation offsets' as proposed by Porter; then, whether or not an innovation offset is generated (or adopted) will depend on the innovation's ability to contribute to the firm's competitiveness. In essence, this may depend on the perceived impact of adoption on costs. The perceived impact of adoption on costs would of course be a reflection of the influence of adoption on firm's profitability or competitiveness.

As demonstrated in chapter 2 , it has also been profoundly argued in economic literature that the size of a firm may determine the ability of the firm to adopt technological innovation. It is particularly necessary to consider firm size as a determinant of EBT adoption because it has been suggested that large firms have more resources to invest in technology responses aimed at improving environmental performance. For example, Howes et al (1997) stressed that:

\footnotetext{
"Palmer et al (1995) presents a rehearsal of the traditional viewpoint in response to Porter's hypothesis on the compatibility of environmental performance and competitiveness; while Hart and Ahuja (1996) gives a recent empirical support to Porter's arguments. It is however important to note that, Jaffe et al (1995) and Jaffe and Palmer (1996) have given comprehensive empirical analyses of the core issues in this debate using data on American firms' performance. They found little evidence to support Porter's hypothesis, and suggested that the truth of the trade-off between competitiveness and environmental performance lies between the two extremes of the arguments.
} 
"There are huge differences between the environmental behaviour of different segments of industry. The multinationals are at the opposite end of the spectrum from small-to-medium-sized enterprises (SMEs) which struggle to remain in business, cannot command the managerial resources required to put environmental management systems in place and have enormous difficulties even in complying with regulation. An important group of middle ranking companies - traditionally operating nationally but increasingly participating in export markets- occupy an intermediate position. These companies are large enough to bring managerial attention to bear on environmental issues but lack the overall level of resources available to the multinationals" (Howes et al, 1997, p.3).

But are smaller firms picking up? Are they coming more into focus in environmental performance? Neither small nor medium-scale firms could be assumed off in the analysis of technology responses to environmental policy; not only because of their vast number and the relative importance of pollution threats they may constitute, but also because they have been proven to have capacity for innovation, especially when given the necessary incentives (Geiser and Crul, 1996; Dijken et al, 1998). It is however noteworthy that firm size is in itself an endogenous variable determined by factors that may include those already identified as determinants of EBT adoption in this chapter. For instance, as demonstrated in section 2.4 of chapter 2 (see also figure 2.2), profitability could be a determinant of firm size. This notwithstanding, it is apparent from the forgoing that firm size could stand as a distinct independent variable in explaining the EBT adoption decision of firms.

From our discussion so far in this subsection, we have suggested one major driver of the adoption of environmentally benign technologies; viz., the regime of environmental policy. Other factors, which we have decided to term auxiliary drivers of adoption, could be enumerated as follows:

i) Firm's internal capability for innovation;

ii) Firm's external network for innovation;

iii)Institutional capacity for environmental regulation;

iv)Environmental policy implementation strategy (co-operative or antagonistic);

v) Firm's environmental disposition;

vi)Intrinsic competitive nature of the firm;

vii) Perceived impact of adoption on costs or firm's profitability; and viii) Firm size.

It is necessary to state that these factors may not be completely shielded from the influence of the prevailing environmental policy regime. As earlier indicated in section 3.2.1, economic imperatives dictate that a firm will not adopt EBT except compelled or induced by environmental policy. Thus, while these factors may be regarded as independent variables determining the adoption of TPA or TPP, they may nonetheless have operational links with existing or proposed environmental policy. Their influence on TPA or TPP should therefore be carefully interpreted. Furthermore, the fact that we have called them auxiliary drivers of adoption should not be mistaken 
for relegation. Depending on the institutional and socio-economic context in which the firm operates, it is conceivable that some of the auxiliary factors may be as important as (or even more important than) the prevailing environmental policy. ${ }^{12}$ Moreover, it is also necessary to point out that in the formulation of environmental policy, the auxiliary factors of EBT adoption are taken into consideration. Thus, there is a twoway interaction between the major and auxiliary drivers of the adoption of EBT. This notwithstanding, our propositions on the relative position of the two set of factors appear amenable for elucidating the reasons why firms adopt environmentally benign technologies. In this respect, whereas environmental policy may be generally reckoned as the major driver of EBT adoption in industrialised countries, the auxiliary drivers of adoption may play equal (or even more) important roles as reasons for EBT adoption especially in developing countries where the regime of environmental policy is perceived to be comparatively weak. ${ }^{13}$

Figure 3.1 is a graphical representation of the framework described in this section. This framework appears to be applicable to industrial firms irrespective of the level of development of the national state where they are operating. However, it is necessary to point out that a trajectory of firms' technological response to environmental policy is identifiable if the national development status is taken into consideration. This is described in the following section.

\footnotetext{
${ }^{12}$ In the subsequent chapters of this treatise, this hypothesis would be elaborately explored by applying the framework developed in this chapter to the case of Nigerian manufacturing industry.

${ }^{13}$ For example, in developing countries where institutions for environmental policy are considered relatively weak, competitiveness drives may override environmental policy in a firm's decision to invest in TPA and TPP.
} 


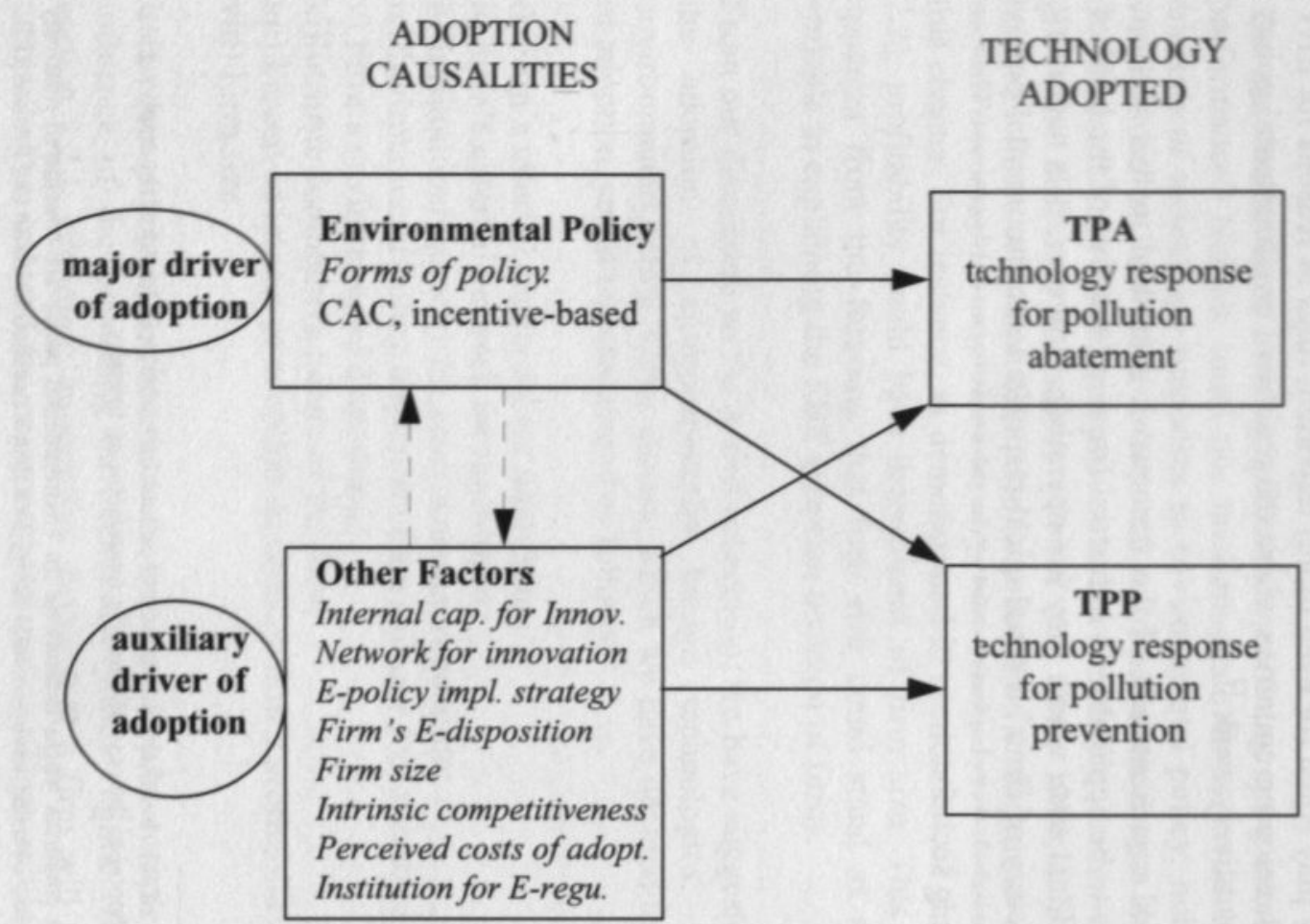

Fig. 3.1. A framework for the analysis of the adoption of nvironmentally benign technologies 


\subsection{A Trajectory of Firms' Technology Responses to Environmental Policy}

Since we have identified environmental policy as a major cause of firms' adoption of EBTs, the scope of our study necessitates taking a closer look at the role it plays in stimulating technological adoption at different stages of national development. When the socio-economic context in which firms operate is considered, it is possible to propose a trajectory of firms' behaviour within the framework of the economic development process. We have conceptualised this trajectory as depicting three stages that reflect different levels of environmental regulation and corresponding technology responses by industrial firms. The first stage could be termed 'weak regulation, limited technology responses'; the second, 'appreciable regulation, notable technology responses'; and the third, 'strong regulation, prominent technology responses'. The characteristic features of this proposed trajectory is summarised in table 3.2 , and graphically described in figure 3.2 .

\subsubsection{Stage 1: Weak regulation, limited technology responses}

In less developed countries, it is generally recognised that there is less awareness of the need for environmental conservation and poor appreciation of citizen's environmental rights. Because of the somewhat desperate need to raise societal standard of living, economic activities are more focused on development. In such a situation, development is more prone to be at the expense of the natural environment, and hence environmental policy regime is expected to be relatively weak. Under such a regime, firms' technology responses to environmental policy would expectedly be low when compared with experiences in developed countries. Accordingly, firms' investment in pollution control technologies would also be relatively low. The challenge of environmentally sustainable industrial development at this stage is more focused on how to tackle the obstacles to firms' adoption of EBTs. Nevertheless, this does not totally preclude the employment in industry of technological innovations aimed at alleviating perceived industrial pollution problems. Besides, important industrial production facilities may be under the control of multinational enterprises that may be relatively favourably disposed to employing EBTs. Hence, while the focus here may be more on obstacles to technological response; the prevailing industrial environment may also present the opportunity to explore the underlying rationale for technological innovation that have positive impacts in preventing or abating industrial pollution. It is also necessary to state that when firms have reasons to adopt EBT at this stage, it may not be largely explainable by environmental policy. However, where environmental policy has some influence, firms' responses to environmental policy may be more weighted towards TPA than it would have been in the more developed countries. The reason for this could lie in the fact that, at this stage of development, regulatory authorities rely more on policy instruments of command-and-control. Alternative regulatory measures such as pollution tax may be contemplated, but are generally not accepted. 


\subsubsection{Stage 2: Appreciable regulation, notable technology responses}

As development progresses and the society becomes more environmentally conscious, citizen's environmental rights begin to come to the fore, and firms can no longer be environmentally complacent. Environmental policy takes root, and TPA becomes entrenched in the environmental regulatory regime, and perhaps becomes a standard. Citizen's environmental rights may still be suppressed, and regulatory measures may still be reasonably permissive as the development imperatives behind economic activities still compel the regulators to allow firms some measure of 'freedom' to pollute. A good illustration of this is the case of delayed consent of developing countries (e.g. China) to the Kyoto protocol ${ }^{14}$ on the reduction of greenhouse gas emissions (Mckibbin and Wilcoxen, 1999). At this stage, firms' investments in pollution control technologies increase considerably, and may continue along the trajectory of TPA, especially if new strategies for environmental regulation are not introduced. The challenge of environmentally sustainable industrialisation would still be reasonably focused on obstacles to the adoption of EBTs like in the earlier stage. However, because of appreciably more established regime of environmental policy and the higher level of technological development, the type of responses (TPA or TPP) that is suited for particular problem situations will begin to be important considerations in firms' technological decisions. Besides, regulatory authorities become more favourably disposed to alternative control measures (e.g. effluent charge or pollution tax) that could improve the traditional approaches to environmental regulation.

\subsubsection{Stage 3: Strong regulation, prominent technology responses}

After a nation has achieved its industrialisation objectives, and is globally reckoned to be industrialised, environmental regulation becomes more scrutinised. This is because the level of environmental awareness has become relatively high, and it accordingly becomes more difficult to disregard environmental rights. New measures are introduced to enhance the performance of the environmental regulatory regime, and the environmental performance of industrial firms becomes a major concern. At this stage of development, the imperative of international competitiveness of industrial firms makes it necessary for both the regulator and the regulated to either cooperatively or independently seek how to achieve the double objective of better environmental performance and competitiveness. In the process, the regulator may introduce new regulatory instrument (e.g. effluent charges, tradable permits, covenants, voluntary agreements, etc.). On the part of the firms, they would become

\footnotetext{
${ }^{14}$ The Kyoto protocol is the United Nations Framework Convention on Climate Change (UNFCCC), which was negotiated in December 1997 at Kyoto, Japan. The objective of this protocol is to impose binding greenhouse gas emission targets on the industrial countries and former communist economies of Europe. The targets, which did not explicitly include developing countries, are to be achieved by 2008-2012 (Mckibbin and Wilcoxen, 1999). The protocol however undergoes periodic review, the last being at Buenos Aires, Argentina in November 1998.
} 
more obsessed with maximising opportunities or restricting new constraints that may be created by the developments in the regulatory process. Though their technological responses at this stage may considerably follow the TPA trajectory because of the relatively less difficulty to 'retrofit' than to replace technological hardware and processes; there would nevertheless be identifiable trajectory of TPP. Initially, TPP may imply additional costs over and above the conventional TPA. But as time progresses, the investment in TPP is offset through gains resulting from firms' better environmental performance. The challenge of environmentally sustainable industrial development is more focused on how to reduce the environmental burden resulting from industrial activities, and the possibility of creating a new regime of firm performance that is TPP based. At this juncture, it is necessary to point out that, though the existence or application of TPP is relatively more pronounced at stage 3 , it could nevertheless be present, howbeit, less observable in the earlier stages. It is also necessary to state that industrial sectoral differences may affect the nature of the trajectory of technology responses.

As apparent from the foregoing, we have proposed that developing countries' firms fall into the first two stages. These two stages span two extremes of developing countries with varying degrees of industrialisation. On one extreme are those whose technology responses are almost comparable to developed countries' firms, while the other comprises of those that portray more of obstacles to technology responses. We suggest that the former could be exemplified by some of the newly industrialising economies (e.g. South Korea, Singapore, China, etc.), while the latter could be illustrated by some of the less developed countries of sub-Saharan Africa (e.g. Togo, Cameroon, Tanzania, etc). The description of the state of Nigerian environmental regulation in the next chapter, and the empirical results of this study presented in chapters 6 to 8 shed light on the possible location of Nigeria in this trajectory of firms' technology responses. 
Table 3.2 : Stages in environmental regulation and technology responses by industrial firms.

FACTOR

STAGE 1

STAGE 2

STAGE 3

National industrial

output

Standard of living

(GDP per capita)

Environmental

conservation awareness

Very low - low

regulators and industry

Principle of pollution control

Firms ' innovation in pollution control

Levels of technology

responses

Challenge of

environmentally

sustainable

industrialisation

Reasons for technology responses by firms
Fluid

Abatement bias

'command-and control'

(CAC)

Weak

Fluid

Low, and largely TPA oriented

Limited

Focus on obstacles to technology responses

Environmental policy important, but auxiliary reasons may dominate
Low - moderate

Appreciable

$\mathrm{CAC}$ and emerging market incentive

Moderate

More of antagonism

High

High

High

Strong

$\mathrm{CAC}$ and strong market incentive

Strong

Emerging co-operation

Abatement bias, but pollution prevention creeps in

pollution prevention bias

Medium, largely TPA, emerging TPP

Notable

Focus on obstacles to technology responses, and strengthening of technology responses

Environmental policy and auxiliary reasons
Prominent

High, TPA \& TPP; emphasis on TPP.

Focus on strengthening technology responses, search for appropriate shift to TPP.

Environmental policy dominated 


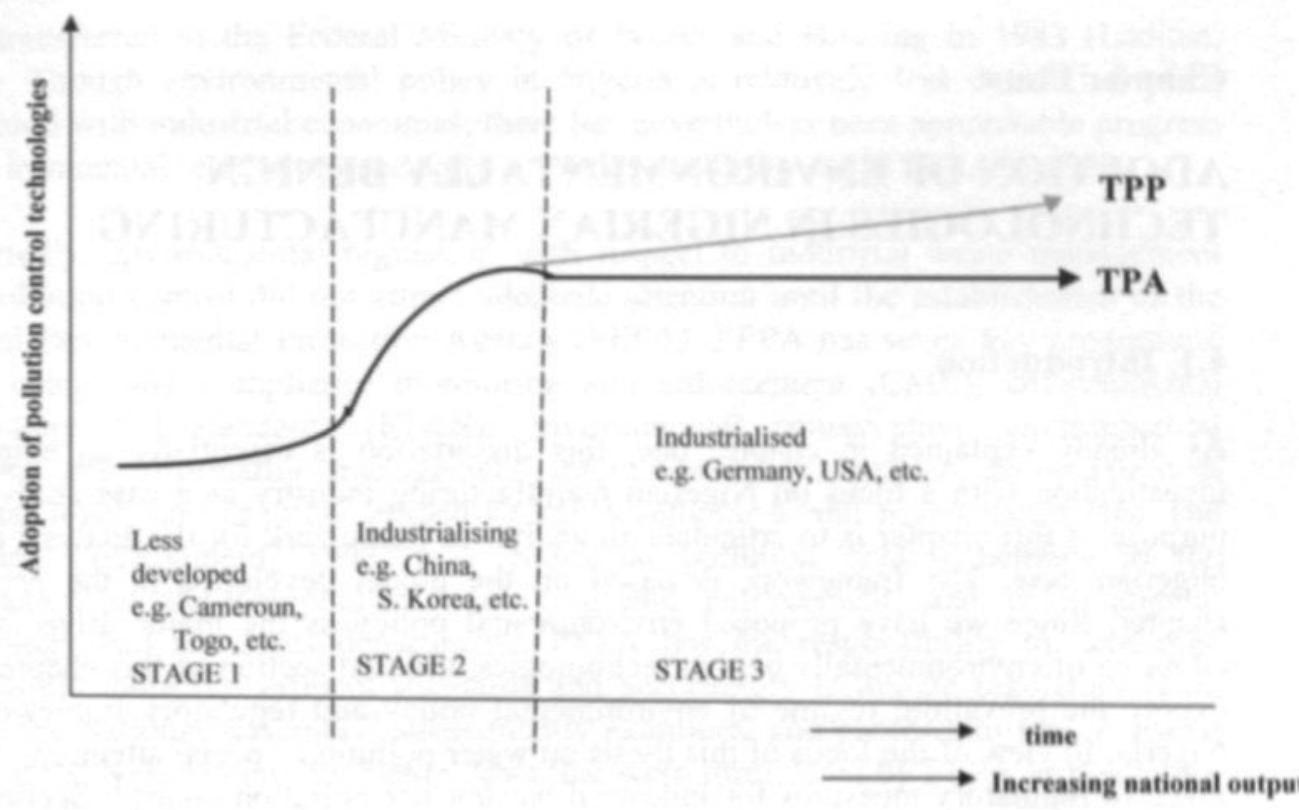

Fig.3.2. A trajectory of technology responses to environmental policy in industry as national development progresses.

\subsection{Conclusion}

The analytical framework developed in this chapter has proposed environmental policy as a major driver of the adoption of environmentally benign technologies, while other factors that essentially signify firm characteristics, technology capabilities, and environmental policy implementation strategy are regarded as auxiliary drivers of adoption. The relative importance of major versus auxiliary drivers may vary according to levels of economic development. We are of the view that the nature and trend of such variation could be ascertained by empirical investigation of specific country or regional cases. In this respect, how can the model described in this chapter be adapted for the analysis of adoption causalities of environmentally benign technologies in developing countries? As earlier suggested in chapter one, we would attempt to answer this question with a focus on Nigerian manufacturing industry. Considering the central role of environmental policy in our model, it is however necessary to first give an overview of the environmental regulatory regime in Nigeria in order to comprehend the propositions and research hypotheses for the case of Nigerian manufacturing. The next chapter therefore discusses the Nigerian environmental policy framework with a particular focus on industrial wastewater pollution control. Thereafter, a detailed description of the application of the theoretical framework in this chapter for the analysis of EBT adoption causalities in Nigerian manufacturing industry is presented. 


\section{ADOPTION OF ENVIRONMENTALLY BENIGN TECHNOLOGIES IN NIGERIAN MANUFACTURING}

\subsection{Introduction}

As already explained in chapter one, this dissertation is essentially an empirical investigation with a focus on Nigerian manufacturing industry as a case study. The purpose of this chapter is to articulate an analytical framework for the analysis of the Nigerian case. The framework is based on the model developed in the previous chapter. Since we have proposed environmental policy as the major driver of the adoption of environmentally benign technologies, the first section of this chapter will expose the prevailing regime of environmental policy and regulatory framework in Nigeria. In view of the focus of this thesis on water pollution, special attention will be given to regulatory measures for industrial wastewater pollution control. Section 4.3 will be devoted to the analytical framework and the laying out of the specific research hypotheses for the study. The final section concludes the chapter by stating some of the limitations of the analytical framework.

\subsection{Environmental Regulation in Nigeria}

\subsubsection{The institutional framework}

Nigeria has been involved in the ratification and signing of international environmental conventions since 1963. However, effective and decisive environmental regulation and pragmatic monitoring of compliance did not begin until 1988 when the dumping of five ship loads (3888 tons) of toxic wastes ${ }^{1}$ of Italian origin provoked the enactment of two laws (Decrees Nos.48 \& 58, 1988); one making toxic dump a criminal act, and the other, an immediate establishment of the Federal Environmental Protection Agency (FEPA) ${ }^{2}$ with extensive mandate to develop institutional and regulatory strategies that would ensure environmentally sustainable development. The antecedent of FEPA was the Environmental Planning and Protection Division (EPPD) ${ }^{3}$ of the Federal Ministry of Industries created in 1975, and

\footnotetext{
'The toxic wastes were dumped at the Nigerian port of Koko, Delta State (FEPA, 1991a).

${ }^{2}$ The Nigerian FEPA became the Federal Ministry of Environment at the end of 1999. In this research, the name FEPA has been retained for clarity sake.

${ }^{3}$ According to Abdullahi (1988), the EPPD replaced the National Advisory Committee on the Environment established after Nigeria's participation in the 1972 United Nations Conference on the Human Environment at Stockholm, Sweden. Before Nigeria's independence, and prior to 1972, environmental issues were administered from the cabinet office.
} 
later transferred to the Federal Ministry of Works and Housing in 1983 (Laditan, 1998). Though environmental policy in Nigeria is relatively less developed when compared with industrial economies, there has nevertheless been appreciable progress in environmental regulation especially since the establishment of FEPA in 1988.

Expectedly, environmental regulation with respect to industrial waste management and pollution control did not attract adequate attention until the establishment of the Federal Environmental Protection Agency (FEPA). FEPA has seven key programme areas comprising compliance monitoring and enforcement (CME); environmental technology and standards (ET\&S); environmental conservation; environmental planning and information management; international collaboration; co-operation at national level; and physical infrastructural development and maintenance (see The Nigerian Environment, 1998, p.5). Industrial pollution control belongs to the jurisdiction of the compliance monitoring and enforcement, and environmental technology and standards departments. FEPA has the responsibility to determine permissible industrial effluent standards and accordingly formulate regulatory laws, which the National Assembly ${ }^{4}$ subsequently examines, and passes into law. A list of some of the Nigerian environmental laws that were formulated by FEPA as regulatory instruments is presented in appendix 1 .

Nigeria has 36 states, and each state has a state environmental protection agency (SEPA). ${ }^{5}$ FEPA is a national agency with seven zonal offices ${ }^{6}$ and field officers in each state. In addition, FEPA has six reference laboratories or linkage centres at various locations (usually academic institutions) in Nigeria (see table 4.1). These laboratories serve as centres for carrying out scientific experiments relating to compliance monitoring, and environmental protection/pollution control related research. Furthermore, FEPA has the responsibility to monitor firms' compliance with the regulatory standards, while at the same time assisting in the building of capacity for environmental regulation at the state environmental protection agencies (SEPAs). The SEPAs are directly responsible for compliance monitoring of industrial firms located within their respective states. However, compliance monitoring is also carried out by FEPA field officials in collaboration with the officials of SEPAs, especially when there is a case of very unpleasant environmental incident. While sanctions have been used to enforce compliance, FEPA also provides some incentives to encourage compliance. These incentives include: free technical advice to firms in the areas of waste management, technology choice and production process changes; encouragement of voluntary compliance; and annual environmentally friendly

\footnotetext{
'As at 1988, Nigeria was under the rule of a military government. Hence, a committee of the ruling junta called Armed Forces Representative Council (AFRC) then symbolically represented the National Assembly.

${ }^{5}$ Nigeria is a federation of 36 states and a federal capital territory (FCT). There is a national FEPA, and each state and FCT has a state environmental protection agency (SEPA).

- As at 1997, FEPA operates zonal offices at Ibadan, Kaduna, Kano, Lagos, Maiduguri, Owerri, and Port Harcourt. FEPA's headquarters is located at Abuja. However, because of the strategic importance of Lagos, the Lagos zonal office is also a branch of the office of the director-general of FEPA, and it is the headquarters of industrial compliance monitoring and enforcement department of FEPA (Laditan, 1998).
} 
industry award which was inaugurated in 1995 (Aina and Adedipe, 1992; Laditan, 1998).

Table 4.1: FEPA research and linkage centres

Location of centre

University of Ibadan, Ibadan

Federal University of Technology, Minna

Federal University of Technology, Owerri

University of Agriculture, Abeokuta

University of Maiduguri, Maiduguri

Ahmadu Bello University, Zaria

University of Lagos, Lagos
Activities at the centre

hazardous waste and clean production

water resources and climate change

gullery erosion

forest conservation and biodiversity

desertification and drought control

human settlements and land use planning

environment and human resources development

Source: Laditan (1998, p.57).

FEPA's assistance to SEPAs in regulatory capacity building has so far included training programmes for compliance monitoring officers, ${ }^{7}$ supply of laboratory and pollution monitoring equipment, ${ }^{8}$ supply of vehicles, and use of FEPA's national reference laboratory (NRL) at Lagos for analyses that SEPA laboratories may not be able to handle. ${ }^{9}$ At this juncture, it is necessary to point out that we carried out a survey of regulators in order to gain a deeper insight into the institutional framework for environmental regulation in Nigeria (see sections 5.2 and 5.3 of chapter 5 for the survey methodology $\left.{ }^{10}\right)$. Generally speaking, regulators are very satisfied with the existing laboratory facilities. From the results of our survey of regulators, $79 \%$ of our

\footnotetext{
${ }^{7}$ FEPA has an environmental enforcement training unit under the CME department. The unit organises training programmes and workshops for both compliance monitoring officers and industry's technical staff responsible for pollution control.

${ }^{8}$ Major support in respect of laboratory equipment and vehicles has been through the World Bank assisted environmental management projects mediated by FEPA (see reports on the public presentation of the World Bank assisted projects in The Nigerian Environment, 1998, Vol. 10, No.2, pp.2-4; 1998, Vol.10, No.4, p.9; and 'Daily Monitor', October 16, 1998, p.16). In the course of this research, I visited laboratories where these equipment are used, and I participated on compliance monitoring visits during which regulators use some of the portable pollution monitoring instruments to assess industrial air and noise pollution levels.
}

${ }^{9}$ For example, the atomic absorption spectrophotometer (AAS) used for testing for heavy metals (e.g. lead, cadmium, mercury, etc.) is available only at the FEPA national reference laboratory in Lagos. Besides, the NRL has four well-equipped units with modern analytical equipment and apparatus. The four units are analytical instrument laboratory; wet analysis laboratory; air radiation laboratory; and microbiology laboratory. Two FEPA zonal laboratories also exist at Kano and Port Harcourt. It is however necessary to stress that these laboratories are focussed on industrial effluent analyses, in contrast to the FEPA university based reference laboratories, which are more research oriented.

${ }^{10}$ The regulators surveyed included both FEPA and SEPA officials, and the sample size comprises 44 regulators. Details of the survey methodology describing the sampling procedure and survey questionnaire are respectively presented in sections 5.2 and 5.3 of chapter 5 . 
sample considers the FEPA/SEPA pollution control laboratories very good, with modern apparatus and analytical equipment. Regulators however consider infrastructural support for pollution monitoring to be deficient in some respects as shown in table 4.2. Everyone views lack of vehicle for inspection visits as an important problem, and it also ranks highest as first and second most important obstacle to compliance monitoring. Following this closely are the problems of inadequate number of compliance monitoring officers, and lack of sufficient training on industrial pollution monitoring. Though the rating of these two problems may be considered subjective since they give some direct benefits to the respondents, it is nevertheless suggestive of possible lack of sufficient number of officials and inadequate in-service training scheme that could help compliance monitoring officials to be abreast with the current scientific and technical knowledge for pollution control in industry. Besides, secondary information obtained from the FEPA/SEPAs showed that, whereas an average of $37 \%$ of the employees have higher degree qualifications, only $25 \%$ have training in environmental science or technology.

As the foregoing suggests, industrial wastewater policy in Nigeria falls within the general framework for industrial pollution control. However, the management of Nigeria's water resources can generally be said to be formally under the jurisdiction of the Nigeria's river basin development authorities (RBDA) and the state water boards/corporations (Salau, 1990; Gobin et al, 1996, p.91; Olokesusi, 1988, p.33). The RBDA are federal agencies with responsibility for the major rivers in the country, particularly for agricultural development purposes; while the water boards are more concerned with the provision of potable water from both surface waters and underground aquifers. It is however pertinent to note that industrial water pollution control has been known to be solely done by FEPA and SEPAs within the framework of FEPA's guidelines for environmental regulation. There appears to be little or no formal link between FEPA, RBDA and the water boards. 
Table 4.2: Regulators' perception of obstacles to firms' compliance monitoring and enforcement in Nigerian industry.

Percent regulators consider reason

Obstacles to compliance monitoring

important most important $2^{\text {nd }}$ most important

Number of monitoring officials not

92.9

19.5

25.6

sufficient

Monitoring officials have no adequate

69.0

24.4

20.5

training

Lack of vehicles to carry out

100.0

36.6

inspection visits

Firms are averse (antagonistic) to

31.0

0.0

0.0

inspection visits

Poor laboratory facility for pollution

monitoring

0.0

0.0

too cumbersome

26.2

4.9

2.6

cumbersome

Other obstacles

9.8

0.0

Total

100.0

100.0

Source : Author's field survey

\subsubsection{The policy instruments}

In Nigeria, industrial wastewater policy falls within the scope of two regulatory measures developed by the Nigerian Federal Environmental Protection Agency. The first is the 'National Guidelines and Standards for Environmental Pollution Control in Nigeria (1991)', which states the basic guides and standards expected in monitoring and controlling industrial and urban pollution (FEPA, 1991a). The second is a composite law termed the 'National Effluent Limitation Regulation (S.I.8 of 1991)' and 'Pollution Abatement and Facilities Generating Wastes Regulation (S.I.9 of 1991) ', which make it mandatory for industrial facilities to install pollution abatement equipment or make provision for effluent treatment, and prescribes maximum limits of effluent parameters allowed for contravention (FEPA, 1991b). The S.I.8/S.I.9 law was enacted in August 1991, and industry was given three years (up to December, 1994) moratorium within which to make necessary technical changes for compliance. Thus, 
the law did not come into full effect until January 1995 (FEPA, 1995; Laditan, 1998; Okorodudu-Fubara, 1998). According to FEPA (1991a, p.17), the preliminary or interim guidelines and standards that gave birth to the S.I.8/S.I.9 law was widely circulated and reviewed by relevant government ministries, industries, universities, and individuals in 1990. Before it became law, S.I.8/S.I.9 document was further reviewed based on comments from industrial stakeholders and data obtained from wide spread previous studies on the physicochemical characteristics of effluents from selected industries in Nigeria. "The review committee also used the experiences of other developing countries with similar climatic conditions such as India and Singapore; and the experiences of developed countries of Europe and North America were also considered.

The instrument for industrial water pollution control in Nigeria is essentially 'command and control (CAC)' in nature. It specifies technology ${ }^{12}$ adoption for firms' compliance with statutorily permissible levels of wastewater effluent parameters. Non-compliance with the base law, S.I.8/S.I.9 is expected to be punished by penalties ranging from a stipulated fine to factory closures and/or imprisonment of owner(s) of a persistently erring factory. Like similar direct regulations in advanced countries, ${ }^{13}$ tachnology epanifieatione for pollution ahatamant are in tarme of hoet availahlo technology (BAT) or best practicable technology (BPT). ${ }^{14}$ The BAT or BPT is expected to bring emissions into compliance with the uniform effluent standards (UES). FEPA also promotes what it has termed "a philosophy of BATELA' 15 which is aimed at encouraging indigenous technology initiatives for pollution control (see The Nigerian Environment, 1997, pp.6-9). Since technological options for pollution control are not defined in very specific terms, the National Effluent Limitation Regulation could also be regarded as an effluent quality based regulation, which allows flexibility for firms' technological responses for compliance.

To give an indication of the level of stringency of UES, table 4.3 presents a comparison of the UES with similar standards being used for industrial wastewater control in Germany (as an illustration for western Europe), and Hungary (as an

\footnotetext{
"The review was done by a 22 member expert technical committee drawn from government ministries, universities, non-governmental organisations and recognised individual experts on industrial pollution control (FEPA, 1991a).

${ }^{12}$ In the usual tradition of technology forcing standards under a CAC regulatory regime, the Nigerian industrial water pollution control law stipulates 'best available technology (BAT), or best practicable technology (BPT), or technology that limit emissions to the uniform effluent standards (UES) for manufacturing enterprises' (FEPA. 1991b).

${ }^{13}$ For example, in Germany technology specifications for water pollution control is based on GATS (generally accepted technological standards) and BAT (EC, 1996).

${ }^{14}$ The Nigerian regulation, however, does not specify the situation in which BAT or BPT is to be applied. For
example, a similar regulation in Indonesia specifies that new investments in highly polluting industries adopt
BAT for wastewater treatment, while existing firms are permitted to use a less costly BPT for industrial
wastewater treatment (O'Connor, 1994, p.13).
}

15 BATELA - Best Available Technology Encouraging Local Adaptation'. 
illustration for the transition economies of eastern Europe). As expected, the German standards are generally more stringent in all identifiable similar parameters. The Nigerian standards, though relatively new, appear remarkably more stringent than the Hungarian standards, and also seem not too far from standards in developed countries where environmental policy is well established. Moreover, the National Guidelines and Standards for Environmental Pollution Control makes provision for regular reviews of the national minimum effluent standards, especially at the state levels. The reviews must however ensure that the effluent standards at the state level are equal to or more stringent than the national minimum. So far, only Lagos State, which has the largest concentration ${ }^{16}$ of industrial firms in Nigeria, is in the process of reviewing the national effluent standard to make the state's requirements more stringent than the National minimum. ${ }^{17}$ Thus, the national effluent standards have been the general regulatory instrument for industrial water pollution control throughout Nigeria.

Table 4.3: Threshold values of allowable concentrations of certain pollutants in effluents into surface waters in Hungary, Nigeria and Germany

\begin{tabular}{|c|c|c|c|}
\hline \multirow{2}{*}{ Parameter } & \multicolumn{3}{|c|}{ Limits for discharge into surface waters } \\
\hline & Hungary & Nigeria & Germany \\
\hline Organic strength & $60 \mathrm{mg} / \mathrm{BOD}$ & $30 \mathrm{mg} / \mathrm{l} \mathrm{BOD}$ & $20 \mathrm{mg} / \mathrm{l} \mathrm{COD}$ \\
\hline Phosphorus & n.a. & $5 \mathrm{mg} / \mathrm{l}$ & $0.1 \mathrm{mg} / \mathrm{l}$ \\
\hline Nitrogen & n.a. & $20 \mathrm{mg} / \mathrm{l}$ & $5 \mathrm{mg} / \mathrm{l}$ \\
\hline Mercury & $2 \mathrm{mg} / \mathrm{l}$ & $0.05 \mathrm{mg} / \mathrm{l}$ & $1 \mu \mathrm{g} / 1$ \\
\hline Cadmium & $10 \mathrm{mg} / \mathrm{l}$ & Less than $1 \mathrm{mg} / \mathrm{l}$ & $5 \mu \mathrm{g} / 1$ \\
\hline Lead & $10 \mathrm{mg} / \mathrm{l}$ & Less than $1 \mathrm{mg} / 1$ & $50 \mu \mathrm{g} / 1$ \\
\hline Chromium & $10 \mathrm{mg} / \mathrm{l}$ & Less than $1 \mathrm{mg} /$ & $50 \mu \mathrm{g} / \mathrm{l}$ \\
\hline Nickel & $2 \mathrm{mg} / \mathrm{l}$ & Less than $1 \mathrm{mg} / \mathrm{l}$ & $50 \mu \mathrm{g} / 1$ \\
\hline Copper & $25 \mathrm{mg} / \mathrm{l}$ & Less than $1 \mathrm{mg} / \mathrm{l}$ & $100 \mu \mathrm{g} / 1$ \\
\hline
\end{tabular}

n.a. $=$ not available

Source: ECE (1984), Kraemer (1995) \& FEPA (199lb).

\footnotetext{
${ }^{16}$ Some estimate claim that Lagos State alone has $60-70 \%$ of Nigerian industries (Lubeck, 1992, p.17; LASEPA, 1999).

${ }^{17}$ For details, see the report titled 'LASEPA raises effluent control committee' in 'Guardian' (Nigeria) of April $17,1999$.
} 
Firms whose effluents already conform to the UES (see appendix 2) before UES came into effect require no permit for effluent discharges. However, in practice, firms do not normally conform to the minimum requirements, and hence they are generally required to obtain discharge permit from FEPA. In addition to the recognised national minimum, permits are based on sectoral guideline requirements that depend on the specific sectoral pollution problems. The sectoral guidelines are usually more stringent than the general requirements. With respect to our sectoral focus in this study (i.e. food and beverages, and textiles), the additional sectoral guidelines are shown in appendix 3 . Permits for industrial effluents are issued by FEPA after a supposedly thorough but long process of ascertaining the type and quantity of the effluent, and the appropriate technology that is suitable for compliance with the effluent limit regulation. The process starts from the relevant SEPA which makes a report to FEPA on the existing industrial facilities and processes for which permit has been applied. The report goes to the compliance monitoring and enforcement (CME) and environmental technology and standard (ET\&S) departments of FEPA. FEPA inspects the industrial plant and examines the current environmental audit (EA) report in the case of an already existing firm, or the environmental impact assessment (EIA) report in the case of a newly established firm. EA or EIA is prepared at the expense of the firm by FEPA's designated environmental studies consultants. ${ }^{18}$ The technology specifications for compliance with BAT or BPT are determined by the CME and ET\&S departments of FEPA in consultation with the firm concerned. After the two FEPA departments have ascertained the situation on ground about the industrial plant, recommendations are made to the FEPA Director-General, who then approves or rejects the permit application. A permit is valid for two years, effective from 1st October of the year of issue. The permit may be revoked at any time if the industrial facility no longer complies with the conditions specified in the permit. Such revocation takes effect, usually after a written warning by FEPA is not heeded.

We wish to state at this juncture that though the permit process is clear and there are designated FEPA officials with mandate for its execution, FEPA's institutional capacity appear insufficient to cope with the demand of the rather elaborate process of permitting. In the course of this research, we discovered that only one firm has succeeded in getting the official permit as at February 2000, and there are many pending applications for permit. Moreover, from our interview with regulatory officials, prominent among reasons for the drag in the issuance of permit is lack of sufficient proof of compliance with UES partly arising from inadequate compliance monitoring inspections. ${ }^{19}$

is These environmental studies consultants are environmental professionals or university based scientists/engineers who FEPA has adjudged capable of analysing and establishing the environmental implications of industrial facilities and processes. FEPA has a process of accreditation for the consultants. Important features of the accreditation process include evidence of high academic qualification and scientific experience in understanding common industrial pollutants, and a proof of possession or access to well established laboratory that could analyse industrial effluents.

\footnotetext{
${ }^{19}$ We could not obtain secondary information on frequency of compliance monitoring inspections as Nigerian regulators have kept no such data. However, regulators interviewed generally have the notion that compliance monitoring inspections are inadequate, and as such, it has been difficult to verify the claims of firms on the technical efficiency of the pollution abatement facilities employed to meet the UES requirements. Regulators are
} 
With respect to economic instrument for industrial wastewater pollution control, there is currently little effort in this direction. From official pronouncements, it appears that the maintenance and the entrenchment of the existing 'command and control' instrument are the major preoccupation of the regulatory authorities. However, from the results of our regulators' survey, $56 \%$ of our sample regulators favour the introduction of wastewater effluent charge or $\operatorname{tax}^{20}$ as an instrument of pollution control. This may suggest that regulators are beginning to realise that the regime of direct regulation is already being appreciated by Nigerian industry, and economic incentive may eventually be needed to enhance industry compliance in future. In fact, as would later be shown in table 6.16 of chapter 6 , lack of market incentive is considered an important obstacle to compliance by nearly two third $(63.6 \%)$ of our sample regulators. In addition, the same factor has the highest rating of $36.6 \%$ as the second most cited important obstacle to compliance.

Having highlighted the environmental policy regime in Nigeria, in the next section we shall discuss how the framework presented in chapter 3 could be applied for the analysis of the rationales for the adoption of environmentally benign technologies in developing countries with specific reference to Nigerian manufacturing industry.

\subsection{A Framework for the Analysis of the Adoption of Environmentally Benign Technologies in Nigerian Manufacturing}

In chapter 3, we have described a general model that could be used for the analysis of the adoption causalities for EBTs irrespective of the level of economic development of the firm's operating environment. With Nigeria as a case study, in this section we adapt the framework to suit the peculiarities of a developing country's socio-economic environment, and accordingly define indicators for the measurement of the identified variables in relevant testable hypotheses that form the basis of the empirical research reported in this thesis.

\subsubsection{Environmental policy as a major driver of adoption}

We have argued that irrespective of the socio-economic context in which a firm is operating, the major driver of adoption of environmentally benign technologies is the prevailing regime of environmental policy. In developing countries, especially the less developed ones, environmental policy usually takes the form of traditional commandand-control. As shown in the last section for the Nigerian case, this approach is currently prevalent particularly in the aspect of industrial water pollution control. The

therefore extremely cautious in making recommendations for permit to avoid being held responsible for issuing 'permit to pollute' to firms not satisfying regulatory requirements.

${ }^{20}$ In this context, wastewater effluent charge serves as a kind of pigovian tax that will spur firms' technology responses that enable them reduce or prevent industrial wastewater pollution. 
approach is represented by the introduction of the S.I.8/S.I.9 environmental regulatory law in 1991. In this study, environmental policy essentially focuses on the use of this instrument in the control of industrial water pollution in Nigerian manufacturing industry. The policy could therefore be viewed as the major driver of the adoption of environmentally benign technologies for water pollution control in Nigerian manufacturing sector. Accordingly, the first main hypothesis for the proposed empirical research is:

\section{H1: The S.I.8/S.I.9 environmental regulatory law has been the major driver of the adoption of water pollution control technologies in the Nigerian mamufacturing industry.}

We suggest that a firm's technology response to the effluent limitation regulation will either be by abatement measures or through prevention of the effluents at the source. To remediate the external diseconomies resulting from industrial wastewater, firms' technology responses for abatement (TPA) have conventionally been done through the application of industrial wastewater treatment plants. The industrial wastewater treatment plant is an end-of-pipe technology with wide acceptance in industry. ${ }^{21}$ This follows the general prevalence of end-of-pipe technologies over cleaner technologies as explained in section 3.2 of chapter 3 . The wastewater treatment plants are in three main categories:

\section{i) Primary (or mechanical) wastewater treatment plants.}

This is the simplest of the three categories, and it is applied for the treatment of wastewater effluents where the requirement is only to achieve the physical removal of settleable and floating solids, and some measure of bio-degradation of the wastewater effluents before letting off the wastewater, while the resulting waste sludge is disposed of separately. The process can normally be accomplished in open concrete or steel basins equipped with a grit chamber carefully designed to suit the expected volume of wastewater flow. A primary wastewater treatment plant may include any or a combination of the following wastewater treatment processes: sedimentation, flotation, stabilisation ponds and lagoons.

\section{ii) Secondary (or biological) wastewater treatment plants.}

This is applied where there is the need to remove colloidal and soluble organic pollutants from wastewater through the bio-degradation of the pollutants using the metabolic action of micro-organisms. The secondary wastewater treatment system is an advancement on the primary treatment, and its efficiency in removing water pollutants is much higher (see table 9 in ECE (1984) for illustrations). The biological wastewater treatment system could either be anaerobic or aerobic depending on

\footnotetext{
${ }^{21}$ For example, it is evident from a review of technology trends in pollution intensive industries by Bartzokas and Yarime (1997) that in each of the pollution intensive industries where water pollution is a major problem, wastewater treatment plants consistently and remarkably featured as the technological option that is heavily relied upon by industry.
} 
whether the biochemical oxidation of organic matter is effected by anaerobic microbes in a closed system under the absence of air or by aerobic microbes in the presence of air. In the aerobic treatment system, air (oxygen) is pumped or 'bubbled' into the wastewater stream to enhance the efficiency of the technology.

The biological wastewater treatment plant consists of tanks or basins made of stainless steel or concrete or both, and has at least two components depending on design. The components include the primary processes or pre-treatment chamber, and the secondary treatment chamber. In the aerobic design, the secondary treatment compartment could be split into an aeration basin and a secondary settling tank or clarifier. Activated sludge system and trickling filter plants (both of which are mainly aerobic systems) are common types of biological wastewater treatment technology.

The anaerobic treatment systems are almost exclusively used for high strength industrial wastewater and for denitrification processes. The anaerobic digestion enables the biological conversion of organic materials in mixtures of primarily settled wastewater and biological sludge into a variety of waste products such as methane $\left(\mathrm{CH}_{4}\right)$, carbon dioxide $\left(\mathrm{CO}_{2}\right)$, and hydrogen sulphide $\left(\mathrm{H}_{2} \mathrm{~S}\right)$. The final quantity of sludge produced by the anaerobic treatment process is considerably less than that of the aerobic systems, and methane ${ }^{22}$ recovery provides an important added economic advantage. However, the process has a disadvantage of long detention times (which could be as high as 30 to 60 days in standard rate reactors) arising from slow growth rates of methanogenic bacteria (TEP, 1999).

\section{iii) Advanced (or tertiary) wastewater treatment plants.}

This is similar to the secondary treatment in design, but includes additional wastewater treatment, usually involving physico-chemical treatment processes. Tertiary wastewater treatment is particularly used when there is the need to remove hazardous pollutants (e.g. heavy metals such as mercury and lead); nutrients (e.g. nitrogen and phosphorus); or suspended substances that cannot be stabilised easily (e.g. chromium and phenols). It is also normally required when the effluent is to be discharged to very sensitive areas such as bathing waters or waters used for recreational purposes. In general, advanced wastewater treatment plants are systems capable of reducing specific water pollutants to levels not normally achieved by a well operated activated sludge system. ${ }^{23}$ Common tertiary wastewater treatment processes include ammonia stripping, micro-screening, selective ion exchange, reverse osmosis, ultra filtration, sand filtration, adsorption, etc. (ECE,1984; Hammer, 1986; UNEP,

22 Through the action of methanogenic microbes, most of the organic waste is converted to methane gas. Methane is combustible and can be used as fuel gas or to operate dual fuel engine to produce electricity and provide heat.

${ }^{23}$ For instance, with respect to $\mathrm{BOD}_{5}$, suspended solids, phosphorous and nitrogen, ECE $(1984$, p.3) reported that an advanced wastewater treatment plant could respectively achieve effluent quality of $5 \mathrm{mg} /, 5 \mathrm{mg} /, 1 \mathrm{mg} /$ and $5 \mathrm{mg} /$; while an efficient activated sludge system could only respectively achieve $15 \mathrm{mg} /, 15 \mathrm{mg} /, 3-11 \mathrm{mg} /$ and $10-20 \mathrm{mg} /$. 
1993). For a glossary of wastewater treatment technologies and processes, see appendix 4 .

It is important to note that, Olokesusi et al (1997) in a study ${ }^{24}$ supported by the ATPS $^{25}$ and FEPA (1995) have already identified wastewater treatment technology as a means by which Nigerian firms abate industrial water pollution. Besides, the use of industrial wastewater treatment plants in developing country firms has been reported by Millette (1991) in Trinidad and Tobago, UNEP (1993) in India, UNEP (1994) in Malaysia, and Dasgupta et al (1996) in China. The first specific research question we will attempt to answer is therefore to ascertain whether or not the S.I.8/S.I.9 environmental regulatory law has been a significant reason why firms in Nigerian manufacturing sector resort to wastewater treatment to abate water pollution. Taking into consideration the level of Nigeria's technological development, our major concern is not whether or not the three categories of wastewater treatment plants are adopted by Nigerian manufacturers. Rather, we will focus on finding out whether or not the Nigerian environmental policy regime has been a significant factor responsible for the stimulation of adoption, in this case, of at least the primary (or mechanical) wastewater treatment technology. Primary wastewater treatment plants have the advantage of small structures, few or no mechanical and electrical installations; and introduce relatively low cost, low energy and ecologically sound solutions. Because of these characteristics, they are often referred to as 'soft technology' to distinguish them from high efficiency technology of the secondary and tertiary wastewater treatments. This notion of 'softness' should however not lead to a mistaken conclusion that primary wastewater treatment technology cannot offer efficient and satisfactory wastewater purification. For instance, the purification performance of 'stabilisation ponds' and 'lagoons' has been reported in some western and east European countries as being very good in terms of removal of oxidizable organic material $(90 \%)$, nitrogen $(50 \%)$, and phosphorous (between 50 and $80 \%$ ). Lagooning is particularly favoured because in addition to offering a high buffering capacity and low sludge yields, its construction and operating costs are relatively low and maintenance easy. In tropical climate such as in Nigeria, ponds and lagoons have the advantage of relative ease of all season management because the problem of possible surface freezing is absent (Hammer, 1986; ECE, 1984; Fair et al, 1981). Thus, the first aspect of hypothesis HI to be investigated can be stated as:

HIa: The introduction of the S.I.8/S.I.9 environmental regulatory law has led to increased adoption of wastewater treatment plants in the Nigerian manufacturing industry.

\footnotetext{
${ }^{24}$ The study's aim was to find out the technological and socio-economic impacts of the implementation of FEPA's effluent standards on eight selected industrial groups, and make recommendation on possible directions for policy improvement.

${ }^{25}$ ATPS is African Technology Policy Studies Network based in Nairobi, Kenya. It was initially funded by the Canadian International Development Research Centre (IDRC), Ottawa, Rockfeller Foundation, and the Carnegie Corporation, New York.
} 
This hypothesis apparently proposes the investigation of firm's likely first technological response to rationally adjust to the socio-economic imperatives engendered by regulation. Apart from the fixed cost for building and maintaining a wastewater treatment plant, effluent treatment cost has a variable component, which of course, in absolute terms, increases with the quantity of the wastewater effluent. Hence, it may be argued that a firm's technological response will not be limited to abatement, but also extend to strategies that reduce wastewater generation at the source. This leads us to the issue of firm's technology responses for water pollution prevention (TPP). We therefore propose that TPP will involve the adoption of process integrated techniques or methods that reduces or prevents the production of wastewater. With respect to water pollution control in industry, these may include any or a combination of the following:

- Water or/and wastewater re-use or recycling.

- Raw material re-use or recycling.

- Reduction in the quantity of raw material inputs.

- Change of one or more raw material input(s).

- Integrated physical device in the production line.

- Modification of chemical reaction or process.

- Change of chemical reaction or process.

- Change in product design (indirect effect).

One of the reasons why the use of process integrated EBTs is generally perceived to be still highly restricted in industry is the sunk cost advantage of the existing production facilities (Hartje and Lurie, 1984; Rothwell, 1992; Ashford, 1993). For developing country firms, this may apparently pose a comparatively more serious problem because they have relatively less access to capital. This not withstanding, could the adoption of any of these technology responses in Nigerian manufacturing industry be ascribed to the pressure resulting from the S.I.8/S.I.9 law? Thus, the second aspect of hypothesis $\mathrm{HI}$ can be stated as:

HIb: The S.I.8/S.I.9 environmental regulatory law has induced the adoption of process integrated techniques/methods for water pollution prevention/abatement in Nigerian manufacturing industry.

It should be noted that some of the process integrated techniques/methods listed above are by nature difficult to quantify in an empirical investigation, especially in a developing country such as Nigeria. We will therefore limit our analysis to material recycling technologies, raw material substitution and integrated physical device in the production process. The test of hypothesis $\mathrm{HI} b$ is expected to give some insight into the use of process integrated techniques or devices since the introduction of the effluent standard. We wish to quickly point out that neither $H \mathrm{Ha}$ nor $H \mathrm{Hb}$ is intended to measure the amount of pollution abatement achieved through TPA or TPP. It is difficult to empirically de-couple the pollution abatement or environmental quality improvement achieved through TPA and TPP. It is however possible to ascertain whether or not the effluent standard has significant influence in promoting TPA or 
TPP; or alternatively, whether or not any observed adoption of TPA or TPP could be ascribed to other reasons for technology adoption (i.e. auxiliary drivers of adoption), an issue which we shall examine in the next subsection.

At this juncture, it is necessary to stress that within the framework of this study, TPA or TPP is considered as a form of technological innovation. With particular reference to developing countries, innovation could be recognised to embrace a comparatively wide spectrum of technological activities ranging from adaptive ${ }^{26}$ or imitative technical changes to original innovative designs (Lall, 1987, 1992; Kim, 1997; Oyelaran-Oyeyinka et al, 1996). Thus, in a developing country context such as Nigeria, TPA in the form of adoption of wastewater treatment plant would be seen as an innovation, though quite unthinkable as such in a developed economy, where the use of wastewater treatment technology is generally accepted as a minimum societal expectation from water polluting firms. In the same vein, TPP is considered as innovation for Nigerian firms where any form of technical changes whether original to the firm or already practised elsewhere conform to any of the earlier defined changes in the process integrated techniques or methods.

\subsubsection{Auxiliary drivers of adoption}

In addition to environmental policy, in section 3.2 of chapter 3 , we identified eight other factors that may be responsible for a firm's adoption of EBT. These auxiliary drivers of adoption include: firm's internal capability for innovation in pollution control, firm's external network for innovation, environmental policy implementation strategy, firm's environmental disposition, firm size, firm's intrinsic competitiveness, perceived impact of adoption on costs, and the institutional capacity for environmental regulation. We will explore the possibility of any of these factors accounting for technological innovations that have positive implication for water pollution abatement and prevention in the Nigerian manufacturing industry. As earlier argued in chapter one, the two selected manufacturing sectors (viz., food processing and textiles) are of high significance in a developing economy, and they are the sectors in which national industrial production efforts are most flourishing in the Nigerian case. The question to be asked at this point is: are the Nigerian manufacturing firms making technological innovations either independently or in partnership with external research network(s)? If yes, are such innovations related to environmental conservation, particularly water pollution abatement and prevention? Apart from environmental policy as a major driver of the adoption of EBT, what are the other reasons why Nigerian firms adopt such innovations; or why do Nigerian manufacturing firms independently engage in technological innovations that have relevance for water pollution control? If apart from the adoption of wastewater treatment, no other significant innovation is being made to tackle the problem of water pollution, why not? We propose that in a developing country such as Nigeria, where the imperatives of industrial development

\footnotetext{
${ }^{26}$ Even for technological innovations in the advanced economies, some authors have strongly argued that technological adaptations are de facto innovations (e.g. see Leonard-Barton 1988, p.265).
} 
and environmental conservation/protection are often at conflict, firms' adoption of EBTs will not only depend on the prevailing environmental policy regime, but also on the auxiliary drivers of adoption.

In addition to the eight proposed auxiliary drivers of adoption in chapter 3 , one other factor that we have not mentioned, but which has important relevance for developing country firms, is the ownership structure ${ }^{27}$ of the firm. Foreign involvement in a firm is supposed, among other things, to improve access to technology and foreign capital; and thereby enhance the firm's capability to adopt new technologies. Besides, it is commonly assumed that foreign interests' participation in a developing country firm supposedly brings in more environmental awareness if the foreign partners are from comparatively industrialised economy. In this respect, reviews of some previous studies on the 'pollution haven hypothesis' have suggested that subsidiaries of foreign firms in developing countries do apply comparable level of environmental standards as those of their parent companies in their local operations (Knödgen, 1979; Hesselberg and Knutsen, 1994; and Lundan, 1996). But would same be true for subsidiaries of multinational industrial firms in the Nigerian manufacturing sector? For now, we assume the affirmative, and therefore propose that for firms in Nigerian manufacturing, the ownership structure will be a determinant of technology responses for water pollution control.

At this juncture, we wish to point out that the auxiliary drivers of adoption of EBTs in developing countries could be classified into three as shown in table 4.4, viz., firmlevel technological capability related factors, firm's characteristics, and regulation implementation related factors. In the light of the foregoing, we state a second major hypothesis that comprehensively embraces all the auxiliary factors of adoption.

H2: In a developing country like Nigeria, the adoption of environmentally benign technologies in the manufacturing sector will not only depend on the existing environmental policy, but also on technology, economic and institutional related factors such as firm's internal capability for innovation in pollution control, firm's external network for innovation, intrinsic competitiveness, perceived impact of adoption on costs, ownership structure of the firm, firm size, environmental policy implementation strategy, firm's environmental disposition, and the institutional capacity for environmental regulation.

For clarity and analytical purposes, it will be necessary to decompose this comprehensive hypothesis. Before proceeding to do so, we wish to affirm that the definitions of technologies adopted remain as stated for TPA and TPP in subsection 4.3.1 of this chapter.

\footnotetext{
${ }^{27}$ This factor was not mentioned in chapter three because it may not be relevant for our theoretical framework, which may also be applied for the analysis of developed country case studies.
} 
Table 4.4: Classification of auxiliary drivers of adoption of environmentally benign technologies in developing countries.

\begin{tabular}{|c|c|c|}
\hline $\begin{array}{l}\text { Firm-level technological } \\
\text { capability related factors }\end{array}$ & Firm's characteristics & $\begin{array}{l}\text { Regulation implementation } \\
\text { related factors }\end{array}$ \\
\hline $\begin{array}{l}\text { Internal capability for } \\
\text { innovation }\end{array}$ & Firm size & $\begin{array}{l}\text { Environmental policy } \\
\text { implementation strategy }\end{array}$ \\
\hline \multirow[t]{3}{*}{ External network for innovation } & $\begin{array}{l}\text { Firm's environmental disposition } \\
\text { Intrinsic competitive nature of the } \\
\text { firm }\end{array}$ & \multirow[t]{3}{*}{$\begin{array}{l}\text { Institutional capacity for } \\
\text { environmental regulation }\end{array}$} \\
\hline & $\begin{array}{l}\text { Perceived impact of adoption on } \\
\text { costs }\end{array}$ & \\
\hline & Ownership structure & \\
\hline
\end{tabular}

\section{Firm's internal capability for innovation}

As explained in chapter 3, a firm's internal capability for innovation depends on the level of technological knowledge embodied in its human resources and machines. The technological knowledge in the human resource component could be measured in terms of the share of scientists, engineers and technicians in the total employment of the firm. For analytical purposes, where there are foreign technical personnel (nonNigerian), the number could be counted as double to signify the importance of the uncodified technological knowledge that the firm may gain from the foreign personnel.

Firms that have invested in expensive foreign technology production facilities may be considered as having a tendency to invest in TPA or TPP due to their relative higher propensity to invest in technology. Such investments have close links with a firm's internal capability to operate, maintain and sustain the efficient use of technological artefacts. Moreover, with respect to TPA, sunk cost effects may also be at work, necessitating investment in end-of-pipe industrial wastewater treatment technology rather than process integrated technical changes (Hartje and Lurie, 1984; Ashford, 1993). Because of the relatively low level of technological development in developing countries, the source of the machinery employed for production could serve as a proxy for the level of technology embodied in the machines. Thus, assuming that imported technologies are superior, the technological level could be indicated in three terms: low, medium, and high, respectively for wholly local, partially imported (a mix of local and foreign machines), and wholly imported technology. It is however necessary to state that such a definition of levels of existing physical capital can only signify internal capability for innovation when a higher level of existing physical capital is accompanied by a higher level of technical knowledge. Otherwise, it only signifies the possible effect of sunk cost that may create inertia for decision to adopt EBTs. When 
existing level of physical capital enhances internal capability for innovation, it could lead to more confidence in managing EBT, and hence more probability of EBT adoption.

Another measure that may serve as an indicator of a firm's internal capability for innovation is the share of R\&D expenses in total annual expenditure. However, developing country firms are generally viewed as lacking in R\&D capabilities (Narayanan and Wah, 2000; Kim, 2000), and where R\&D is carried out, it may be difficult to ascertain the credibility of the accounting procedure for the R\&D expenses. For these reasons, we will therefore ignore firm's commitment to R\&D.

From the foregoing, we can draw two sub-hypotheses as follows: the first directly relating to internal capability for innovation with human capital aspect as an indicator; the second relating to the level of existing investment in physical capital as indicated by the source of the main production equipment.

H2a: The adoption of EBT will be positively correlated with the firm's internal capability for innovation as defined by the share of technical personnel in the total employment.

H2b: The adoption of EBT may be related to the existing level of investment in capital equipment for the main production activities.

\section{Firm's external network for innovation}

As earlier mentioned in section 3.2 .2 of chapter 3 , with regard to the role of networks in a firm's capability for innovation, this study focuses on the external network for innovation which we have defined to include the technological knowledge network and some aspects of the business network. The distinguishing feature of the external network for innovation is the exchange of technological information between the firm and other economic agents involved in its network relationships. Since we are considering a firm's capability for innovation, the backward linkages on which a firm could draw to enhance its technical capabilities become important. It may however not be a backward linkage in the strict sense because it may involve the sharing of technological information. For Nigerian manufacturing industry, knowledge network may be considered in terms of the number and the firm's perception of the quality of links it has with any other institution whether private or public, from which the firm could gain technology related knowledge and information. Such institutions could include government funded R\&D institutes, universities/polytechnics/colleges of technology, FEPA research laboratories, companies in the same business, international R\&D institutions, parent company (in case of affiliates of MNEs), foreign technical partners, and private consultancy firms. We expect the quality of linkages as perceived by the firm to be more important than the number of linkages. However, the number of linkages may be a reflection of a firm's dynamism in search activities that may contribute to the firm's knowledge stock. For analytical purposes, we define a network 
that could contribute to a firm's technological capability as one that involves physical contacts such as exchange of technological knowledge by technical/scientific personnel either through skill upgrading/training programmes, workshops/conferences, or through in-plant problem solving that involves external agents. Some previous studies (e.g., Lall et al 1994; Enos, 1995; Oyelaran-Oyeyinka et al, 1996) have observed that technological innovation related linkages are poorly developed in African manufacturing. Has environmental policy in Nigeria been able to introduce some changes by promoting the possible emergence of linkages that encourage environmentally friendly innovation in industry? It is noteworthy that in developing countries, the environmental goods and services sector is generally not yet well developed, ${ }^{28}$ and may therefore not have important linkages with firms in the Nigerian manufacturing. Nevertheless, it is plausible that the pressure of environmental policy could create an awareness that encourages firms to look towards their traditional sources of technological products and innovation for possible solutions to environmental pollution problems. We therefore propose that the type of the external network for innovation that a firm has will inherently affect its capability to respond to the technological imperatives dictated by environmental policy.

With respect to Nigeria, for analytical convenience, we will limit the definition of the external network for innovation to include only three categories of technological knowledge related network links. These include, first, the Nigerian higher institutions (universities and polytechnics/colleges of technology) that run programmes in science and technology. Nigeria is known to have 38 universities, ${ }^{29} 45$ polytechnics and colleges of technologies. ${ }^{30} \mathrm{~A}$ lot of research at these institutions are expected to provide useful technological information that could improve the technical performance of industrial firms. As earlier remarked, some previous investigations have indicated that linkages between these institutions and manufacturing firms are poor. However, this does not imply that they have not at all been useful in providing some technological support especially for local manufacturing firms. For example, Adeboye (1995), Adjebeng-Asem (1995) and Sanni et al (1998), all suggest that the food processing firms in Nigeria are inclined to tap from the technological knowledge output of local higher educational institutions and local research institutes. The second category is local research institutes, ${ }^{31}$ while the third is the international research institutes. Links with a multinational firm's parent company or foreign technical partners will be assumed to belong to the third category. Though this assumption may

\footnotetext{
${ }^{2}$ To illustrate this, in 1992, North America accounted for US\$145 billion (49\%) of total global environment market; Europe, US\$108 billion (37\%); Asia Pacific, US\$30 billion (10\%); and the rest of the world, US\$12 billion (4\%) (OECD, 1996, p.10).

${ }^{29}$ As at the time of this research, Nigeria has 38 universities among which 24 are federally owned, 11 are state owned, and three are privately owned (JAMB, 1999a, pp.33-34).

${ }^{30}$ As at the time of this research, Nigeria has 45 polytechnics/colleges of technology; 17 are federally owned, 26 are state owned, while two are privately owned (JAMB, 1999b, pp.30-34).
}

${ }^{31}$ By 1988 Nigeria has 23 R\&D institutes (Osunbor, 1990), and currently, the number is at least 26 (see The World of Learning, 1998). 
be considered a strong one, its effects may however be mellowed if, considering the fact that Nigeria is a developing country, we view links with international research institutes and parent companies/foreign technical partners to result in the provision of technological information that is higher than those normally available in Nigeria. The next sub-hypothesis could thus be stated as:

H2c: The capability of a firm to adopt an EBT will be inherently determined by the technological knowledge related network contacts a firm has.

Hypotheses $H 2 a, H 2 b$ and $H 2 c$ are expected to shed some light on whether or not there is need for significant endogenous technological capability upgrading in Nigerian manufacturing before we could expect environmental policy to have the desired impact of technology adoption for water pollution abatement/prevention.

\section{Ownership structure of the firm}

Generally speaking, wastewater treatment plant is a capital-intensive technology. Likewise, process integrated techniques that reduce wastewater generation can be an expensive endeavour for firms. Given the fact that developing country firms have comparatively less access to capital, it may follow that firms with foreign participation will be more favourably disposed to adopting EBTs, particularly the wastewater treatment plant. This is more so because modern industrial production facilities in developing countries have largely followed the pattern in developed capitalist economies. To demonstrate this for Nigeria, table 4.5 shows that more than two-thirds of foreign technology agreement registered in Nigeria between 1990 and 1992 came from Western Europe. Since the type of waste stream generated by these presumably largely foreign technologies would most likely be comparable with those produced when they are used in their countries of origin; it follows that, firms' technology responses for pollution control in developing countries (Nigeria) would be considerably influenced by the experiences of industrial economies. As earlier indicated in section 4.3.1, the wastewater treatment plant is industry's prevalent choice for water pollution control. For analytical purposes, the ownership structure of the firm could be defined in terms of the share of foreign capital in the total capital outlay of the firm. Thus, our next sub-hypothesis is:

H2d: Because wastewater treatment is a relatively simple technology but especially expensive for local firms in a developing country such as Nigeria, the use of wastewater treatment plants will not depend only on the technological capability in the manufacturing industry, but also on the ownership structure of the firm.

This hypothesis may give indication of the possible implication of ownership structure (whether foreign, local or joint) on firms' technology responses to the imperatives of environmentally sustainable industrial development in Nigeria. 
Table 4.5: Number and sources of foreign technology agreement registered in Nigeria between 1990 and 1992

\begin{tabular}{|c|c|c|c|c|c|}
\hline Source of technology & \multicolumn{3}{|c|}{ Number of agreement registered } & Total & $\begin{array}{l}\text { Percent of } \\
\text { total }\end{array}$ \\
\hline Western Europe & 94 & 139 & 84 & 317 & 68.0 \\
\hline Eastern Europe & - & - & 3 & 3 & 0.6 \\
\hline North and South America & 34 & 34 & 10 & 78 & 16.7 \\
\hline Asia & 23 & 17 & 6 & 46 & 9.9 \\
\hline Others & 9 & 7 & 6 & 22 & 4.7 \\
\hline Total & 160 & 197 & 109 & 466 & 100 \\
\hline
\end{tabular}

Source: Extracted from data in Laditan (1998, p.47).

\section{Firm size}

It is generally accepted that large firms are prone to being more environmentally conscious than small firms (Howes et al, 1997, p.3). This notion is expected to be no less true for Nigerian firms. In a developing country setting, most large firms comparatively have better access to financial and technological resources that could make it less difficult for them to adopt new technology. Moreover, in Nigeria, many of such firms involve not only foreign interests (e.g. multinational enterprises), but also have contacts that place them in a better position to access local capital that may facilitate their investment decision (Biersteker, 1987; Forrest, 1994). We therefore propose that the larger a firm is in the Nigerian manufacturing sector, the more the likelihood that it will adopt technology for water pollution control. We will measure the firm size in terms of the number of persons employed in a firm.

H2e: The adoption of EBT will be positively correlated with firm size

\section{Environmental policy implementation strategy}

Since our focus is on firm behaviour, the environmental implementation strategy will be viewed from the perception of industrial firms. However, the interpretation of the outcome of the firms' perception will be carefully explained in the light of the views that regulators may hold. The policy implementation strategy will essentially be limited to whether it is viewed as co-operative, in which case there is effective dialogue on compliance mechanism between the firm and the regulator in the process of compliance monitoring; or antagonistic, in the sense of lack of dialogue, either 
because of poor monitoring or inflexibility of the regulator. We assume here that whether the relationship is co-operative or antagonistic, the firms will adopt technology. As earlier indicated in section 3.2 of chapter 3 , the difference will be the type of technology adopted, whether TPA or TPP. Hence we could further hypothesise that:

H2f: The type of EBT adopted for compliance with the S.I.8/S.I.9 regulation depends on the strategy for environmental policy implementation, whether co-operative or antagonistic.

\section{Competitiveness}

To ascertain the influence of a firm's intrinsic competitive nature on the adoption of EBT as enunciated in section 3.2.2 of chapter 3 will be difficult for a developing country such as Nigeria. The reason for this is that, information on market share over some previous period of time will be needed to give some measure of intrinsic firm competitiveness. Such information is currently not available for Nigerian firms. We would therefore limit our consideration of competitiveness to the influence of the expected cost of technology investment in pollution control on the likelihood of EBT adoption. In this respect, it is important to stress that cost is a factor that has to do with firm's profitability. Generally speaking, it may be hard for companies to give $\operatorname{cost}^{32}$ figures for pollution control activities, more so, in a developing country context. Moreover, the response to our firm survey (see sections $5.2 \& 5.3$ of chapter 5 for survey methodology) may be too low if cost figures are demanded from firms. Because of these data availability constraints, the competitiveness variable would be limited to the influence of costs of technology investment in pollution control on firm's probability of EBT adoption.

In view of the fact that a well established regime of environmental regulation is comparatively new in many developing countries, could there be some 'ten dollar bills on the wayside' being currently picked by ingenious firms in the Nigerian manufacturing industry? As Porter and Linde (1995b) pointed out, the motivation behind total quality management (TQM) when it began in Japan was to improve product quality, but it latter became a useful tool of environmental conservation. We propose that in a developing country where functional regime of environmental policy is comparatively new, the adoption of technological innovation that are environment conserving could depend more on the competitiveness of such innovation, rather than the fear of sanctions that may be attracted by non-compliance with environmental policy. Accordingly, competitiveness may be seen in terms of cost reduction possibilities that the adoption of an environmentally friendly innovation may offer. As already indicated above, it may be difficult to get the quantitative values of specific cost reductions from Nigerian firms. However, a firm manager will usually have a fair

\footnotetext{
32 It is pertinent to note that quantitative values of pollution control expenditures, as far as we know, are currently non-existent in Nigeria.
} 
appreciation of the cost implications of a new technology in the total production cost schedule. It will therefore be assumed that, all things being equal, prospects for lower production costs imply more competitiveness, same costs imply no effect on competitiveness, and higher costs imply less competitiveness.

H2g: The adoption of EBT in a developing country such as Nigeria will be related to cost saving or competition motivated reasons that are not necessarily inspired by environmental policy.

For developing country firms, we suggest that the profitability reason, which is closely related to competitiveness, may not be worth investigating separately. This also arises from difficulties that may be involved in obtaining credible and detailed information on firm's financial accounting.

\section{Firm's environmental disposition}

It is necessary to point out at this juncture that, from an empirical perspective, the differentiation of firms into the dispositional categories identified in section 3.2.2 of chapter 3 seems largely applicable to firms in developed economies. While acknowledging that there could be some cases of environmentally 'offensive' or 'proactive' firms in developing countries, the current attitudes of developing country firms however suggest that most of these firms will cluster into the 'defensive' and 'indifferent' categories. Besides, distinguishing features of a firm's environmental disposition such as firm's internal comprehensive environmental programme, EU/EMAS, BS7750, ISO14000, presently have wide application only in developed countries. Even the cost implication of getting any of these environmental management systems' (EMS) certification as reported by World Bank (1999), constitutes considerable obstacles especially to firms in developing countries. We will therefore restrict our search for empirical evidence on the role of firm's environmental disposition in technology adoption to case study analysis of firms identified to be outstanding in environmental performance in Nigerian manufacturing industry.

\section{Institutional capacity for environmental regulation}

Because of the intricate nature of the institutional variable, it may not be possible to give it a detail consideration in this study. However, as revealed by our discussion in chapter 3 , it is apparent that it could be an important determinant of technology responses for water pollution control in Nigerian manufacturing sector. As earlier stated in section 4.2 of this chapter, until the establishment of the Nigerian Federal Environmental Protection Agency (FEPA) in 1988, there was no functional institutional framework to address the problem of industrial wastewater effluents in Nigeria. In analysing regulatory institution as a determinant of firm's technology responses, it will be necessary to find out if FEPA has sufficient capacity to perform its substantive role, and whether or not it is effective in performing its functions. The 
institutional questions raised in section 3.2 .2 of chapter 3 would require ascertaining FEPA's capability as may be reflected by the quality of its manpower; power relations within the organisation; management of its relationship with SEPAs; equipment for compliance monitoring (e.g. laboratory facilities); etc. All these will affect FEPA's capability for effectively implementing industrial wastewater policy that could stimulate technical change for water pollution abatement/prevention. In this respect, we consider it modest to regard the institutional capacity variable $\mathrm{e}^{33}$ as one important factor that may be responsible for some of the unexplained variations that may not be accounted for by our empirical analysis in chapter 7. The forgoing notwithstanding, the case studies in chapter 8 give some insight into the potential impact of institutional capacity for environmental regulation on firms' technology responses for water pollution control in Nigerian manufacturing industry.

\subsection{Conclusion}

In this chapter we have described the institutional framework for environmental regulation in Nigeria with a focus on industrial wastewater pollution control activities. Nigeria appears to have articulated a well established and functional system of industrial pollution control, especially in the area of industrial wastewater pollution. There is an organized structure of compliance and enforcement monitoring activities that cover all industrial activities in Nigeria, particularly those belonging to the formal private sector. The current regime of environmental policy is 'command and control' in nature, and it appears that regulators are beginning to realise that there may be need for the use of economic instrument in future. More than half $(56 \%)$ of regulators surveyed favour the introduction of wastewater effluent charge/tax as an instrument of pollution control. The environmental protection agencies have well equipped pollution control laboratories, which most regulators ( $79 \%$ of our regulators' sample) consider very good, with modern apparatus and analytical equipment. We have nevertheless shown from available secondary information and findings from our field survey of regulators that the institutional capacity for environmental regulation in Nigeria may have significant manpower and infrastructural deficiencies. Although an average of $37 \%$ of employees in the various FEPA/SEPAs that provided information on employment statistics have higher degree qualifications, only $25 \%$ have industrial pollution control related training in environmental science and technology. In addition, regulators view inadequate number of compliance monitoring officers and lack of training as important obstacles to effective regulatory enforcement activities.

\footnotetext{
33 The importance of institutional capacity for environmental regulation may necessitate a completely new study, which we would like to recommend as a further development on the findings of this research. The institutional analysis could afford the opportunity to ascertain the weaknesses (or strengths) of the institutional framework for industrial wastewater pollution control in Nigeria, and thus give indications on possible policy directions that could enhance the effectiveness of existing measures, particularly in the stimulation of environmentally benign technical change in Nigerian manufacturing. For example, in addition to all the institutional questions raised in section 3.2 .2 of chapter 3 , will a reform in the tax policy to include wastewater effluent charge lead to more resources for environmental regulation compliance monitoring, which could in turn engender improved firms' environmental performance in terms of technology adoption?
} 
Furthermore, the problem of lack of vehicles for inspection visits constitutes one single most important problem that faces the regulatory authorities.

After establishing the nature and extent of environmental policy in Nigeria with respect to industrial wastewater pollution control, we applied the analytical framework developed in chapter 3 to the case of Nigerian manufacturing. Two main hypotheses emerged from the analytical framework. The first, which may be termed 'major driver hypothesis' seeks to ascertain whether environmental policy could be regarded as the major driver of the adoption of environmentally benign technologies in a developing country context as represented by Nigerian manufacturing. The second, which may be called the 'auxiliary driver hypothesis', is aimed at finding out whether other factors which have specific bearing on firm-level technological capabilities, firm's characteristics, and regulation implementation strategy play important roles as determinants of the adoption of environmentally benign technologies in Nigerian manufacturing. For analytical purposes, we have decomposed the major driver hypothesis into two, while seven sub-hypotheses are sieved out of the auxiliary driver hypothesis. An important postulation driving this research is what we may call 'major versus auxiliary driver hypothesis' which stress that in developing countries where environmental policy regime is perceived to be relatively weak, some other factors (i.e. auxiliary drivers) may take precedence over environmental policy as rationale for the adoption of environmentally benign technologies (EBTs) in the manufacturing industry. By this hypothesis, we seek to ascertain the relative importance of environmental policy and the auxiliary factors as determinants of EBT adoption.

Expectedly, the analytical framework presented in this chapter may not explain all the reasons why firms in the two selected water pollution intensive sectors adopt technology to abate or prevent water pollution. We are however of the view that the model appears fairly comprehensive enough to expose the important adoption causalities for environmentally benign technologies in a developing country context. Moreover, we wish to state that the analytical framework presented in this chapter is not intended to result in any generalisation for developing countries. Such generalisation may require further application of the model to other developing country cases, a programme beyond the scope of the present study.

As apparent from our discussion so far, this study is an empirical research. Accordingly, in the next section we present a description of our research methodology and the econometric model employed. 


\section{Chapter Five}

\section{RESEARCH METHODOLOGY}

\subsection{Introduction}

The research methodology employed for this study includes survey of firms in the food \& beverages and textile sectors of the Nigerian manufacturing; survey of regulators responsible for environmental regulation with respect to industrial wastewater pollution control; detailed firm-level case study interviews in the two selected manufacturing sectors; and use of relevant secondary information on manufacturing and environmental regulation activities in Nigeria.

The survey method employed used three different questionnaires for three categories of respondents. The first category of targeted respondents is plant managers or production managers and environmental care managers (in case of large firms); ${ }^{1}$ managing directors or CEOs (in case of small or medium-sized firms with sole proprietorship). The second category is environmental regulators at the Federal and State Environmental Protection Agencies, while the third comprises of plant managers of firms selected for detailed firm-level case study interviews. The firm survey process included repeated visits to Nigerian manufacturing enterprises in the two selected water pollution intensive sectors, and where accessibility to the firms are constrained by distance, notably in the Northern and Eastern parts of Nigeria, several mailed questionnaires were used. ${ }^{2}$ The same approach was adopted to elicit information from environmental regulators at the Federal and State Environmental Protection Agencies. In addition, relevant secondary data was also obtained from the various institutions visited; and under strict confidentiality, use was made of environmental audit reports (EAR) ${ }^{3}$ of companies. The following section presents a

\footnotetext{
' In the course of the actual survey of firms, officers who responded to the questionnaires were plant managers or designated officers in charge of quality control at the plant level (usually, quality assurance/control managers). We observed on many occasions that the quality control officers liaise with the production manager or technical directors and the personnel manager or director to get the questionnaire completed.
}

${ }^{2}$ Within the resources available for this research, it was not possible for the researcher to travel to major industrial centres in the North and Eastern parts of Nigeria. During the fieldwork, the researcher was based at the Nigerian Institute of Social and Economic Research (NISER), Ibadan, Western Nigeria. According to kilometre chart for Nigerian cities presented in NISER (2000), Ibadan is $1009 \mathrm{~km}, 759 \mathrm{~km}$ and $863 \mathrm{~km}$ respectively from the Northern Nigerian industrial cities of Kano, Kaduna and Jos; and $526 \mathrm{~km}$ and $625 \mathrm{~km}$ respectively from Eastern Nigerian industrial cities of Enugu and Port Harcourt. It should however be noted that most Nigerian Manufacturing enterprises are located in Western Nigeria. Some estimate claim that Lagos State alone has $60-70 \%$ of Nigerian industries (Lubeck, 1992, p. 17; LASEPA, 1999).

${ }^{3}$ S.I.9 law authorises regulators to demand from existing industrial facilities periodic environmental audit of their activities using FEPA accredited environmental consultants; while new industrial facilities should have FEPA approved environmental impact assessment report before commencement of production. Presently, there is no agreed time frame for conducting environmental audit by firms because the national guideline is silent on this. Regulators use their discretion in demands for companies' EARs. From our interviews and interactions with regulators and company directors, we discovered that regulators in some states demand yearly EARs while some 
detailed description of the sampling and data collection procedures. Section 5.3 gives insights into the design and contents of the research questionnaires, while the final section of the chapter describes the econometric tools employed for the analysis of our field data.

\subsection{Sampling and Data Collection}

In order to generate a comprehensive firm level primary data, two data gathering procedures were used for the survey of manufacturing firms. This includes sector wide survey of firms employing a structured questionnaire, and detailed case study interviews carried out at the firm level with the aid of a personally administered semistructured questionnaire.

A recent review of manufacturing activities in developing countries demonstrated that the emphasis on small scale production not only correlates negatively with per capita income levels across countries, but also within countries through time (Tybout, 2000, p.16). Thus, for a low-income country such as Nigeria, small-scale manufacturing enterprises are of much importance. However, from preliminary fieldwork carried out in the month of January 1999, it was discovered that environmental regulatory activities in Nigeria are yet to target small-scale enterprises, especially in the informal sector of the economy. From my discussions with regulators then, the focus of regulation and compliance monitoring was (and still is) on formal sector manufacturing enterprises, particularly those in the medium and large-scale enterprises categories. This conforms to the generally observed trend in developing countries. Environmental regulation with respect to industrial pollution control in developing countries focuses more on well established formal sector medium and large-scale enterprises because they are presumed to have capability and resources to technologically respond to demands for pollution abatement or prevention. Moreover, the social welfare considerations arising from employment generation effects of smallscale industrial facilities make regulatory authorities either to ignore them or be extremely lenient on them (Blackman and Bannister, 1998; Dasgupta, 2000; Adeoti, 2000). This study therefore deals largely with Nigerian formal sector firms, particularly the medium and large-scale manufacturing plants.

Like in most countries of sub-Saharan Africa, secondary statistical information is difficult to obtain in Nigeria; and when found, there could be significant discrepancies in information from different sources. ${ }^{4}$ Thus, as a starting point for the sector wide

\footnotetext{
regulators believe a biennium or even three to four years will be realistic for EAR so that firms have enough time to implement recommended environmental action plans. Though most company directors agree that the EARs are very useful tools of environmental management, they however consider annual EARs burdensome because of the cost involved, and would prefer nothing earlier than two years for a repeat or review of EARs. This notwithstanding, we discovered that many companies have either submitted one or more EARs or are already in the process of preparing their first EAR.
}

${ }^{4}$ Mosley (1992) and Thoburn (2000) also attest to this fact. 
survey, the latest published version of the industrial directory of the Manufacturing Association of Nigeria (MAN) was used to ascertain the firms that are the likely candidates for the survey. MAN is the foremost association of industrial organisations in Nigeria. Membership comprises of formal sector firms in all manufacturing sectors of the Nigerian economy. The MAN directory (1994) contains names, addresses, factory locations, and possible contact persons (in some cases) of about 2000 Nigerian firms.

In literature, there has been diverse classification of firms into small, medium and large-scale enterprises, either based on sales turnover, capital outlay or persons employed. In Africa, according to Lall et al (1994) and Oyelaran-Oyeyinka (1997a), firms employing less than 10 persons are generally regarded as microenterprises. Firms employing 10 to 49 persons are usually considered small-scale, 50 to 199 medium-scale, and firms employing 200 or more persons are regarded as large scale (Winston, 1981; Liedholm, 1992; Oyelaran-Oyeyinka, 1997b). FOS (1998) ${ }^{5}$ gave a detailed statistics of firms employing 10 or more persons in Nigeria. $55 \%$ of firms employing 10 or more persons in the food processing industry belong to the category employing between 10 and 19 persons. However, for the textiles sector only $18 \%$ of the firms employing 10 or more persons belong to the category employing between 10 and 19 persons. Moreover, searching through the MAN directory, scarcely is any firm employing less than 20 persons. $^{6}$ In view of our decision to target formal sector manufacturing firms, we intuitively concluded that it is unlikely any of our respondent firms would be employing less than 20 persons. For the purpose of this study, we therefore define small-scale firms to be firms employing 20 to 49 persons; and following Winston (1981) and Liedholm (1992), we consider medium-scale firms to be those employing 50 to 199 people. Companies employing 200 or more people are regarded as large-scale enterprises. For the two sectors under investigation, table 5.1 shows the distribution of the manufacturing firms in these categories. ${ }^{7}$

\footnotetext{
${ }^{3}$ This recently published survey report of the Nigerian federal office of statistics (FOS) contains relatively detailed information on the Nigerian manufacturing industries. However, the report covers only 1991 and 1992.

${ }^{6}$ Some of the firms listed in the MAN directory signified the number of persons employed.

${ }^{7}$ According to FOS (1998), in 1992 there were a total of 5203 manufacturing firms employing 10 or more persons in Nigeria, out of which $929(18 \%)$ belong to the food and beverages industry, and $115(2.2 \%)$ belong to the textile industry. It should however be noted that whereas the food \& beverages sector has relatively large number of small and microenterprises, medium and large-scale firms dominate the textiles sector.
} 
Table 5.1: Distribution of firms in Nigerian food \& beverages and textiles sectors in 1992 (according to number of persons employed)

\begin{tabular}{lccccc}
\hline SECTOR & $\begin{array}{l}20-49 \\
\text { persons }\end{array}$ & $\begin{array}{l}50-199 \\
\text { persons }\end{array}$ & $\begin{array}{l}200 \text { and } \\
\text { more } \\
\text { persons }\end{array}$ & Total & $\begin{array}{l}\text { Total } \\
\text { (MAN) }\end{array}$ \\
\hline Food \& Beverages & 217 & 99 & 68 & 384 & 286 \\
Textiles & 18 & 20 & 47 & 85 & 67 \\
\hline TOTAL & 235 & 119 & 115 & 469 & 353 \\
\hline
\end{tabular}

- This total is according to the number of formal sector firms listed in the 1994 MAN directory.

Sources: Extracted from data in FOS (1998, p.10), MAN (1994).

The MAN directory listed 286 food \& beverages firms and 67 textile firms. Since the MAN directory was published in 1994 and the FOS (1998) statistics refer to the 1992 countrywide industrial survey, we did not expect much discrepancy in the figures from the two sources. However, as table 5.1 shows, the discrepancy may not be overlooked. Whereas FOS (1998) claimed that the total numbers of Nigerian food processing and textile firms in 1992 were 384 and 85 respectively; the MAN directory gave the numbers as 286 and 67 respectively in 1994. Our enquiries and discussions with MAN officials revealed that not all Nigerian formal sector manufacturing firms belong to MAN because MAN is a voluntary association. Thus, the FOS survey could have captured other firms not listed in the MAN directory. Besides, the rate of firms' exit and entry into manufacturing activities in the two sectors might have had a negative sum due to the uncertain economic atmosphere arising from the Nigerian 1993/94 political problems. ${ }^{8}$ At any rate, we went into the field with the MAN directory as a guide, but without limiting the selection of firms to the directory. Regulatory agencies (FEPA and relevant SEPAs) were consulted for their working lists of firms. We used these as supplements to the MAN directory.

Since it was difficult to ascertain the actual number and distribution of existing firms, we decided to extend the sector-wide survey to all firms in the two sectors. In effect, this denies us the benefit of a stratified sample that follows a predetermined population distribution.

The fieldwork for the survey lasted six months. ${ }^{9}$ The selection of the firms for the detailed case studies was delayed till mid-way during the survey so that in addition to

\footnotetext{
"There was a serious political problem starting from mid 1993 when a widely accepted election of a civilian president was annulled by the ruling military junta (see Lewis, 1994, p.448). 1993/94 thus formed a period of high political instability in Nigeria.

'November 1999 to April 2000 inclusive.
} 
field information from regulation compliance monitoring officers about firms that may be favourably disposed to entertaining detailed firm-level interview, we had the opportunity to scrutinise some returns obtained from the sector wide survey. Actually, case study firms were also supposed to have first completed the structured questionnaire before the case study interview. The case studies are expected to expose in more detail the factors that guide the technology adoption decisions of firms with respect to water pollution control technologies.

As table 5.1 indicates, the number of food \& beverages firms is at least four times that of the textiles. So we set out to select 12 food and beverages firms and three textile firms for the case studies. We identified six food and beverages subsectors ${ }^{10}$ that could reasonably contribute to industrial water pollution problems, and decided that no subsector will have more than three plants in our case study sample. Because firm's technology response in terms of TPA is relatively easy to recognise as an indication of firm's commitment to investment in technology that minimise external diseconomy, we decided that two-thirds of the case study firms should be firms that have adopted TPA. It is also expected that such firms would be able to give us considerable insight not only into the TPA adoption rationales, but also expose reasons for TPP adoption where applicable. Preliminary cursory look through the initial returns from the sectorwide survey indicated that most of the respondents are medium and large-scale industrial plants. None of the few small-scale plants that responded have adopted TPA. We therefore decided that at least one of the firms in the food \& beverage case studies should belong to the category of small-scale industry so that we can gain a deeper insight into obstacles to TPA adoption among this class of industry. We decided not to bother about doing the same for the textile firms because table 5.1 already indicated that small-scale firms are relatively few in textile industry, apparently due to scale economy requirement for efficient textile production.

In addition to the foregoing, senior officials ${ }^{11}$ of the regulatory agencies were interviewed at various levels and at different locations. Most of the interviews conducted were with officers in the director cadre who could have comprehensive and deep insight into the past and current status of regulation and compliance monitoring. The directors were generally co-operative, and through them the questionnaire for regulators were distributed, and thus administered to the regulatory officials. Visits were made to pollution control laboratories of the regulatory agencies to physically see the kind of facility/equipment available for industrial wastewater effluent analysis.

\footnotetext{
${ }^{10}$ The food and beverages subsectors included are dairy products (ISIC 3112); fruit juices \& soft drinks (ISIC 3113/3134); vegetable oil \& fat products (ISIC 3115); confectionery, bakery products \& sugar factories (ISIC $3117 / 3118 / 3119$ ); distilleries \& wine factories (ISIC 3131/3132); and brewing factories (ISIC 3133).

"The researcher spent a lot of time with the officials of FEPA and SEPAs both during official and unofficial hours. Generally speaking, my interaction and interviews were with officers not lower than Grade Level 12 (i.e. Principal Scientific Officer). I observed that among compliance monitoring officials (especially at FEPA, Lagos SEPA, \& Ogun SEPA) are highly qualified officers. Some of them have at least a higher degree of Masters or considerable experience in a technical related public or private sector employment. Most of the personal interviews conducted were however with officers in the director cadre.
} 
Use was also made of annual reports of FEPA/SEPAs and companies' environmental audit reports to extract useful secondary information for this research.

Like the case of firm survey, it was difficult to get a stratified sample of the regulators. This is because we could not obtain necessary secondary statistical information on the distribution of regulators at various FEPA and SEPA offices. Besides, we did not make distinction between FEPA and SEPA regulators because both institutions currently use the S.I.8/S.I.9 law as the main regulatory instrument for industrial pollution control. Thus, the sampling of the regulators is largely random. It is however restricted to senior officers who perform regulatory compliance monitoring functions.

\subsection{Research Questionnaires}

As the foregoing reveals, we employed three different questionnaires for the research. The first is a structured questionnaire aimed at eliciting information from plant managers or the designated officers in charge of environmental management or pollution control issues at the plant level. This questionnaire was designed during the months of April/May, 1999. It was pre-tested and confirmed with minor adjustments between June and August 1999. Information required in the questionnaire include basic information on the firm's establishment, ownership structure, affiliation to multinational enterprises, capacity utilisation, and employment structure with special focus on the scientific and engineering composition. Also requested were information on the kind of technology adopted for water pollution control, when adopted, source of the technology (whether local or foreign or combination of both), reasons for adoption, gains or loses expected from adoption, sources of technical management of the technology, and the rating of firm's own technical capability to manage the technology. Questions were also raised on the obstacles to adoption before adoption took place; and for firms that have not adopted at all, they also had the opportunity to state the current obstacles to adoption. Firms were also asked whether they are planning to make new investments in TPA or TPP. Furthermore, in order to gain some insight into the capital vintage of the firm, firms were asked to state the age, source, and where possible, the current replacement costs of their main production equipment. To ascertain the kind of external knowledge network associated with Nigerian firms, firms were asked to identify institutions or organisations from which they derive technological knowledge or innovation either for regular business activities or relating to technical solutions to water pollution problems.

Another area of attention in the structured questionnaire is the firm's perception of environmental regulation and management. The questions relating to management seek to extract information on the firm's attitude to environmental management currently, before and after January 1995 when the moratorium granted firms on the enforcement of S.I.8/S.I.9 law came to an end. In case the firm is an affiliate of a multinational enterprise, information was also elicited on how the firm's environmental management in Nigeria compares with that of the parent company. From the regulatory perspective, questions were asked to ascertain firms' perception 
of the attitudes of regulatory officials in the process of compliance monitoring, and whether the regulatory officials have significant impact on firms' decision to adopt TPA/TPP. The questionnaire concludes with questions aimed at obtaining information on firms' rating of gains or losses due to environmental regulation in the years following the enforcement of S.I.8/S.I.9 law.

The second type of questionnaire employed for the research is a semi-structured questionnaire, which served for case studies to gain deeper insight into why Nigerian firms adopt TPA/TPP, and the likely obstacles to adoption in cases of non-compliance with S.I.8/S.I.9 law. The questions asked are quite similar to those in the structured questionnaire except that they are extended to include open-ended questions, thus allowing for respondent's free comments. In addition, questions on input resources and their sources were asked to give insight into the kind of material flow from which the wastewater is derived. Sources of water use were also identified, and information on the effluent quality of wastewater discharge before and after treatment (where treatment occurs) was also requested. More probing questions were asked on the nature and vintage of the main production technology hardware and the production process(es). Questions were raised on whether firms engage in R\&D and the type of R\&D involved.

Questions on environmental regulation and management were extended to ascertain whether case study firms have environmental policy statements; the objectives/targets of such policy; and whether the practice of formal environmental management system (EMS), such as EU/EMAS, BS7750 or ISO14000 has been adopted. Firms were also asked to assess the technical and scientific competence of compliance monitoring officials. In concluding the case study, firms were requested to comment freely on the future of environmental regulation in Nigeria, and particularly on the prospects for using economic instrument of wastewater effluent charge or tax for industrial water pollution control.

The third questionnaire is also semi-structured. As earlier indicated, it was administered to environmental regulators. The objective of the questionnaire is to elicit information that may complement the views expressed by firms so that we may have deeper and relatively fair understanding of the reasons why firms adopt (or not adopt) TPA/TPP. Besides, regulatory activities have so far been shrouded in what may be termed 'expected performance syndrome'. Little is known about the actual performance of regulatory activities. The questionnaire thus started with a question asking regulators to identify the specific monitoring activities they implement with regard to industrial pollution control in Nigerian manufacturing. They were then asked to assess the attitudes of firms to compliance monitoring; whether most firms cooperate or antagonise compliance monitoring in general, and inspection of pollution control equipment in particular. They were also asked to rate the pollution control laboratories and equipment available for water pollution control at their agencies.

In order to ascertain reasons for and obstacles to technical change for pollution control from the perspective of the regulatory authorities, the regulators were also asked to 
identify reasons for and obstacles to TPA/TPP adoption. Regulators' views were also elicited on the kind of technical change that has taken place in favour of water pollution control in the two sectors under investigation. In addition, their opinion on the performance of the entire manufacturing sector with respect to technology adoption for water pollution control was also sought. Regulators were also asked whether they favour effluent charges as an instrument of industrial water pollution control, and they were requested to freely comment on the likely impact of such a charge on firms' technology adoption for water pollution control. In concluding the questionnaire, they were asked to give important obstacles to compliance monitoring, and indicate whether or not there is conflict of role between FEPA and SEPAs in compliance monitoring.

Having given a detailed description of the fieldwork procedure and tools employed, the next section describes the econometric model that would be applied for the analysis of the adoption causalities of environmentally benign technologies in the two water pollution intensive sectors under investigation.

\subsection{Econometric Analysis}

The general model in this research can be formally stated as follows:

Let $A_{i}$ be a dichotomous variable representing adoption (1) or non-adoption ( 0$)$ of an environmentally benign technology $i$. We express $A_{i}$ as a linear function of vector, $X_{i j}$ :

$$
A_{i}=b_{o}+\sum_{j=1}^{k} b_{k} X_{i j}+e_{i}
$$

where

$X_{i j}$ is a vector of factors determining adoption;

$b_{o}, b_{k}$ are the parameters to be estimated; and

$e_{i}$ is the error term.

As proposed in section 4.3 of chapter 4 , with respect to water pollution control, a firm is considered to have adopted an environmentally benign technology when it uses an industrial wastewater treatment plant (TPA) or when it applies a process integrated techniques/method that reduces the generation of wastewater at the source (TPP). The vector $X_{i j}$ consists of the following earlier defined explanatory variables (refer to section 4.3 of chapter 4 ). The indicator(s) or measure(s) to be used for each variable are given in the parenthesis. These indicators/measures have earlier been discussed in section 4.3 of chapter four.

$E P L=$ national environmental policy law S.I.8/S.I.9 [yes (1) or no (0)] $O S T=$ ownership structure of the firm [share of foreign equity in total capital outlay] $F S=$ Firm size [number of people employed]

$I C H$ = firm's internal capability for innovation - human capital [share of scientists and engineers in total employment] 
$I C K=$ firm's internal capability for innovation - physical capital [wholly local (1), partially imported (2), and wholly imported (3) technological hardware for the production process].

$E N I$ = firm's external network for innovation [higher educational institutions (1); local research institutes (2), international research institutes/parent company/foreign technical partner (3)]

$E P S=$ environmental policy implementation strategy [co-operative (1); antagonistic $(0)]$

According to Maddala (1992), the type of dummy dependent variable that we have employed in the model above (equation 5.1) can be regressed on the explanatory variables using any of the following three models, all of which are rooted in the linear probability model:

i) the linear discriminant function (LDF),

ii) the logit model, and

iii)the probit model.

The difference between the linear discriminant function and the logit/probit models is that, whereas the LDF analyses the dichotomous variable of adoption (or nonadoption) just as they are; the other two models assume the existence of an underlying latent variable for which we observe a dichotomous realisation. In our case, this latent variable could be expressed as 'propensity to adopt or probability of adoption'. The logit and probit models are identical, but differs in the specification of the distribution of the error term. In the former, the distribution is assumed to be logistic, while it is assumed to be normal for the later.

Only the estimation of the logit and the probit models appears relevant to our study because the underlying assumption of the existence of a latent variable connoting the firm's probability of adoption (or propensity to adopt) is closer to reality than the straight-forward analysis of the dichotomous variable as either 'adoption' or 'no adoption' envisaged by the LDF. In practice, it is possible to speak of a firm's probability of adopting a technology, rather than the certainty of adoption of a technology. A firm that has a good chance of adoption may eventually never adopt.

Models based on the assumption of the logistic distribution have found wide application in empirical research on adoption and diffusion of technologies. (e.g. Griliches, 1957; Mansfield, 1961; Stoneman, 1983; Boahene, 1995; etc.). Following in the same tradition, we assume that the distribution of the error term in equation (5.1) would follow the logistic distribution in order to estimate the logit model. Drawing on Maddala (1983; 1992, pp.327-328) and Liao (1994), the adoption of environmentally 
benign technologies as defined in equation (5.1) could be equated to the log-odds $s^{12}$ of the logit model. Thus,

$$
A_{i}=\log \frac{P_{i}}{1-P_{i}}=b_{o}+\sum_{j=1}^{k} b_{k} X_{i j}
$$

where,

$P_{i}$ is the probability of adopting environmentally benign technology $i$, given the vector of factors determining adoption, $X_{i j}$.

The logit regression framework represented by equation (5.2) can be estimated to give the estimated parameters as the change in the log-odds that can be attributed to unit change in an independent variable. However, such estimation results would be relatively difficult to explain because the log-odds is itself an endogenous variable. To get round this problem, using matrix notations, equation (5.2) can be rewritten as shown in equation (5.3), and then transformed to give the probability of adoption as a non-linear function of $X_{i j}$ shown below as equation (5.4).

$$
\log \frac{P_{i}}{1-P_{i}}=b^{\prime} X_{i j}
$$

where

$b^{\prime}$ is the transpose of the matrix of parameters to be estimated. Thus,

$$
P_{i}=\frac{\exp \left(b^{\prime} X_{i j}\right)}{1+\exp \left(b^{\prime} X_{i j}\right)}=\frac{1}{1+\exp \left(-b^{\prime} X_{i j}\right)}
$$

Using maximum likelihood estimator, the estimation of the regression parameters in the logit model (equation 5.2) can therefore be carried out, and the conditional probability of adoption $P_{i}$, given the vector of independent variables $X_{i j}$, can be obtained. The logit model as expressed in equation 5.4 leads to what has been termed "logistic regression" because of the cumulative logistic distribution function (see Liao, 1994, p.12). Liao has observed that distinction between the two names of logit models and logistic regression is sometimes based on whether continuous explanatory variables are included in the analysis. When explanatory variables are all categorical variables, the model is termed logit model; and models with mixed categorical and continuous explanatory variables are termed logistic regression models. However, some researchers consider this distinction unnecessary. This is the approach in Liao (1994), and we have adopted it for this study.

The cumulative logistic and normal distributions are very close to each other except at the tails. ${ }^{14}$ Hence, estimation results are not likely to be different using either the logit

\footnotetext{
${ }^{12}$ With respect to this study, we define the odds of adoption as the ratio of the probability of adoption to the probability of non-adoption of EBT: odds $=P_{i} /\left(I-P_{i}\right)$. In the same manner, some authors (e.g. Hamilton, 1992; Mukherjee et al, 1998) refer to $P_{i} /\left(I-P_{i}\right)$ as the odds.

${ }^{13}$ For detailed proof on the derivation of this relationship of the logit model, see Maddala, (1992, pp.327-328).

${ }^{14}$ The logistic is thicker at the tails (see Pindyck and Rubinfeld, 1998, p.308).
} 
or probit models unless the samples are very large so that we have enough observations at the tails (Aldrich and Nelson, 1984, p.65; Maddala, 1992). As would be shown in the next chapter, our research sample is not large enough to give sufficient reason to expect different estimation results from the logit and probit model specifications. We will therefore limit our analytical considerations to the logit framework.

For the purpose of interpreting of the logit regression coefficients, we will consider the odds of adoption. In this respect, the odds of adoption could be obtained from the exponential transformation of equation 5.3. Thus, the odds of adoption would be given by:

$$
\frac{P_{i}}{1-P_{i}}=e^{b X_{i j}}=e^{b_{t}} \cdot e^{\sum_{j=1}^{b_{2} x_{i}}}
$$

Following the illustrations given by Liao (1994, p.16) and Mukherjee et al (1998, pp.322-323), ${ }^{15}$ the change in the odds of the adoption of environmentally benign technologies by Nigerian manufacturing firms per unit change of an independent variable while other independent variables remain unchanged (i.e. other things being equal) could provide a good indication of the relative influence of each of our hypothesised explanatory variables on EBT adoption. 


\section{Chapter Six}

\section{TRENDS IN TECHNOLOGY RESPONSES FOR WATER POLLUTION CONTROL IN NIGERIAN MANUFACTURING}

\subsection{Introduction}

So far, we have largely presented the theoretical underpinnings and the research methods employed for this study. Beginning from this chapter, the subsequent treatise deals with details of our empirical analysis and findings.

Before we proceed to analyse the adoption rationales for environmentally benign technologies in Nigerian manufacturing, it is necessary to first establish that there is significant evidence that technologies are being adopted to abate or prevent pollution. With respect to industrial wastewater pollution, this chapter is therefore aimed at exposing the current trends in technology responses that ameliorate the external diseconomies of production in the two selected water pollution intensive sectors, viz., food \& beverages, and textiles.

As a prelude to the exposition on the kind and trends in the identifiable environmentally benign innovations in the two sectors, the following section concentrate on giving some insight into the nature and characteristics of Nigerian manufacturing. Section 6.3 presents the current trends in technology responses, while obstacles to technology responses are highlighted in section 6.4. The final section concludes the chapter with remarks on the extent to which the descriptive analysis presented has indicated the reasons for the technology adoptions observed.

\subsection{Characteristics of Nigerian Manufacturing}

The characteristics of the Nigerian food \& beverages and textiles sectors discussed in this section are based on the findings of our field survey. The two sectors are among the oldest manufacturing sectors in Nigeria (Forrest, 1994). We will consider industry characteristics such as firm size distribution; affiliation to multinational enterprises; age in production; human and physical capital; sources of technological knowledge; and environmental management.

\subsubsection{Firm size distribution}

As already indicated in chapter 5, the survey sampling for the two sectors is skewed in favour of the medium and large-scale industries because small-scale industries are generally considered to lack resources or capability to embark on technical change 
that may reduce the social costs of their productive activities. At the end of the sectorwide survey, a total of 130 questionnaires were returned from the two sectors (101 from food \& beverages and 29 from the textiles). Eight of the questionnaires (six from food \& beverages and two from textiles) were rejected due to poor or inadequate responses, ' leaving a balance of 122 firms in our sample. Table 6.1 shows the size distribution of the sample firms in the two sectors according to our classification of small, medium and large-scale industries. As expected, the size distribution is skewed in favour of medium and large-scale firms in the two sectors. The skewdness is more pronounced in the textiles sector apparently because of the generally higher minimum efficient scale in textiles compared to most food processing. ${ }^{2}$ For example, the smallest food \& beverages plant in our sample employs 23 persons, whereas the smallest textile plant employs 154 persons, and only two textile plants in the sample employs less than 200 persons. It is also noteworthy that the number of food \& beverages firms is almost four times that of textiles. It can be shown from table 5.1 of chapter 5 that the number of food \& beverages firms in the actual population of our chosen category of firms may just be between four and five times that of the textiles. ${ }^{3}$

Table 6.1: Distribution of sample firms according to size

\begin{tabular}{|c|c|c|c|c|}
\hline \multirow[t]{2}{*}{ SECTOR } & \multicolumn{3}{|c|}{ Number of firms employing } & \multirow[t]{2}{*}{ Total } \\
\hline & $20-49$ & $50-199$ & 200 or more & \\
\hline Food \& beverages & $15(16 \%)$ & $35(37 \%)$ & $45(47 \%)$ & $95(78 \%)$ \\
\hline Textiles & 0 & $2(7 \%)$ & $25(93 \%)$ & $27(22 \%)$ \\
\hline Total & $15(12 \%)$ & $37(30 \%)$ & $70(58 \%)$ & $122(100 \%)$ \\
\hline
\end{tabular}

Note: Parenthesis contains percentage of total

Source : Author's field survey

\footnotetext{
'Three-quarters of these rejected questionnaires were those delivered by post. Problem of rejection was grossly minimised because the researcher had physical contacts with most of the respondents. This enabled the retrieval of most of the questionnaires to be done personally. Where responses appeared unsatisfactory, immediate clarification was sought from the respondent. This rendered all personally retrieved questionnaires useful except two.

${ }^{2}$ In addition, it is widely acknowledged that the textile industry is relatively more labour intensive than other industries (see Mytelka, 1985). Since our size classification is based on number employed, it is thus more likely that the tendency towards large firm size would comparatively favour the textile firms.

${ }^{3}$ From table 5.1 in chapter 5, based on the FOS (1998) data, the number of food \& beverages firms is 4.5 times that of textiles; while it is 4.3 times when based on the MAN directory listing.
} 


\subsubsection{Affiliation to multinational enterprises}

The involvement of multinational companies in Nigerian manufacturing in the two sectors is indicated in table 6.2. As the table shows, about one quarter of our sample firms are affiliates of multinational companies, and more than two-thirds of these are large-scale industries. It is necessary to mention that hardly is any of the multinational affiliates in the small-scale industry category. The only exception is a technology intensive beverage plant ${ }^{4}$ producing an important intermediate product for the Nigerian beverages industry. None of the other MNE affiliates employs less than 100 persons. Among the 25 food \& beverages multinational affiliates, $15(60 \%)$ have North American based parent companies, while $10(40 \%)$ are affiliates of Western European based firms. All the textile firms that indicated multinational affiliation have Asian based parent companies.

Table 6.2: Multinational companies' involvement in Nigerian manufacturing

\begin{tabular}{|c|c|c|c|c|c|}
\hline \multirow[t]{2}{*}{ SECTOR } & \multicolumn{3}{|c|}{ Number of firms employing } & \multirow{2}{*}{$\begin{array}{l}\text { Total MNE } \\
\text { affiliate. }\end{array}$} & \multirow{2}{*}{$\begin{array}{l}\text { Total No. } \\
\text { of firms } \\
\end{array}$} \\
\hline & $20-49$ & $50-199$ & 200 or more & & \\
\hline Food \& beverages & 1 & 5 & 19 & $25(26 \%)$ & 95 \\
\hline Textiles & 0 & 0 & 6 & $6(22 \%)$ & 27 \\
\hline Total & 1 & 5 & 25 & $31(25 \%)$ & 122 \\
\hline
\end{tabular}

Note: Parenthesis contains percentage of multinational enterprise affiliate in total number of firms. Source : Author's field survey

\subsubsection{Distribution of age in production}

Another interesting characteristic of the sample firms is the age distribution of the plants. As table 6.3 shows, nearly half of the sample firms are older than 20 years; $40 \%$ is between 11 and 20 years old; and just a little above one-tenth is ten years old or less. ${ }^{5}$ It is however necessary to state that we excluded all firms not established before 1994 from our sample because of our objective of determining the influence of

\footnotetext{
"This plant is the only one of its type in West Africa. In sub-Saharan African industrial contextual setting, it will actually be classified as a large-scale industry, especially if sales turnover is used as criteria for firm size.

${ }^{5}$ Age indicated by firms in the questionnaire is years of first establishment. We did not bother to take into consideration incidences of temporary closure due to economic reasons. Cases of temporary plant closures or very low capacity utilisation are not uncommon since the mid 1980s when the World Bank structural adjustment programme was introduced (see Lall, 1999b; Singer and Roy, 1993).
} 
FEPA's S.I.8/S.I.9 law ${ }^{6}$ on firms' technology responses for industrial water pollution control. The age distribution for the food \& beverages firms is a little different from that of total firms with less proportion $(40 \%)$ in the older than 20 years category, and relatively more in the ages $1-10$ years $(17 \%)$ and $11-20$ years $(43 \%)$. There is no plant not more than 10 years old among the textiles sample, and $70 \%$ of the firms are older than 20 years. This may be an indication that last decade witnessed little or no new establishment in the textiles sector, whereas the food \& beverages had new firm entrants. Overall, only two plants in the sample are older than 40 years; indicating the widely held view that industrial production activities in Nigeria are largely a postindependence experience ${ }^{7}$ (Forrest, 1994; Singer and Roy, 1993; Helmsing, 1993; Ohiorhenuan, 1990). In addition, it appears that the relatively older firms are the biggest plants. This is not unexpected because older firms would normally have grown, and perhaps overcome the hazards that would have sent them off the scene.

Furthermore, table 6.4 demonstrates that whereas more than half of the MNE affiliates is older than 20 years, most of the local firms ${ }^{8}$ are not older than 20 years. ${ }^{9}$ The trend reflected in table 6.4 could be a pointer to the widely held view that MNE manufacturing investment in Nigerian manufacturing has declined since the end of the oil boom years (see Biersteker, 1987 and Bevan et al, 1999). At any rate, the trend confirms the finding of Lall et al (1994) in which they discovered that newer firms are local firms in their study of Ghanaian industries under economic structural adjustment.

\footnotetext{
'As earlier stated in section 4.2 of chapter 4, the S.I.8/S.I.9 law was enacted in August 1991, and came into full effect in January 1995.

${ }^{7}$ Nigeria obtained her political independence from Britain on October 1, 1960. It is widely acknowledged that prior to independence foreign merchant firms dominated the modern sector in Nigeria. Modern manufacturing activities became a notable feature of the Nigerian economy after independence (see Hoogvelt, 1979; Brautigam, 1992; Helmsing, 1993; Forrest, 1994; and Bevan et al, 1999).

${ }^{8}$ Calling them local firms should not be misconstrued to imply that they have no foreign capital or human resources involvement. They are only 'local' in the sense that they are not MNE affiliates; in fact, a good number of them have foreign technical partners.

${ }^{9}$ In addition to the statistics in table 6.4, note also that the median age of firms is 20 years.
} 
Table 6.3: Age distribution of sample firms

\begin{tabular}{lcccc}
\hline $\begin{array}{c}\text { SECTOR } \\
\& \text { firm size }\end{array}$ & $1-10$ yrs. & $\begin{array}{c}\text { No. of firms with age } \\
11-20 \text { yrs. }\end{array}$ & Total \\
\hline Food \& beverages & 5 & 6 & 4 & \\
SSI & 7 & 20 & 8 & 15 \\
MSI & 4 & 14 & 26 & 35 \\
LSI & $16(17 \%)$ & $40(43 \%)$ & $38(40 \%)$ & $94(78 \%)$ \\
Total & 0 & 0 & 0 & 0 \\
\hline Textiles & 0 & 1 & 1 & 2 \\
SSI & 0 & 7 & 18 & 25 \\
MSI & 0 & $8(30 \%)$ & $19(70 \%)$ & $27(22 \%)$ \\
LSI & & & & $121^{*}(100 \%)$ \\
Total & $16(13 \%)$ & $48(40 \%)$ & $57(47 \%)$ & \\
\hline
\end{tabular}

Notes: Parenthesis contains percentage of total

* There is one missing value, hence total here is 121 firms.

SSI = small-scale industry; $\mathrm{MSI}=$ medium scale industry; $\mathrm{LSI}=$ large-scale industry .

Source : Author's field survey

Table 6.4: Age distribution of MNE affiliates vs. Local firms

\begin{tabular}{lcccc}
\hline Type of Firm & $1-10$ yrs. & $\begin{array}{c}\text { No. of Firms with age } \\
11-20 \text { yrs. }\end{array}$ & Total \\
\hline MNE affiliates & $2(7 \%)$ & $12(40 \%)$ & $16(53 \%)$ & $30(25 \%)$ \\
Local Firms & $14(15 \%)$ & $36(40 \%)$ & $41(45 \%)$ & $91(75 \%)$ \\
\hline Total & $16(13 \%)$ & $48(40 \%)$ & $57(47 \%)$ & $121^{\circ}(100 \%)$ \\
\hline
\end{tabular}

Note: Parenthesis contains percentage of total

- There is one missing value in the MNE affiliate, hence total here is 121 firms.

Source : Author's field survey

\subsubsection{Human and physical capital}

For the food \& beverages and textile firms in our sample, the smallest plants employ 23 and 154 persons respectively, while the largest plants employ 3000 and 3211 persons respectively. Since engineering and scientific skills play very important role in production, we calculated a skill intensity ratio for the sample firms in order to have a fair idea of the depth of the engineering and scientific skills involved in the firms. The skill intensity ratio is calculated as the ratio of the number of engineering and 
scientific personnel employed to the total number of persons employed by a firm. In this respect, we calculated local skill intensity ratio based on the number of Nigerian engineers, technicians and scientists employed; and the foreign skill intensity ratio based on the number of foreign engineers, technicians and scientists employed.

As table 6.5 demonstrates, the highest and lowest local skill intensity ratios of 0.714 and 0.012 respectively are in the food \& beverages sector. However, the highest local skill intensity ratio for the textiles firms is only 0.135 . For the two sectors pooled together, the mean local skill intensity ratio is 0.113 , while the median is 0.086 . Thus, whereas the mean for the textiles $(0.016)$ is lower than the pooled sample mean, the mean for the food \& beverages $(0.126)$ is higher than that of the pooled sample. This indicates that, though the lowest local skill intensity ratio may be found in the food \& beverages sector, there may generally be relatively lower local skill intensity in the textile firms when compared to the food \& beverages sector. However, with regards to the qualification for plant management, there appears to be no appreciable difference between the two sectors. Over $80 \%$ of firms in the two sectors are run by managers with at least a university degree or higher diploma.

Table 6.5: Local and foreign skill intensity ratios of the research sample firms.

\begin{tabular}{lccc}
\hline $\begin{array}{c}\text { FACTOR } \\
\text { \& statistic }\end{array}$ & $\begin{array}{c}\text { Food \& } \\
\text { beverages }\end{array}$ & Textiles & $\begin{array}{c}\text { Pooled } \\
\text { sample }\end{array}$ \\
\hline $\begin{array}{c}\text { Local skill intensity ratio } \\
\text { Mean }\end{array}$ & 0.126 & 0.016 & 0.113 \\
Median & 0.098 & 0.014 & 0.086 \\
Minimum & 0.012 & 0.013 & 0.012 \\
Maximum & 0.714 & 0.135 & 0.714 \\
\hline Foreign skill intensity ratio & & & \\
Mean & 0.008 & 0.068 & 0.010 \\
Median & 0.006 & 0.063 & 0.008 \\
Minimum & 0.000 & 0.002 & 0.000 \\
Maximum & 0.086 & 0.032 & 0.086 \\
\hline
\end{tabular}

With respect to foreign skill intensity ratio, the minimum of zero is found in the food \& beverages sector. In fact, $41 \%$ of the plants in the food \& beverages sector have no foreign (non-Nigerian) engineer or scientist. However, the highest foreign skill intensity ratio of 0.086 is also in the food \& beverages (see table 6.5). The mean and median for the food \& beverages sector are nevertheless below the mean and median for the pooled sample. There is no textile firm without foreign skill input in our sample; the foreign skill intensity ratio statistics are generally above the corresponding pooled statistics, except for the maximum skill intensity ratio, which did not exceed 0.032 . Thus, while textile plants in our sample may generally be higher in foreign skill intensity than the food \& beverages firms, the most foreign skill intensive firms are 
nevertheless in the food \& beverages sector. Since we earlier observed that food \& beverages firms generally have higher local skill intensity, this may be an indication that relatively less skill intensive food \& beverages firms have been able to successfully substitute local for foreign skills.

Generally speaking, we may deduce from the foregoing that whereas the food \& beverages plants in our sample use relatively more local scientific and technical skills, the textile plants engage relatively more foreign scientific and technical skills for their production activities. This may help to explain our findings in table 6.6, which indicates that the food \& beverages firms have relatively more educated Nigerian workforce than the textile firms. Besides, this is expected because the food processing industry demands stringent hygienic control, which may perhaps necessitate relatively highly educated and enlightened workforce. Such a workforce may however not necessarily include substantial foreign element. Furthermore, it is noteworthy that foreign engineers and scientists' presence in the two sectors may be considered relatively low. The plant employing the highest number of foreign engineers \& scientists belongs to the food \& beverages sector, employs only 23 engineers/scientists, and has a foreign skill intensity ratio of 0.016 .

Table 6.6: Mean proportion of workers according to their educational qualification

\begin{tabular}{lccc}
\hline Workers with & $\begin{array}{c}\text { Food \& } \\
\text { beverages }\end{array}$ & Textiles & Pooled sample \\
\hline Higher education & $29 \%$ & $23 \%$ & $27 \%$ \\
Secondary education & $54 \%$ & $64 \%$ & $57 \%$ \\
Primary education & $17 \%$ & $13 \%$ & $16 \%$ \\
\hline
\end{tabular}

Source : Author's field survey

With respect to physical capital in the two sectors, the vast majority of the sample firms sourced their main capital equipment from abroad (see table 6.7). The situation is however more pronounced in the textiles sector, which indicated that almost all the sample firms use imported completely foreign technology equipment for their main production. This result is not surprising because the Nigerian capital goods sector is noted to be relatively underdeveloped (see Nambudiri, 1983, pp.7-8; OyelaranOyeyinka, 1997b, p.316; Okejiri, 2000; Narula, 1997). More than two-thirds (73\%) of the food \& beverages and about two-thirds $(67 \%)$ of the textile firms signified that the foreign equipment come from Western Europe. However, there is an indication of the use of some locally manufactured capital goods in the food \& beverages sector. About 
one third of the food processing firms use either completely locally fabricated equipment or hybrid of local and foreign equipment.

Table 6.7: Source of main production equipment

\begin{tabular}{lccc}
\hline \multicolumn{1}{c}{ SOURCE } & $\begin{array}{c}\text { Food \& } \\
\text { beverages }\end{array}$ & Textiles & Pooled sample \\
\hline $\begin{array}{l}\text { Locally fabricated } \\
\begin{array}{l}\text { Combination of local \& } \\
\text { foreign equipment }\end{array}\end{array}$ & $3(3 \%)$ & 0 & $3(2 \%)$ \\
$\begin{array}{l}\text { Completely foreign } \\
\text { technology equipment }\end{array}$ & $64(67 \%)$ & $26(96 \%)$ & $90(74 \%)$ \\
\hline Total & $95(100 \%)$ & $27(100 \%)$ & $122(100 \%)$ \\
\hline
\end{tabular}

Note: Parenthesis contains percentage of total

Source : Author's field survey

The present age vintage of the main physical production equipment in the food \& beverages sector ranges from a minimum of two to a maximum of 36 years with a mean age of 15 years. In the case of the textiles, it ranges from a minimum of 5 to a maximum of 35 years with a mean age of 19 years. Mode of acquisition of the production technology was at the open market in $91 \%$ of the cases in our research sample; while only $5 \%$ acquired technology through licensing, ${ }^{10}$ and these are all in the food \& beverages sector.

The unweighted average current ${ }^{11}$ capacity utilisation in the pooled sample is $49.5 \%$ (the minimum is $10 \%$ and the maximum is $100 \%$ ). Though the mean appears relatively low, it is however above the industry average which has never been up to $40 \%$ in recent years (see Okejiri, 2000; MAN, 2000; Akinbinu, 1997). This indicates that our sample is skewed towards comparatively healthy firms in the Nigerian manufacturing sector. It should nevertheless be noted that the textile firms in the sample appear to be relatively more active with an unweighted average capacity utilisation of $55.2 \%$; whereas the unweighted average capacity utilisation of the food \& beverages sector is $47.9 \%$.

\footnotetext{
${ }^{10}$ Note that the balance of $4 \%$ is missing values.

"The survey was carried out from November 1999 to April 2000.
} 


\subsubsection{Sources of technological knowledge}

From the results of the sector wide survey, important sources of technological knowledge or innovation for most firms in the pooled sample include supplier of the main production technology or equipment; firm's in-house R\&D; parent company (in cases of multinational affiliates); and firm's foreign technical partners (see table 6.8). Firm's in-house R\&D is considered the most important source of technological knowledge or innovation by our sample firms, followed by foreign technical partners. It should however be noted that, as detailed case study findings will reveal in chapter $8, R \& D$ in the conventional sense is minimal in Nigerian manufacturing. This confirms similar findings by Oyelaran-Oyeyinka (1997b, p.316) and Okediri (2000, pp.197-198). What most of the firms indicated as R\&D are no more than technical activities targeted at adapting and maintaining existing technology to suit local production conditions or requirements. It should also be noted that, when the textiles sample is treated separately, the supplier of the main production technology is not an important source of technical knowledge. This could be an indication of a good mastery of the operation of the existing level of textile technology in Nigerian manufacturing. Alternatively, it could also be an indication of lack of recent change in machinery, in which case, existing technical service agreement with technology supplier might have expired.

With respect to technical solutions to industrial water pollution problems, firm's inhouse R\&D is signified as the most important source of technological knowledge by the food \& beverages sample, while the textiles sample indicates foreign technical partners as the most important source. This may not be unconnected with the fact that textiles wastewater effluent is more difficult to handle compared to the food \& beverages effluent; ${ }^{12}$ and hence, textile firms may be prone to consulting their foreign technical partners to solve wastewater effluent treatment problems.

\footnotetext{
${ }^{12}$ Whereas the food \& beverages wastewater effluents contain largely organic load that can be treated with conventional biological treatment, the textiles effluent usually contain substantial amount of chemical load that need additional tertiary treatment.
} 
Table 6.8: Sources of technological knowledge or innovation

\begin{tabular}{|l|c|c|}
\hline \multicolumn{1}{|c|}{ Source } & $\begin{array}{l}\text { Percent of respondent } \\
\text { firms that consider } \\
\text { source as important }\end{array}$ & $\begin{array}{l}\text { Percent of respondent firms } \\
\text { that consider source as } \\
\text { most important }\end{array}$ \\
\hline Supplier of main production technology & $62 \%$ & $21.8 \%$ \\
Supplier of environmental technology & $10 \%$ & $0.8 \%$ \\
Local research institutes & $31 \%$ & $0.0 \%$ \\
International research institutes & $26 \%$ & $4.2 \%$ \\
Nigerian higher educational institutions & $18 \%$ & $0.8 \%$ \\
Firm's in-house R\&D & $81 \%$ & $31.1 \%$ \\
Firm's parent company & $81 \%$ & $13.4 \%$ \\
Firm's foreign technical partners & $66 \%$ & $26.1 \%$ \\
Other manufacturing firms & $29 \%$ & $1.7 \%$ \\
\hline Total & & $100.0 \%$ \\
\hline
\end{tabular}

Source: Author's field survey

\subsubsection{Environmental management}

From the perspective of the sample firms, more than $70 \%$ of plant managers or their representatives rated current top management commitment to environmental management as high or top priority. Understandably, this rating might have been exaggerated. From our discussions with regulators, they affirm that only the management of some MNE affiliates may be considered to merit such a high performance rating. Regulators however agree that firms have generally made considerable improvement in their commitment to environmental management. In the case of MNE affiliates, $43 \%$ claim that the standard of their environmental management in Nigeria is lower than that of their parent company, $54 \%$ claim it is the same, while $3 \%$ claim it is higher. ${ }^{13}$

\footnotetext{
${ }^{13}$ This result should be taken with caution since it reflects more of the food \& beverages firms: the MNE affiliates sample comprises 25 food $\&$ beverages firms and 6 textile firms.
} 
With regard to the impact of S.I.8/S.I.9 law, $83 \%$ of the respondents claim that their commitment to environmental management before its enforcement in January 1995 ranges from very low to moderate; while $66 \%$ claim their commitment after January 1995 ranges from high to very high. Again, the commitment after January 1995 might have been exaggerated. We may only suggest that the responses signify that the enforcement of S.I.8/S.I.9 law has apparently raised the level of firms' commitment to environmental management.

Almost all respondents claim they discuss technical solutions to pollution problems with regulators; and more than three-quarters rated regulators' technical suggestions from useful to very useful. More than $80 \%$ of the respondents affirm that the attitudes and disposition of regulators to compliance monitoring are co-operative. About the same proportion also claims never to have had disagreement with regulators about the most appropriate compliance technology or method of water pollution control. As complement to this, regulators also disclosed that most firms co-operate on compliance monitoring and enforcement issues. ${ }^{14}$ It is however necessary to add a caveat to this apparently favourable perceptions of regulator-industry relationship.

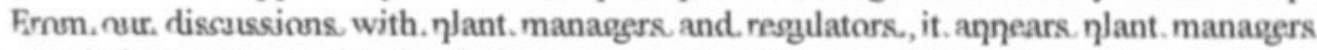
are being extra polite in their assessment of their relationship with regulators. Generally speaking, plant managers view some regulators to be antagonistic and unmindful of the economic implications of their suggested technical solutions to water pollution problems. Thus, though regulators also claim to be friendly and normally adopt a persuasive approach to compliance enforcement, the situation may however not be as co-operative as the responses depict. Besides, $89 \%$ of the respondents claimed that environmental regulation has led to substantial increases in their production costs in the last four years. Viewed from the perspective of generally low capacity utilisation, it would not have been easy for firms to absorb the cost burden arising from pollution control expenditures.

The foregoing has given a fairly detail description of the characteristics of the two selected Nigerian water pollution intensive manufacturing sectors. However, what has so far been done by firms in these two sectors in terms of technical change in response to the imperatives of environmentally sustainable industrial development? The following section gives an overview of recently observed trends that may shed light on the answer to this question.

\footnotetext{
"More than half of the respondents in our regulators' survey acknowledge that most firms' attitude to compliance monitoring and enforcement is co-operative. More than two-thirds (73\%) of the respondents also claim that when disputes arise, the most important approach used in effecting compliance is dialogue and persuasion; followed by issuance of warnings (17\%); and court action / ceiling of plant $(10 \%)$. Pecuniary penalty such as 'fine' is not mentioned perhaps because it is not used. This may be due to the fact that the statutory specification in this respect is so small that it presently makes no sense. The S.I.8/S.1.9 law specifies a maximum fine of $500,000.00$ Naira (currently about US\$5,000.00) for a non-complying firm. This has never been reviewed to catch up with the trends in the progressive devaluation of the Nigerian currency.
} 


\subsection{Trends in Technology Responses for Industrial Water Pollution Control}

As expected, most respondents $(81 \%)$ in the sector wide survey acknowledged that the most important pollution issue in the two selected sectors is industrial wastewater. As earlier mentioned in chapter three (section 3.2), the perceived trade-off between private costs and social benefits of technical change to mitigate or prevent pollution has made environmental policy an acknowledged major driver of adoption of environmentally benign technologies (EBTs). Before we proceed to investigate how far this is true in the case of Nigerian manufacturing under a relatively weak regime of environmental regulation, it is necessary to first ascertain whether significant technology responses are identifiable in the two selected sectors.

\subsubsection{Technology responses for pollution abatement (TPA)}

In section 3.2 of chapter 3, we classified EBTs into two: viz., TPA and TPP. TPA is technology response for pollution abatement, while TPP is technology response for pollution prevention. As earlier explained, TPA with respect to water pollution control in industry is industrial wastewater treatment plant. $38 \%$ of our pooled sample claim to have adopted TPA. As table 6.9 shows, about half of the TPA adoption is primary wastewater treatment, $39 \%$ is secondary wastewater treatment, while $13 \%$ is advanced wastewater treatment. Whereas about $60 \%$ TPA in food \& beverages sector is primary wastewater treatment, only $16 \%$ TPA is primary treatment among the textiles sample. Furthermore, only $3 \%$ TPA is tertiary treatment in food \& beverages sector, while $42 \%$ TPA in textiles is advanced wastewater treatment. It is nevertheless noteworthy that approximately $40 \%$ of TPA in each sector are secondary treatment. It thus appears that the trend in TPA adoption in the two sectors differ in the sense that most of the food \& beverages firms engage in only primary treatment; whereas relatively substantial number of textile firms engage in tertiary treatment.

$20(48 \%)$ TPA adopters claim to have adopted before January 1995, while $24(52 \%)$ claim adoption after January 1995 (see table 6.10). This gives an impression that the enforcement of the S.I.8/S.I.9 law in January 1995 might have made little or no significant difference to firms' technology responses to mitigate industrial water pollution. However, the average age of TPA in our pooled sample is 7 years. This gives a clear indication that most TPA adoption took place after the enactment of the S.I.8/S.I.9 law in August 1991. By implication, it appears that firms prepared and anticipated that actual enforcement of the law would take place as planned at the end of the three year moratorium that the regulatory authority gave firms to effect necessary technical change for compliance. In the food \& beverages sample, mean age of TPA is about eight and half years, minimum age is one year and maximum age is 27 years; whereas for the textiles sample, mean age is three and half years, minimum age is six months and maximum is eight years. It is thus apparent that TPA existed in the food \& beverages industry before the advent of S.I.8/S.I.9 law, and the food \& beverages industry responds faster than the textile firms in Nigeria with respect to 
TPA adoption. Furthermore, table 6.10 shows that most of TPA adoption before January 1995 is primary wastewater treatment, while most of post January 1995 adoption is secondary and advanced wastewater treatment. This may be an indication that most TPA adoption before January 1995 was pre-emptive, just to have something to show regulators when mandatory enforcement started. Adoption of more effective TPA is largely a post January 1995 impact of S.I.8/S.I.9 law. The impact may however be more pronounced in the textiles sample as suggested by the relatively lower TPA average age of only three and half years. In fact, it may be inferred from table 6.10 that there was little TPA adoption in the textiles sector before January 1995.

Table 6.9: Adoption of industrial wastewater treatment plant in Nigerian manufacturing

\begin{tabular}{|c|c|c|c|}
\hline \multirow{2}{*}{$\begin{array}{l}\text { Type of industrial wastewater } \\
\text { treatment plant }\end{array}$} & \multicolumn{2}{|c|}{ Number adopted } & \multirow[b]{2}{*}{ Total } \\
\hline & $F \& B^{*}$ & Textiles & \\
\hline Primary & $19(59 \%)$ & $2(16 \%)$ & $21(48 \%)$ \\
\hline Secondary & $12(36 \%)$ & $5(42 \%)$ & $17(39 \%)$ \\
\hline Advanced & $1(3 \%)$ & $5(42 \%)$ & $6(13 \%)$ \\
\hline Total & $32(73 \%)$ & $12(27 \%)$ & $44 "(100 \%)$ \\
\hline
\end{tabular}

\footnotetext{
Note: Parenthesis contains percentage of total

* Food \& beverages

** Out of 46 TPA adopters only 44 gave type of TPA.
}

Source : Author's field survey

Table 6.10: Number of TPA adoption according to time and sectoral distribution of adoption

\begin{tabular}{|c|c|c|c|c|c|}
\hline \multirow{3}{*}{ Type of TPA } & \multicolumn{4}{|c|}{ When adopted } & \multirow{3}{*}{ Total } \\
\hline & \multicolumn{2}{|c|}{ before 1995} & \multicolumn{2}{|c|}{ after 1995} & \\
\hline & $F \& B^{\prime}$ & Textiles & $F \& B^{\circ}$ & Textiles & \\
\hline Primary wastewater treatment & 11 & 2 & 8 & $\mathbf{0}$ & 21 \\
\hline Secondary wastewater treatment & 5 & 1 & 7 & 4 & 17 \\
\hline Advanced wastewater treatment & 1 & 0 & 0 & 5 & 6 \\
\hline Total & 17 & 3 & 15 & 9 & $44^{* \prime}$ \\
\hline
\end{tabular}

* Food \& beverages

** Out of 46 TPA adopters only 44 gave type of TPA.

Source : Author's field survey 
An interesting trend to note in TPA adoption is that, $21(48 \%)$ of the adopters are affiliates of multinational enterprises (see table 6.11), and chi-square test showed that the association of TPA adoption with affiliation to multinational enterprises (MNEs) is significant. ${ }^{15}$ Expectedly, the same is true of TPA adoption's association with firm size according to our size distribution classification. It is also necessary to point out that more than $60 \%$ of TPA adoption by MNE affiliates ${ }^{16}$ is post January 1995 . However, chi-square test showed that the association of time of TPA adoption with affiliation to MNE is not significant. It is thus difficult to say whether the implementation of the S.I.8/S.I.9 law in January 1995 has significant impact in stimulating more TPA adoption among MNE affiliates. Furthermore, though the sample indicates relatively more adoption of secondary and advanced wastewater treatment by MNE affiliates, the association of type of TPA adopted with affiliation to MNE is not significant. It is thus also difficult to say whether MNEs adopt TPA that are significantly superior to those adopted by local firms.

It is worth mentioning that our survey finding also revealed that half of the wastewater treatment plants in our sample TPA adopters are locally built or fabricated; $37 \%$ have substantial local and foreign components; while only $13 \%$ are essentially completely foreign technology equipment. The source of the foreign components is largely Western Europe (81\%); Asia 14\%; and North America 5\%.

Table 6.11: TPA Adoption by affiliates of multinational enterprises (MNE)

\begin{tabular}{|c|c|c|c|c|}
\hline \multirow[b]{2}{*}{ Type of TPA } & \multicolumn{3}{|c|}{ Number of MNE affiliate adopters } & \multirow{2}{*}{$\begin{array}{c}\text { No. of tota } \\
\text { adopters }\end{array}$} \\
\hline & F\&B & Textiles & Total & \\
\hline Primary & 10 & 0 & 10 & 21 \\
\hline Secondary & 7 & 1 & 8 & 17 \\
\hline Advanced & 1 & 2 & 3 & 6 \\
\hline Total & 18 & 3 & 21 & $44^{* *}$ \\
\hline
\end{tabular}

* Food \& beverages

** Out of 46 TPA adopters only 44 gave type of TPA.

Source : Author's field survey

\footnotetext{
${ }^{15}$ Significant at $0.00 \%$ level.

${ }^{16} 13$ out of a total of 21 MNE affiliate TPA adopters in our sample are post January 1995 adopters.
} 


\subsubsection{Technology responses for pollution prevention (TPP)}

As earlier indicated in section 4.3 .1 of chapter 4 , the TPP types identified for this research include water or/and wastewater recycling; raw material re-use or recycling; change in raw material input(s); and integrated physical device in the production line. Half of our sample claims to have adopted TPP. The sectoral distribution of the type of TPP adopted according to time of adoption is shown in table 6.12. Half of the TPP adoption in the sample took place before January 1995. Most of the pre and post January 1995 TPP adoptions were in the food \& beverages sector. No strong conclusion can directly be drawn from this because our sample is biased in favour of the food \& beverages sector. However, if we define a technology adoption quotient as the proportion of adopters in a given sectoral sample; then, for the food \& beverages sector, the pre and post January 1995 TPP adoption quotient will be 0.32 and 0.44 respectively. For the textiles sector, the pre and post January 1995 TPP adoption quotient are 0.63 and 0.22 respectively. ${ }^{17}$ Thus, whereas the TPP adoption quotient for the food \& beverages sector improved slightly, that for the textiles sector declined sharply. The underlying reason for this may not be unconnected with the earlier demonstrated trend in TPA adoption, in which case, the textile sector's TPA adoption was largely a post January 1995 occurrence. ${ }^{18}$ It appears that investment in TPA might have diverted the attention of the textile firms from more investment in TPP. In effect, while there is indication that the enforcement of S.I.8/S.I.9 law has a positive impact in stimulating TPA adoption in the two sectors, the impact is relatively less visible with respect to TPP adoption. The impact on TPP adoption in the food \& beverages sector appears only marginal, while the impact appears negative (i.e. decline in TPP adoption) in the textiles sector.

Furthermore, table 6.12 also indicates that water or wastewater reuse/recycling and integrated physical device in the production line are relatively common among the food \& beverages plants. Integrated physical devices observed in the course of the fieldwork include improved bottle washing devices; metering devices/equipment; reengineering of aspects of process lines which result in leakage prevention or minimisation; improved $\mathrm{CIP}^{19}$ procedure with introduction of pressurised nozzle points at strategic locations that enhance efficiency of water use during CIP; caustic soda recovery/recycling tanks/process; replacement of high waste producing machines with low liquor dying equipment in the textile sector; mixing of spent oil with LPFO (low pour fuel oil) for reuse in boilers; etc. After January 1995, the textile plants might not have taken full advantage of some of these opportunities; but focus rather

\footnotetext{
${ }^{17}$ These TPP adoption quotients were calculated by dividing the total pre and post January 1995 TPP adoption given in table 6.12 by the size of each sectoral sample (i.e. 95 for food \& beverages, and 27 for textiles).

${ }^{18}$ Alternatively, it may also be connected with the age of the firm or the date of installation of new production equipment. As shown in section $6.2 .3,70 \%$ of our research sample textiles firms are older than 20 years, whereas only $40 \%$ of our food \& beverages sample firms are older than 20 years. Older plants may relatively have less opportunity for TPP except some often expensive re-engineering of plant machinery takes place.

${ }^{19}$ 'Clean -in-place' process for periodic cleaning/washing of process lines and equipment.
} 
on end-of-pipe TPA processes that could mitigate the relatively more severe external diseconomy of the textiles production. ${ }^{20}$

Table 6.12: Number of TPP adoption according to time and sectoral distribution of adoption

\begin{tabular}{|c|c|c|c|c|c|}
\hline \multirow{3}{*}{ Type of TPP } & \multicolumn{4}{|c|}{ When adopted } & \multirow{3}{*}{ Total } \\
\hline & \multicolumn{2}{|c|}{ before 1995} & \multicolumn{2}{|c|}{ after 1995} & \\
\hline & $F \& B^{\circ}$ & Textiles & $\mathrm{F} \& \mathrm{~B}^{*}$ & Textiles & \\
\hline Water/wastewater recycling & 11 & 0 & 19 & 1 & $31(33 \%)$ \\
\hline Raw material reuse/recycling & 7 & 9 & 9 & 3 & $28(29 \%)$ \\
\hline Change raw material input(s) & 4 & 7 & 2 & 1 & $14(15 \%)$ \\
\hline Integrated physical device & 8 & 1 & 12 & 1 & $22(16 \%)$ \\
\hline Total & $\begin{array}{c}30 \\
(32 \%)\end{array}$ & $\begin{array}{l}17 \\
(18 \%)\end{array}$ & $\begin{array}{c}42 \\
(44 \%)\end{array}$ & $\begin{array}{c}6 \\
(6 \%)\end{array}$ & $\begin{array}{c}95 \\
(100 \%)\end{array}$ \\
\hline
\end{tabular}

Parenthesis contains the percentage of total number of TPP adoption

* Food \& beverages

Source : Author's field survey

The option of change in raw material input(s) appears relatively less common compared to other TPP in food processing perhaps due to the stringent public control of the food \& beverages industry. In the case of the textiles, the raw material reuse/recycling appears relatively more common than other types of TPP perhaps due to the introduction of wax recovery process in some textile plants. It was however observed during the fieldwork that this practice could be ascribed to economic reason of cost savings ${ }^{21}$ resulting from repeated use of the same stream of wax than environmental protection factor.

\footnotetext{
${ }^{20}$ As will later be demonstrated in our discussion of some case studies in chapter 8 , the most advanced TPA facility was found in the textiles sector.

${ }^{21}$ It was gathered during the fieldwork that textile firms producing African wax prints presently import wax. The recovery of wax from wastewater effluent stream is a very dirty and difficult process. However, because of the foreign exchange implications of wax importation, textile plants are being compelled to introduce wax recovery processes.
} 
As shown in table 6.13, most MNE affiliate TPP adopters are in the food \& beverages sector. $^{22}$ Chi-square test results showed that the association of TPP adoption with affiliation to MNE in our sample is significant for food \& beverages plants except for the case of change in raw material input(s). The result for the textile plants showed that the association is not significant for any of the TPP types. As expected, Chisquare test also showed that the association of TPP adoption with firm size is significant for all the four TPP types.

Table 6.13: TPP Adoption by affiliates of multinational enterprises

\begin{tabular}{|c|c|c|c|c|}
\hline \multirow{2}{*}{ Type of TPP } & \multicolumn{3}{|c|}{ Number of MNE affiliate adopters } & \multirow{2}{*}{$\begin{array}{l}\text { No. of total } \\
\text { adopters }\end{array}$} \\
\hline & $F \& B$ & Textiles & Total & \\
\hline Water/wastewater recycling & 14 & 0 & 14 & 31 \\
\hline Raw material reuse/recycling & 9 & 4 & 13 & 28 \\
\hline Change raw material input(s) & 3 & 2 & 5 & 14 \\
\hline Integrated physical device & 12 & 0 & 12 & 22 \\
\hline Total & 38 & 6 & 44 & 95 \\
\hline
\end{tabular}

* Food \& beverages

Source : Author's field survey

Overall, according to nearly two-third $(64 \%)$ of our respondents, the most effective pollution control technology with respect to industrial water pollution control is TPA. This is understandable because TPP is generally perceived as being highly restricted in industry compared to the option of retrofitting with end-of-pipe TPA solution, which most of the time derive a sunk cost advantage from existing production facilities (Hartje and Lurie, 1984; Rothwell, 1992). However, the foregoing results indicate that more needs to be done in Nigeria to encourage TPP adoption, especially among the textile firms. Moreover, most of the TPP adopters $(82 \%)$ indicated that the adoption resulted in net economic gain for their firms.

\footnotetext{
${ }^{22}$ Because of this dominance of the food \& beverages plants among MNE affiliate TPP adopters, chi-square test shows that the association of affiliation to MNE with TPP adoption is significant. This is misleading, as the opposite is the truth for the textile sector. Hence, the sectoral distinction that follows this sentence.
} 


\subsubsection{Sources of technical solution to TPA/TPP problems}

More than two-thirds $(69.6 \%)$ of the sample firms claim that the most important source of technical solution to TPA/TPP problems is firm's in-house technical staff. Table 6.14 shows the relative importance of the identified sources of technical solutions to TPA/TPP problems. There are indications that firms' foreign technical partners, Nigerian engineering firms, and parent companies of MNE affiliates may also be playing important roles.

On a five level scale spanning "very low" to "very high", $62 \%$ of the sample firms rated their capability to use the adopted TPA from high to very high; while $38 \%$ rated their capability from moderate to low. With respect to TPP, $71 \%$ rated their capability to use the adopted TPP from high to very high; while $29 \%$ rated their capability from moderate to very low. From these results, it appears that firms may feel more competent to manage TPP except in some extreme cases of perhaps not well understood TPP. It also seems capability for TPA is not as developed compared to TPP.

Table 6.14: Sources of technical solution to TPA/TPP problems

Technical solution source

$\%$ of respondent firms

$\%$ respondent consider source most important

Technology supplier

$21 \%$

7.2

Firm's in-house technical staff

$96 \%$

69.6

Foreign technical partners

$43 \%$

13.0

Parent company

$58 \%$

1.4

Nigerian engineering firms

$47 \%$

8.7

Total

100.0

Source : Author's field survey

\subsection{Obstacles to Technology Responses for Water Pollution Control}

The summary of the results of our survey with respect to obstacles to technology adoption for water pollution control in Nigerian manufacturing sectors under investigation is as shown in table 6.15 . More than half $(51.6 \%)$ of our sample firms claimed high cost of installing and operating TPA as the most important obstacle to 
adoption. As earlier mentioned in section 6.3 .2 of this chapter, $64 \%$ of our research sample considers industrial wastewater treatment as the most effective solution to the problem of industrial wastewater pollution. This underscore the importance of high cost of TPA as obstacle to adoption when compared to high cost of TPP. High cost of TPP is nonetheless an important obstacle as it ranked highest among factors cited as second most important obstacle to adoption. Furthermore, information asymmetry between firms and regulators notwithstanding, the result of the regulators' survey presented in table 6.16 appears to confirm the relative importance of high cost of pollution control technologies as hindrance to adoption. More than two thirds (71\%) of regulators view high cost of water pollution control technologies as the most important hindrance to firms' compliance with the Nigerian S.I.8/S.I.9 environmental regulatory law.

Table 6.15: Obstacles to the adoption of environmentally benign technologies (EBTs)

Obstacles to adoption

Percent respondent firms consider reason

important most important $2^{\text {nd }}$ most important

Lack of information about EBTs

36.9

8.2

High cost of installing and operating TPA

83.6

51.6

Lack of technical capability to use TPA

0.8

High cost of TPP

61.5

0.8

26.1

Lack of capability to implement TPP

0.0

Poor technical feasibility of TPP

0.0

Uncertainty about impact of EBTs on competitiveness

36.9

2.5

Lack of credit to invest in EBTs

45.5

6.6

No compelling reason to invest EBTs.

58.2

29.5

14.8

Total

100.0

100.0

Source : Author's field survey 
Table 6.16: Regulators' perception of obstacles to firms' compliance with Nigerian S.I.8/S.I.9 law

Percent regulators consider reason

Obstacles to regulatory compliance

important most important $\quad 2^{\text {nd }}$ most important

Lack of technical information on relevant

68.2

9.5

22.0

technologies for compliance

Firms are incapable of operating TPA

18.2

2.4

4.9

Firms are incapable of implementing TPP

31.8

4.8

9.8

High cost of pollution control

97.7

71.4

14.6

technologies

Inadequate monitoring of compliance

29.5

7.1

7.3

Inadequate market incentive for firms to

63.6

0.0

36.6

comply

Too stringent national effluent limits

11.4

0.0

4.9

Other obstacles to compliance

4.8

0.0

Total

100.0

100.0

Source : Author's field survey

It is interesting to note that, 'no compelling reason to invest in EBTs' ranked second in the hierarchy of most important obstacles to EBT adoption (see table 6.15). The option, 'no compelling reason to invest in EBTs' is intended to serve as a proxy for firms' perception of the general state of environmental regulation in Nigeria. It is assumed that if environmental regulatory pressure is much, then firms will signify the compelling nature of regulation. However, the position occupied by this reason is a distant second because while $52 \%$ of the sample claimed high cost of TPA as most important obstacle, only $30 \%$ claimed 'no compelling reason' for adoption. Thus, the result only suggests that the 'command and control' type of environmental regulation being practised in Nigeria may not be sufficiently strong to compel firms to adopt EBTs. It is however necessary to point out that, as table 6.17 would later show, 'no compelling reason' originate only from the food and beverages plants. No textile firm in our sample accept that there has been no compelling reason for EBT adoption. This is understandable because textile wastewater problems appear more difficult to conceal when compared to food and beverages effluents. Moreover, from our field interview, it appears the Nigerian regulators view the textile sector as a relatively worse culprit of wastewater pollution, and hence comparatively more focus might have been placed on the textile plants. Besides, our regulators' survey results also 
show that, whereas $50 \%$ of respondent regulators consider the regulatory compliance status of the food and beverages sector to range from "good" to "very good" on a five step scale ranging from "very poor" to "very good"; none of the regulators consider the textiles sector compliance situation as "very good", and only $22 \%$ of the regulators consider the textile sector's compliance as "good".

Table 6.17: Sectoral distribution of most important obstacles to the adoption of environmentally benign technologies (EBTs)

\begin{tabular}{lccc}
\hline Obstacles to adoption & \multicolumn{2}{c}{$\begin{array}{c}\text { No. of respondent firms in sector } \\
\text { Food \& beverages }\end{array}$} & $\begin{array}{l}\text { Total no. of } \\
\text { respondent } \\
\text { firms }\end{array}$ \\
\hline $\begin{array}{l}\text { Lack of information about EBTs } \\
\text { High cost of installing and operating TPA }\end{array}$ & 74 & 3 & 10 \\
Lack of technical capability to use TPA & 1 & 19 & 63 \\
High cost of TPP & 1 & 0 & 1 \\
$\begin{array}{l}\text { Lack of capability to implement TPP } \\
\text { Poor technical feasibility of TPP }\end{array}$ & 0 & 0 & 1 \\
$\begin{array}{l}\text { Uncertainty about impact of EBTs on } \\
\text { competitiveness }\end{array}$ & 0 & 0 & 0 \\
$\begin{array}{l}\text { Lack of credit to invest in EBTs } \\
\text { No compelling reason to invest EBTs. }\end{array}$ & 3 & 0 & 0 \\
\hline Total & 36 & 0 & 3 \\
\hline
\end{tabular}

Source : Author's field survey

The result reported in table 6.15 also indicates that most firms do not see reasons such as lack of information ${ }^{23}$ on water pollution control technologies, lack of technical capability to manage TPA or implement TPP, uncertainty about impact of EBTs on firm's competitiveness, and lack of credit to invest in EBTs as important hindrances to their technological responses for industrial wastewater pollution control. However,

\footnotetext{
${ }^{23}$ The regulators' survey result in table 6.16 appears to give some importance to lack of information on compliance technologies as obstacle to investment in pollution control. Lack of technological information ranked second both as most important, and second most important cited hindrance to firms' compliance with the requirements of Nigerian environmental regulatory law. However, considering information asymmetry between firms and regulators, this result should be treated with caution.
} 
when the most important obstacles to adoption are viewed according to their sectoral distribution (see table 6.17), lack of credit to invest in EBTs and lack of information on water pollution control technologies become notable for the textiles sector. This may be explained by the more intricate nature of textile effluents. As earlier mentioned in section 6.2 .5 of this chapter, textile effluents require chemical treatment, which is apparently more expensive when compared to the largely organic pollutants handled by wastewater treatment facilities in the food and beverages sector. The cost implications might have prompted desire for credits, while the more complex nature of treatment process might have made information on appropriate treatment methods relatively less accessible for textile firms.

\subsection{Conclusion}

In this chapter, we have presented some of the salient features of Nigerian manufacturing with a focus on food \& beverages and textile sectors. The descriptive analysis given has been based on a sample of 122 firms in the two sectors. However, because the sample is biased towards the medium and large-scale enterprises, conclusions that may be drawn from this chapter sideline the small-scale industries which are regarded as a significant feature of manufacturing in sub-Saharan Africa (see Lall et al, 1994; Stewart et al, 1992; Lundvall and Battese, 2000). An important feature of the two Nigerian manufacturing sectors is that they depend heavily on imported capital goods. However, there is indication of some local manufacture of food processing equipment. About one third of the food \& beverages plants use either completely locally fabricated equipment or hybrid of local and foreign equipment. More research is needed to expose details of this. If verified, it is an area that should be encouraged. Furthermore, we discovered that $41 \%$ of food \& beverages plants in our sample had no foreign (non-Nigerian) engineer or scientist. The sector has an average local skill intensity ratio of 0.126 compared to an average of 0.016 for the textile sector. Likewise, the highest local skill intensity ratio among food \& beverages firms is 0.714 compared to only 0.135 for textile firms. However, while the average foreign skill intensity ratio is 0.068 for the textile sector, it is only 0.008 for the food \& beverages sector. It appears the food \& beverages sector is able to source much of its technical and scientific skills locally when compared to the textile sector, or has made some success in substituting local for foreign skills.

The chapter describes current trends in technology responses for water pollution control in the two sectors. We discover evidence that Nigerian firms are actively involved in adopting both conventional end-of-pipe technologies such as industrial wastewater treatment plants, and process related innovations that may reduce or eliminate the generation of wastewater at the source. Our findings revealed that most adoption of secondary and advanced industrial wastewater treatment plants in the two sectors took place after the end of the moratorium period given Nigerian firms to comply with the S.I.8/S.I.9 law. This may imply that substantial adoption of relatively more effective pollution control technologies did not occur until after serious enforcement activities were on course. Likewise, the two sectors show appreciable 
evidence of water or/and wastewater recycling; raw material reuse or recycling; change in raw material input(s); and the use of process integrated physical devices/equipment that reduce wastewater generation. There are indications that investments in these technologies were also driven by the environmental regulatory regime in Nigeria. However, the environmental regulatory impact is more visible with respect to technology response for industrial wastewater pollution abatement in the two sectors under investigation. The regulatory policy impact on technical change that reduces water pollution at the source is only marginal for the food \& beverages industry, and not evident in the textile industry. It thus appears that there is need to fine-tune the environmental regulatory regime in Nigeria to enhance technology response for industrial wastewater pollution prevention, especially among the textile firms. Moreover, most of the TPP adopters $(82 \%)$ indicated that the adoption resulted in net economic gain for their firms.

Furthermore, our results indicate that the association of the adoption of environmentally benign technologies, whether TPA or TPP, with firm size is significant. We also discovered that the association of affiliation to multinational enterprises (MNE) with the adoption of industrial wastewater treatment technology (TPA) is significant. In addition, more than $60 \%$ of TPA adoption by MNE affiliates is post January 1995. However, chi-square test showed that the association of affiliation to MNE with time of TPA adoption is not significant. It is thus difficult to say whether the implementation of the S.I.8/S.I.9 law in January 1995 has significant impact in stimulating more TPA adoption among MNE affiliates. It seems that affiliates of multinational enterprises may be expected to adopt appropriate technology to abate or prevent pollution independent of the enforcement of the host country's environmental regulation. It is also noteworthy that though there is relatively more adoption of secondary and advanced wastewater treatment plants by MNE affiliates, the association of type of TPA adopted with affiliation to MNE is not significant. It is thus difficult to say whether MNEs adopt TPA that are significantly superior to those adopted by local firms. The case study illustrations in chapter eight will shed more light on this. It is nonetheless noteworthy that, irrespective of whether or not a firm is a multinational affiliate, there is a marked improvement in technology adoption for water pollution control after the enforcement of the S.I.8/S.I.9 environmental regulatory law in Nigeria.

In addition to the foregoing, this chapter also highlights the obstacles to the adoption of environmentally benign technologies for water pollution control in Nigerian manufacturing. The most important hindrances to adoption are identified as the high cost of installing and operating industrial wastewater treatment facilities, and the high cost of implementing technological innovations that reduce wastewater generation. Generally speaking, firms do not consider reasons such as lack of information on water pollution control technologies, lack of technical capability to manage pollution control technologies, uncertainty about impact of adoption on competitiveness, and lack of credit for technology investments as important obstacles to adoption. However, firms in the textile sector appear to consider lack of information on pollution control technologies and lack of credit as notable hindrances to adoption. 
While we may not be able to immediately adduce conclusive reasons for the adoption of environmentally benign technologies (EBTs) by firms in Nigerian food \& beverages and textile sectors, the descriptive analysis presented in this chapter nevertheless appreciably confirms the major driver hypothesis HI. Further analysis that takes into consideration the auxiliary drivers as stated in hypothesis $\mathrm{H2}$ is necessary before final conclusions can be drawn. We intend to employ the logit regression analysis for this purpose in the next chapter. Thereafter, in chapter 8 , we present some selected case study illustrations, which are expected to shed further light on the rationales for and obstacles to the adoption of EBTs in Nigerian manufacturing industry. 


\section{TECHNOLOGY RESPONSES FOR WATER POLLUTION CONTROL IN NIGERIAN MANUFACTURING: AN ANALYSIS OF ADOPTION CAUSALITIES}

\subsection{Introduction}

As demonstrated in the descriptive analysis of our field data in chapter 6 of this dissertation, there are indications that the major driver hypothesis $\mathrm{HI}$ is valid for the adoption of environmentally benign technologies in the two water pollution intensive sectors under investigation. In this chapter, we extend our analysis by employing the tool of logistic regression analysis to further establish whether or not hypothesis $\mathrm{HI}$ can be supported by our data. Moreover, the logistic regression provides an opportunity to simultaneously test for the validity or otherwise of the auxiliary driver hypothesis $\mathrm{H} 2$ along with hypothesis $\mathrm{HI}$. This chapter will thus test for empirical evidence of the hypotheses set out in chapter four on the adoption causalities for environmentally benign technologies in Nigerian manufacturing. The basic econometric model that is applied for the analysis has been described in section 5.4 of chapter 5. In the following section, we make some adjustments to the model's explanatory variables to suit the exigencies of our field data. In sections 7.3 we discuss the adoption causalities of environmentally benign technologies (EBTs) without specifying technology type. Attempts are made in sections 7.4 and 7.5 to isolate the adoption causalities for technology responses for water pollution abatement and prevention respectively. The last section of the chapter concludes with a synthesis of our findings on why firms in Nigerian manufacturing adopt EBTs.

\subsection{The Empirical Model}

Our field data do not warrant any change in the structure of the empirical model as presented by equations 5.1-5.4 in chapter 5 . In this chapter, we apply the model to carry out the empirical test of the hypotheses proposed in chapter 4 . The logistic regression analysis that will be employed gives parameter estimates for the logit model illustrated by equation 5.3. As earlier mentioned in section 5.4 of chapter 5 , the conditional probability of adoption $P_{i}$, given the vector of independent variables, $X_{i}$ would also be obtained.

Whereas the dependent variable remains unchanged as specified in chapter 5 , we however made some adjustments to some of the independent variables to suit the reality of our field data. The variables ownership structure of the firm (OST), firm size $(F S)$, and environmental implementation strategy $(E P S)$ remain as defined in chapters 4 and 5 . However, the explanatory variables environmental policy $(E P L)$, external 
network for innovation (ENI), and internal capability for innovation $(I C H, I C K)$ are modified as described below.

\section{Environmental policy variable}

For the logistic regression analysis, our data restricted us from directly relating the adoption of water pollution control technologies to the binary environmental policy variable, EPL. Since only firms that adopted TPA or TPP would naturally have responded to the question on whether $E P L$ was a reason for adoption, the dependent variable is limited to only the adopter cases, and hence the non-adopters would not be recognised as eligible for the regression analysis. To get over this problem, we had to ignore the adopter firms' response to $E P L$ as a reason for adoption. Instead, we reckoned that commitment to environmental management engendered by the implementation of the Nigerian S.I.8/S.I.9 law in January 1995 would have increased firms' propensity to adopt environmentally benign technologies. We assume that the extent to which a firm's commitment to environmental management increased after January 1995 is an indication of the environmental policy impact. Thus, the binary environmental policy variable, $E P L$ is indicated by proxy as the impact of the national environmental policy law (S.I.8/S.I.9) on firms' commitment to environmental management after the enforcement in January 1995. If the effect of environmental regulation on commitment to environmental management before January 1995 compared to after January 1995 has gone up by at least two steps on a five step scale spanning "very low" to "very high", we consider $E P L=1$. We consider otherwise, $E P L=0$, to imply that the enforcement of the S.I.8/S.I.9 law in January, 1995 has had little or no impact on firm's commitment to environmental management activities that may result in EBT adoption.

\section{External network for innovation variable}

As already shown in table 6.8 of chapter 6 , most Nigerian firms in our sample consider firm's in-house R\&D, parent company, foreign technical partners, and supplier of main production equipment as important sources of technological knowledge. However, these firms do not consider Nigerian higher educational institutions, local and international research institutes as important sources of technological knowledge or innovation. This confirms the widely held view about poor linkage between research and industry in most developing countries (Lall et al, 1994; Oyelaran-Oyeyinka et al, 1996). Supplier of environmental technology appears the least considered source of innovation, apparently because the environmental good and services sector is yet to be well appreciated by Nigerian manufacturing. In addition, less than one-third of the firms consider other manufacturing enterprises in their subsector important source of technological knowledge. Thus, our data indicates that local network for technological knowledge for manufacturing activities in Nigeria is weak. In addition, table 6.8 also showed that virtually none of our sample firms consider Nigerian higher educational institutions and local research institutes as most 
important source of technological knowledge. In view of the foregoing, we modified our earlier definition of external network for innovation variable, ENI in chapter 5 to be restricted only to knowledge/innovation network relating to the parent company or foreign technical partners. In essence, the external network for innovation is reduced to a binary variable. Thus, $E N I=1$ if most important source of technological knowledge or innovation is parent company or technical partner, otherwise, $E N I=0$.

\section{Internal capability for innovation variables}

As presented in chapter 4 , the internal capability for innovation has two components. The first variable, internal capability for innovation (human capital), ICH has been defined as the fraction of the number of Nigerian and foreign engineers/scientist in total employment of a firm. ${ }^{1}$ The second variable, internal capability for innovation (physical capital), ICK indicates the level of technology in a firm's existing machines and equipment.

Though our data does not require a fundamental change in the way ICK has been defined in chapter 4 , it is necessary to emphasise that the variable may not necessarily indicate the internal capability for innovation. Rather, it might deal with the effect of existing investment in physical capital on firm's decision to adopt EBTs. Thus, whether or not the existing level of physical capital directly contributes to internal capability for innovation is a question our model may not be able to explicitly answer. Furthermore, as could be seen in table 6.7 of chapter 6 , only three out of 122 firms in our sample have low level ICK. The remaining are distributed between medium and high level $I C K$. Treating the three kinds of $I C K$ as seasonal variables, and running the logistic regression on two with one of the variables as the reference point, results in very strong correlation between the parameter estimates of the ICK variables. We therefore decided to consider the three firms with low level $I C K$ as omitted variables, thereby reducing $I C K$ to a variable of either completely foreign main production equipment or mixed (i.e. local \& foreign) main production equipment. When main production equipment is completely foreign, $I C K=1$; when mixed, $I C K=0$.

\subsection{Adoption Causalities for Environmentally Benign Technologies (EBTs)}

Table 7.1 shows the sample distribution of the proportion of adopters for the two classifications of water pollution control technologies (TPA and TPP) in this study. Whereas about $37 \%$ of our sample has adopted TPA, nearly half $(49.2 \%)$ have adopted TPP. ${ }^{2}$ Firms that have adopted at least TPA or TPP accounted for $54 \%$ of the

\footnotetext{
' $\mathrm{ICH}$ is computed as specified in chapter 4 . Before division by total number employed, the number of foreign engineers/scientists is doubled and added to the number of Nigerian engineers/scientists. The number of foreign engineers/scientists is doubled to signify the supposedly relatively higher intangible knowledge a foreign engineer/scientist may bring into a firm's knowledge stock.

${ }^{2}$ Note that a firm may adopt both TPA and TPP. Hence, TPA or TPP adoption does not respectively imply that a firm has adopted only TPA or TPP.
} 
sample. In effect, $46 \%$ are completely non-adopters, that is, they have neither adopted TPA nor TPP. In this analysis we refer to the adoption of at least TPA or TPP as EBT adoption. It should be noted that the $54 \%$ in this category include firms that have adopted both TPA and TPP.

Table 7.2 presents the summary of the logistic regression results for EBT adoption. The first model (model 1) includes all the variables reflected in equation 5.1 as discussed in section 7.2 of this chapter. Because our firm size distribution has a long span (smallest firm employs 23 person, largest employs 3211 persons), we decided to use the log of firm size to improve the fit of the model, which resulted in model 2 . The human capital aspect of internal capability for innovation, $\mathrm{ICH}$ is strongly correlated with the percent of workforce with higher education, $H E D .^{3}$ In addition, we discovered that replacing $I C H$ with $H E D$ improved the model fit, and the percent of cases the model correctly classified or predicted increased from $79 \%$ to $84 \%$. This resulted in model 3. Moreover, whereas $\mathrm{ICH}$ parameter estimate is only significant at $5 \%$ level, that of $H E D$ is significant at $1 \%$ level. Model 3 thus appears to present a fair and better fit for our data, and would therefore be used for discussing the adoption causalities with respect to EBT adoption.

Table 7.1: Distribution of types of water pollution control technologies adopted by the sample firms.

Type of technology adopted

TPA (industrial wastewater treatment plant)

TPP (technology that reduce wastewater at the source)

TPA or TPP
Percent of total no. of firms

49.2

54.1

Source: Author's field survey

The correlation matrix of the parameter estimates given in table 7.3 shows that the estimated coefficients are fairly uncorrelated. ${ }^{4}$ In table 7.4, we give the exact levels of significance of each of the parameter estimates for our model explanatory variables, and the corresponding factors by which the odds ${ }^{5}$ of EBT adoption would be affected

\footnotetext{
${ }^{3}$ This is expected because engineers/scientists are subset of workforce with higher education.
}

${ }^{4}$ According to Hamilton (1992, p.233), one of the methods of diagnosing multicollinearity among the variables is to examine the matrix of correlation among estimated coefficients. Since each of the correlation among the estimated coefficients is less than 0.5 , we accept the estimated coefficients to be fairly uncorrelated.

${ }^{5}$ As earlier defined in chapter 5 , the odds of adoption is the ratio of the probability of adoption to the probability of non-adoption. 
given unit increases in the explanatory variables. Given the coefficients in table 7.4, the odds of adoption of EBT would be:

$\frac{P_{E B T}}{1-P_{E B T}}=e^{-14.855} \cdot e^{(2.349 E P L-1.307 / C K+0.734 E N I+0.03305 T+2.061 L F S+0.789 E P S+0.071 \text { HED })}$

For the Nigerian manufacturing firms in this study, equation 7.1 could also be used to predict the probability of EBT adoption. For our research sample firms, figure 7.1 is a demonstrative graph of how likely the model would distinguish between EBT adopters and non adopters at estimated probabilities of adoption. Our fitted model appreciably classifies firms with fairly high or low estimated probabilities of EBT adoption correctly. For example, only four firms in our sample would be wrongly predicted as EBT adopters at estimated probabilities greater than 0.75 , and only three firms in the sample would be wrongly predicted as non adopters of EBT at estimated probabilities of less than 0.25 . 
Table 7.2: Summary of the logistic regression for technology responses for water pollution control (i.e. EBT adoption).

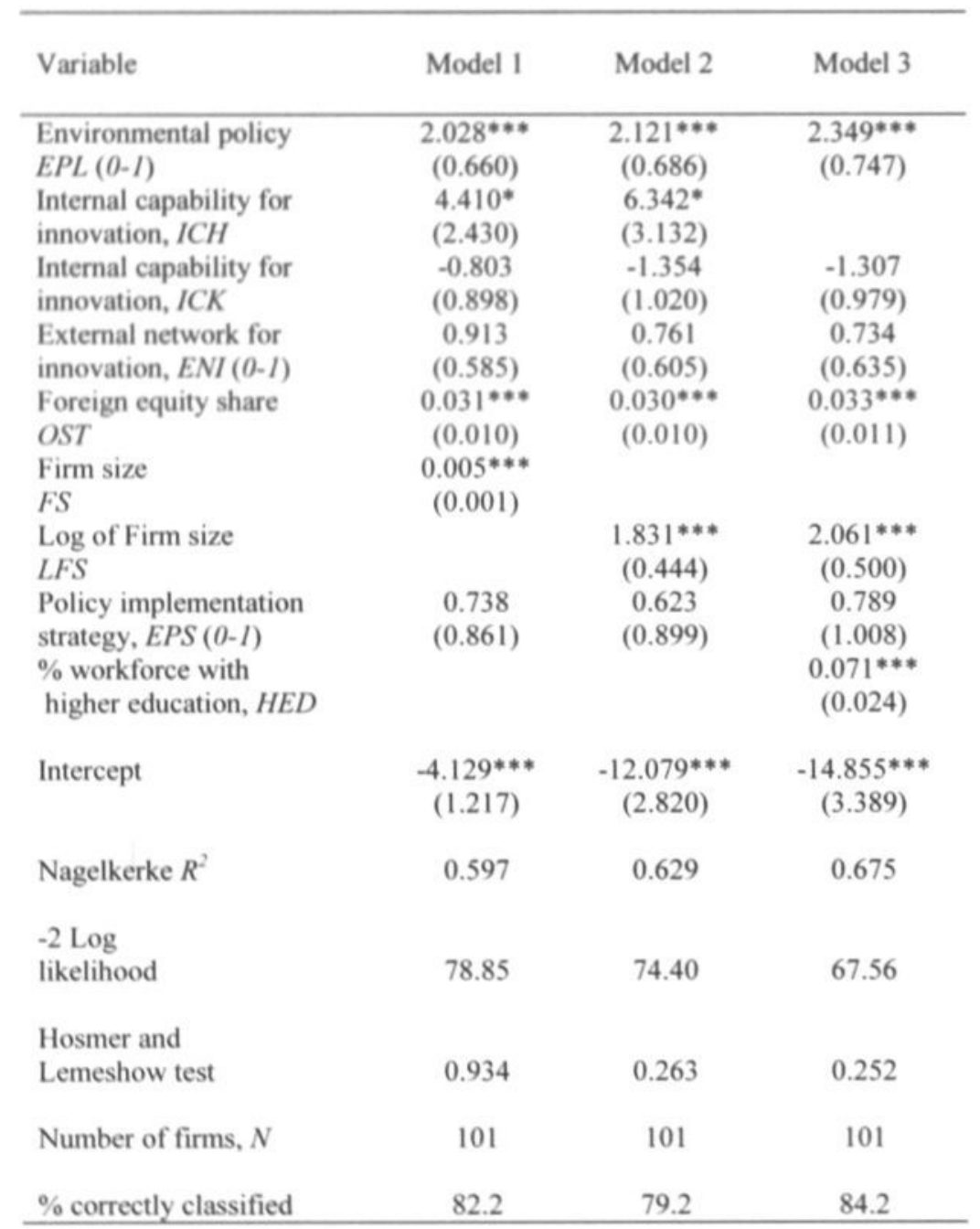

$*,{ }^{* *},{ }^{* *}$ represent $10 \%, 5 \%$, and $1 \%$ levels of significance respectively. Standard errors are given in the parenthesis. 
Table 7.3: Correlation matrix of the logistic regression estimated coefficients for EBT adoption

\begin{tabular}{lcccccccc}
\hline & $\begin{array}{c}\text { Cons- } \\
\text { tant }\end{array}$ & EPL & ICK & OST & LFS & EPS & ENI & HED \\
\hline $\begin{array}{l}\text { Cons- } \\
\text { tant }\end{array}$ & 1.000 & & & & & & \\
EPL & -.327 & 1.000 & & & & & & \\
ICK & .161 & -.347 & 1.000 & & & & & \\
OST & -.392 & .170 & -.090 & 1.000 & & & \\
LFS & -.905 & .342 & -.402 & .323 & 1.000 & & \\
EPS & -.365 & -.011 & -.090 & .032 & .124 & 1.000 & & \\
ENI & -.187 & .131 & .001 & -.097 & .099 & .042 & 1.000 & \\
HED & -.580 & .199 & -.101 & .155 & .436 & .068 & .075 & 1.000 \\
\hline
\end{tabular}


Table 7.4: Final model for the logistic regression for technology responses for water pollution control (i.e. EBT adoption).

\begin{tabular}{|c|c|c|c|}
\hline Variable & $\begin{array}{c}\text { Parameter } \\
\text { estimate (B) }\end{array}$ & $\begin{array}{c}\text { Significance } \\
\text { level }\end{array}$ & $\operatorname{Exp}(B)$ \\
\hline Environmental policy & $2.349 * * *$ & 0.002 & 10.476 \\
\hline$E P L(0-I)$ & $(0.747)$ & & \\
\hline $\begin{array}{l}\text { Internal capability for } \\
\text { innovation, } I C K\end{array}$ & $\begin{array}{l}-1.307 \\
(0.979)\end{array}$ & 0.182 & 0.271 \\
\hline $\begin{array}{l}\text { External network for } \\
\text { innovation, ENI }(0-I)\end{array}$ & $\begin{array}{c}0.734 \\
(0.635)\end{array}$ & 0.248 & 2.083 \\
\hline $\begin{array}{l}\text { Foreign equity share } \\
\text { OST }\end{array}$ & $\begin{array}{c}0.033 * * * \\
(0.011)\end{array}$ & 0.003 & 1.033 \\
\hline $\begin{array}{l}\text { Log of Firm size } \\
\text { LFS }\end{array}$ & $\begin{array}{c}2.061^{* * *} \\
(0.500)\end{array}$ & 0.000 & 7.854 \\
\hline $\begin{array}{l}\text { Policy implementation } \\
\text { strategy, EPS }(0-I)\end{array}$ & $\begin{array}{c}0.789 \\
(1.008)\end{array}$ & 0.434 & 2.201 \\
\hline $\begin{array}{l}\% \text { workforce with } \\
\text { higher education, } H E D\end{array}$ & $\begin{array}{l}0.071^{* * * *} \\
(0.024)\end{array}$ & 0.003 & 1.074 \\
\hline Intercept & $\begin{array}{c}-14.855^{* * * *} \\
(3.389)\end{array}$ & 0.000 & 0.000 \\
\hline Nagelkerke $R^{2}$ & 0.675 & & \\
\hline $\begin{array}{l}-2 \text { Log } \\
\text { likelihood }\end{array}$ & 67.56 & & \\
\hline $\begin{array}{l}\text { Hosmer and } \\
\text { Lemeshow test }\end{array}$ & 0.252 & & \\
\hline Number of firms, $N$ & 101 & & \\
\hline$\%$ correctly classified & 84.2 & & \\
\hline
\end{tabular}

$*, * *, * * *$ represent $10 \%, 5 \%$, and $1 \%$ levels of significance respectively.

Standard errors are given in the parenthesis. 

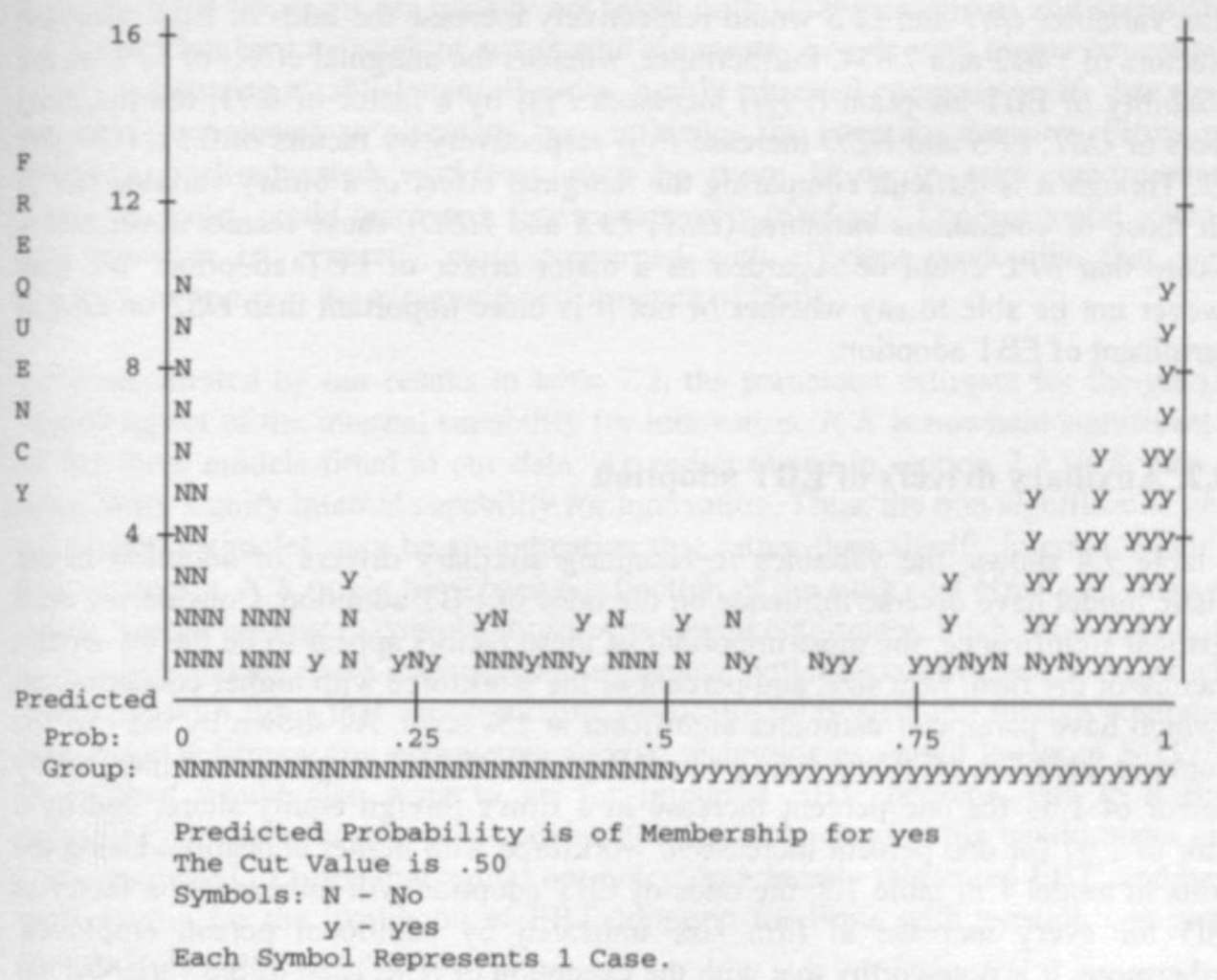

Figure 7.1: A histogram of predicted probabilities of EBT adoption based on model presented in table 7.4.

\subsubsection{Environmental policy as a major driver of EBT adoption}

When viewing the adoption of environmentally benign technologies as one whole aggregate, the EBT adoption model in table 7.4 shows that the enforcement of the Nigerian environmental policy in January 1995 has a significant influence on the adoption of EBTs among firms in our research sample. The estimated coefficient of $E P L$ has the expected positive sign as stated in hypothesis $H I$ in chapter 4. Like ownership structure ( $O S T)$, firm size (LFS), and percent of workforce with higher education $(H E D)$, the parameter estimate is significant at $1 \%$ level. Besides, EPL is consistently significant at $1 \%$ level in all the three models fitted to our data in table 7.2. The variables, $O S T$ and $L F S$, are also consistently statistically significant at $1 \%$ level in table 7.2. Table 7.4 however showed that a unit increase in EPL would 
increase the odds ${ }^{6}$ of EBT adoption by a factor of 10.476; while a unit increase in each of the variables $O S T$ and $L F S$ would respectively increase the odds of EBT adoption by factors of 1.033 and 7.854. Furthermore, whereas the marginal effect of $E P L$ on the probability of EBT adoption $\left(P_{E B T}\right)$ increases $P_{E B T}$ by a factor of 0.91 , the marginal effects of $O S T, L F S$ and $H E D$ increase $P_{E B T}$ respectively by factors of $0.51,0.89$ and 0.52 . Though it is difficult comparing the marginal effect of a binary variable $(E P L)$ with those of continuous variables (OST, LFS and HED), these results nevertheless indicate that EPL could be regarded as a major driver of EBT adoption. We may however not be able to say whether or not it is more important than OST or LFS as determinant of EBT adoption.

\subsubsection{Auxiliary drivers of EBT adoption}

As table 7.4 shows, the variables representing auxiliary drivers of adoption in the logistic model have diverse influence on the odds of EBT adoption. Considering their statistical significance, the most important of these factors appear to be the ownership structure of the firm, firm size, and percent of the workforce with higher education, all of which have parameter estimates significant at $1 \%$ level. As shown by the $\exp (B)$ column in table 7.4, all things being equal, the odds of EBT adoption will increase by a factor of 1.03 for one percent increase in a firm's foreign equity share; and by a factor of 1.07 for one percent increase in workforce with higher education. Using the results in model 1 of table 7.2, the odds of EBT adoption will increase by a factor of 1.005 for every increase in firm size indicated by additional person employed. Furthermore, it is noteworthy that with the exception of $I C K$, each of the variables has positive influence on the odds of EBT adoption, thereby conforming to the expectations of the corresponding sub-hypotheses in chapter 4 .

With respect to the internal capability for innovation, it should be noted that the parameter estimate for the human capital aspect, $\mathrm{ICH}$ is significant at $10 \%$ level in the two previous models (models 1 and 2 in table 7.2) before it was replaced by HED. However, HED improved the model fit significantly. Its estimated coefficient, which was previously significant only at $10 \%$ level, became significant at $1 \%$ level, and the pseudo $R^{2}$ (i.e. Nagelkerke $R^{2}$ ) improved from 0.597 to $0.675 .^{8}$ As detailed case

\footnotetext{
${ }^{6}$ It is important to emphasise at this juncture that the odds of adoption indicated here (and in subsequent similar cases in this chapter) has a direct relationship with the probability of adoption. It should be recalled that the odds of adoption is $\frac{p}{1-p}$, where $P=$ probability of adoption. In the logistic regression results shown in table 7.4 and subsequent similar tables, $\operatorname{Exp}(B)$ is the factor by which a unit change in an independent variable (while all other explanatory variables remain unchanged) affects the odds of adoption.

${ }^{7}$ For ownership structure and firm size, the sub-hypotheses are $H 2 d$ and $H 2 e$ respectively. For percent higher education, the sub-hypothesis $H 2 a$ should be assumed because $H E D$ replaced $I C H$.

${ }^{8}$ Nagelkerke $R^{2}$ is a coefficient of determination similar in intent to the $R^{2}$ in OLS. It is a measure of the percent of total variation in the probability of adoption that is explained by the model's explanatory variables (see Norusis, 1999).
} 
studies in the next chapter will reveal, the reason for this may be due to the fact that EBT adoption decisions are usually not taken only among engineers and scientists in the factory but by a network of actors who are mostly people with higher education in the manufacturing establishment. Besides, highly educated company staffs that are not necessarily engineers or scientists may influence the adoption decision. Firms with relatively well-educated workforce may be more likely to raise environmental concerns, which could increase a firm's propensity to adopt. ${ }^{9}$ Engineers and scientists may however be generally more concerned with efficient production that would maintain or improve the economic performance of firms.

As demonstrated by our results in table 7.2 , the parameter estimate for the physical capital aspect of the internal capability for innovation, $I C K$ is nowhere significant for all the three models fitted to our data. As earlier stated in section 7.2, ICK may not necessarily signify internal capability for innovation. Thus, the non significance of the coefficient estimates may be an indication that rather than signify internal capability for innovation, $I C K$ might have been a reflection of the sunk cost effects on firms that have invested heavily in completely foreign capital equipment. Such firms may not be as prone to making more investment in expensive pollution control technologies when compared with firms that uses a mixture of locally fabricated and foreign equipment. Moreover, if firms using completely foreign technologies would invest in EBT, it is likely they would also want to go for imported EBT, perhaps, due to a firm's technology investment norm that prefers foreign technology. This would mean more costs compared to firms that would not object to a locally fabricated EBT; and hence more inertia for the likelihood of EBT adoption for firms with existing completely foreign technology equipment.

The external network for innovation (ENI) parameter estimate, though positive, is however not significant. This may be an indication that being an affiliate of a multinational or having a foreign technical partner does not necessarily guarantee EBT adoption. This however runs counter to our earlier finding in chapter 6 especially with regard to TPA adoption (see sections 6.3.1. and 6.3.2). The result in chapter 6 indicated that multinational affiliation's association with EBT adoption is significant. This discrepancy may be due to the incorporation of technical partnership into our specification of the variable, ENI. Technical partnership may be strongly uncorrelated with EBT adoption. Alternatively, the simple relationship tested in chapter 6 may not be very reliable since other explanatory variables were not taken into consideration. Moreover, one of the case study illustrations in chapter 8 (FB6) will later demonstrate that multinational affiliation is not an automatic guarantee of a better likelihood of EBT adoption.

Like the ENI variable, the policy implementation strategy variable $(E P S)$ has a positive impact on the odds of EBT adoption, but the parameter estimate is not

\footnotetext{
This finding presents a complement to that of Pargal and Wheeler (1996), which discovered for Indonesian firms that plant level pollution abatement is positively correlated with the educational level of the community where the firm is located. Our result indicates that the educational level of people employed within the plant has positive correlation with plant level technology adoption aimed at achieving pollution abatement.
} 
significant. This indicates that a co-operative approach to environmental policy monitoring and enforcement has possibly no influence on the observed EBT adoption in Nigerian manufacturing.

In order to give a clearer view of the adoption rationales for environmentally benign technologies in Nigerian manufacturing, it is necessary to isolate the adoption causalities for technology responses for water pollution abatement (TPA) and technology responses for water pollution prevention (TPP). The next two sections explore this approach.

\subsection{Adoption Causalities for Technology Responses for Water Pollution Abatement (TPA)}

As specified in the theoretical framework for this study in chapter 3, industrial wastewater treatment plants represent technology response for water pollution abatement (TPA) in industry. The summary of the logistic regression for TPA adoption is presented in table 7.5. Model 1 includes all the variables specified for our empirical model in equation 5.1. However, the Hosmer and Lemeshow test showed that the model's goodness of fit is poor. ${ }^{10}$ For this reason, and the earlier stated opportunity of improving model fit by using the log of firm size, the firm size variable was replaced with the log of firm size. The model obtained (model 2) has an improved goodness of fit. Like in the case of EBT adoption, we discovered that substitution of percent of workforce with higher education (HED) for internal capability for innovation $(\mathrm{ICH})$ results not only in improved goodness of fit, but also improvement in the significance level of some of the parameter estimates. ${ }^{11}$ Thus, we arrived at model 3 on which the discussion of TPA adoption causalities would be based. The correlation matrix (see table 7.6) of the estimated coefficients showed that they are all fairly uncorrelated. ${ }^{12}$ The specific levels of significance of each of the coefficients of the explanatory variables in model 3 are presented in table 7.7 along with the corresponding factors by which the odds of TPA adoption would be affected by a unit change in each explanatory variable.

Given the logistic regression results in table 7.7, the odds of TPA adoption in Nigerian manufacturing represented by our data would be as presented below in equation 7.2. Figure 7.2 is a graphical demonstration of how well our fitted model would classify TPA adoption occurrences among our sample firms at various levels of estimated probabilities of adoption.

\footnotetext{
${ }^{10}$ Hosmer and Lemeshow test is a model calibration goodness of fit test. It shows how closely the observed and predicted probabilities match, which is an indication of how reasonably the model fits the data. Normally, the Chi-square level of significance should be more than $10 \%$. In which case, the null hypothesis that there is no difference between the observed and predicted probabilities is not rejected (Hosmer and Lemeshow, 1989; Norusis, 1999).

II The coefficient of determination (Nagelkerke $R^{2}$ ) improved from 0.35 to 0.399 ; the parameter estimate for $I C H$, which was not significant becomes significant at $5 \%$ level when replaced by $H E D$; the coefficients of $E P L$ and EPS, which were not significant, become significant, each at $10 \%$ level; and the significance of the parameter estimate for ICK improved from $10 \%$ to $5 \%$ level.
}

${ }^{12}$ See footnote no.4. 
Like figure 7.1, figure 7.2 also largely classified firms with high or low probabilities of TPA adoption correctly. For example, only four firms in our sample would be wrongly classified as non-adopters of TPA at estimated probabilities more than 0.75 ; and only four would be wrongly regarded as TPA adopters at estimated probabilities less than 0.25 .

$$
\frac{P_{\text {IPA }}}{1-P_{\text {TPA }}}=e^{-9.115} \cdot e^{(0.931 E P L-1.825 I C K+0.719 E N I+0.01505 T+1.194 L F S+1.460 E P S+0.038 \text { HED })}
$$

Table 7.5: Summary of the logistic regression for technology responses for water pollution abatement (i.e. TPA adoption).

\begin{tabular}{|c|c|c|c|}
\hline Variable & Model 1 & Model 2 & Model 3 \\
\hline Environmental policy & 0.699 & 0.737 & $0.931^{*}$ \\
\hline$E P L(0-I)$ & $(0.498)$ & $(0.510)$ & $(0.537)$ \\
\hline Internal capability for & 0.593 & 1.004 & \\
\hline innovation, $\mathrm{ICH}$ & (1.888) & (2.019) & \\
\hline Internal capability for & -0.886 & $-1.547^{*}$ & $-1.825 * *$ \\
\hline innovation, ICK & $(0.706)$ & $(0.829)$ & $(0.866)$ \\
\hline External network for & $0.899^{*}$ & 0.715 & 0.719 \\
\hline innovation, $E N I(0-I)$ & $(0.491)$ & $(0.497)$ & $(0.518)$ \\
\hline Foreign equity share & $0.016^{* *}$ & $0.016^{*}$ & $0.015^{*}$ \\
\hline OST & $(0.008)$ & $(0.008)$ & $(0.008)$ \\
\hline Firm size & $0.002^{* * * *}$ & & \\
\hline FS & $(0.001)$ & & \\
\hline Log of Firm size & & $1.045^{* * *}$ & $1.194^{* * *}$ \\
\hline$L F S$ & & $(0.304)$ & $(0.333)$ \\
\hline Policy implementation & 1.262 & 1.208 & $1.460^{*}$ \\
\hline strategy, EPS $(0-I)$ & $(0.821)$ & $(0.805)$ & $(0.850)$ \\
\hline$\%$ workforce with & & & $0.038 * *$ \\
\hline higher education, $H E D$ & & & $(0.017)$ \\
\hline Intercept & $-2.857^{* * * *}$ & $-7.278 * * *$ & $-9.115 * * *$ \\
\hline & (1.008) & $(1.848)$ & (2.197) \\
\hline Nagelkerke $R^{2}$ & 0.304 & 0.350 & 0.399 \\
\hline$-2 \log$ & & & \\
\hline likelihood & 111.31 & 106.78 & 101.59 \\
\hline Hosmer and & & & \\
\hline Lemeshow test & 0.022 & 0.345 & 0.848 \\
\hline Number of firms, $N$ & 101 & 101 & 101 \\
\hline$\%$ correctly classified & 77.2 & 73.3 & 76.2 \\
\hline
\end{tabular}

**,*** represents $10 \%, 5 \%$, and $1 \%$ levels of significance respectively. Standard errors are given in the parenthesis. 
Table 7.6: Correlation matrix of the logistic regression estimated coefficients for TPA adoption

\begin{tabular}{lcccccccc}
\hline & $\begin{array}{c}\text { Cons- } \\
\operatorname{tant}\end{array}$ & EPL & ICK & ENI & OST & LFS & EPS & HED \\
\hline $\begin{array}{l}\text { Cons- } \\
\text { tant }\end{array}$ & 1.000 & & & & & & \\
EPL & -.147 & 1.000 & & & & & \\
ICK & .234 & -.314 & 1.000 & & & & & \\
ENI & -.177 & .087 & -.048 & 1.000 & & & \\
OST & -.135 & .022 & -.120 & -.302 & 1.000 & & \\
LFS & -.839 & .049 & -.488 & .073 & .073 & 1.000 & & \\
EPS & -.493 & .139 & -.129 & .110 & .044 & .127 & 1.000 & \\
HED & -.509 & .216 & -.233 & .053 & -.053 & .315 & .202 & 1.000 \\
\hline
\end{tabular}


Table 7.7: Final model for the logistic regression for technology responses for water pollution abatement (i.e. TPA adoption).

\begin{tabular}{|c|c|c|c|}
\hline Variable & $\begin{array}{c}\text { Parameter } \\
\text { estimate (B) }\end{array}$ & $\begin{array}{c}\text { Significance } \\
\text { level }\end{array}$ & $\operatorname{Exp}(B)$ \\
\hline $\begin{array}{l}\text { Environmental policy } \\
E P L(0-I)\end{array}$ & $\begin{array}{l}0.931^{*} \\
(0.537)\end{array}$ & 0.083 & 2.537 \\
\hline $\begin{array}{l}\text { Internal capability for } \\
\text { innovation, } I C K\end{array}$ & $\begin{array}{c}-1.825^{* *} \\
(0.866)\end{array}$ & 0.035 & 0.161 \\
\hline $\begin{array}{l}\text { External network for } \\
\text { innovation, ENI }(0-I)\end{array}$ & $\begin{array}{c}0.719 \\
(0.518)\end{array}$ & 0.165 & 2.053 \\
\hline $\begin{array}{l}\text { Foreign equity share } \\
\text { OST }\end{array}$ & $\begin{array}{l}0.015^{*} \\
(0.008)\end{array}$ & 0.076 & 1.015 \\
\hline $\begin{array}{l}\text { Log of Firm size } \\
\text { LFS }\end{array}$ & $\begin{array}{l}1.194^{* * * *} \\
(0.333)\end{array}$ & 0.000 & 3.299 \\
\hline $\begin{array}{l}\text { Policy implementation } \\
\text { strategy, EPS }(0-I)\end{array}$ & $\begin{array}{l}1.460^{*} \\
(0.850)\end{array}$ & 0.086 & 4.306 \\
\hline $\begin{array}{l}\% \text { workforce with } \\
\text { higher education, } H E D\end{array}$ & $\begin{array}{l}0.038 * * \\
(0.017)\end{array}$ & 0.026 & 1.039 \\
\hline Intercept & $\begin{array}{c}-9.115^{* * * *} \\
(2.197)\end{array}$ & 0.000 & 0.000 \\
\hline Nagelkerke $R^{2}$ & 0.399 & & \\
\hline $\begin{array}{l}-2 \text { Log } \\
\text { likelihood }\end{array}$ & 101.59 & & \\
\hline $\begin{array}{l}\text { Hosmer and } \\
\text { Lemeshow test }\end{array}$ & 0.848 & & \\
\hline Number of firms, $N$ & 101 & & \\
\hline$\%$ correctly classified & 76.2 & & \\
\hline
\end{tabular}

*,**, *** represents $10 \%, 5 \%$, and $1 \%$ levels of significance respectively. Standard errors are given in the parenthesis. 

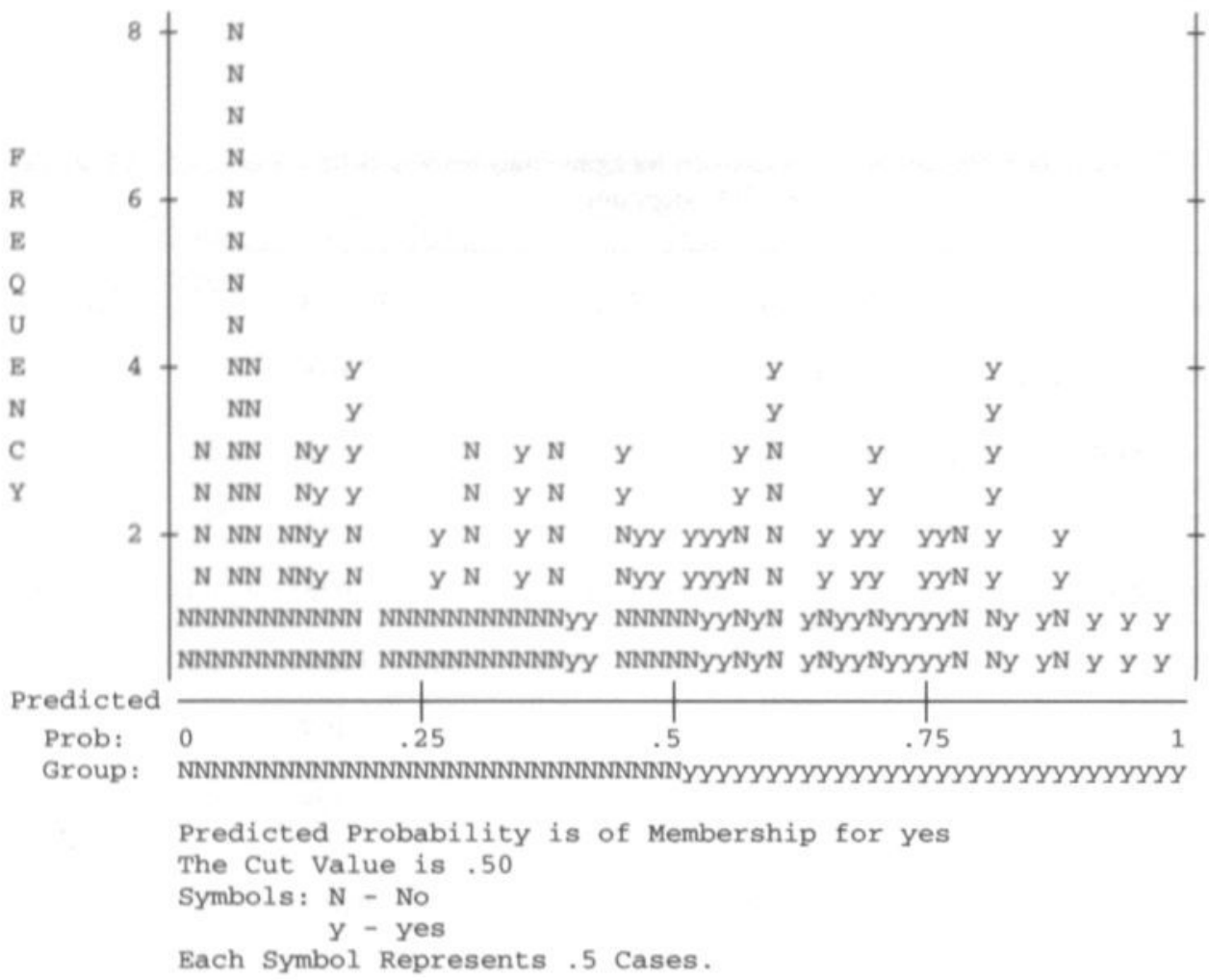

Figure 7.2: A histogram of predicted probabilities of TPA adoption based on model presented in table 7.7.

\subsubsection{Environmental policy as a major driver of TPA adoption}

Whereas the environmental policy variable $(E P L)$ appears to be a major driver of the 'bundled' EBT adoption (see section 7.3.1), from the trends in the three models presented in table 7.5, it seems unlikely that EPL is a major driver of TPA adoption. It is however apparent from model 3 that the enforcement of the Nigerian environmental policy (S.I.8/S.I.9 law) in January 1995 is no doubt an important rationale for the TPA adoption observed. The coefficient of EPL is positive and statistically significant at $10 \%$ level. This further establishes one of our findings in chapter 6 , where we discovered that most TPA adoption in the two sectors under investigation took place after the expiration of the three-year moratorium given firms to comply with the S.I.8/S.I.9 law (see section 6.3 .1 of chapter 6). This notwithstanding, the regression result in table 7.7 shows that other factors such as percent workforce with higher education $(H E D)$, firm size $(L F S)$, and internal capability for innovation $(I C K)$ have 
parameter estimates with higher levels of significance. ${ }^{13}$ Moreover, whereas the coefficient of $E P L$ was not significant until model 3 was fitted, the parameter estimates of $L F S$ and $O S T$ are consistently significant in all the three models fitted to our data in table 7.5. For the case of EPS, which is also a binary variable like $E P L$, it is apparent that EPS would have more influence on the odds of TPA adoption than $E P L$ would. While the odds of TPA adoption increases by a factor of 4.306 for a unit increase in EPS, a unit increase in EPL increases the odds of TPA adoption by a factor of only 2.537. Furthermore, whereas the marginal effect of EPS on the probability of TPA adoption $\left(P_{T P A}\right)$ increases $P_{T P A}$ by a factor of 0.81 , the marginal effect of $E P L$ increases $P_{T P A}$ by a factor of 0.72 .

\subsubsection{Auxiliary drivers of TPA adoption}

With the exception of the physical capital aspect of internal capability for innovation $(I C K)$, all the auxiliary drivers of TPA adoption incorporated in the model have positive coefficients. The negative coefficient for ICK may be due to similar reason as earlier explained for EBT adoption; the only difference being that it is now significant at $5 \%$ level whereas it was not significant for EBT adoption. It should however be reiterated that $I C K$ might represent the existing level of physical capital rather than internal capability for innovation (see section 7.2). The new level of significance may be explained by the fact that TPA solutions are usually regarded as capital intensive with no direct private economic benefit to firms. Thus, firms may perceive the existing level of investment in expensive foreign physical capital a constraint on the availability of funds for further technology investment in the form of TPA. Besides, as earlier mentioned in section 6.3 .2 of chapter $6,82 \%$ of TPP adopters indicated that adoption resulted in net economic gains to their firms. Hence, the implicit economic incentive that may be provided by investment in TPP might have made firms' perception of the influence of ICK on TPP adoption to be relatively mild. Compared to TPA, firms might have thus viewed TPP as having contributed relatively less to the observed negative drag of the existing level of investment in physical capital on the aggregate EBT adoption.

The parameter estimate for the human capital aspect of the internal capability for innovation $(I C H)$ is not significant in models 1 and 2 . However, when the percent of workforce with higher education (HED) was substituted for computed proportion of engineers/scientists in total workforce $(I C H)$, coefficient of the new internal capability for innovation (i.e. $H E D$ ) retained its positive sign and became significant at $5 \%$ level. Comparing these results with those presented in table 7.2, the importance of the human capital aspect of internal capability for innovation seems to be relatively less for TPA adoption than for EBT adoption. Whereas ICH and HED coefficients are respectively significant at $10 \%$ and $1 \%$ levels in models 2 and 3 of table 7.2 (the case of EBT adoption); $I C H$ parameter estimate is not significant, and $H E D$ coefficient is

\footnotetext{
${ }^{13}$ Whereas EPL coefficient is significant at only $10 \%$ level; the coefficients of HED, LFS and ICK are respectively significant at $5 \%, 1 \%$ and $5 \%$ levels.
} 
only significant at $5 \%$ level in table 7.5 (the case of TPA adoption). This may be an indication that factory engineers, scientists and even relatively well educated non technical workforce at the plant level may contribute relatively less to TPA adoption decisions when compared to their contribution to the overall EBT adoption decision issues of the firm. As some of the case studies may show in the next chapter, TPA adoption is relatively capital intensive, and the final decision on TPA adoption would normally be taken at the high management level of the firm. Such high level management decision would most likely at best include only a representative of the plant engineers and scientists.

Firm size has positive parameter coefficient, which is outstandingly significant at $1 \%$ level. This demonstrates that firm size has a very important influence on the odds of TPA adoption. This is not surprising because the relatively large capital outlay for a functional and effective TPA apparently implies that large firms are more likely to be able to make the required technology investments. Large firms have better access to finance. Moreover, it has been established by previous studies (e.g. ECE, 1984, pp.45; Kemp, 1997, p.142) on industrial wastewater treatment that there are significant scale economies in the use of industrial wastewater treatment technology. For small firms, it is less economical (more costs in relative terms) to invest in TPA because the unit costs of abatement decrease with firm size. For example, Kemp demonstrated that the total annual unit cost of $\mathrm{BOD}_{5}$ reduction decreases with the cleaning capacities of biological wastewater treatment plants employed in the Dutch food \& beverages industry. ${ }^{14}$ Although the cost variable has not been included in our analysis due to data limitation, it is obvious from the foregoing that large firms having relatively more wastewater effluent volumes would have cost advantage in TPA adoption.

Firm's ownership structure indicated by per cent foreign equity share (OST) has a positive coefficient, which is only significant at $10 \%$ level. This is an indication that the level of foreign equity share may be an important factor in explaining the rationales for TPA adoption in Nigerian manufacturing industry. However, other factors such as firm size and human capital aspect of internal capability for innovation $(H E D)$, have higher levels of statistical significance (i.e. $1 \%$ and $5 \%$ respectively).

Like in the case of EBT adoption, the external network for innovation variable (ENI) has a positive but insignificant coefficient for TPA adoption. However, unlike in the case of EBT adoption, the parameter estimate for the policy implementation strategy variable $(E P S)$ is positive and significant at $10 \%$ level. This indicates that whereas regulators' co-operative approach to environmental policy implementation may generally have no impact on the odds of EBT adoption, it is particularly important for the promotion of TPA adoption. Our interviews with both regulators and plant

\footnotetext{
${ }^{14}$ Furthermore, ECE (1984, pp.4-5) affirms that there is scale economy not only in the operation and maintenance of wastewater treatment plants, but also in the construction/installation costs. For example, construction costs per cubic metre of wastewater treatment for plants equipped with the common high-rate activated sludge process may be $50 \%$ lower for medium-sized wastewater treatment plants compared to smallsized ones, and $30 \%$ less for large-sized plants compared to medium-sized ones. Operation and maintenance costs are also reported to follow similar trends.
} 
managers also support this view. Nigerian manufacturing enterprises, like others in sub-Saharan Africa, have been operating in the last two decades under an atmosphere of economic recession (Lall et al, 1994; Jalilian and Weiss, 2000). Both regulators and operators of the manufacturing enterprises laid emphasis on the need to co-operate to achieve regulatory compliance at reasonable and affordable costs to firms. This finding nonetheless contrasts some earlier findings indicating that a co-operative strategy of environmental policy enforcement discourages TPA adoption in some developed countries ${ }^{15}$ (see Murphy and Gouldson, 1997; Laudise and Graedel, 1998).

On the whole, it may be affirmed that, for TPA adoption causalities, factors such as firm size, human capital aspect of internal capability for innovation (HED), and a cooperative approach to environmental policy enforcement (EPS) dominate rather than the Nigerian S.I.8/S.I.9 law as drivers of technology responses for water pollution abatement.

\subsection{Adoption Causalities for Technology Responses for Water Pollution Prevention (TPP)}

Technology responses for water pollution prevention as defined in chapter 3 comprise of firms' technological measures or innovations that reduce industrial wastewater at the source. As demonstrated in chapter 6, four types of TPP are analysed in this study. We are of the view that it would be too cumbersome or unwieldy to analyse each of the four types of TPP separately. ${ }^{16}$ Hence, in this section we analyse the adoption causalities for the 'pooled' TPP adoption. TPP adoption in this sense thus means that a firm has adopted at least one of the four types of TPP. As shown in table 7.1, almost half $(49 \%)$ of our sample firms belong to this category.

The summary of the logistic regression results for technology responses for water pollution prevention (TPP adoption) is presented in table 7.8. Model 1 contains all the variables in our empirical model. Model 1 is a relatively good fit. To get the advantage of an improved goodness of fit, model 2 was fitted to data substituting log of firm size for firm size. The resulting model has improved Nagelkerke $R^{2}$, the coefficient of the environmental policy variable becomes significant, the significance level of the coefficient of the internal capability for innovation $(\mathrm{ICH})$ improved, while that of the external network for innovation $(E N I)$ lost its significance. The loss of significance by the parameter estimate of $E N I$ was not considered strange because it has been almost consistently insignificant in the other models considered for the causality analysis (see tables 7.2 and 7.5 ). However, the model has Hosmer and Lemeshow test statistic that is significant at $5 \%$ level. This is unacceptable because

\footnotetext{
Is United Kingdom, The Netherlands and Denmark (see Murphy and Gouldson, 1997; Laudise and Graedel, 1998).

${ }^{16}$ An analysis of each of the four types of TPP would involve running the logistic regression with the adoption of each type of TPP as dependent variable. We strongly view this as unnecessary to achieve the objectives of this study.
} 
the Hosmer and Lemeshow test statistic should be statistically insignificant for a model with a fair goodness of fit. ${ }^{17}$ Replacing $I C H$ by $H E D$ as done in the previous models yielded a model (model 3 ) with the coefficient of $H E D$ significant at $1 \%$ level compared to $5 \%$ significance level of the coefficient of $\mathrm{ICH}$ in model 2 . The Hosmer and Lemeshow statistic however still remains significant at $5 \%$ level. On dropping the external network for innovation variable, the resulting model 4 has a comparatively very good goodness of fit, and an insignificant Hosmer and Lemeshow statistic. ${ }^{18}$ Thus, model 4 is employed as the main empirical model for the discussion of TPP adoption causalities. Table 7.9 presents the correlation matrix of the parameter coefficients of model 4, while table 7.10 displays the details of the model. Model 4, as presented by equation 7.3 , could be used to predict probabilities that a firm would adopt TPP. Figure 3 depicts the likely outcomes of how well the model could classify our sample firms at different levels of estimated probabilities of TPP adoption. For example, only two among our sample firms would be wrongly classified as non TPP adopters at estimated probabilities greater than 0.75 ; and only two firms would also be wrongly classified as adopters at estimated probabilities of TPP adoption less than 0.25 .

$\frac{P_{\text {TPP }}}{1-P_{\text {TPP }}}=\boldsymbol{e}^{-10.571} \cdot \boldsymbol{e}^{(0.989 \text { EPL-0.733 ICK }+0.019 \text { OST }+1.473 \text { LFS }+0.245 \text { EPS }+0.66 \text { HED })}$

\footnotetext{
${ }^{17}$ See comments in footnote no. 10.

${ }^{18}$ It should also be noted at this juncture that, substituting ICH for $H E D$ in model 4 also yields a model with a Hosmer and Lemeshow statistic significant at $10 \%$ level. Besides, the coefficient of $I C H$ will be significant at $5 \%$ level compared $1 \%$ level for HED in model 4 . Model 4 therefore appears to be better than the other possible alternatives that could be fitted to data for TPP adoption analysis.
} 
Table 7.8: Summary of the logistic regression for technology responses for water pollution prevention (i.e. TPP adoption).

\begin{tabular}{|c|c|c|c|c|}
\hline Variable & Model 1 & Model 2 & Model 3 & Model 4 \\
\hline Environmental policy & 0.867 & $0.880^{*}$ & $1.011^{*}$ & $0.989^{*}$ \\
\hline$E P L(0-I)$ & $(0.534)$ & $(0.534)$ & $(0.561)$ & $(0.553)$ \\
\hline Internal capability for & $3.765^{\circ}$ & $4.792 * *$ & & \\
\hline innovation, $\mathrm{ICH}$ & $(2.107)$ & $(2.409)$ & & \\
\hline Internal capability for & -0.407 & -0.783 & -0.832 & -0.733 \\
\hline innovation, $I C K$ & $(0.791)$ & $(0.858)$ & $(0.866)$ & $(0.820)$ \\
\hline External network for & $0.934^{*}$ & 0.750 & 0.762 & \\
\hline innovation, $E N I(0-I)$ & $(0.516)$ & $(0.520)$ & $(0.547)$ & \\
\hline Foreign equity share & $0.018 * *$ & $0.015^{*}$ & $0.017^{*}$ & $0.019 * *$ \\
\hline OST & $(0.009)$ & (0.009) & $(0.009)$ & $(0.008)$ \\
\hline Firm size & $0.004^{* * * *}$ & & & \\
\hline FS & $(0.001)$ & & & \\
\hline Log of Firm size & & $1.261^{* * *}$ & $1.446 * * *$ & $1.473 * * *$ \\
\hline$L F S$ & & $(0.335)$ & $(0.380)$ & $(0.362)$ \\
\hline Policy implementation & 0.305 & 0.230 & 0.354 & 0.245 \\
\hline strategy, EPS $(0-I)$ & $(0.766)$ & $(0.770)$ & $(0.835)$ & $(0.839)$ \\
\hline$\%$ workforce with & & & $0.064^{* * * *}$ & $0.66^{* * *}$ \\
\hline higher education, $H E D$ & & & $(0.021)$ & $(0.021)$ \\
\hline Intercept & $-3.014^{* * *}$ & $-8.295^{* * *}$ & $-10.639 * * *$ & $-10.571 * * \bullet$ \\
\hline & (1.031) & $(2.053)$ & (2.526) & (2.448) \\
\hline Nagelkerke $R^{2}$ & 0.439 & 0.444 & 0.509 & 0.498 \\
\hline$-2 \log$ & & & & \\
\hline likelihood & 99.56 & 99.10 & 91.40 & 94.56 \\
\hline \multicolumn{5}{|l|}{ Hosmer and } \\
\hline Lemeshow test & 0.744 & 0.045 & 0.043 & 0.540 \\
\hline Number of firms, $N$ & 101 & 101 & 101 & 103 \\
\hline$\%$ correctly classified & 72.3 & 69.3 & 75.2 & 75.7 \\
\hline
\end{tabular}

$*, * *, * * *$ represents $10 \%, 5 \%$, and $1 \%$ levels of significance respectively.

Standard errors are given in the parenthesis. 
Table 7.9: Correlation matrix of the logistic regression estimated coefficients for TPP adoption

\begin{tabular}{lccccccc}
\hline & $\begin{array}{c}\text { Cons- } \\
\text { tant }\end{array}$ & EPL & ICK & OST & LFS & EPS & HED \\
\hline $\begin{array}{l}\text { Cons- } \\
\text { tant } \\
\text { EPL }\end{array}$ & 1.000 & -.072 & 1.000 & & & & \\
ICK & .076 & -.297 & 1.000 & & & & \\
OST & -.300 & -.009 & .027 & 1.000 & & & \\
LFS &.- .875 & .069 & -.350 & .175 & 1.000 & & \\
EPS & -.358 & -.013 & -.047 & .004 & .062 & 1.000 & \\
HED & -.563 & .093 & -.153 & .113 & .410 & .060 & 1.000 \\
\hline
\end{tabular}


Table 7.10: Final model for the logistic regression for technology response for water pollution prevention (i.e. TPP adoption).

\begin{tabular}{|c|c|c|c|}
\hline Variable & $\begin{array}{c}\text { Parameter } \\
\text { estimate (B) }\end{array}$ & $\begin{array}{c}\text { Significance } \\
\text { level }\end{array}$ & $\operatorname{Exp}(\mathrm{B})$ \\
\hline $\begin{array}{l}\text { Environmental policy } \\
\text { EPL }(0-I)\end{array}$ & $\begin{array}{l}0.989^{*} \\
(0.553)\end{array}$ & 0.074 & 2.687 \\
\hline $\begin{array}{l}\text { Internal capability for } \\
\text { innovation, } I C K\end{array}$ & $\begin{array}{l}-0.733 \\
(0.820)\end{array}$ & 0.373 & 0.480 \\
\hline $\begin{array}{l}\text { Foreign equity share } \\
O S T\end{array}$ & $\begin{array}{l}0.019 * * \\
(0.008)\end{array}$ & 0.023 & 1.019 \\
\hline $\begin{array}{l}\text { Log of Firm size } \\
\text { LFS }\end{array}$ & $\begin{array}{l}1.473 * * * \\
(0.362)\end{array}$ & 0.000 & 4.360 \\
\hline $\begin{array}{l}\text { Policy implementation } \\
\text { strategy, EPS }(0-I)\end{array}$ & $\begin{array}{c}0.245 \\
(0.839)\end{array}$ & 0.771 & 1.277 \\
\hline $\begin{array}{l}\% \text { workforce with } \\
\text { higher education, } H E D\end{array}$ & $\begin{array}{l}0.66 * * * \\
(0.021)\end{array}$ & 0.001 & 1.068 \\
\hline Intercept & $\begin{array}{c}-10.571^{* * *} \\
(2.448)\end{array}$ & 0.000 & 0.000 \\
\hline Nagelkerke $R^{2}$ & 0.498 & & \\
\hline $\begin{array}{l}-2 \text { Log } \\
\text { likelihood }\end{array}$ & 94.56 & & \\
\hline $\begin{array}{l}\text { Hosmer and } \\
\text { Lemeshow test }\end{array}$ & 0.540 & & \\
\hline Number of firms, $N$ & 103 & & \\
\hline$\%$ correctly classified & 75.7 & & \\
\hline
\end{tabular}

*, **, $* * *$ represents $10 \%, 5 \%$, and $1 \%$ levels of significance respectively. Standard errors are given in the parenthesis. 

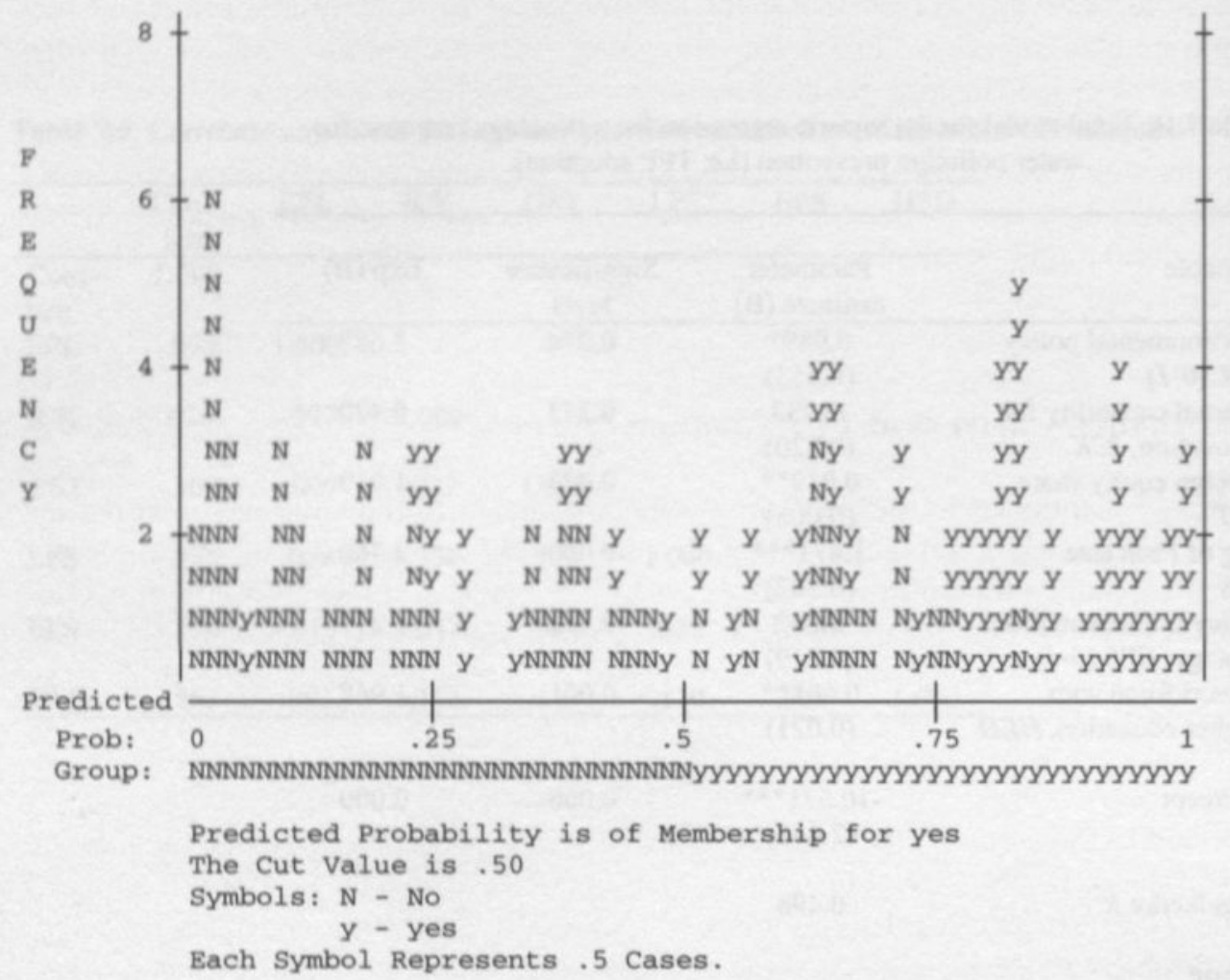

Figure 7.3: A histogram of predicted probabilities of TPP adoption based on model presented in table 7.10.

\subsubsection{Environmental policy as a major driver of TPP adoption}

Like in the case of TPA adoption in the previous section, the environmental policy variable does not appear to have a dominant role as the stimulus for TPP adoption. As expected, the estimated coefficient for environmental policy is positive. However, whereas the parameter estimate for environmental policy $(E P L)$ is only statistically significant at $10 \%$ level, the coefficients of log of firm size $(L F S)$, percent of workforce with higher education (HED), and ownership structure (OST) are respectively significant at $1 \%, 1 \%$ and $5 \%$ levels. In fact, the coefficient of $E P L$ was statistically insignificant in model 1 (see table 7.8), whereas the parameter estimates for $L F S, H E D$, and $O S T$ are consistently significant for all models fitted to our data in table 7.8. Furthermore, calculation of marginal effects showed that, while the marginal effect of EPL on the probability of TPP adoption $\left(P_{T P P}\right)$ would increase $P_{T P P}$ by a 
factor of 0.73 , the marginal effects of other comparable binary variables such as ICK and $E P S$ would increase $P_{T P P}$ by factors of 0.32 and 0.56 respectively. It is difficult however to draw any conclusion about the impact of specific value changes of the latter variables on $P_{T P P}$. From the foregoing, it thus appears that though the enforcement of the Nigerian S.I.8/S.I.9 law in January 1995 is an important reason for the TPP adoption observed in our sample firms, it may not be a major driver of TPP adoption. Some auxiliary driver factors such as firm size, percent workforce with higher education, and ownership structure of the firm (indicated by percent foreign equity share) might be equally or even more important in explaining the rationales for TPP adoption.

\subsubsection{Auxiliary drivers of TPP adoption}

As already mentioned in the previous subsection, added to the environmental policy variable in model 4, other important drivers of TPP adoption include firm size, internal capability for innovation indicated by the percent of workforce with higher education $(H E D)$, and firms' ownership structure indicated by the level of foreign equity shares. All these variables have positive parameter estimates. It is also important to note that the coefficients of firm size and $H E D$ have statistical significance levels of $1 \%$.

Compared to the case of TPA adoption in table 7.7, the coefficient of HED improved in significance level to $1 \%$ (identical to what obtained for EBT adoption). It appears that the $H E D$ variable is relatively more important for TPP adoption. A high percent of workforce with higher education may contribute more to TPP adoption than to TPA adoption. It is also necessary to note that, although the $\mathrm{ICH}$ component of internal capability for innovation is not included in our final model 4 , it also has a positive coefficient, and is significant ${ }^{19}$ in two previous models (models 1 and 2 in table 7.8). It should be recalled that the coefficient of $I C H$ was not significant in models 1 and 2 for the case of TPA adoption in table 7.5. Thus, in contrast to the case of TPA adoption, in addition to the role of a firm's educated workforce variable (HED), the technical and scientific personnel at the plant level could be said to actively influence the odds of TPP adoption. ${ }^{20}$

The internal capability for innovation, ICK retains its negative coefficient as in the case of TPA adoption. However, unlike the case of TPA adoption, the ICK coefficient is statistically insignificant. As earlier mentioned in section 7.3.2 of this chapter, the negative sign of the ICK parameter estimate exposes the fact that $I C K$ might have only represented levels of physical capital investment among our research sample firms. If it had truly contributed to the internal capability for innovation, the coefficient would most likely be significant and bear a positive sign. It is nonetheless noteworthy that the statistical insignificance of the ICK coefficient for TPP adoption may indicate that

\footnotetext{
${ }^{19} \mathrm{ICH}$ is significant at $10 \%$ level in model 1 and $5 \%$ level in model 2.

${ }^{20}$ It should also be recalled that $I C H$ is a subset of $H E D$.
} 
firms with expensive imported capital equipment may not be averse to TPP adoption as they would to TPA adoption. It should however be pointed out at this juncture that this apparently strange result might signify that the TPP investments in this study are not extensive or deep capital investment such as complete change in a production process or core capital equipment. If environmentally benign process or production equipment changes that may lead to appreciable sunk cost effects are significant components of TPP adoption among our sample firms, it is very unlikely that firms will not be averse to TPP investments.

It is also interesting to note that the statistical significance of the coefficient of the ownership structure (OST) as a reason for increased odds of TPP adoption improved to $5 \%$ level as compared to only $10 \%$ level for the case of TPA adoption. However, it should be recalled that without de-coupling TPP and TPA in our analysis, the coefficient of OST for EBT adoption is significant at $1 \%$ level. It does appear that high foreign equity share holdings will generally improve the odds of EBT adoption. But the importance of the OST variable decreases if EBT is disaggregated into its two components as done in this study. The specific impact of increase in foreign equity on adoption appears to be more important or at least a little more pronounced for TPP adoption than for TPA adoption. In addition, the magnitude of the OST coefficient and the factor by which a percent increase in foreign equity will improve the odds of adoption are greater for TPP than for TPA adoption.

Unlike for TPA adoption, the coefficient of the policy implementation strategy (EPS) though positive, is not significant for TPP adoption. The rationale for this may be explained by the fact that TPP innovations are more firm specific. They mostly originate from firms' innovative activities, which may not normally require the cooperation of regulators to implement.

At this juncture, it is necessary to point out that our empirical model has not been able to explain the contribution or otherwise of three variables among the factors hypothesised in chapter 4 as auxiliary drivers of technology responses for industrial wastewater pollution control. These unaccounted adoption causalities include firm's competitiveness, firm's environmental disposition, and institutional capacity for environmental regulation. The likely importance of these variables is further signified by the fact that, the Nagelkerke $R^{2}$ for our fitted models did not exceed $50 \%$ for the models we have used in explaining adoption causalities, except for the case of EBT adoption. ${ }^{21}$ This implies that at least $50 \%$ of the unexplained variations in some of our fitted models could be due to factors exogenous to our empirical model. While not limiting reasons for the unexplained variations to the three factors mentioned above; based on our field survey data, we have in the next section highlighted the possible roles they could play as EBT adoption causalities. In addition, the section concludes

\footnotetext{
${ }^{21}$ The Nagelkerke $R^{2}$ is $67.5 \%$ for the case of EBT adoption in table $7.4,39.9 \%$ for the case of TPA adoption in table 7.7 , and $49.8 \%$ for the case of TPP adoption in table 7.10 .
} 
this chapter with a synthesis of the adoption causalities for environmentally benign technologies in Nigerian manufacturing industry.

\subsection{Conclusion: A Synthesis of Adoption Causalities}

From our findings in this chapter, our field data largely supports the hypotheses we proposed in chapter 4 . With respect to hypothesis $\mathrm{HI}$ that aimed at ascertaining whether or not Nigerian S.I.8/S.I.9 environmental regulatory law has been effective in stimulating technology responses for water pollution control, it has been demonstrated in this chapter that the law has contributed significantly to technology adoption for water pollution control reported by our field data. We discovered that when environmental benign technologies are not disentangled according to type, firms portend environmental policy as a main reason or a major driver of their decisions to embark on technology investment that reduce industrial wastewater pollution (see section 7.3.1). However, when types of technology responses are isolated according to our classification in this study, viz., TPA or TPP, it becomes apparent that environmental policy could not be said to play the role of a major driver of technology responses. Some of the adoption rationales identified in hypothesis $\mathrm{H} 2$ become more dominant when compared to the role of environmental policy as adoption stimulus. Environmental policy nonetheless remains important reason for the adoption of both TPA and TPP, but seemly more important for the promotion of TPA adoption. This is further buttressed by the results shown in table 7.11, which displays the percent of firms in our research sample that signify the most important reasons why they have adopted TPA (industrial wastewater treatments plants). Environmental policy ranked highest as the most important reason for TPA adoption. ${ }^{22}$

With respect to the auxiliary driver factors as technology adoption rationales, the following conclusions could be drawn from our findings in this chapter.

Hypothesis $H 2 a$ on the impact of firm's internal capability for innovation on the adoption of environmentally benign technologies is supported by our data when firm's technical workforce $(I C H)$ or the percent of workforce with higher education (HED) are used as indicators of human capital contributions to firm's capability to carry out water pollution control related innovation. It is discovered that the role of technical workforce is more important for TPP adoption than for TPA adoption.

In hypothesis $H 2 b$, we did not make any prior specification on the direction of influence of the existing level of investment in physical capital on the adoption of TPA or TPP. It was however discovered from our analysis that it has a negative impact on adoption in each of the models fitted to our data. The influence is found to

\footnotetext{
${ }^{22}$ It should however be pointed out that, compared to the adoption rationales considered by our auxiliary driver hypothesis $\mathrm{H2}$, the reasons listed in table 7.11 are relatively difficult to quantify. Besides, it is not possible for a non-adopter to answer the related question. Hence, most of the factors in table 7.11 have largely been excluded from the analysis reported in this chapter. Hypothesis $\mathrm{H}_{2}$ incorporates reasons relating to firms' characteristics, technological capabilities, and environmental policy implementation strategy.
} 
be more pronounced for TPA than for TPP. This may perhaps be due to the fact that, heavy investment in physical capital may make firms in a developing country such as Nigeria comparatively more reluctant to embark on further technology investment that would not directly contribute to increased output or profitability.

Table 7.11: Reasons for the adoption of industrial wastewater treatment plants.

Percent respondent firms consider reason

TPA adoption reason

important most important $2^{\text {nd }}$ most important

Prevent environmental incidents

91.3

34.8

28.3

Nigerian environmental policy

78.3

41.3

International norm of parent company

34.8

6.5

17.4

Improve environmental image

71.7

13.0

13.0

Products acceptance in intern. market

Pacify local community

Pacify NGOs

Other reasons

7.0

4.3

Total

100.0

100.0

Source: Author's field survey

Our data could not support hypothesis $H 2 c$, which states that the chances of a firm's adoption of TPA/TPP would depend on the technological knowledge related network that the firm maintains. In all models used for the analysis of adoption causalities, the external network for innovation variable though positive, consistently have statistically insignificant parameter estimate. It appears that innovation related external network would normally have a positive influence on technology adoption for water pollution control, but the impact may not be important in view of other relatively more important factors. For example, compliance with international norm of a firm's parent company, which is closely linked with the external network for innovation variable, is shown in table 7.11 to be most important reason for TPA adoption by only $6.5 \%$ of the responding firms, whereas more than one third $(34.8 \%)$ of the sample firms consider it an important reason for adoption. Moreover, as would be revealed later by the case studies in chapter 8 , parent companies could play very active roles in ensuring that subsidiaries adopt technologies for water pollution control. Thus, firm's technological knowledge related external network could be 
important for TPA/TPP adoption, but its significance may be considerably reduced in view of other more important reasons for adoption.

Hypothesis $H 2 d$ on the role of the ownership structure of the firm in promoting technology adoption for pollution control is supported by our data. In the technology adoption types analysed, the odds of adoption increase with increase in the percent of foreign equity. As foreign equity increases, it appears that firms are able to release more resources for pollution control. Moreover, foreign participation may also result in firms being more conscious of international environmental norms that may induce improved tendency to invest in technology for water pollution control.

The hypothesis $\mathrm{H} 2 \mathrm{e}$ on firm size appears to be the most strongly supported of all the hypotheses tested in this study. The odds of technology adoption for industrial wastewater pollution control is strongly correlated with firm size in all the adoption scenarios analysed in this chapter. ${ }^{23}$ This corroborates the findings of Hettige et al (1996), which discovered that pollution intensity is consistently negatively associated with scale in a review of evidence drawn from three empirical studies of firm-level abatement practices among developing country firms in South and Southeast Asia. As explained in chapter 2 of this study, firm size as a variable incorporates many characteristics that may not be easy to single out as the principal determinant of the observation recorded in response to changes in firm size. From the findings reported in this chapter, it is however clear that policies that encourage large-scale greenfield manufacturing investments or promotes growth of existing small and medium-scale industries into large scale manufacturing, will contribute positively to technology investments in water pollution control.

Hypothesis $H 2 f$, which addresses the issue of regulators' environmental policy implementation strategy, was found to contribute positively to firms' technology responses for water pollution control when regulators use a co-operative approach to compliance enforcement. However, the estimated coefficient for the policy implementation strategy is statistically significant only for TPA adoption. This may be due to the fact that firms in our research sample generally perceive TPP to have some economic gains, and hence they may not need the co-operation of regulators before embarking on TPP innovations. Unlike TPP, TPA is perceived as potential net contributor to increasing production costs by $85 \%$ of TPA adopters before they implemented TPA. Hence, the strategy employed by regulators for compliance monitoring may have more impact on TPA adoption because of the cost implications of TPA to firms.

Our field data could not provide information that can be used to test hypothesis $\mathrm{H} 2 \mathrm{~g}$ in the logistic regression analysis. Hypothesis $\mathrm{H} 2 \mathrm{~g}$ deals with the impact of cost savings or competitiveness motivated reasons as impetus to technology responses for water

\footnotetext{
${ }^{23}$ Assuming firms' technology investment in pollution control to be positively associated with plant-level abatement expenditures, this result is also consistent with the findings of Aden et al (1999) on the determinants of pollution abatement expenditure behaviour of Korean manufacturing plants.
} 
pollution control. ${ }^{24}$ As reported in the foregoing, firms generally perceive TPA to engender costs. Thus, following the apparent universal norm, competitiveness motivation or cost saving intentions would not normally promote TPA adoption in Nigerian manufacturing. However, with respect to TPP adoption, it appears that the cost savings reason play an important role in promoting technology adoption for water pollution control. As shown in table 7.12, for all the TPP types investigated in this study, more of our responding firms indicated that their decision to adopt TPP was due to cost saving reasons rather than as a result of environmental regulatory pressure. On the average, whereas $72 \%$ of TPP adopters claimed to have adopted because of TPP cost reduction possibilities, only $41 \%$ of the TPP adopters claimed to have adopted because of environmental regulation.

Table 7.12: Motivations for TPP adoption

\begin{tabular}{lccc}
\hline \multicolumn{1}{c}{ TPP type } & $\begin{array}{c}\text { Percent TPP adoptions due to } \\
\text { Cost reduction } \\
\text { reasons }\end{array}$ & $\begin{array}{c}\text { Environmental } \\
\text { regulation }\end{array}$ & $\begin{array}{c}\text { Total no. of } \\
\text { TPP adopters } \\
\text { responding }\end{array}$ \\
\hline Water/wastewater re-cycling & $85 \%$ & $70 \%$ & 33 \\
Raw material re-use/recycling & $92 \%$ & $30 \%$ & 36 \\
Change raw material input(s) & $38 \%$ & $29 \%$ & 21 \\
Integrated physical device & $71 \%$ & $33 \%$ & 24 \\
\hline Average & $72 \%$ & $41 \%$ & \\
\hline
\end{tabular}

Source: Author's field survey

As already indicated in chapter 4 , the case studies presented in the next chapter would provide interesting insights into the role of the two remaining variables (viz., firm's environmental disposition, and institutional capacity for environmental regulation) identified as auxiliary drivers of technology responses for industrial wastewater pollution control. Furthermore, table 7.11 indicates that intangible reasons such as prevention of environmental incidents, improvement of environmental image of company, and community pressure could play considerable role as drivers of adoption. The case study illustrations also pay close attention to these adoption rationales.

\footnotetext{
${ }^{24}$ As explained in chapter 4 (section 4.3.2), information on costs of technology investments in pollution control are difficult to obtain in a developing country context, as is the case in this study. Records on pollution control expenditures are currently non-existent in Nigeria's environmental regulatory agencies. Where such records exist at plant level, companies are averse to releasing such information to outside parties. Hence, the limitation of this study with respect to the relationship between odds of EBT adoption and cost savings that may be reflected by pollution control expenditures.
} 
In conclusion, it is important to point out that, the empirical analysis in this chapter has shown that the indication given in the previous chapter about environmental policy being a major driver of the adoption of environmentally benign technologies is limited. It has been demonstrated in this chapter that, environmental policy could be accepted as a major driver of the adoption of environmentally benign technologies (EBTs) in Nigerian manufacturing only when EBT is not disaggregated or classified into its functional types. In such a situation, it is difficult to make inferences that would be helpful for real life decision making that usually involve assessing the costs and benefits of specific technology option available for pollution control. When specific types of EBTs as being used in Nigerian manufacturing are considered, environmental policy becomes only an important driver of adoption. For TPA, it was discovered that factors such as firm's internal capability for innovation as indicated by the level of human capital, firm size, and the existing level of investment in machines/equipment are equally or more important than environmental policy as drivers of technology responses for industrial wastewater pollution control. For TPP, we found that the level of foreign equity share, firm size, and firm's internal capability for innovation as indicated by its level of human capital are equally or more important than the enforcement of the Nigerian environmental policy as rationales for the adoption of environmentally benign technologies. Thus, we may conclude that auxiliary driver factors such as firm size, firm's internal capability for innovation, and the ownership structure of the firm are equally or more important than the prevailing regime of environmental policy in explaining the adoption of environmentally benign technologies in the Nigerian manufacturing industry. 


\section{CASE STUDY ILLUSTRATIONS OF FIRMS' TECHNOLOGY RESPONSES FOR WATER POLLUTION CONTROL IN NIGERIAN MANUFACTURING}

\subsection{Introduction}

This chapter presents twelve detailed firm level case studies to illustrate technological responses of manufacturing enterprises to demands of environmentally sustainable industrialisation with respect to industrial wastewater pollution in Nigeria. As earlier stated in section 5.2 of chapter 5 , we planned to carry out twelve case studies in the food \& beverages sector and three in the textiles sector. We however succeeded in carrying out ten case studies in food \& beverages sector, and two in the textiles sector. In the food \& beverages sector, five out of the six subsectors identified for our study were represented (see table 8.1). The wines/distilleries subsector is not represented because all our efforts to get a firm willing to grant detailed firm level interview proved abortive. We however ensured that not more than three case studies per subsector were done. Although we had opportunity to go through the production process and wastewater treatment facilities of eight out of the 27 plants in our textiles sample, only two firms were willing to oblige us detailed firm-level interview. At any rate, the two textile case studies give pertinent insights into the reasons for, and obstacles to technological responses for water pollution control among textile plants.

The case studies are based on our questionnaire aided interviews with plant managers or their designated representatives; verification of their claims from regulators; use of documentary evidence such as company's annual reports, environmental audit reports, and regulators' annual reports; and direct observations of their production and wastewater treatment facilities in all cases. Each of the twelve case studies is discussed under firm background and basic characteristics, production technology and innovation, environmental problems and management, and technology adoption for water pollution control. In the following two sections, we present the case study illustrations for the food \& beverages industry, while the textile case studies are reported in section 8.3 . The final section gives the conclusions that could be drawn from the case study analysis with respect to the adoption causalities for environmentally benign technological innovation in Nigerian manufacturing. 
Table 8.1: Summary of the key features of the case study firms

\begin{tabular}{|c|c|c|c|c|c|c|c|c|c|c|c|c|}
\hline Firm & $\begin{array}{c}\text { Subsector } \\
\text { or sector }\end{array}$ & $\begin{array}{l}\text { Current } \\
\text { Capacity } \\
\text { Util. (\%) }\end{array}$ & $\begin{array}{l}\text { Age } \\
\text { (yrs.) }\end{array}$ & $\begin{array}{c}\text { No. } \\
\text { employed }\end{array}$ & $\begin{array}{l}\text { No. of } \\
\text { Nigerian } \\
\text { ETS }^{*}\end{array}$ & $\begin{array}{l}\text { No. of } \\
\text { foreign } \\
\text { ETS }\end{array}$ & $\begin{array}{l}\text { MNE } \\
\text { affiliate }\end{array}$ & $\begin{array}{c}\% \text { local } \\
\text { ownership }\end{array}$ & $\begin{array}{c}\text { Adopt } \\
\text { TPA }\end{array}$ & $\begin{array}{c}\text { Type of } \\
\text { TPA } \\
\text { adopted }^{\prime}\end{array}$ & $\begin{array}{c}\text { Adopt } \\
\text { TPP }\end{array}$ & $\begin{array}{c}\text { Type of } \\
\text { TPP } \\
\text { adopted }^{2}\end{array}$ \\
\hline FBI & Brewing & 60 & 18 & 800 & 470 & 0 & yes & 60 & yes & $b$ & yes & $d, e$ \\
\hline FB2 & Brewing & 30 & 17 & 300 & 6 & 2 & no & 0 & yes & $b$ & yes & $g$ \\
\hline FB3 & Soft drink & 60 & 10 & 41 & 11 & 1 & yes & 0 & yes & $a$ & yes & $d$ \\
\hline FB4 & Soft drink & 40 & 20 & 160 & 13 & 1 & yes & 60 & yes & $a$ & yes & $g$ \\
\hline FB5 & Soft drink & 40 & 40 & 350 & 20 & 1 & no & 60 & no & - & yes & $g$ \\
\hline FB6 & Confectionery & 85 & 8 & 210 & 150 & 5 & yes & 15 & no & - & yes & $e$ \\
\hline FB7 & Confectionery & 62 & 39 & 1131 & 200 & 7 & yes & 43 & yes & $a$ & yes & $g$ \\
\hline FB8 & Confectionery & 20 & 32 & 40 & 4 & 0 & no & 80 & no & - & no & - \\
\hline FB9 & Dairy products & 20 & 37 & 477 & 30 & 1 & no & 20 & no & - & yes & $g$ \\
\hline FB10 & Vegetable oil & 60 & 17 & 248 & 19 & 1 & yes & 48 & yes & $b$ & yes & $d, g$ \\
\hline TEI & Textile & 65 & 34 & 700 & 50 & 7 & yes & 40 & yes & $c$ & yes & $e$ \\
\hline TE2 & Textile & 20 & 23 & 376 & 17 & 7 & no & 30 & yes & $c$ & yes & $e$ \\
\hline
\end{tabular}

* ETS = engineers, technicians \& scientists.

1: $a=$ primary industrial wastewater treatment plant

$b=$ secondary industrial wastewater treatment plant

$c=$ advanced industrial wastewater treatment plant

$2: d=$ water or/and wastewater re-use or recycling

$e=$ raw material re-use or recycling

$f=$ change in raw material input(s)

$g=$ integrated physical device in the production line.

Source: Author's field data 


\subsection{The Case Studies: Firms in the Food and Beverages Sector}

The following are our findings with respect to the ten food \& beverages case studies.'

\section{Firm FB1}

\section{Background and Basic Characteristics}

Firm FB1 is a large-scale brewing plant producing two of the popular larger beer brands in Nigeria. It also produces stout and a non-alcoholic malt drink. The plant is $60 \%$ Nigerian owned, and is an affiliate of a European multinational brewing company, which was involved in the establishment of the plant in the early 1980s. The plant employs about 800 persons among whom are nearly 500 engineers, technicians and scientists. Three quarters $(75 \%)$ of the workforce have higher or more than secondary education. ${ }^{2}$ The plant is reputed as one of the biggest brewing plants in Nigeria. It is well laid out on a large expanse of land in a designated industrial area on the outskirts of one of Nigerian large cities. The owners of the plant have four other brewing plants in Nigeria, and no foreigner is involved in any of the manufacturing activities at the plant level. The company is almost completely run by Nigerians. The few foreigners (two in number at the time of this research) are involved as directors at the company's headquarters. FB1 has succeeded in exporting some of its products not only to the West African subregion, but also to the UK and USA. The plant's sales turnover in 1998 was 1.9 billion Naira (about US\$ 22 million).

\section{Production Technology and Innovation}

The firm engages in conventional brewing processes using completely foreign technology equipment. The firm has three lines, which are about 17 years old, and currently produces at about $60 \%$ of its installed capacity. Beer has shelf life of only six months, and hence only two out of the three lines are used except during peak demand seasons. The firm is presently embarking on a re-engineering programme with the assistance of its parent company. The most important raw material is water, which is obtained from a public waterworks and treated on site at the plant. The water requirement at the plant is $2,000-3,000$ cubic metre per month. The plant presently uses 7 to $8 \mathrm{hl}$ water for every hectolitre beer produced. Efforts are on to achieve the

\footnotetext{
'We have as much as possible hidden the identity of the firms in view of our commitment to confidentiality in the use of the information provided by the firms. Accordingly, the official names and exact locations of the firms are not revealed in this thesis. Nevertheless, we do not rule out the possibility that anyone familiar with the Nigerian manufacturing sector may be able to identify some of the firms. In such a case, we expect information obtained from this thesis to be strictly used only for academic research purpose.

2 'more than secondary education' as used in this thesis implies an educational level not lower than Nigerian National (Ordinary) Diploma or its equivalent. Ordinary National Diploma is the first level diploma awarded by Nigerian Polytechnics or Higher Technical Colleges. It involves at least two years of technical education after a successful secondary school education.
} 
target of less than $7 \mathrm{hl}$ water per hectolitre beer produced. Other important major inputs include malted sorghum, maize grits, sugar and malted barley. Until few years ago when the gale of liberalisation made government to relax the ban on malted barley, Nigerian brewers have successfully substituted local malted sorghum for malted barley. FB1 currently uses both barley and sorghum in its production process in order to minimise difficulty that may arise in switching back to malted sorghum in case barley's import is again restricted.

The plant has an R\&D unit, which includes an engineering section and quality control laboratory. The R\&D unit carries out minor product design and development to maintain quality of its known brands. The unit also engages in search activities that are aimed at improving the technical performance of current production technology. In recent years, improving the environmental performance of current technology has also been a concern of the R\&D unit. The most important focus of the unit is however to maintain an efficient operation of the current technology. The firm has a foreign technical agreement for regular maintenance of plant and verification of quality of its products. It appears that the so-called R\&D are driven by the expectations of the technical agreement rather than an actual impetus to innovate and thereby improve on product or process. The firm acknowledges that its parent company is its main source of technological knowledge or innovation.

\section{Environmental Problems and Management}

Environmental management at FB1 is largely related to the management of wastewater effluent and solid wastes resulting from spent grains, broken bottles, defective corks and crates. The firm considers wastewater management as the most important aspect of environmental problem confronting the plant. While spent grains have some economic value through sales to some local agents for livestock feeds, other aspects of solid waste management appear not to command much attention. The firm monitors its wastewater generation, which is currently at an average of nearly 100 cubic metre per day. The wastewater is laden with organic load largely traceable to wort and beer. The firm claims that environmental concerns are a top priority for its corporate management. The plant prides itself in being one of the firms that have notably been committed to environmental management even before the enforcement of S.I.8/S.I.9 law in 1995. The firm's most important reasons for embarking on environmental management are to enhance the positive image of the firm and prevent avoidable environmental incidents. The firm regularly engages FEPA and SEPA officials in active discussions on appropriate solutions to perceived environmental problems, and suggestions from regulators are considered useful, but sometimes costly

\footnotetext{
${ }^{3}$ The story of local sorghum substitute for barley in Nigerian brewing is one of the few successful cases of industrial innovation in Nigeria. The innovation was borne out of search for local substitutes for imported raw materials when scarcity of foreign exchange led to restrictions in importation of malted barley in the late 1980s (see lhonvbere, 1993, p.145; Ogun, 1995; Moser et al, 1997, pp. 28-29). However, it appears that policy inconsistency aided by the dictates of liberalisation has sabotaged an innovation that has saved substantial foreign exchange. If the innovation had been further encouraged, sorghum would possibly have been improved upon and made competitive with imported barley.
} 
to implement. At times the regulators' attitude is cordial, while at other times it is antagonistic especially when regulators insist on regulatory demands that are beyond the firm's current capacity. FB1 nevertheless considers regulatory enforcement visits regular and effective.

Added to the regulatory pressure in recent years, the firm has been under intense pressure from the local community, which claimed that effluents from FB1 have caused series of environmental damages to their farmland and water. ${ }^{4}$ Moreover, as at the time of this research, FB1 has no environment related corporate social responsibility towards this complaining community. The community has thus formed an association demanding compensation from FB1. However, FB1 has refused to accept responsibility for perceived environmental damages, which it claimed, could have arisen from elsewhere (e.g. other relatively smaller plants operating in the industrial estate). ${ }^{5}$ Besides, FB1 displays an old map of the adjacent community, which shows that the local communities settled in their present locations after the establishment of FB1.

FB1 practices no formal environmental management system. The firm acknowledges that its commitment to environmental management is lower than that of its parent company. However, in response to the recent challenges posed by the regulatory and communal pressures, FB1 appears to have become relatively more committed to environmental management. It carried out a comprehensive environmental audit of its activities in 1998. Its environmental management committee has been formally inaugurated in 1999, and the plant manager directly oversees the environmental management committee with the technical manager directing the operational aspects. The firm's current environmental strategy draws largely from the corporate environmental policy of its parent company. The environmental management strategy adopted focuses on good housekeeping, waste reduction and waste recycling, which FB1 regards as inevitable prelude to a cost effective wastewater treatment. Highlight of the strategy as adopted by FB1 is presented in box 8.1.

This strategy forms the basis for the long-term environmental management objectives of FB1. The firm's environmental management committee meets regularly (at least once a month), and is made up of representatives from every operational unit of the plant. At each meeting environmental related performances are reviewed, and targets to be achieved before next meeting are set. It is also worth mentioning that environmental regulation compliance is not only internally self-monitored, but also presently involves external monitoring by the parent company. The firm however

\footnotetext{
${ }^{4}$ The alleged environmental problem arising from the wastewater pollution traceable to FB1 include poisoning of underground water, thereby making well water undrinkable; rendering the nearby stream bereft of aquatic life, especially fish; withering of palm trees and some other economic plants, thus signalling threats to their farmlands' ability to support farming activities, which are major source of income for residents (Company's environmental consultant's report on investigation into the community's complaints, 1998; Tell Newsmagazine, January 24, 2000).

${ }^{5}$ The communal association has taken their grievances to court, and it is one of the important cases of current environmental right litigation in Nigeria (see Tell Newsmagazine of January 24, 2000).
} 
regards internal self-monitoring as the most effective in enhancing its compliance with regulatory requirements.

Box 8.1: FB1 Environmental Strategy

- A maximum water consumption of $7 \mathrm{hl}$ per $\mathrm{hl}$ of beer produced;

- A maximum water consumption of $4 \mathrm{hl}$ per $\mathrm{hl}$ of soft drinks produced;

- No yeast discharge into the drains;

- No kieselguhr discharge into the drains;

- Proper waste management;

- Only use biodegradable cleaning and disinfection additives;

- Average wastewater characteristics for beer and soft drinks: influent COD and BOD approximately $2,000 \mathrm{mg} / \mathrm{l}$ and $1,250 \mathrm{mg} / \mathrm{respectively;}$

- Separate drains for process and storm water,

- Recover re-usable water,

- Re-engineering to implement up to date production technology to meet global competitiveness challenges;

- Modern cost-effective wastewater treatment

Source: Company's manual on 'cost-effective wastewater treatment' (1999).

FB1 expects stricter regime of environmental regulation in future. It however does not support the use of effluent charges to control industrial wastewater pollution because it believes that such cannot be effective in Nigeria. The firm claims that, apart from the attending problems of tax administration, technology forcing standards are straight forward, and make firms to clearly understand what to do to abate pollution.

\section{Technology Adoption for Water Pollution Control}

In spite of the fact that a multinational company was a major actor at the establishment of the plant, no provision was made for adequately handling the attendant water pollution associated with the brewing process. What was provided was a simple lagoon consisting of two concrete ponds and three earthen ponds built in 1983. However, with the advent of regulatory enforcement process, a primary settling tank was built in 1991 incorporating a grit chamber, a sedimentation basin and an oil schemer. Seeking to improve environmental image in line with the improved environmental awareness in Nigeria, the primary wastewater treatment facility was extended in 1994 to include more oil schemers, from where oil and grease are collected regularly. In addition, water hyacinth was introduced as macrophytes to enhance wastewater purification in the lagoon (see box 8.2 for a description of the action of the water hyacinth). 
Box 8.2: Water hyacinth aided biological wastewater treatment at FB1

\begin{abstract}
Water hyacinth is an aquatic weed, the roots of which absorb nitrates, phosphates and heavy metals. Phosphate is an important nutrient, which the weed needs to bloom and flower. It also prevents algae bloom at the ponds. Thus, as the water hyacinth grows, the wastewater is 'polished'. However, the weed withers overtime. The withered water hyacinth is removed regularly from the pond, otherwise, it rapidly increase the organic load of the final effluent. It should nevertheless be noted that water hyacinth is $95 \%$ water, and it thus takes time before the withered weed can constitute much problem. The lagoon at FB1 has five ponds. The first pond of the lagoon is concrete, and is divided into four compartments. The first two compartments are open, and serve as aeration basins before the wastewater flows into the remaining two compartments, which are covered by water hyacinth. The water hyacinth shuts the effluent off from air, and thus provides opportunity for some anaerobic digestion process before the wastewater flows into the remaining four unpartitioned ponds. The second pond is also concrete, but uncovered with water hyacinth. The remaining three ponds are earthen ponds. Ponds three and four are partially covered with water hyacinth for further 'polishing' of the wastewater. The last earthen pond is open, and discharges a relatively clear supernatant into a nearby stream. Using BOD as a measure of wastewater quality, the system reduces the $B O D$ from an average of $650 \mathrm{mg} / \mathrm{l}$ at the influent pond to 70 $\mathrm{mg} / \mathrm{l}$ at the point of discharge into the stream. However, this does not meet the regulatory requirement of $30 \mathrm{mg} / \mathrm{l}$. Sludge produced is evacuated to government landfills by a local contractor.
\end{abstract}

Source: Author's field interviews and direct observations during visits to FB1

In line with the firm's strategy of reducing waste, the scrapped oil is used to supplement fuel for firing boilers. Thus, apart from reducing the environmental problem constituted by waste oil, there is economic gain through savings in the quantity of $\mathrm{LPFO}^{6}$ bought to fire the boilers. However, despite the introduction of more oil schemers in 1994, trace oil and grease, which inhibit biodegradation in the ponds, still constitute a problem. FB1 consulted a scientist at one of Nigerian universities. In 1997, the scientist solved the problem of waste oil in effluent through the application of an organic digester, which he had earlier invented. The industrial wastewater is dosed with the organic digester called 'Oso biodegrader plus' (OBD') at various points before the effluent reaches the lagoon ${ }^{7}$ (see box 8.3 for details about the invention of $\mathrm{OBD}^{+}$). Furthermore, the firm has recently separated the stormwater drains and non-process wastewater flow direction from that of process wastewater to

\footnotetext{
${ }^{6}$ Low pour fuel oil
}

'The researcher carried out a detailed interview with the inventor of $\mathrm{OBD}^{*}$. 
improve the efficiency of the wastewater treatment system. There is also a close monitoring of areas susceptible to leakage in the process lines, and water is recycled or reused, especially because of high cost of water abstraction. ${ }^{8}$ FB1 claims water economy and other wastewater reduction efforts have yielded considerable reduction in wastewater effluent. Wastewater effluent, which used to be an average of 140 cubic metre per day up to the end of 1997 has by mid 1999 been reduced to an average of not more than 100 cubic metre per day.

Box 8.3: Discovery of 'Oso biodegrader plus' (OBD').

The OBD* research started in 1985 after the discovery of an invasion of the Lagos lagoon by water hyacinth in 1984/85. The water hyacinth invasion became a national problem, and the scientist (i.e. the $\mathrm{OBD}^{+}$ inventor) was nominated to serve on a national committee to solve the 'strange weed problem'. The committee was handicapped apparently because of government bureaucracy. However, in the process the scientist found that the strange weed could afterall have some economic value. He embarked on a self-sponsored research project on which he discovered some of the possible uses of water hyacinth. The weed is $95 \%$ water, and its fibre could be used for mat, pulp and paper, animal feed, manure, mushroom compost, and as a carrier medium for microorganisms. The $\mathrm{OBD}^{+}$research came to its high point in 1992 when he discovered that water hyacinth could successfully serve as a carrier medium for microbes that breakdown toxins and digest oil and grease. He further experimented and found that the resulting substance, which could be either in powder or suspension form, can be produced on a commercial scale. He termed the invention $\mathrm{OBD}^{*}$, and got it patented in Nigeria in 1997. According to him, apart from the efficacy of OBD* in treating oil and grease, it has also been proven to breakdown refuse into fertiliser in four to six weeks, crude oil into less objectionable substances, and industrial sewage into nutrients on which water hyacinth thrives. Apart from holding workshops for industries to introduce OBD* in 1996 and 1997, the researcher however claimed that he has refused to make publication on his discovery in order to keep his patent safe.

Source: Author's field interviews

In spite of the apparent solution to the oil and grease problem, the wastewater effluent treatment system still performs below satisfaction. According to the 1998 environmental audit report, the effluent quality fails to meet regulatory requirement in

\footnotetext{
'Government increased the cost of raw water abstraction by $100 \%$ in 1999.
} 
some key parameters such as ${ }^{9}$ BOD, COD, TSS, nitrate, and DO. With the encouragement of its parent company, the firm has therefore decided to embark on what it called 'cost-effective wastewater treatment' system. The system entails a stateof-the-art secondary industrial wastewater treatment technology incorporating an 'upflow anaerobic sludge blanket reactor' (UABR) and a 'sequence batch reactor' (SBR). The new system is a completely foreign technology to be imported from the Netherlands, and if well operated, will automatically treat the wastewater effluent to satisfy all regulatory demand with respect to effluent quality. The technology is however very expensive as the company claims to be investing about US\$ 1 million on the project. FB1 claims that the cost factor has hitherto been the obstacle to the adoption of this technology. At the time of this research, work has however started on the site where the UABR/SBR will be installed, and the installation is expected to be completed by October 2000. After the installation, the existing three earthen ponds would be closed because they will no more be necessary. The new technology will also generate biogas (methane) which FB1 hope to bottle for sale as fuel gas.

FB1 has operated and maintained the existing biological wastewater treatment technology using in-house technical staff and Nigerian environmental consultants. It is also confident that the in-house technical staff will be able to operate the new and relatively modern treatment system after necessary training, and with occasional consultation with the parent company just like the main production system is maintained.

FB1 claims that the main reasons for the adoption of existing and the new wastewater treatment technology are to prevent environmental incidents; to comply with S.I.8/S.I.9 law; to comply with international norm of the parent company; to improve the firm's environmental image; and as a mark of corporate environmental responsibility. Among these adoption rationales, the improvement of environmental image and pressure due to the implementation of S.I.8/S.I.9 law are considered the most important reasons.

Overall, FB1 believes that investments in environmental management and water pollution control technologies have had no impact on product quality, new product development efforts, and first mover advantage for exports. ${ }^{10}$ The impact is felt only in the contribution to raising production costs. It believes that, though measures that were adopted to reduce wastewater or improve water use economy could significantly contribute to cost reduction on the long run, they could in no way offset the overall cost increases arising from technology adoption for pollution control.

\footnotetext{
BOD, COD, TSS, DO are respectively biochemical oxygen demand, chemical oxygen demand, total suspended solids and dissolved oxygen.

${ }^{10} \mathrm{FB} 1$ currently exports to the UK, USA and West Africa, and it claims UK as its most important export destination.
} 


\section{Firm FB2}

\section{Background and Basic Characteristics}

FB2 is a medium-scale brewing firm, which was completely locally owned until few years ago when some Asian industrialists purchased it. "It produces two brands of larger beer and a non-alcoholic malt drink. At establishment in the early $1980 \mathrm{~s}$, it has a strong technical partnership agreement with a Europe based multinational brewing company. Though the agreement has been formally terminated when the ownership changed, FB2 still benefits technically from the multinational company through the intermediary of a Nigerian brewing firm, ${ }^{12}$ which maintains technical links with the multinational firm. FB2 employs 300 persons, out of which only $20 \%$ have more than secondary education. The plant's workforce includes six Nigerian engineers/scientists, and two foreign engineers. FB2 is an example of a typical local firm producing for only Nigerian market.

\section{Production Technology and Innovation}

Like FB1, this firm also employs conventional brewing technology using completely foreign technology equipment acquired from Italy. The main production facility is only five years old. The capacity utilisation was however only $30 \%$ at the time of this research. Our respondent however expressed optimism that the new democratic dispensation in Nigeria will stimulate a boost in demand for its products, and subsequently lead to the activation of substantial part of the idle capacity. Apart from water, which the firm abstracts from own borehole, other important raw material inputs include sorghum, sugar, caramel, enzymes, and 'chemicals'. Water consumption at the plant is nearly $80,000 \mathrm{hl}$ per month. Sugar, enzymes and chemicals are imported. It is noteworthy that the plant maintains its production on sorghum.

FB2 claims to have an R\&D unit. However, what we saw in the course of this research were no more than a quality control laboratory and some technical personnel that see to the efficient running of the plant. The most important function of the unit is to maintain an efficient operation of the current production technology. The former foreign technical partner remains the most important source of innovation and solution to technical problems relating to the production process.

\section{Environmental Problems and management}

The main environmental problem identified by FB2 is the management of wastewater effluent. All its processing lines generate wastewater. The firm is well acquainted with the regulatory requirements of S.I.8/S.I.9 law. The firm's management regards

\footnotetext{
"These Asians also bought four other brewing plants in Nigeria and organised them under a holding company.

${ }^{12}$ This firm was actually a sister company to FB2. When FB2 terminated its technical agreement with the European multinational, the sister company retains the agreement. The multinational however allows the firm to share technical information arising from the agreement with FB2.
} 
environmental management as important, but not an issue of top priority. It however acknowledges that the enforcement of environmental regulation in recent years has considerably improved their commitment to environmental management. The firm considers regulators' attitude during compliance monitoring co-operative, and their suggestion useful. However, the firm feels that regulators lack enough technical knowledge to advise on the implementation of appropriate water pollution control technologies. For FB2, environmental concerns have been important before the S.I.8/S.I.9 law enforcement process started. However, lack of information on technical options to solve wastewater problems, and the cost implications of implementing pollution control are the two reasons deterring the firm's commitment to environmental management.

The firm has set up an environmental management committee with the quality assurance manager as chairman. However, the committee is yet to clearly articulate a statement of environmental policy or targets. The quality assurance manager recently attended a workshop on pollution control organised for the food \& beverages sector by the environmental enforcement training centre of FEPA. He claimed to have obtained useful information that could help his committee design an effective pollution control strategy for the firm. He stressed that his committee has the objective of reducing all emissions from the firm with wastewater as priority. So far, environmental compliance activities at FB2 have been principally self-monitored. Inspection visits from regulators have been few and irregular except when there is environmental incident.

The firm does not expect stricter environmental regulatory regime in Nigeria, and feel that introduction of effluent charges to control wastewater pollution would be unnecessary. The firm suggests that more attention should be paid to enforcement of existing regulation, and efforts should be made to encourage cleaner production because wastewater treatment is expensive.

\section{Technology Adoption for Water Pollution Control}

Technology adoption for water pollution control at FB2 did not receive substantial attention until an environmental incident occurred in 1996. The firm claimed that it did not consider implementing technical change to abate water pollution prior to 1996 because during the moratorium period (1991-1994) given for firms to comply, there was no serious enforcement activity. ${ }^{13}$ In 1995 the state owned Water Corporation discovered that high cost of water treatment was due to impurities traceable to the wastewater effluent from FB2. Effluent from FB2 flows directly into a perennial stream from which the water corporation abstracts raw water. After repeated warning from SEPA on the need to find acceptable solution was not heeded, SEPA shut down FB2 in 1996. The firm was not allowed to resume production until an agreement was

\footnotetext{
${ }^{13}$ According to FB2, there was only occasional visit from FEPA prior to the establishment of SEPA in 1995. After the establishment of SEPA, the environmental incident was exposed, and SEPA enforced the necessary regulation.
} 
reached on the adoption of a secondary wastewater treatment plant, which was built immediately, and commissioned in 1996. It is however necessary to note that the firm claimed that though regulatory pressure played an important role in the adoption decision, the most important reasons for adoption are to improve the environmental image of the company and to prevent future environmental incident.

The wastewater treatment system is locally designed and constructed. Although the firm and SEPA regard the wastewater treatment facility as an interim solution, the treatment system appears fairly good. It is a very compact system occupying an area of about 150 sq. metre. It consists of locally fabricated tanks and series of concrete basins. The wastewater treatment process include artificial aeration through air injection; coagulation using aluminium sulphate solution; a secondary aeration by further air injection; chlorination for disinfection; $\mathrm{pH}$ correction using calcium hydroxide (lime); and a filtration unit using a galvanised steel plate. The system also incorporates primary and secondary sedimentation. The final effluent is relatively clear, though both FB2 and regulators agree that laboratory analysis has shown that the effluent does not meet regulatory requirement for effluent quality. ${ }^{14}$ The wastewater treatment system is operated and maintained by in-house technical staff at the plant. FB2 claims to be searching for technical assistance on how to improve the efficiency of the existing facility. A chemist, who apparently concentrated on efficient chemical reactions that could neutralise the pollutants, designed the facility. Despite the fact that the firm has no space constraint, the detention time of the wastewater is only 45 minutes. We observed that there was no need to make the system so compact such that there is apparently no sufficient time for biodegradation before the final effluent is released. The firm has contracted an environmental consultant to carry out a comprehensive environmental audit of all activities at FB2 in accordance with regulatory demands. The firm was at the time of this research waiting for the outcome of the audit before taking decision on how to improve the performance of the wastewater treatment plant.

It is also noteworthy that after the environmental incident, the cost of wastewater treatment prompted FB2 to implement measures that reduce wastewater generation. Such action include replacement of old pasteurisers which were leaking due to rust; use of metering devices to control water use; and records of water use for various operational units during each of the firm's three shifts are regularly compared to identify areas of wastage, and prevent such.

As a general observation, FB2 accepts responsibility for taking charge of the environmental consequences of its production activities. However, it appears the firm would have remained nonchalant but for the pressure from the public water corporation and the advent of SEPA, which enforce the statutory expectation with respect to industrial pollution. Moreover, the firm stressed that environmental

\footnotetext{
${ }^{14}$ For example, the firm reported to us that the $\mathrm{BOD}_{5}$ of the final effluent has an average of about $45 \mathrm{mg} / 1$ instead of the standard of not more than $30 \mathrm{mg} /$, and that the wastewater system achieves $70 \% \mathrm{BOD}_{5}$ removal.
} 
management and regulation have led to significant increases in production costs in recent years.

\section{Firm FB3}

\section{Background and Basic Characteristics}

FB3 is located on a large expanse of land acquired within an industrial district. According to our firm size classification (see table 5.1. of chapter 5), FB3 belong to the category of small-scale firms. ${ }^{15}$ However, the firm is a technology intensive firm, and a subsidiary of an American multinational company. The firm was established at the close of the $1980 \mathrm{~s}$, and it is completely foreign owned. It employs less than 50 persons including 11 Nigerian engineers/scientists and one foreign engineer. About four-fifth $(78 \%)$ of its workforce has higher educational qualification. The firm produces a range of intermediate beverage products for Nigerian food and beverages industry.

\section{Production Technology and Innovation}

The firm employs completely foreign technology equipment imported from the United States. The plant operates at $60 \%$ of its installed capacity at the time of this research. All raw material inputs, except water, are imported. The main inputs include caramel, phosphoric acid and flavourings. Water is abstracted from the firm's own borehole.

The plant has no R\&D unit. It concentrates on sustenance of efficient production, and depends absolutely on the parent company for technological knowledge or innovation. This may not be unconnected with the nature of the production process. It is a highly guarded process during which more than 40 different chemicals are mixed or compounded to form concentrates.

\section{Environmental Problems and Management}

The most important environmental problem at the plant is the management of wastewater. It has the reduction of wastewater generation as the main objective of its environmental management activities. The wastewater is essentially process wastewater comprising $\mathrm{CIP}^{16}$ rinse water, container rinse water, floor wash water, and wastewater from backwashing of the factory's water treatment plant. The factory generates an average of about 500 cubic metre wastewater per month. As an affiliate of a reputable multinational company, FB3 claims that environmental issues have been top priority to its management since the inception of production at the plant. It however acknowledges that commitment became more serious after 1994. The plant

\footnotetext{
${ }^{15}$ If sales turnover were used for firm classification, FB3 might interestingly fall into the category of large-scale plants in Nigerian context.
}

${ }^{16}$ 'Clean in place' operation for periodic washing of process lines and equipment. 
practices only total quality management, and it has no statement of environmental policy specific to its Nigerian operation. It claims to be committed to continual improvement in environmental performance with its parent company's statement on environmental responsibility as the guiding principle. Box 8.4 presents the main features of the parent company's environmental statement. Besides, the parent company carries out environmental audit of the plant as part of the regular international auditing of its subsidiaries. At each audit, the parent company checks the level of compliance with its corporate environmental norms and all known local environmental regulation.

Relationship of FB3 with regulators has been co-operative, and regulators rate the company as one of the good environmental performers in Nigerian manufacturing. The firm expects environmental regulation to become stricter in future, and it has plans to keep improving on its investment in environmental management. The firm does not favour introduction of wastewater effluent charge as instrument of water pollution control. Rather, it stresses that government should give tax relief to firms that have invested in pollution control technologies. Moreover, the firm complains that environmental regulation and management have generally had considerable impact on its production costs in the last four years.

Box 8.4: Main features of the statement of environmental responsibility by FB3's parent company

- Operating in an environmentally responsible manner, meeting or exceeding applicable regulatory requirements;

- Minimising environmental impacts through research and the application of new technology;

- Using responsible pollution control practices to minimise environmental discharges;

- Conducting periodic audits of operations to ensure accountability for environmental performance and practices;

- Co-operating with and proactively supporting internal and external efforts that seek solutions to environmental problems; and

- Committing each associate to protecting and preserving the environment.

Source: Parent company's corporate environmental policies and standards (1999).

\section{Technology Adoption for Water Pollution Control}

The plant adopted a secondary wastewater treatment plant at its establishment in the late 1980s. The technology is a multi-filter activated sludge process imported from the United States. The firm ascribed two reasons for adoption: to prevent environmental incident, and in conformity with the environmental norm of the parent company. The 
firm's in-house technical staffs manage the operation and maintenance of the wastewater treatment plant and wastewater re-use measures. The technical staffs have also become the most important source of solution to technical problems associated with the wastewater treatment facility. They were trained initially to manage the plant, and consult the parent company in cases of problems that they could not solve. They have over the years gained competence through learning by doing, and now run the wastewater treatment plant without consulting the parent company. Both regulators and the firm agree that the wastewater technology is efficient, except the inability of the plant to reduce phosphates in effluent to the regulatory acceptable levels. FB3 however complained that the Nigerian standard for phosphate ${ }^{15}$ is too stringent, otherwise the firm would have no problem with phosphate.

The wastewater treatment system incorporates two oil separating tanks which act as oil schemers, and a wastewater reserve tank which has capacity to hold up to 1,300 cubic metres of wastewater. Schemed out oil are manually removed from the oil separating tanks for sale to local informal sector operators. With the advantage of a relatively large wastewater reserve tank, the wastewater treatment is carried out in batches. The treatment process includes colour removal, $\mathrm{pH}$ adjustment, aeration, and chlorination. No wastewater is discharged outside the premises of the factory. The treated wastewater effluent is used to regularly spray the green lawns in the factory's premises by means of spray jets. ${ }^{18}$ The firm is thus able to safe on water abstraction for gardening purposes. Furthermore, there are two aquifer monitoring wells on the green field. The wells ${ }^{19}$ serve as observatory points to periodically confirm that the reuse of treated effluent for spraying the green lawn does not constitute any hazard to underground water.

The firm claimed to have improved on water use economy in recent years for cost related reasons which may not be de-coupled from the need to minimise wastewater generation. Such measures include the introduction of more sensors along the production line to monitor chemical cans as inputs are dispensed into the process line ${ }^{20}$ limiting washwater flow only to when the mechanical washer is operating; and concentration on batch production of single item so that CIP can be delayed to after a relatively long production schedule. In line with the firm's focus on water use economy and wastewater reduction, FB3 claimed that these measures have resulted in economic gains in the past two years. Comparatively less water has been consumed, and there have been less wastewater generation and treatment. The firm however

\footnotetext{
${ }^{17}$ The Nigerian standard for phosphate in wastewater is $5 \mathrm{mg} /$ (see appendix 2).
}

${ }^{18}$ There are 48 sprinklers or spray jets on the field (green lawns).

19 These are shallow wells. The underlying principle is that, wastewater that leaks into these wells cannot be more dangerous than leakage into the aquifer far below. Thus, if water in the observatory wells is safe, then the underground aquifer is safe.

${ }^{20}$ This measure has aided spill prevention, and hence reduces cleaning requirements, chemical loss, and pollutants in wastewater. 
affirmed that such economic gains have not offset the economic implication of wastewater treatment on production costs.

\section{FB4}

\section{Background and Basic Characteristics}

FB4 is a medium-scale soft drink plant producing one of the popular Nigerian nonalcoholic malt drinks. It is an affiliate of a European multinational company, and was established at the close of the $1970 \mathrm{~s}$. The firm is located in a privately organised industrial estate, and it is $60 \%$ Nigerian owned. The firm employs about 160 persons including 13 Nigerian engineers/scientists and one foreign engineer. About one quarter $(26 \%)$ of the workforce have more than secondary education. Its sales turnover in 1998 was 470 million Naira (about US\$ 5.5 million).

\section{Production Technology and Innovation}

The plant employs completely foreign technology equipment, and operates at $40 \%$ of its installed capacity at the time of this research. The main raw material inputs are malt extract, 'compound', sorghum extract, sugar, glucose, and water. Water is abstracted from own borehole; sorghum extract and sugar are obtained locally from Nigerian manufacturers, while the other inputs are imported.

The plant has no R\&D unit, and the parent company is the main source of technological knowledge and innovation. The firm also derives technological knowledge from local and international professional journals on food science and technology.

\section{Environmental Problems and Management}

The main issues of environmental management at FB4 are wastewater and solid wastes. While local contractors handle the solid waste, the wastewater is managed directly by the plant with the quality assurance manager acting as environmental officer of the firm. The wastewater sources are processing water and occasional lubricant spill. The plant claims that environmental management is a top priority, and that it has been committed to improving environmental commitment before the Nigerian regulatory enforcement process began. However, the firm acknowledged that regulatory pressure and the need to prevent environmental incident have had appreciable impact on the firm's commitment to environmental management. This notwithstanding, the relationship with regulators has been co-operative.

The parent company is not involved in monitoring regulatory compliance, and the firm appears to operate without due regard for the environmental norm of the parent company. However, because of Nigerian regulatory pressure, the firm is in the process of carrying out its first comprehensive environmental audit of its activities, and a 
statement of environmental policy is also being prepared. The environmental officer has also embarked on visits to plants identified as good environmental performers to learn from their experiences. The firm expects stricter environmental regulation in future, and supports effluent charges as an instrument of industrial wastewater pollution control. It believes that such will instil discipline in firms with respect to effluent generation, and encourage investment in water pollution control technologies.

\section{Technology Adoption for Water Pollution Control}

FB4 is located in an industrial estate with a central industrial wastewater treatment plant $^{21}$ (see box 8.5). At inception of production, the firm was linked with the estate's sewerage system that carries the wastewater effluent to the treatment facility. However, as environmental regulation became more serious, regulators expressed their dissatisfaction with the central wastewater treatment facility's performance. Firms in the estate therefore decided to individually carry out pre-treatment of their effluent before release into the central wastewater treatment system. This was expected to reduce pollution load being released into the central system, and thereby improve the wastewater treatment facility's efficiency. Accordingly, FB4 adopted a primary sedimentation tank in 1995, and views the adoption rationale as being principally due to pressure arising from environmental regulation. Moreover, the firm claimed that the environmental norm of the parent company gave an added motivation for the adoption decision. In the tank, the wastewater is dosed with alum as coagulant. The sedimentation tank is locally designed and built by a Nigerian engineering firm. Regular operation and maintenance of the primary treatment system are carried out by FB4's in-house technical staff, while the local engineering firm get involved only when technical problem arises.

Furthermore, FB4 introduced the use of a caustic recovery tank in 1995 to reduce caustic soda in wastewater. Apart from regulatory reason for adopting the caustic recovery process, the cost reduction factor also played an important role. The caustic recovered is recycled to be used for further washing. The firm acknowledges that this has led to appreciable economic gains for the plant.

The firm believes that it is better to have own industrial wastewater treatment plant because it would reduce wastewater treatment related expenses. The firm claims that obstacle to adopting own wastewater treatment plant before 1995 were lack of information on water pollution control technologies, and the cost implication of installing and operating an industrial wastewater treatment technology. Moreover, when the firm was established, it was assumed that the central wastewater treatment plant would take adequate care of effluent treatment. Hence, there was no need to bother about investing in additional technology for water pollution control.

\footnotetext{
${ }^{21}$ There are only two centrally operated industrial wastewater treatment plants in Nigeria. The industrial estate management privately manages this, while the other is publicly managed. The publicly managed central wastewater treatment facility is however not functional at the time of this research.
} 
Box 8.5: A centralised industrial wastewater treatment plant.

This centralised industrial wastewater treatment facility is one of the two such plants existing in Nigeria at the time of this research. It is privately owned and managed by the industrial estate management. The plant is a large open pond aerated lagoon designed and built locally in 1975. It is currently operated and maintained by Nigerian engineers stationed at the wastewater treatment plant.

The plant receives effluent only from food \& beverages and pharmaceutical firms. 17 plants are linked to the treatment facility out of which nine were operating at the time of this research. The firms are levied according to the volume of discharge. To qualify for discharge into the facility, a firm must prove type of manufacturing, and analysis is done to confirm quality and nature of effluent. Individual manufacturing plant must at least have a grit chamber and an oil trap/schemer. Firms are generally encouraged to have own primary treatment system. Officers responsible for environmental management at the manufacturing plants also meet regularly to review environmental issues relating to the wastewater treatment plant.

The wastewater treatment system has had no serious problem since inception, except in 1997 when the estate management compelled the engineers operating the facility to accept a batch of wastewater from a chemically contaminated ship. After the incident, regulators temporarily shut down the facility until remedial process was completed to clear off the strange chemical pollution. The wastewater treatment facility consists of three large ponds, surface area of each pond is about $1500 \mathrm{sq}$. metre. Each of the first two ponds has four giant electrically powered aerators. The third pond has no aerator, and serves as a sedimentation basin from which the final supernatant flows into a nearby natural lagoon. The wastewater is recycled continuously from the third to the first pond until the supernatant is allowed to flow out. No detention time is observed at the pond. The treated effluent is let off by rule of thumb. Because the ponds are considerably large, this has constituted no problem. The wastewater is sufficiently recycled before problem of volume constraint could arise. No chemical treatment is carried out except the introduction of chlorination for disinfection after the chemical problem of 1997. De-sludging of the system is done once a year. No drying bed exists. The sludge is disposed off as solid waste through local contractors or taken away by informal sector operators.

A private environmental consultant monitors the effluent quality at the facility. It is generally agreed that the facility is not efficient in bringing effluent quality to the required regulatory standards. Regulators however appear relatively handicapped in applying sanctions to the facility due to the implication for companies linked to the facility. The complex network of socio-political and economic interests involved at the industrial estate appears to constitute a strong deterrent to effective regulatory action on the centralised wastewater treatment plant.

Source: Author's field interviews, company visits, and observations at the centralised industrial wastewater treatment plant. 


\section{Firm FB5}

\section{Background and Basic Characteristics}

FB5 is a relatively old plant established about 40 years ago. It is a medium-scale local soft drinks plant producing a popular brand of cola and orange drinks. The firm employs 350 persons, among who are 20 Nigerian engineers/scientists and one foreign engineer. Only $10 \%$ of the plant's workforce has more than secondary education. The firm is located in an industrial estate in one of Nigerian large cities, and it is $60 \%$ Nigerian owned. It produces under license from the American owners of its range of products. The owners of the plant have five other similar plants in Nigeria.

\section{Production Technology and Innovation}

The plant uses completely foreign technology equipment imported from Germany. The main production equipment was 15 years old at the time of this research. The major raw material inputs are water, concentrate/flavours, acidulants and carbon dioxide. The plant generates its carbon dioxide by burning diesel in its $\mathrm{CO}_{2}$ plant. The plant's water use is about 16,000 cubic metre per month, and it obtains raw water from a tanker service and own borehole. The other major inputs are imported.

The firm has no R\&D unit. It concentrates on efficient operation and maintenance of its production equipment. Whenever there is need for innovation in product or process, the suppliers of the main production equipment and the owner of its brand products serve as the source of technological knowledge and innovation.

\section{Environmental Problems and Management}

The plant's environmental problems include wastewater, solid wastes, air and noise pollution. It however considers the wastewater problem as the most pressing challenge. The wastewater arises from utility water that has been used in bottle washer, cleaning of process lines, and scrubbing of floors. The chiller and boiler also generate some wastewater. The management of the plant claims that it considers environmental concerns as important. It also claims to be committed to environmental management before the S.I.8/S.I.9 law enforcement regime came on course in January 1995. It however acknowledges that commitment became appreciably more serious after 1994.

Although environmental management at the plant is part of the responsibility of the quality assurance manager, the plant manager also pays close attention to environment related issues because of the importance it has gained in recent years. The plant carried out a comprehensive environmental audit of its facilities in 1998. The plant has articulated an environmental policy statement (see box 8.6), and appears to be in the process of implementing other recommendations of the audit report. 
The firm claims that though regulators' attitude is co-operative, they monitor compliance only when pollution problems are reported. In addition, FB5 find regulators' suggestions on technical solution to pollution problems only sometimes useful. Generally, it considers compliance monitoring officials' technical and scientific knowledge of solution to water pollution problems inadequate. The firm expects stricter environmental regulation in future, but does not believe wastewater effluent charges will be a useful instrument to make firms more responsive to the need to control industrial wastewater pollution. It stressed that such a charge will only increase the burden of the consumer as such costs will be transferred to them. This view is important because the firm's market in Nigeria is essentially a duopoly operated by two major companies.

Box 8.6: Summary of FB5's statement of environmental policy

- Manufacture and distribution of high quality products in a manner that is environment friendly;

- Commitment to a programme of efficient use of raw materials, waste minimisation, and a safe working environment: all necessary training and resources will be made to achieve these goals;

- Striving towards environmental sustainability of our business activities through continual review of their impacts on the environment;

- Commitment to environmental management strategy that would ensure compliance with all relevant environmental regulation; and

- Development of partnership with regulatory agencies and the community in which we operate to achieve our environmental management objectives.

Source: Company's environmental policy statement (April, 1999).

\section{Technology Adoption for Water Pollution Control}

So far, FB5 has not adopted technology for water pollution abatement. It only disinfects its raw effluent by chlorination before it flows into a nearby perennial stream. Its reasons for non-adoption include high cost of installing wastewater treatment technology, and high cost of re-engineering that may bring about cleaner production. It also complains of lack of credit facilities to implement such technical change. It however affirms the firm's commitment to build a wastewater treatment plant as recommended by its environmental audit report, and in conformity to regulatory demands. It was nevertheless observed in the course of this research that regulators appear not to mount sufficient pressure that could make FB5 to technologically respond in the near future. This situation is perhaps due to the fact that the raw effluent does not look particularly objectionable because it resembles heavily 
diluted spilled product. ${ }^{22}$ However, from the discharge monitoring reports of 1998 to 1999 , it was observed that key parameter such as $\mathrm{BOD}_{5}$ was consistently beyond the regulatory limit. As a further illustration, table 8.2 indicates the nonconforming effluent parameters normally reported by the discharge monitoring reports submitted monthly to FEPA.

The foregoing notwithstanding, FB5 has introduced a new bottle washer in 1998. The main reason for this was cost reduction motivated. The new technology has led to reduction in both water use and wastewater generation.

Table 8.2: Sample of some effluent parameters in FB5's untreated wastewater.

\begin{tabular}{|c|c|c|}
\hline Parameter & Result & FEPA standard \\
\hline $\mathrm{pH}$ & $9.28^{\circ}$ & $6-9$ \\
\hline Temperature & $30^{\circ} \mathrm{C}$ & $<40^{\circ} \mathrm{C}$ within $15 \mathrm{~m}$ of outfall \\
\hline Total suspended solids $(m g / l)$ & $84^{\circ}$ & 30 \\
\hline Total dissolved solids $(m g / l)$ & 315 & 2,000 \\
\hline $\mathrm{BOD}_{5} @ 20^{\circ} \mathrm{C}$ & $235^{\circ}$ & 30 \\
\hline Oil and grease $(m g / l)$ & $27^{\circ}$ & 10 \\
\hline Copper $(m g / l)$ & 0.01 & $<1.0$ \\
\hline Zinc $(m g / l)$ & 0.04 & $<1.0$ \\
\hline Nitrogen $(m g / l)$ & 3.6 & 20 \\
\hline Phosphorous $(m g /)$ & 0.2 & 5 \\
\hline Total coliform $/ 100 \mathrm{ml}$ & $600^{\circ}$ & 400 \\
\hline
\end{tabular}

* parameters not conforming to standard.

Source: FB5's effluent discharge monitoring report (1999)

${ }^{2 n}$ Moreover, there is no community whose livelihood is directly threatened in nearby vicinity. 


\section{FB6}

\section{Background and Basic Characteristics}

FB6 is a subsidiary of an American multinational company. It was established in the early 1990s through the purchase of the premises of a former pharmaceutical company located in an industrial estate. The plant is a large-scale firm producing a brand of candy sweets. It employs 210 persons, among who are 150 Nigerian engineers/scientists and five foreign engineers/scientist. The firm is $85 \%$ foreign owned. More than $80 \%$ of the employees have university degrees or diplomas. The plant exports to the West African subregion.

\section{Production Technology and Innovation}

The plant uses a completely foreign technology equipment imported from Germany. The first main equipment installed for production was of Indian origin. It was however replaced in 1997 because it was inefficient in meeting the firm's production standards. The plant was operating at $85 \%$ capacity utilisation at the time of this research. With the exception of water, all major raw material inputs are imported. These include glucose, sugar and ascorbic acid (vitamin C). Water is abstracted from two own boreholes, and treated in-house to meet production requirement. The firm maintains a technical service agreement with the supplier of the main production technology.

The senior staffs of the firm have opportunities for regular overseas training. The parent company encourages innovation at the various plant locations, and maintains a functional R\&D unit at each production site. Successful innovation is rewarded by pecuniary awards. However, we observed that innovations appear to be restricted to process or adaptation of equipment to achieve improved productivity. The firm claims that the Nigerian factory, through the ingenuity of one of its process line operators, ${ }^{23}$ recently achieved an outstanding productivity level not matched by any other production site of its parent company. Although the plant claimed to be involved in major product design and development, we could get no record of such during this research. It appears such search effort could be limited because the firm produces a branded product. The firm's sources of technological knowledge include supplier of the main technology equipment, publications from international research institutes on products and processes, in-house R\&D, and the parent company. It claims the internal R\&D to be the most important source of production related technological knowledge, while the parent company has been most important source of technical knowledge that relate to water pollution control.

\section{Environmental Problems and Management}

Among environmental challenges confronting FB6, the problem of wastewater is rated as the most serious. The main sources of wastewater are candy making vessels and

\footnotetext{
${ }^{23}$ The operator was rewarded with shares in the company.
} 
product line washouts. As an affiliate of a multinational corporation, the firm claims that environmental concerns are priority because of the norms of the parent company. The parent company monitors the environmental performance of all subsidiaries. Thus, environmental issue has been addressed since inception of production. The firm has an environmental and health officer, who is responsible for environmental issues at the plant. Environmental management is directed from the headquarters of the parent company, and the standard of environmental management is considered to be the same as that of the parent company.

The firm makes regular discharge monitoring report to FEPA as regulation demands. Regulators' attitude is viewed by FB6 as co-operative. The firm also considers regulators' inspection visits as regular, and their suggestions with respect to technical solution to pollution problems have been useful. However, FB6 claimed that the observed regulatory compliance has rather been due to internal monitoring, monitoring by company's local environmental consultant, and compliance monitoring by the parent company. The monitoring by the parent company is considered to have had the most impact. The firm strives to meet parent company's international standards, and thereby hope to exceed the Nigerian standards.

The firm practices total quality management, and it is ISO 9001 certified. Since establishment, it has adopted the parent company's environmental management system and policy. The environmental management strategy of the company in termed DMWO (designing manufacturing waste out). Based on this strategy the Nigerian subsidiary has developed a comprehensive environmental statement and targets. Box 8.7 presents excerpts from the environmental policy statement. The firm has set a target of reducing liquid and solid wastes by $15 \%$ annually since 1995 . The firm's environmental policy is driven by a commitment to operate in an environmentally responsible manner with emphasis on continuous improvement in the environmental performance of products, packages and processes.

The parent company carries out an annual environmental audit rating of its subsidiaries. Every subsidiary is expected to achieve a rating of nothing less than eight on a scale of 10 . As a rule, any subsidiary that fails to achieve 8 points rating for five consecutive years would be shut down by the parent company. In this respect, FB6 has consistently improved performance since 1995, achieved 8.0 in 1998, and 8.6 in 1999. ${ }^{24}$ To achieve this feat, in between the external environmental audits by the parent company, FB6 also carries out internal environmental self auditing.

The most important impact of regulation and environmental management on the plant is increase in production costs. FB6 does not expect stricter environmental regulation in future, and neither does it support the use of effluent charges for controlling industrial wastewater pollution. It views the current regulatory enforcement regime as weak. It encourages adequate enforcement of existing regulation. After the impact of

\footnotetext{
${ }^{24}$ From the data given to us, FB6 achieved a rating of only 3.8 in 1995. It improved to 5.3 in 1996, 7.4 in 1997, 8.0 in 1998, and 8.6 in 1999.
} 
enforcement is evaluated, then it would be understood whether or not introduction of new instrument would be necessary to stimulate technology responses for abatement or prevention of industrial wastewater pollution.

Box 8.7: Main features of FB6's environmental policy statement

- Ensure products, packaging, and operations are safe for employees, consumers, and the environment;

- Reduce or prevent the environmental impact of our products and packaging in their design, manufacture, distribution, use, and disposal whenever possible;

- Meet or exceed the requirements of all environmental laws and regulations;

- Continually assess implemented environmental technology and programmes, and monitor progress toward environmental goals;

- Provide consumers, customers, employees, communities, public interest groups, and others with relevant and appropriate factual information about the environmental quality of our products, packaging, and operations;

- Ensure every employee understands and is responsible and accountable for incorporating environmental quality considerations in daily business activities; and

- Have operating policies, programmes, and resources in place to implement environmental policy.

Source: Company's statement on environmental quality policy (1999).

\section{Technology Adoption for Water Pollution Control}

In spite of the apparent commitment of FB6 to environmental management, it has not implemented adequate technical change to abate or prevent water pollution. The firm stated that the obstacle to adoption has been the cost implication of technology adoption, and the relatively weak environmental policy enforcement. This suggests that, if policy enforcement has been serious, the firm would have invested more in environmental management (and by implication in pollution control technology) in view of the corporate norm of the parent company. Nonetheless, with the improving environmental awareness in Nigeria, the firm has planned to adopt a secondary wastewater treatment plant to be imported from Western Europe. Discussions on the adoption have reached an advanced stage with FEPA and at the company's management. At the initial stage of the adoption process, there was disagreement with FEPA because FB6 wanted to install an anaerobic digester, whereas FEPA recommended aerated activated sludge system because it is considered to be more efficient in achieving the standard requirement of $\mathrm{BOD}_{5}$ less than $30 \mathrm{mg} /$. FB6 was 
nevertheless allowed to freely make the final decision as long as the achievement of the effluent standard requirements is guaranteed. FB6 agreed to install the aerated activated sludge system only after a visit by the parent company's head of environmental management section. The head of environmental management section advised on the suitability of the aerated activated sludge system as the preferred solution because apart from efficiency reasons, the methane and other gaseous products of the anaerobic digester may constitute another problem for the plant. There was thus a consensus between regulators and FB6 on the choice of technology. The agreement with FEPA stipulated that the wastewater treatment plant should be installed by June 2000 .

Since inception of production, the wastewater is collected in underground reserve tanks, and evacuated periodically by a local contractor to a dumpsite. The dumpsite is a perennial stream, and the plant has a temporary approval for this from the local SEPA. In line with the objective of waste reduction, in 1998 the firm started the recovery and recycling of some of the raw material remains ${ }^{25}$ that used to go into the waste stream. This resulted in sharp decline of the $\mathrm{BOD}_{5}$ of the raw effluent from $1,500-2,000 \mathrm{mg} / \mathrm{l}$ in 1995 to $350-500 \mathrm{mg} / \mathrm{l}$ in 1998 , and the average for 1999 is 232 $\mathrm{mg} / \mathrm{l}$. Furthermore, in the month of June, 1999, the operators of the plant discovered that records showed the plant generated over 60,000 litres of wastewater in the month of April, 1999 when the plant did not produce. The plant's management became curious about the source of the wastewater. Consequently, the company decided to separate process and non-process wastewater. The decision was implemented in November 1999, and wastewater declined dramatically ${ }^{26}$ by $90 \%$. FB6 claims that the impact of the wastewater reduction measures has led to substantial economic gains to the plant in terms of savings in the costs of wastewater disposal.

After the feat achieved in the large reduction in wastewater in November 1999, the firm suggested to regulators the possibility of diluting the wastewater since it is now relatively small. The regulators have rejected this idea, and consented only to possible scaling down of the proposed wastewater treatment plant if the efficiency of the treatment technology will not be jeopardised.

\section{FB7}

\section{Background and Basic Characteristics}

FB7 is one of the foremost food processing firms in Nigeria. It is a very large-scale plant located in the same industrial estate where FB4 is sited. The estate is one of the largest industrial clusters in Nigeria. The firm was established about 40 years ago, and is a subsidiary of an European multinational company. It employs 1131 persons,

\footnotetext{
${ }^{25}$ These include recycled scrap candies. Scrap candies are those that are undersized, oversized or broken during the production process. The sorted candies are recycled during the regeneration and kneading processes.

${ }^{26}$ Wastewater generated in November 1999 was 210,000 litres, while that of December 1999 was only 21,000 litres.
} 
including about 200 Nigerian engineers/scientists and seven foreign/engineers. More than one third $(35 \%)$ of the firm's workforce has more than secondary education. The firm is $43 \%$ Nigerian owned, and its range of products includes cocoa based confectioneries, cereal foods, culinary and seasonings. Its sales turnover in 1998 was 6.1 billion Naira (about US\$ 72 million).

\section{Production Technology and Innovation}

The firm employs relatively sophisticated foreign technology equipment for its production. This appears to conform to its pursuance of cleaner production. The plant operates at $62 \%$ capacity utilisation at the time of this research. The main raw material inputs are water, soya, maize, sorghum extract, sugar, and milk powder. All these are locally sourced except milk powder, which is imported. The company abstracts water from own borehole, and treats it to meet production requirements.

The firm maintains a relatively well equipped R\&D unit. However, the firm disclosed that regional R\&D activities ${ }^{27}$ that would have resided in Nigeria were taken elsewhere because of the uncertain political climate in Nigeria in the mid 1990s. The sources of technological knowledge for both process and product include the parent company, suppliers of main production equipment through feedback and technical service agreement, and firm's in-house R\&D unit. The most important of these with respect to product and process is the parent company, while the plant's R\&D unit is the most important with respect to technical solution to water pollution problems.

\section{Environmental Problems and Management}

The most important environmental problem confronting the firm has been wastewater. The main sources of wastewater are equipment and floor cleaning. Environmental management appears to be appreciably integrated into the production strategies of FB7. The firm is ISO 9001 certified, and it has embarked on its corporate environmental management system that could earn it certification under the ISO 14000 series. $^{28}$ The firm claims that environmental concerns are top priority to its management, and it has always been highly committed to environmental management before Nigerian environmental regulations became effective. The environmental management strategy conforms to the environmental norms and practices of the parent company. The firm considers Nigerian regulators co-operative during regulatory enforcement monitoring, but their suggestions on technical solutions to pollution problems are only sometimes useful.

\footnotetext{
${ }^{27}$ Compared to other affiliates of the parent company, the Nigerian plant is the biggest in West African subregion.

I FB7 has been recognised for very good environmental performance in Nigeria. It has twice won the Nigerian 'environment friendly industry award' for 1995 and 1997; and it emerged first position in the 'first national roll of honour for environmental achievement in the corporate category during the occasion for the celebration of the $10^{\text {th }}$ anniversary of FEPA in 1998.
} 
Based on the parent company's environmental policy, the firm has articulated an environmental policy statement. Box 8.8 gives the main features of FB7's environmental policy statement as presented in the 1998 annual report of the company. The parent company monitors the subsidiary's environmental performance through its annual international environmental auditing. This notwithstanding, the plant considers its own internal environmental self monitoring as the most important for success achieved in environmental management. The firm claimed to be committed to cleaner production, which are sometimes process (or even plant) specific. The plant's philosophy of cleaner production focuses on minimisation of water use in all its production activities in order to reduce wastewater and restrict microbial infection. ${ }^{29}$

The plant expects stricter environmental regulation in future. However, it does not believe the use of wastewater effluent charge could stimulate technology adoption for water pollution control among Nigerian firms. Instead, it suggested a stiff penalty for non compliance as an effective instrument that could stimulate technology adoption to achieve compliance.

Box 8.8: Main features of FB7's environmental policy statement

- Conservation and sustainable utilisation of resources through source reduction;

- Waste minimisation through recycling;

- Monitoring of waste through the life cycle assessment approach;

- Adoption of waste conversion and waste-to-wealth strategy; and

- Self-monitoring and corrective action.

Source: Company's 1998 annual report.

\section{Technology Adoption for Water Pollution Control}

With respect to technology adoption for water pollution control, FB7 has only a primary wastewater treatment as prelude to the release of its effluent to the centralised industrial wastewater treatment system (see box 8.5). The primary wastewater treatment was adopted in 1995. It consists of oil and grease traps and a locally designed and fabricated sedimentation tank. The reasons listed for adoption include prevention of environmental incident; compliance with international norm of parent company; compliance with Nigerian environmental regulation; and to improve environmental image of company. The prevention of environmental incident is considered the most important, followed by the environmental norm of parent

\footnotetext{
${ }^{29}$ In most food processing, more water increases the likelihood of microbe infection.
} 
company. The only reason the firm considers as obstacle to adoption before 1995 is the cost implication of adoption. The plant provides technical support for the central wastewater treatment plant. It helps in wastewater analysis in its well-equipped laboratory, and facilitates the meetings of officers responsible for environmental management in the industrial estate.

It is however necessary to state that FB7 considers its cleaner production endeavour as the most important technical solution to water pollution problems. It claims that environmental reasons override cost reduction reasons in its adoption of cleaner technology for production. In pursuance of its waste minimisation strategy, the firm adopted a spent grain drier in 1998. Though the adoption was borne out of environmental rationale, it achieved both environmental and economic objectives. The spent grain drier turns wet spent grains such as malt extracts into animal feeds, which are bagged for sale. The drying process helps reduction in wastewater due to water evaporation and reduction of spent grain particles that would have entered the wastewater stream. The firm claims that these water pollution prevention measures have led to considerable economic gain for the plant, and the gains have offset perceived costs of environmental regulation and management.

The important sources of solution to technical problems relating to the firm's wastewater treatment technology and cleaner production systems are firm's in-house technical staff; firm's parent company; and Nigerian engineering maintenance firms. The most important of these is the firm's in-house technical staff; and the firm considers itself very successful with respect to technical capability in managing its water pollution control technologies.

\section{FB8}

\section{Background and Basic Characteristics}

FB8 is a typical Nigerian small-scale industry that has survived the apparently unstable economic policy environment in which Nigerian firms operate. The firm was established over 30 years ago as a small-scale family production outfit. The owner of the firm is the general manager of the company. The plant is $80 \%$ Nigerian owned, the balance share of $20 \%$ is held by a foreign family relation. At the time of this research, FB8 employs 40 people, among who are four Nigerian engineers/scientists. $15 \%$ of its workforce has more than secondary education. Its range of products, which has been maintained over the years, includes peanut butter, jams and marmalade, and cocoa beverages repack. The sales turnover in 1998 was 8 million Naira (about US\$ $94,000.00)$.

\section{Production Technology and Innovation}

The plant employs locally fabricated equipment for its production activities. The firm affirms that these equipment are cheap, reliable, locally maintained, and have the 
advantage of labour intensive. The oldest vintage among the equipment currently in use at the time of this research is 8 years. The capacity utilisation at the plant has been only $20 \%$, largely due to power supply problems. ${ }^{30}$ The main raw material inputs are water, fruits, flavourings, cake ingredients, and cocoa powder. All inputs except flavourings are obtained locally. Water is pumped to the factory from a private dam, and is treated in-house to suit production requirements.

The firm also claimed to have a small R\&D unit, from where some experimentation takes place. We however observed that the unit functions more as a quality control unit, and perhaps as a source of minor innovations in process and product. The firm considers an international research institute ${ }^{31}$ in Nigeria as its most important source of technological knowledge. Other sources of technological knowledge include supplier of the main production equipment and in-house R\&D.

\section{Environmental Problems and Management}

The environmental problem of the firm includes wastewater, solid waste, noise and air pollution. According to FB8, the most important environmental problem facing the firm is that of air pollution arising from dust particulate in the packaging section of the plant. Wastewater is also acknowledged as an important issue but not a challenge that raises serious environmental concern. Sources of wastewater include washing of fruits, an essential raw material, and the cleaning of production equipment. The firm does not see reason why it should bother about water pollution while the public authorities could not even guarantee adequate water supply. The firm stresses that its concern about environmental management with respect to water has to do only with safe water supply for its use. Furthermore, the firm considers it unfair for regulators to expect wastewater treatment from small firms because they generally lack resources to implement such a technology. The firm disclosed that regulators' inspection visits have not been regular, and it is not aware of the specific regulatory standards with respect to industrial wastewater pollution control. The firm however acknowledged that it has become fairly committed to environmental management after 1994 when regulatory issues gained public emphasis. For the firm, this has led to added costs. FB8 however believes introduction of wastewater effluent charge could be effective for industrial water pollution control among small firms if government will supply portable water to industry, and take up the responsibility of treating wastewater, for example, in a centralised industrial wastewater treatment system.

\section{Technology Adoption for Water pollution Control}

As already indicated, FB8 has no record of technology adoption for water pollution control, and the environmental regulatory regime has not exerted appreciable pressure

\footnotetext{
${ }^{30}$ FB8 recently lost its electricity generator to thieves. At the time of this research, the plant operates only when there is public power supply, which is highly unreliable.

${ }^{31}$ The institute is International Institute of Tropical Agriculture (IITA). Its headquarters is in Nigeria, and its main objective is to research into production and processing of existing and new varieties of agricultural products in sub-Saharan Africa. FB8 has benefited from some of IITA technology diffusion programmes.
} 
in this respect. As far as FB8 is concerned, external diseconomy from its wastewater is minimal, if at all appreciable. The wastewater from the factory is channelled directly into the company's orchard and piggery farm. Thus, for the firm, the wastewater serves an economic purpose.

The firm however acknowledges the following as obstacles to adoption of technology for water pollution control: high cost of wastewater treatment technology or process related techniques that may reduce wastewater; lack of information on pollution control technologies; lack of technical capability to manage pollution control technologies; and no compelling reason for adoption. Lack of compelling rationale for adoption is considered the most important obstacle by FB8, followed by the high costs reason.

\section{FB9}

\section{Background and Basic Characteristics}

FB9 is a large-scale dairy product plant established nearly 40 years ago. It employs 477 persons including 30 Nigerian engineers/scientists and one foreign engineer. The firm is $20 \%$ Nigerian owned, and the owners of the plant have one other similar plant in Nigeria. One fifth $(20 \%)$ of the plant's workforce have higher or more than secondary education. Its range of products include yoghurt, chocolate milk, ice cream, pineapple, orange and blackcurrant drinks.

\section{Production Technology and Innovation}

The plant employs relatively modern foreign technology equipment largely acquired during a major re-engineering of its facilities in 1985. The capacity utilisation at the plant was only $20 \%$ at the time of this research, but the plant manger is hopeful that the situation will improve because of the economic policy of the new democratic government in Nigeria. The main raw material inputs are skimmed milk powder, cocoa powder, refined palm kernel oil, and water. All major inputs are obtained locally except skimmed milk powder, which is imported. Water use is about 8000 cubic metre per month, and is obtained from various sources ${ }^{32}$ and treated in-house to meet production requirements.

The firm has an R\&D unit, which according to FB9, carries out both major and minor product design and development. It appears there is some substance in this claim because apart from the yoghurt and chocolate milk, which the company was previously identified with, other products are relatively new and Nigerian market specific. The plant also has an engineering unit which works with the R\&D unit not only to ensure efficient operation of current production technology, but also to achieve improved technical performance. The firm also maintains technical agreement with a

\footnotetext{
${ }^{32}$ Public water supply, tanker service and own borehole.
} 
foreign technical partner for occasional problems beyond the capability of local staff. The firm regards the foreign technical partners as the most important source of technological knowledge and innovation, especially with respect to process.

\section{Environmental Problems and Management}

The plant's management views environmental issues as important, but acknowledges that its commitment in this respect has been low until regulation enforcement process set in early 1995. The firm disclosed that regulators' attitude has been co-operative, but inspection visits have been only once in a while. In 1995, the firm commissioned an environmental consultant to carry out a comprehensive auditing of its facilities. It appears the recommendations of the audit are being implemented, but at a relatively slow pace because of economic constraints. The plant has been under economic stress, and would have closed down but for the intervention of its technical partners who injected new fund into the company in 1998.

The main environmental problem at the plant is wastewater. The wastewater is essentially acidic ${ }^{33}$ organic dairy effluent generated during equipment washing and from the packaging section during product filling. The firm practices total quality management, and embarks on environmental management because of Nigerian regulatory demands and the need to give the company a good environmental image. The plant has recently set up an environmental management committee to oversee environmental concerns of the plant. The committee is directed by the plant's senior research and development manager, and has the reduction of wastewater generation as the main target. The firm is planning to articulate company's environmental policy statement at the time of this research. The firm expects stricter environmental regulation in future because it believes that global trends will influence Nigeria. It however does not support the use of wastewater effluent charge in Nigeria because it would be difficult to administer.

\section{Technology Adoption for Water Pollution Control}

In view of increasing environmental awareness and regulatory demands in Nigeria, FB9 has decided to adopt a secondary wastewater treatment technology. The site for the installation has been cleared at the time of this research. The firm affirmed that the only obstacle to adoption has been the high cost of installing and operating a wastewater treatment technology. Meanwhile, in line with its objective of reducing wastewater, the firm has introduced water recycling. The rationale for water recycling are however environmental and economic. Water abstraction has become more expensive, ${ }^{34}$ and through recycling FB9 claimed to have made substantial savings in costs.

\footnotetext{
${ }^{33}$ The characteristic acidic nature of dairy effluents results from the fermentation of milk sugar to lactic acid. In the case of FB9, the 1995 environmental audit report gave the combined factory wastewater effluent pH of 4.62 .

${ }^{34}$ Water rate for industrial facilities was increased by $100 \%$ in 1999.
} 


\section{FB10}

\section{Background and Basic Characteristics}

FB10 is a large-scale plant established nearly 20 years ago. It is located in the same industrial estate where FB4 is sited. It is a subsidiary of an European multinational company. Its range of products includes vegetable oil, bakery fats, margarine, seasonings, and tea. The plant also produces some intermediate products for confectionery and beverages subsectors. The firm employs 248 persons including 19 Nigerian engineers/scientists and one foreign engineer. Nearly two-fifth $(38 \%)$ of the workforce has more than secondary education. The firm is $48 \%$ Nigerian owned. The owners of the plant have three other plants producing different consumer products in Nigeria. The firm exports its products to West African subregion.

\section{Production Technology and Innovation}

The firm employs a combination of local and foreign technology equipment. The firm operates at $60 \%$ capacity utilisation at the time of this research. The most important source of technological knowledge is the parent company. The main raw material inputs are palm kernel oil, palm oil, milk, salt and water. All major inputs are locally sourced except milk, which is imported. Water consumption at the plant is about 22,000 cubic metre per month, and it is abstracted from own borehole.

The firm has a relatively well-equipped and functional R\&D unit. Though the unit engages in major product design, ${ }^{35}$ its efforts are directed more towards improvement of the technical performance of the current technology.

\section{Environmental Problems and Management}

The most important environmental problem of FB10 is wastewater generation as industrial liquid waste. The most important source of wastewater is the vegetable oil refinery operation. Environmental issues are top priority to the management of the plant, and it has been committed to environmental management since inception of production. The plant has an environmental manager, and the plant manager also take special interest in environment related issues. FB10 however acknowledged that though environmental commitment has increased since early 1995, the level of environmental management and practice at the plant is lower than that of the parent company. The most important reasons for the firm's environmental management initiatives are to comply with the Nigerian regulation and prevention of environmental incidents. The environmental management objective has the reduction of wastewater as the main target. The firm has an environmental policy statement, which is reviewed annually. Main features of the current statement are presented in box 8.9.

\footnotetext{
${ }^{35}$ In addition to its branded products, the firm has successfully designed and produced essentially Nigerian edible products.
} 
The firm practices total quality management, and eco-auditing of its products and processes. Regulatory enforcement monitoring is mainly internal self-monitoring and external monitoring by the parent company. International auditors from the parent company regularly carry out environmental auditing of the plant's activities. Although the firm regards Nigerian regulators' attitude to enforcement monitoring as cooperative, inspection visit is only once in a while. Regulators' suggestions on technical solutions to water pollution problems have however been useful.

FB10 expects stricter environmental regulations in future, and believes wastewater effluent charge could be an effective instrument to make firms implement technical change for water pollution control. It however suggested that such a policy should be supplemented with tax relief on investments in technology for water pollution control.

Box 8.9: Main features of FBI0's environmental policy statement

- Operate to the best standards of industry, meeting the requirements of all relevant regulation;

- Provide environmental training and awareness programmes to ensure support for positive environmental attitudes at all levels of the company;

- Reduce wastes, conserve energy and explore opportunities for reuse and recycling:

- Review and continuously improve the performance of its products, services and operations with a view to contain their environmental impact, well within legal limits;

- Support the development and implementation of technologies which reduce environmental impact;

- Manufacture and market products whose use or disposal have minimum adverse impact on environment;

- Work in co-operation with members of industry, govemment bodies, non-governmental organisations, suppliers and customers to promote the achievement of high standards of environmental care and protection;

- Ensure that adequate plans are made to limit the adverse consequences of any failure in preventive measures that may impact on the environment through programmes of emergency preparedness;

- Operate a programme of corporate environmental audits to ensure compliance with company and legal standards; and

- Provide necessary resources aimed at achieving the intent of this policy.

Source: Company's statement on environmental policy (August, 1999). 


\section{Technology Adoption for Water Pollution Control}

As already indicated, FB10 is located in the large industrial estate with centralised industrial wastewater treatment system. However, due to the nature of the refinery process $^{36}$ involved in FB10's operation, the firm adopted a secondary wastewater treatment plant since inception of production in 1983. The system is a combination of local and foreign technology equipment. The technology has fat traps and oil separators. It serves as a pre-treatment facility prior to final treatment in the centralised wastewater treatment plant (see box 8.5). FB10 engages Nigerian engineering firms and the parent company in solving technical problems relating to the wastewater treatment plant. However, the firm's in-house technical staffs serve as the most important source of solution to technical problems relating to the wastewater treatment plant. The wastewater treatment facility was designed as an appendage to the process lines because the factory's vegetable oil refinery is relatively large. The reasons ascribed for adoption are compliance with the environmental norm of the parent company and prevention of environmental incidents. However, the wastewater treatment plant generates fat residue, which is an important input for soap making plants. $^{37}$ Thus, there is an important economic reason for the adoption of the wastewater treatment plant at the inception of production. Oil and fats are manually collected from the oil separators and fat traps.

In line with the firm's commitment to wastewater reduction, wastewater is recycled back for flushing the refinery after the oils and fats have been separated. Though this has environmental benign outcome, the motivation for it is economic. It enhances the amount of oils and fats recoverable from the wastewater. FB10 also disclosed that it is committed to good water house keeping to minimise costs and for environmental reasons. There is metering everywhere along the lines, monitoring water use at various locations and for specific production processes. Overall, the firm stressed that the water pollution prevention measures have led to economic gains for the plant.

The firm claimed to be committed to further improvement in its technologies for water pollution control, and in this respect, advocates for credit facilities from government. Besides, the international auditors from the parent company are not satisfied with the existing wastewater treatment system. Presently, the plant is planning to install an advanced wastewater treatment technology to make its environmental performance conform to the international norm of the parent company.

\footnotetext{
${ }^{3}$ The refinery generates about 4,000 cubic metre of very dirty wastewater per month.

"Actually, fats and oils are collected from the wastewater treatment facility and sold to soap makers.
} 


\subsection{The Case Studies: Firms in the Textiles Sector}

As earlier mentioned in the introduction, we have only two firms in the textile industry case studies. One firm is a case of adopter multinational affiliate, while the other firm is a case of adopter local firm.

\section{TE1}

\section{Background and Basic Characteristics}

TE1 is one of the oldest textile plants in Nigeria. It was established in the mid 1960s, and is an affiliate of an Asian based multinational company. It is a large-scale plant employing 700 persons including 50 Nigerian engineers/scientists and seven foreign engineers/scientists. One quarter of its workforce have more than secondary education. The firm is $40 \%$ Nigerian owned, and produces African prints. The owners of the plant have another plant, which produces gray cloth in Nigeria.

\section{Production Technology and Innovation}

The firm uses completely foreign technology equipment for production. The equipment came from four countries: Germany, the Netherlands, China and India. The firm operates at $65 \%$ capacity utilisation at the time of this research. The major raw material inputs of TE1 are dyestuff, 'chemicals', gray cloth, and water. The chemicals are partially locally sourced, dyestuff is obtained locally, and a sister company supplies gray cloth. Water is abstracted from own borehole.

The plant has a R\&D unit, which engages in product design and development. The unit and the technical department also work together on minor search activities aimed at improving the performance of the current production technology. The firm considers this as the most important function of the R\&D unit. The firm maintains a technical service agreement with suppliers of the production technology. Local staffs generally maintain the plant's production facilities. Only for occasional intractable problems are the suppliers of the production technology invited. For TE1, sources of technological knowledge or innovation include the suppliers of the main production equipment, the firm's in-house R\&D and the parent company. The parent company however serves as the most important source of technological knowledge both for production and water pollution control.

\section{Environmental Problems and Management}

Environmental problems at TE1 are diverse, but the most important according the plant manager is the wastewater problem. The wastewater is heavily coloured and has its main source at the printing and dyeing departments. The firm considers environmental management an issue of top priority. The firm claimed to embark on 
environmental management to prevent environmental incident, and to evolve an integration of environmental issues into the overall firm strategy.

Regulators' attitude is regarded as co-operative, their suggestions on technical solution to water pollution problems useful, and inspection visits are considered regular and effective. Though the plant claimed that its level of environmental management is the same as that of the parent company, the parent company is not involved in the compliance monitoring. The firm carries out internal self-monitoring. The firm considers the internal self monitoring very helpful in making the firm to achieve its present level of compliance.

The firm has set up an environmental management committee under the office of the plant manger. It started to consider options for seriously abating water pollution after the enactment of the S.I.8/S.I.9 law in 1991. TE1 acknowledged that it became more committed to environmental management between 1991 and 1994. It commissioned its first environmental audit report in 1995 and engaged the services of an environmental consultant as adviser to the company on environmental issues. The environmental consultant monitors the firm's compliance with national regulations, and submits monthly discharge monitoring reports to the regulatory authorities in behalf of TE1. Though the firm has no statement of environmental policy, it has set reduction in wastewater generation as the main objective of environmental management. It is one of the few Nigerian firms that have done repeated (or reviewed) environmental auditing of its activities. The plants environmental audit report of 1999 showed that the firm has achieved considerable reduction in wastewater between 1995 and 1999. Using the firm's main product ${ }^{38}$ as an indicator of total production level, table 8.3 shows that, compare to 1995 , its output increased slightly, but wastewater generation was reduced by more than $30 \%$.

TE1 expects stricter environmental regulation in future. However, it does not believe introduction of wastewater effluent charge will help firms' technology response for pollution control because most firms will view it as another means of government tax that results only in cost increases for firms.

Table 8.3: Wastewater reduction at TE1

\begin{tabular}{ccc}
\hline Year & $\begin{array}{c}\text { Output } \\
\text { (metres of African prints) }\end{array}$ & $\begin{array}{c}\text { Wastewater produced } \\
\text { (cubic metre/day) }\end{array}$ \\
\hline 1995 & 88,000 & 2160 \\
1999 & 90,000 & 1440 \\
\hline
\end{tabular}

Source: TEl environmental audit reports $(1995,1999)$

\footnotetext{
As reported by the company's 1995 and 1999 environmental audit reports, the firm produced only $2,000 \mathrm{~m}$ and $2,500 \mathrm{~m}$ of other textile items in 1995 and 1999 respectively.
} 


\section{Technology Adoption for Water Pollution Control}

TE1 has adopted a tertiary wastewater treatment system for water pollution abatement since 1997. The wastewater system is a completely foreign technology equipment imported from India. It is relatively compact, and employs a trickling filter technology. The adoption was sequel to the recommendations of the environmental audit report of 1995. The rationales for adoption include prevention of environmental incidents; compliance with international norm of parent company; improvement of environmental image of company; and compliance with Nigerian environmental laws. Among these, prevention of environmental incidents is ranked most important, followed by compliance with international norm of parent company. The treatment process is relatively comprehensive and the resulting treated effluent appreciably complies with regulatory requirements. The wastewater treatment system includes oil traps/separators; effluent reaction tanks where coagulation, $\mathrm{pH}$ correction and colour removal take place with the aid of polyelectrolite, lime, and ferrous sulphate respectively; primary and secondary sedimentation units; two primary filters; and one master filter. As an illustration of the treatment plant's efficiency, table 8.4 shows a recent effluent analysis result. However, the firm complains of not only high cost of adoption, but also high operating cost arising mainly from cost of chemicals required for wastewater treatment. ${ }^{39}$ TE1 imports most of the wastewater treatment chemicals. The R\&D unit and the technical department have been involved in activities aimed at improving the performance of the wastewater treatment plant.

Waste oil is manually recovered from the oil separators, and is sold to the informal sector operators who use it for firing purposes. The plant has also adopted caustic soda recovery system, size trap, and steam trap in a bid to minimise wastewater and improve on wastewater effluent quality. However, all these measures have potential cost reduction motives, which serve as added incentive for adoption. The firm however stressed that the economic gains from these measures could in no way offset the cost increase arising from wastewater treatment.

\footnotetext{
${ }^{30}$ The industrial wastewater treatment plant was installed by the firm at a cost of 20 million Naira (about USS $235,000.00$ ) in 1997. At the time of this research, TE1 was spending 100,000 Naira (about USS 1,000) per month to buy chemicals for wastewater treatment.
} 
Table 8.4: Result of physico-chemical analysis of TE1 wastewater effluent (March, 2000)

\begin{tabular}{lccc}
\hline Parameter & Raw effluent & Treated effluent & FEPA standard \\
\hline Colour $(p t-c o)$ & 200 & 15 & 7 \\
pH & 10.08 & 6.05 & $6-9$ \\
Total dissolved solid $(m g /)$ & 2412 & 214 & 2,000 \\
Total suspended solid $(m g /)$ & 612 & 38 & 30 \\
BOD $(m g / l)$ & 112.5 & 28.2 & 30 \\
COD $(m g /)$ & 805 & 99 & 80 \\
Detergent $(m g /)$ & 4.0 & 0.55 & 15 \\
Iron $(m g / l)$ & 4.4 & 2.2 & 20 \\
Copper $(m g /)$ & 0.2 & 0.2 & $<1$ \\
Calcium $(m g /)$ & 10.5 & 4.85 & 200 \\
Magnesium $(m g /)$ & 14.45 & 9.03 & 200 \\
Zinc $(m g / l)$ & 0.62 & 0.25 & $<1$ \\
Sulphate $(m g / l)$ & 180.0 & 30.0 & 500 \\
Chloride $(m g /)$ & 37.49 & 2.0 & 600 \\
Nitrate $(m g / l)$ & 22.15 & 4.43 & 20 \\
\hline
\end{tabular}

* the only parameter not conforming to FEPA standard

Source: Company's discharge monitoring report for March, 2000.

\section{TE2}

\section{Background and Basic Characteristics}

TE2 was established in the late $1970 \mathrm{~s}$, and is an example of a local large-scale textile plant. It employs 376 persons, among who are 17 Nigerian engineers/scientists and seven foreign engineers/scientists. $35 \%$ of its workforce has more than secondary education. Like TE1, the plant also engages in the manufacture of African fabrics. The plant is however only $30 \%$ Nigerian owned. Some Chinese entrepreneurs bought the 
majority share in the company few years ago. The firm's sales turnover in 1998 was 423 million Naira (about US\$ 5 million).

\section{Production Technology and Innovation}

The plant uses completely foreign technology equipment of Chinese origin. The company presently operates at only $20 \%$ capacity utilisation, but hopes to reactivate some of the idle capacity in the near future. The capacity utilisation is actually presently so low because the plant has suspended production in its large-scale spinning section. TE2 considers spinning as currently uneconomical for the plant. It buys yarn and weave. TE2's main raw material inputs are dyes, 'chemicals', cotton yarns and water. Water is abstracted from own borehole, while other major inputs except cotton yarns are imported.

The firm has an engineering section, which maintains and oversees the efficient operation of the production equipment. The firm has no R\&D unit, and depends on its foreign technical partners for innovation both in process and product.

\section{Environmental Problems and Management}

Since TE1 and TE2 manufacture the same type of fabrics, as expected, their environmental problems are also identical. Major problem is wastewater effluents arising from liquid effluents of textile dyes and chemicals used in printing and dyeing departments. The only additional problem at TE2 is the problem arising from the use of wax $^{40}$ which TE1 does not use. TE2 claimed that it considers environmental management a top priority issue. However, the firm disclosed that commitment to environmental management was a post 1994 occurrence at the plant. The plant has an environmental management committee comprising the assistant general manager, technical director, and the wastewater treatment plant operator.

With respect to regulation compliance monitoring, TE2 considers regulators' attitude as co-operative, and their suggestions on technical solution to pollution problems very useful. However, regulators' inspection visits have not been regular except when there is environmental incident or problem. The firm's main reasons for environmental management are to comply with Nigerian environmental regulatory standards and to pacify local communities complaining about its wastewater effluents. Since 1996, the plant has had problems with neighbouring communities, which complained about leakage of textile wastewater into their wells, and thereby rendering the well water undrinkable. ${ }^{41}$ The problem is yet unresolved, and the community involved has filed a court action against the firm.

\footnotetext{
${ }^{40}$ Since 1998, TE2 manufactures some African wax prints.

41 A casual view of the vicinity around TE2 shows that the plant is located at a relatively higher altitude compared to the surrounding local community. Hence, it is plausible that wastewater leakage could be a problem for nearby wells. The community demanded that the firm should pipe away the effluent to bypass the community. The firm refused because such has no regulatory backing. Besides, it is a costlier alternative in
} 
The most important impact of environmental management and regulation at TE2 is the increase in production costs. The firm expects stricter environmental regulation in future because of the growing importance of environmental awareness in Nigeria. However, the firm does not believe effluent charge on wastewater could guarantee technology adoption for water pollution control. Firms will likely consider it as tax, pay it, and continue to pollute. TE2 suggested that government should rather consider subsidies or tax relief for plants that have invested in technology for pollution control.

\section{Technology Adoption for Water Pollution Control}

TE2 adopted a secondary wastewater treatment plant in 1998, after a period of partial closure of the plant by the local SEPA. SEPA had to close the dyeing and printing section of the plant because the plant refused to comply with the advice and warnings of the agency on the need to adopt an industrial wastewater treatment plant. Moreover, the pressure from the neighbouring community was much. The adopted wastewater treatment technology was locally designed and installed by a Nigerian environmental consulting firm. The system has a combination of local and foreign technology equipment. It incorporates oil traps/schemers, ${ }^{42}$ ferrous and aluminium sulphate dosing units, four large open concrete ponds, eight filters in series with fine granite sand and activated carbon, two pumping machines, and a final pond where final effluent collects before discharge into a nearby stream. The reasons given for adoption are prevention of environmental incidents; pacification of local communities around the plant; compliance with Nigerian environmental laws; and to improve the environmental image of the company. Among these, the prevention of environmental incident is considered by TE2 as most important reason for adoption, followed by the pacification of local communities. The performance of the wastewater treatment technology has however not been satisfactory, and regulatory pressure persists on the need to make discharged effluent parameters comply with permissible standards.

Also in 1998, when the plant started to produce wax prints, it introduced a wax recovery system. Though the system helps to reduce the amount of wax that gets into the wastewater stream, the rationale for adopting the wax recovery system was economic. Wax is imported, and Nigerian textile manufacturers consider the foreign exchange gains in repeated use of the same wax stream significant.

With respect to obstacle to adoption before 1998, the firm claims that high costs of water pollution control technologies have been the main hindrance. For solution to technical problems relating to its water pollution control technologies, the firm uses Nigerian engineering firms and in-house technical staffs.

\footnotetext{
comparison to effluent treatment. The deadlock resulted in the community instituting a court action against the firm.

Waste oil recovered from this unit is sold to the informal sector operators.
} 


\subsection{Conclusion}

In the foregoing discussion of the twelve case studies, we have endeavoured to briefly depict the characteristic background of each firm, and the key features of its production technology and innovation activities. For each case study, we have also presented the main environmental problems and management strategies, the nature and type of technical change for water pollution control, with a view of exposing the underlying rationales for the technology responses observed. In this concluding section, we shall give an overview of the reasons for adoption, and ascertain their relevance with respect to our major versus auxiliary driver hypothesis for technology responses for industrial wastewater pollution abatement/prevention in Nigerian manufacturing industry.

We have in chapter 7 demonstrated that the hypothesis $\mathrm{Hl}$, which postulated environmental policy as the major driver of the adoption of environmentally benign technologies (EBTs) in Nigerian manufacturing can not he validated hv the emnirical evidence from our sector-wide survey data. From further insights as given by the case studies, it appears that environmental policy is an important stimulus for the environmentally benign technical change observed. However, it is difficult to affirm environmental policy as the major driver of EBT adoption. The case studies suggest that the effective implementation of the Nigerian environmental policy in 1995 was a premise on which other reasons acted to stimulate technology adoption for water pollution control. The case study summaries in tables 8.5 and 8.6 demonstrate that some other reasons may take precedence over environmental policy as stimuli for the adoption of EBTs. As shown in the case studies' summary in table 8.5, the following reasons appear prevalent as adoption causalities with respect to technology response for water pollution abatement (TPA):

- prevention of environmental incident;

- parent company's environmental norm;

- improvement of company's environmental image;

- regulatory pressure; and

- pacification of community pressure 
Table 8.5: Summary of reasons for TPA adoption by case study firms

\begin{tabular}{|l|l|c|l|}
\hline Firm & \multicolumn{1}{|c|}{$\begin{array}{c}\text { Subsector } \\
\text { or sector }\end{array}$} & $\begin{array}{c}\text { Type of TPA } \\
\text { adopted }\end{array}$ & \multicolumn{1}{c|}{$\begin{array}{c}\text { Two reasons for adoption } \\
\text { (listed in order of importance) }\end{array}$} \\
\hline FB1 & Brewing & $b$ & Environmental image; regulatory pressure \\
\hline FB2 & Brewing & $b$ & Environmental image; prevent environmental incident \\
\hline FB3 & Soft drink & $a$ & Prevent environmental incident; parent company's environmental norm \\
\hline FB4 & Soft drink & $a$ & Regulatory pressure; parent company's environmental norm \\
\hline FB5 & Soft drink & - & $n \cdot a$. \\
\hline FB6 & Confectionery & - & $n \cdot a$. \\
\hline FB7 & Confectionery & $a$ & Prevent environmental incident; parent company's environmental norm \\
\hline FB8 & Confectionery & - & $n \cdot a$. \\
\hline FB9 & Dairy products & - & $n \cdot a$. \\
\hline FB10 & Vegetable oil & $b$ & Parent company's environmental norm; prevent environmental incident \\
\hline & & & \\
\hline TE1 & Textile & $c$ & Prevent environmental incident; parent company's environmental norm \\
\hline TE2 & Textile & $c$ & Prevent environmental incident; pacify community pressure \\
\hline
\end{tabular}

1: $a=$ primary industrial wastewater treatment plant

$b=$ secondary industrial wastewater treatment plant

$c=$ advanced industrial wastewater treatment plant

n.a. $=$ not applicable

Source: Author's field data 
Table 8.6: Summary of reasons for TPP adoption by case study firms

\begin{tabular}{|c|c|c|c|c|c|c|}
\hline Firm & $\begin{array}{l}\text { Subsector } \\
\text { or sector }\end{array}$ & $\begin{array}{c}\text { Type of } \\
\text { TPP } \\
\text { adopted }^{\prime}\end{array}$ & $\begin{array}{l}\text { Two reasons for adoption } \\
\text { (listed in order of importance) }\end{array}$ & $\begin{array}{l}\text { Cost reduction offset } \\
\text { compliance costs? }\end{array}$ & $\begin{array}{l}\text { Favour effluent } \\
\text { charge? }\end{array}$ & $\begin{array}{l}\text { Expect stricter } \\
\text { regulation? }\end{array}$ \\
\hline FB1 & Brewing & d,e & Cost reduction; environmental regulation & No & No & Yes \\
\hline FB2 & Brewing & $g$ & Cost reduction & No & No & No \\
\hline FB3 & Soft drink & $d$ & Costs reduction; environmental regulation & No & No & Yes \\
\hline FB4 & Soft drink & $g$ & Cost reduction; environmental regulation & No & Yes & Yes \\
\hline FB5 & Soft drink & $g$ & Cost reduction & No & No & Yes \\
\hline FB6 & Confectionery & $e$ & Environmental regulation & No & No & No \\
\hline FB7 & Confectionery & $g$ & Environmental regulation; cost reduction & Yes & No & Yes \\
\hline FB8 & Confectionery & - & n.a. & n.a. & No & Can't say \\
\hline FB9 & Dairy products & $d$ & Cost reduction; environmental regulation & No & No & Yes \\
\hline FB10 & Vegetable oil & $d, g$ & Cost reduction; environmental regulation & No & Yes & Yes \\
\hline TE1 & Textile & $e$ & Environmental regulation; cost reduction & No & No & Yes \\
\hline TE2 & Textile & $e$ & Cost reduction & No & No & Yes \\
\hline
\end{tabular}

$1: d=$ water or/and wastewater re-use or recycling

$e=$ raw material re-use or recycling

$f=$ change in raw material input(s)

$g=$ integrated physical device in the production line.

n.a. $=$ not applicable

Source: Author's field data 
It is difficult to attach relative importance to these adoption rationales because the case study sample may not be sufficiently representative of the population of firms in the two sectors under investigation. Furthermore, from the results in table 8.5, it appears unlikely that the regulatory pressure arising from the S.I.8/S.I.9 law would top the list. With the exception of FB8, which is a small-scale firm, all the case study firms are fully aware of the regulatory standards for water pollution control. In addition, all firms acknowledge the existence of compliance monitoring activities. However, there is a general impression among the case study firms that the regulatory enforcement regime is weak except when environmental incident occurs. A few of the firms (e.g. FB2 and FB5) stated clearly that regulatory compliance monitoring is regular only when environmental incidents are reported; and only FB1 and FB4 ascribed adoption of industrial wastewater treatment plant to pressure arising from the Nigerian environmental regulation. In spite of the relatively weak industrial pollution liability rule in Nigeria, the results in table 8.5 indicate that the desire not to be associated with cases of environmental incident is a very important motivation for firms' implementation of technical change to abate industrial wastewater pollution. As earlier mentioned in chapter 6 (section 6.2.6), the maximum fine for an erring firm is not more than US $\$ 5,000.00$, and the result of our regulators' survey showed that the options of firm closure or court action are seldom used. ${ }^{43}$ Moreover, even in the cases of FB1, FB2, TE1, and TE2, where regulatory pressure apparently played important roles for TPA adoption, firms could find more important reasons to which they ascribe their technology adoption decision. Thus, though environmental policy is important, other factors such as firm's commitment to prevent environmental incident, having a parent company with international norm for environmental management, environmental image ${ }^{44}$ consciousness, and community pressure for good environmental behaviour could also play equally important or more important roles as TPA adoption rationales.

Furthermore, firms generally consider local (i.e. Nigerian) environmental policy as a given variable, a necessary condition for technology investment in pollution control. Except for FB3, which complained that the Nigerian permissible level for phosphate in wastewater effluent is too stringent, firms seem to have accepted the effluent standards as a challenge to be met. It however appears that most firms are not meeting the regulatory requirement for wastewater effluent quality. In all cases of EBT adoption reported in this chapter, only two (i.e. FB3 and TE1) clearly satisfy regulatory requirement with respect to the final wastewater effluent quality. This is perhaps a reflection of a relatively weak environmental policy enforcement regime. Companies are adopting EBTs, and with a better environmental policy enforcement regime, it may be possible to considerably improve the performance of the adopted

\footnotetext{
${ }^{43}$ From the regulators' survey, more than two thirds $(73 \%)$ of the regulators claimed that they use dialogue/persuasion when dealing with non-complying firms; $17 \%$ claimed the use of warnings; and only $5 \%$ each claimed the use of court action and sealing of firm.

${ }^{44}$ We are not really sure if environmental image is an important motivation for EBT adoption because it is a factor that makes firms look good. We expect environmental image to be actually important only if their sales depend on it. From the case study illustrations presented in this chapter, this does not appear to be the case.
} 
EBTs to meet the regulatory standard for wastewater effluent quality. It is also important to note that the two wastewater treatment plants that satisfy regulatory requirements for effluent quality are imported technology hardware. Thus, added to insufficient regulatory enforcement, there is an apparent lack of indigenously designed and built wastewater treatment facility with satisfactory technical efficiency. In addition, TE1 (one of the two best performer case studies with respect to TPA) also signified that chemicals for wastewater treatment are largely imported, a situation which further limits firms' capability to achieve the required effluent quality standard. ${ }^{45}$

With respect to technology response for water pollution prevention (TPP), the overview given in table 8.6 shows that cost reduction factor dominates the environmental regulation reason as rationale for TPP adoption. This confirms our earlier findings in the descriptive analysis presented in chapter 6 (sections 6.3 .1 \& 6.3.2), where it was discovered that the enforcement of S.I.8/S.I.9 law had positive impact in stimulating TPA adoption but less visible impact on TPP adoption. TPP adoption might have been spurred by reasons beyond environmental policy. From table 8.6 , it is also noteworthy that though cost reduction reason came out as an important reason for environmentally benign innovation that reduce wastewater at the source, the economic gains from such measures were never sufficient to offset the cost of implementing the technical change or environmentally benign measure. The only exception to this among our case studies, FB7, may represent an anecdotal confirmation of Porter's hypothesis ${ }^{46}$ in a developing country.

On obstacles to the adoption of environmentally benign technologies, the case study firms appear unanimous in stressing the high cost of adoption as the most important obstacle. ${ }^{47}$ Even the small-scale plant (FB8) that seemed relatively unaware of what technical options are available for water pollution control suggested a centralised approach to tackling wastewater problem in order to minimise costs. In this chapter, we have also described an example of a centralised industrial wastewater treatment facility. However, the cost implication of it has not been our focus. Further study would be necessary to address the technical and economic viability of a centralised industrial wastewater treatment technology that could meet the Nigerian regulatory standards.

As shown in table 8.6, most of the case study firms expect stricter future environmental regulation in Nigeria but would not support wastewater effluent

\footnotetext{
4s Apart from foreign exchange constraints to importation of chemicals for wastewater treatment, from our discussions with plant managers, the process of clearing industrial goods at Nigerian ports sometimes creates unexpected delay in the delivery of chemicals for wastewater treatment.

${ }^{46}$ Michael Porter's hypothesis states that environmental regulation could engender environmentally benign innovation that would result in economic benefits that offset the cost of compliance to the environmental regulation (see Porter and Linde, 1995a\&b).

${ }^{47}$ In all the case studies, except FB2 and FB3, high cost of installing and operating water pollution control technologies is the most important obstacle to adoption.
} 
charge/tax as an instrument of industrial wastewater pollution control. Generally speaking, they agree in their view that a regime of wastewater effluent charge may not achieve the objective of stimulating technology responses for water pollution control. Reasons given for this include difficulty of administration of effluent charge; effluent charge more difficult to understand for developing country firms compared to environmental technology forcing standards; imperfect nature of the market of some firms may result in costs ${ }^{48}$ arising from effluent charge being easily transferred to consumers; some firm will simply view effluent charges as another instrument of government tax; and there is need to gain mastery of the enforcement of the existing regulation before proceeding to economic instrument.

It is also necessary to point out that there is an apparent lack of subsidy or tax relief for investments in technology for pollution control in Nigeria. Expectedly, some of the case study firms pointed out that such subsidy would be more effective in stimulating technology responses rather than introduction of effluent charges. Inasmuch as we may like to share such a view with respect to firms in a developing country context, ${ }^{49}$ it is difficult to conclude from this study that there is a special need to subsidise investment in technology for pollution control in Nigeria. To arrive at such conclusion, a fair knowledge of the existing tax regime supported by information on the cost implication of internalising pollution costs in Nigerian manufacturing would be necessary. Moreover, in contrast to industry's view, we have earlier indicated in chapter four (section 4.2.2) that $56 \%$ of regulators would support the introduction of wastewater effluent charge as an instrument of industrial wastewater pollution control.

At this juncture, it is important to make a distinction between effluent charge and tax. An effluent charge is normally perceived as an economic instrument for raising money to finance regulation enforcement activities and implement subsidies for firms' investment in pollution control. The German wastewater effluent charge is an illustration of this ${ }^{50}$ (see Kraemer, 1995). Effluent tax is perceived as not just serving as incentive measure by making polluter to pay, but also an instrument of revenue generation for state authorities. As the foregoing discussion shows, firms in Nigeria would rather see wastewater effluent charge simply as pollution tax. Plant managers do not appreciate the difference between a charge and a tax. Both are viewed as instruments that will create cost increases for companies, and thus appeared

\footnotetext{
"As Olokesusi et al (1997) reported that pollution control costs is already up to 5 percent of total production costs of Nigerian industries in 1996. This appears rather high as it falls in the range for industrialised countries where pollution control is relatively more intensive (see Reed, 1992). Firms may therefore be reluctant to internalise further increase in pollution control costs in the form of direct taxation based on effluent discharged.
}

\footnotetext{
"Subsidies have however been shown to have very limited incentive capability in promoting environmentally benign innovations among firms in developed economies (see Kemp, 1997, 2000). 
unfavoured. However, economic theory suggests that external costs should be internalised so that there is an incentive for polluters to prevent or abate pollution (i.e., the so-called polluters pays principle). Though Nigerian manufacturers are presently averse to the idea of effluent charge or tax, with proper enlightenment among stakeholders in Nigerian industry, it may nevertheless be a useful instrument to generate necessary subsidy for technology investments in industrial wastewater pollution control. 


\section{Chapter Nine}

\section{SUMMARY AND CONCLUSIONS}

\subsection{Introduction}

This dissertation began with an investigation into the theoretical and empirical findings on why firms adopt normal business technological innovations. This was intended to serve as a background to our study of the reasons why manufacturing enterprises in developing countries adopt environmentally benign technologies. The initial insights derived revealed that reasons that motivate firms' investment in technologies generally include economic reasons such as profitability and competitiveness; technological capabilities of the firm as represented by the calibre and educational level of the workforce, R\&D capabilities and intensity, etc; indirect influence of the supply-side factors; the impact of the output market; and institutional factors in the firm's operating environment. We have however demonstrated in chapter three that economic theory on firms' investment in pollution control has shown that these reasons are limited in their ability to explain the adoption causalities for technologies that reduce or prevent external diseconomies of industrial production activities.

Studies that have shed light on the determinants of firms' adoption of environmentally benign technologies are largely based on developed countries' experiences. With respect to developing countries, especially Africa, there is limited knowledge on the determinants of manufacturing firms' technology responses aimed at industrial pollution control. The central objective of this thesis is to contribute to the bridging of this knowledge gap. In doing so, we have elucidated and analysed the links between factors responsible for the adoption of environmentally benign technologies in a developing country context with Nigerian manufacturing as a case study. In the process, we have analysed the technological impact of the existing regime of environmental policy in Nigeria, and signified its effectiveness in stimulating technology responses aimed at industrial wastewater pollution control. We have also attempted to ascertain the relative importance of other factors, apart from environmental policy, that may determine technology adoption for water pollution control in Nigerian manufacturing industry.

In this concluding chapter, we present the summary of our findings, and discuss their implications for policies that relate to environmentally sustainable industrial development in Nigeria. In the following section, the summary of the theoretical framework we developed for this research is given, and its contribution to existing theories is indicated. Section 3 presents a brief overview of our empirical findings, while section 4 discusses the policy implications. The final section gives directions for further research emanating from this thesis. 


\subsection{Major versus Auxiliary Driver Hypothesis}

In the introductory chapter to this dissertation, we stressed that research into the determinants of environmentally benign technical change in developing countries' manufacturing industry is relatively new, and in Africa, not much is known. Based on theoretical thoughts that are essentially rooted in the experiences of industrial economies, we have developed a theoretical framework for the analysis of the adoption of environmentally benign technologies (EBTs). The model developed is original to this research, and thus presents another conceptual viewpoint on the links between technology responses for pollution control in industry and the underlying rationales for firms' technology adoption decisions. In this model, we decomposed EBTs into two types; viz., technology response for pollution abatement (TPA) and technology response for pollution prevention (TPP); and presented a trajectory of technology responses to environmental policy depending on national development status. We have enumerated the adoption determining factors; proposed one of them as the major driver of adoption, while we classified the remaining factors as the auxiliary drivers of adoption.

The major driver of adoption is identified to be the prevailing regime of environmental policy under which firms are operating. The auxiliary drivers of adoption include firm's internal capability for innovation in pollution control, external network for innovation, firm's disposition to environmental regulation, firm size, firm's intrinsic competitiveness, perceived impact of adoption on costs, environmental policy implementation strategy, and the institutional capacity for environmental regulation. For developing countries, the auxiliary factors also include the ownership structure of the firm. We however pointed out that the major and auxiliary drivers of adoption are interdependent. We also demonstrated that their relative importance as specified in our model may not always hold sway, and can be verified only by empirical investigation. Certain auxiliary drivers of adoption could become as important as the major driver of adoption especially under a relatively less developed regime of environmental policy, as may be exemplified in a developing country such as Nigeria. On this premise, we embarked on an empirical investigation of the Nigerian case with a focus on water pollution control technologies in the food \& beverages and the textile sectors. The core of our theoretical propositions for which this thesis has sought for empirical evidence is what we have termed, major versus auxiliary driver hypothesis. This hypothesis has attempted to ascertain which is more important in a developing country: is it environmental policy as a major driver of EBT adoption, or auxiliary driver(s) of EBT adoption? This question challenges existing mainstream economic theory that emphasises environmental policy as the main rationale for the adoption of EBTs in industry. The ensuing empirical results from this thesis are contributions toward the development of an appreciative theory that redefines the bounds of environmental policy as stimulus for environmentally benign technology responses that reduce external diseconomy of manufacturing enterprises. 


\subsection{The Empirical Results in Brief}

Our empirical analysis presented tests of the two main hypotheses in this study; viz., the major driver hypothesis, and the auxiliary driver hypothesis. The major driver hypothesis sought to ascertain the role of environmental policy as the major driver of firms' technology responses to the imperatives of industrial wastewater pollution control. This hypothesis was subdivided into two in order to isolate the impact of environmental policy on firms' technology responses for water pollution abatement (TPA) and firms' technology responses for water pollution prevention (TPP). The auxiliary driver hypothesis gave rise to seven sub-hypotheses based on the factors identified as auxiliary drivers of EBT adoption within our analytical framework in chapter four.

In view of the importance attached to environmental policy in our theoretical considerations, we have presented a description of the environmental regulatory regime in Nigeria based on available secondary information and our field survey data. We discovered that Nigeria has emerged as a country where environmental regulation with respect to industrial wastewater pollution control has an organised structure. The current environmental policy instrument is largely 'command and control' in nature. However, there are indications that regulators are beginning to realise that some form of economic incentive-based instrument may be necessary in future. $56 \%$ of regulators surveyed in this study favour the introduction of wastewater effluent charge or tax as an instrument of pollution control. However, the case studies showed that most plant managers do not believe wastewater effluent charge would be an effective instrument for stimulating technology investment in pollution control (see table 8.6 in chapter eight).

The Nigerian environmental regulatory agencies have pollution control laboratories that are reasonably equipped, at least, to the satisfaction of the large majority of the regulators. However, the institutional regulatory capacity for environmental regulation appears to have significant manpower and infrastructural deficiencies. Though an average of $37 \%$ of employees of environmental regulatory agencies that provide information on their employment structure have higher degree educational qualification, only $25 \%$ have industrial pollution control related training in environmental science or technology. Moreover, regulators surveyed consider inadequate number of compliance monitoring officers and lack of training as very important obstacles to effective compliance monitoring. In addition, the problem of lack of vehicles for compliance monitoring stands out as the single most important hindrance to compliance monitoring.

As a prelude to the analysis of the EBT adoption causalities, chapter six exposed the characteristics of Nigerian manufacturing in the two sectors investigated, and presented the trends in technology responses for water pollution control. We found evidence that Nigerian firms are actively involved in the adoption of conventional end-of-pipe technologies such as industrial wastewater treatment plants. We also 
discovered evidence of the adoption of process related innovations that may reduce industrial wastewater pollution at the source. Most of the adoption of secondary and tertiary industrial wastewater treatment plants in the two sectors took place after the end of the moratorium given to Nigerian firms to comply with the S.I.8/S.I.9 environmental regulatory law in January 1995. This gives an indication that the enforcement of S.I.8/S.I.9 law has been effective in stimulating adoption of EBTs with respect to water pollution abatement. Similar effects were not as vividly observable with respect to the adoption of technologies that reduce water pollution at the source especially in the textile industry. Furthermore, our results in chapter six showed that the association of affiliation to multinational enterprises (MNE) with the adoption of industrial wastewater treatment technology (TPA) is significant. However, the association of affiliation to MNE with time of TPA adoption is not significant. This may imply that the implementation of the S.I.8/S.I.9 law in January 1995 did not result in significant increase in multinational firms' decisions to adopt environmentally benign technologies, especially industrial wastewater treatment plants. As some of the case studies in chapter eight demonstrated (e.g. FB1, FB3, FB6), the international norm or environmental policy of the parent companies of multinational subsidiaries plays important roles in firms' decisions to adopt EBTs. It appears that even before the host country enforces a clearly defined environmental policy (as in the Nigerian case), the international norm or environmental policy of the MNE affiliates' parent companies stimulates technology responses that are not less than the minimum requirements of the host country's policy.

With regard to obstacles to EBT adoption in Nigerian manufacturing, our results indicated high cost of pollution control technologies as the most important obstacle. Generally speaking, firms do not consider reasons such as lack of information on pollution control technologies, lack of technical capabilities, uncertainty about impact of EBT adoption on competitiveness, and lack of credit for technology investments as important obstacles to adoption. However, firms in the textile sector appear to view lack of information on pollution control technologies and lack of credit as important hindrances to adoption. We consider this to stem from the relatively more stringent technology requirement for compliance in the textile industry, and the attending higher costs of installing and operating pollution control technologies.

For the purpose of testing the two main hypotheses, we employed the logistic regression analysis in chapter seven. The analysis was carried out in three stages. The first treated environmental benign technologies as a 'bundle'; the second focussed on firms' technology responses for water pollution abatement (TPA); and the third focussed on firms' technology responses for water pollution prevention (TPP). In addition to environmental policy, other explanatory variables specified for our econometric analysis include firm's internal capability for innovation (human capital), internal capability for innovation (physical capital), external network for innovation, ownership structure, firm size, and policy implementation strategy.

The results of the regression analysis showed that when technology adopted for water pollution control is treated as aggregate without distinguishing the type of technology, 
environmental policy appears significant as a major driver of adoption. The auxiliary driver variables such as ownership structure, firm size, and policy implementation strategy also appear equally significant.

The second stage of the regression analysis that considered technology responses for water pollution abatement (TPA) also demonstrated that the environmental policy variable is significant as adoption causality. However, the result showed that our data do not support environmental policy as a major driver of TPA adoption. Auxiliary driver variables such as firm size, and human capital aspect of internal capability for innovation (represented by percent workforce with higher education) emerged more likely stimuli for TPA adoption than the environmental policy variable. Ownership structure of the firm, firm size, and policy implementation strategy appear particularly important as stimuli for TPA adoption. Moreover, the result also showed that policy implementation strategy would clearly influence the odds of TPA adoption than the environmental policy variable.

The third stage of the regression analysis also demonstrated that environmental policy does not appear to play the role of a major driver as adoption causality for firm's technology responses for water pollution prevention (TPP). Whereas the coefficient of the environmental policy variable is significant at barely $10 \%$ level, the parameter estimates of the auxiliary driver variables such as firm size, human capital aspect of internal capability for innovation (represented by percent workforce with higher education), and firm ownership structure are respectively statistically significant at $1 \%, 1 \%$ and $5 \%$ levels.

Overall, our field survey data support most of the sub-hypotheses that we proposed in chapter four. From the findings of our empirical analysis, the sub-hypotheses could be presented as follows:

HIa: The introduction of the S.I.8/S.I.9 environmental regulatory law has had a positive impact on firms' investment in industrial wastewater treatment plants in Nigerian manufacturing industry.

HIb: The S.I.8/S.I.9 environmental regulatory law has stimulated the adoption of process integrated techniques/methods for the reduction of industrial wastewater at the source in Nigerian manufacturing.

H2a: Technology investment in pollution control in Nigerian manufacturing is positively linked with the share of technical personnel in total employment. The link is stronger with percent of workforce with higher education, especially in respect of investment in TPA. It was also discovered that the technical workforce plays relatively more important role for TPP adoption than for TPA adoption.

$\boldsymbol{H} 2 \boldsymbol{b}$ : The adoption of environmentally benign technologies in Nigerian manufacturing has a negative correlation with the existing level of investment in main production capital equipment. Firms that have concentrated technology investment in expensive 
foreign technology equipment are more reluctant to invest in technology for water pollution control when compared with firms that employ a mixture of foreign and local equipment for the main production activities.

H2c: Our data could not support the sub-hypothesis that 'the capability of a firm to adopt EBT will be inherently determined by the technological knowledge related network contacts the firm has'. The parameter estimates for this variable was consistently positive, but statistically insignificant. It should nevertheless be pointed out that, the case studies in chapter eight revealed that external network contacts could play an important role in stimulating technology investment in pollution control, especially among the subsidiaries of multinational firms (see case studies FB1, FB3, and FB6).

$\boldsymbol{H} \mathbf{d}$ : Increasing share of foreign ownership of firms in Nigerian manufacturing industry has positive links with firms' investment in industrial wastewater treatment plants and technologies that reduce wastewater generation at the source.

H2e: The adoption of environmentally benign technologies in Nigerian manufacturing is positively correlated with firm size.

H2f: The strategy for S.I.8/S.I.9 environmental policy implementation, whether cooperative or antagonistic, has impact on the adoption of environmentally benign technologies in Nigerian manufacturing. It should however be noted that, whereas appreciative theory of developed country experiences showed that a co-operative strategy will enhance TPP adoption, and possibly deter TPA adoption (see section 4.3.2 of chapter four); in the Nigerian case, co-operative strategy encourages TPA adoption while TPP adoption has no identifiable link with policy implementation strategy.

$\mathrm{H} 2 \mathrm{~g}$ : Due to data limitations, the logistic regression does not afford us a test of the sub-hypothesis $\mathrm{H} 2 \mathrm{~g}$ on the relationship between the odds of EBT adoption and cost savings or competitiveness motivated reasons. However, based on a descriptive analysis using available data, there is evidence supporting the hypothesis with respect to investments in TPP. For TPA, we have no evidence. Hence, we can state that the adoption of environmentally benign technologies that reduce wastewater generation at the source in Nigerian manufacturing is related to cost savings or competition motivated reasons that are not necessarily inspired by environmental policy.

At this juncture, we wish to also state that the case study illustrations in chapter eight indicated some EBT adoption rationales difficult to capture by econometric analysis of EBT adoption. For TPA, prominent among such adoption causalities are prevention of environmental incident; parent company's environmental norm; improvement of environmental image; and pacification of community pressure. It was however not possible to rank the importance of these reasons by our case study analysis. For TPP, the case studies revealed that cost reduction motivation dominated environmental policy as adoption rationale. 
From the foregoing exposition, it appears that Nigeria can be located in the stage two of the trajectory described in section 3.3 of chapter three; i.e. a stage of appreciable regulation, and notable technology responses. Most of the observed characteristics of the environmental policy regulatory regime and the technology responses suit what may be expected of a country in the early part of the second stage in the trajectory of firms' technology responses. The empirical evidence however demonstrated that the existing environmental regulation, though appreciable, is not strong enough to explain the notable technology responses observed. In this respect, the auxiliary driver factors represent additional important rationales for the observed technology responses.

What policy implications do our findings portend for Nigeria and other developing countries whose manufacturing may be comparable to that of Nigeria? The next section addresses this issue.

\subsection{Policy Implications}

For developing countries, the conflict between the notion of 'industrialise now, and clean up later', and that of 'environmentally sustainable industrialisation' as a wise option to prevent future costs of 'clean up', makes it necessary to first establish the extent to which our 'major driver versus auxiliary driver' model is valid for developing countries. Tentatively, the current debate suggests that both the major and auxiliary drivers need to be strengthened in developing countries. But the question that remains is: where should we devote more efforts/resources in a bid to achieve the objective of technology adoption for environmentally sustainable industrial development? If we should go by the experiences of developed economies, theory and empirical evidence have mostly suggested that we should focus more on environmental policy. However, for developing economies, the empirical results we have reported from the Nigerian case in this treatise give a contrary indication. Our findings suggest that the need to promote 'techno-economic' factors and the institutions that enhance them are equally, if not more important for encouraging the adoption of EBTs in developing countries' manufacturing industry. This is the profound but modest conclusion that we have drawn from the findings of this thesis.

As shown in the theoretical chapters of this dissertation, the debate on environmental policy and technical change has largely focused on the major driver of adoption, particularly the forms of policy, and how to improve the policy regime to reduce the perceived constraints that environmental policy imposes on industrial performance. This mainstream thinking hangs on the notion that environmental policy as the major driver of EBT adoption essentially seeks to internalise the external diseconomies of firms' production activities. The auxiliary driver factors as reflected in this study are not reckoned as constituting important stimuli for firms' adoption of environmentally benign technologies. However, in a developing country context as represented by Nigeria, the findings of this study show that the underlying notion of environmental policy as the major driver of EBT adoption is doubtful. 
For the Nigerian case, analysis focussing on environmentally benign technologies without disaggregating into types of technologies involved may give a wrong impression that environmental policy is the major driver of EBT adoption. However, as would be necessary for policy decisions, consideration of technology types for pollution control revealed that the auxiliary drivers might constitute a host of factors that reasonably improve firms' EBT adoption than would environmental policy. As stated in section 4.3 .2 of chapter four, it should be reiterated that, auxiliary drivers are factors having direct bearing on firm characteristics, technological capabilities, and environmental policy implementation strategy.

Policies aimed at encouraging multinational investments in manufacturing such as foreign direct investment (FDI) policies or those of divestment that may increase foreign ownership in publicly owned manufacturing enterprises, have potentials of improving firms' performance in technology investment in pollution control. In this respect, the larger the firm, the more the prospect of better environmental performance. In the same vein, policies that encourage large-scale greenfield manufacturing investments or promote the growth of small and medium-scale industries into large-scale manufacturing have potentials for stimulating EBT adoption.

Our results also indicated that technology policies that foster internal technical capability development among manufacturing enterprises would inadvertently stimulate firms' technology investments in pollution control. In this respect, relevant technology policies would be those that promote the availability of highly educated/trained technical manpower for industrial employment. In the Nigerian case, it was demonstrated that firms (including multinational affiliates) largely source their manpower resources locally.

The environmental policy implementation strategy also represents important factor that may determine firms' decisions to adopt EBT. In the Nigerian case, it was discovered that when regulators adopt a co-operative strategy in dealing with compliance enforcement issues, firms' compliance is improved especially with respect to TPA (i.e. industrial wastewater treatment technology). This is particularly important for countries where firms are operating under a relatively difficult economic environment as typified by Nigeria. An understanding attitude on the part of regulators may serve as encouragement rather than deterrent to EBT adoption. It is also noteworthy that our findings in chapter six point to the need to fine-tune the Nigerian environmental regulatory regime to encourage technical change that reduces industrial water pollution at the source especially among the textile firms.

Furthermore, the case study illustrations in chapter eight signify that the industrial wastewater treatment plants that satisfy regulatory requirements for effluent quality are imported technology hardware. Besides, chemicals for wastewater treatment are also largely imported (see case study TE1). The improvement of the technical efficiencies of locally designed (\& built) industrial wastewater treatment technologies 
and the development of local (or less expensive) substitutes for wastewater treatment chemicals should be major focus of R\&D policies with respect to technology for industrial wastewater pollution control in Nigeria. Moreover, with the possible exception of one firm (FB7), the case studies show that there is generally lack of well defined/articulated cleaner production programmes among Nigerian firms. The current Nigerian environmental policy lays much emphasis on TPA (end-of-pipe) solutions to industrial wastewater problems, and the Nigerian industrial/technology policies (e.g. FMST, 1986; FMI, 1988) have so far been silent on cleaner production as industrial or technology policy objective. Evidence of TPP adoption provided in this thesis however demonstrates that there is a good prospect for cleaner production programmes in Nigerian manufacturing industry. Environmental, industrial and technology policies could be made to encourage environmentally benign technical change that would result in a regime of cleaner production among Nigerian firms.

In conclusion, it is pertinent to stress that policy focus aimed at strengthening the ability of the auxiliary drivers to provide stimuli for EBT adoption could be more attractive to industry, and at the same time achieve the social welfare objectives. It may thereby be possible to not only promote the eco-restructuring of industry; but also increase the capacity of stakeholders, industrial firms, and policy makers to overcome the perceived conflicts between environmental regulation and industrial development. Furthermore, though we have only an anecdotal confirmation of Porter's hypothesis (see the discussion of hypothesis $\mathrm{H} 2 \mathrm{~g}$ in chapter seven, and case study FB7 in chapter eight), the promotion of the auxiliary drivers as determinants of environmentally benign technology responses could be an exploration that might lend some credence to Porter's hypothesis on the compatibility of environmental regulation and industrial development for the Nigerian case.

\subsection{Directions for Further Research}

At this juncture, we wish to affirm that the research findings reported in this thesis appear satisfactorily robust, and have appreciably achieved the study objectives laid out in chapter one. However, the outcome of the study signifies the need for more research that may further deepen the understanding of the technological and socioeconomic factors that influence developing countries' firms' decisions to adopt technologies that improves their environmental performance.

In chapters three and four, we pointed out that the institutional capacity for environmental regulation is an important determinant of firms' technology responses to the imperatives of environmentally sustainable industrialisation. The institutional capacity for environmental regulation is difficult to quantify, and as such, could not be incorporated into our empirical analysis in chapters six and seven. A study entirely devoted to unveiling the evolution of the Nigerian environmental regulatory institutions may be necessary to ascertain the strength and/or weaknesses of the institutional capacity for environmental regulation in Nigeria, and to what extent they influence firms' decisions to adopt environmentally benign technologies for water 
pollution control. Furthermore, the scope of the Nigerian case study could be enlarged to include the chemicals sector. Figure 1.2 shows that the chemical industry is also an important water pollution intensive sector; and for Nigeria, it is one of the sectors where industrial activities flourish (see figure 1.1). An analysis including this sector may further enrich the findings of this study with respect to Nigeria.

Added to the foregoing, we wish to also suggest an investigation into the possibility of introducing privately owned centralised industrial wastewater treatment plants in major industrial clusters in Nigeria. Successful centralised industrial wastewater treatment among manufacturing firm clusters have been reported for some East Asian developing countries such as Thailand, Indonesia and South Korea (see O'Connor, 1994 and Aden et al, 1999, p.1204). Out of the two currently in Nigeria the time of this study, one is owned by a private concern while the other is publicly owned (see box 8.5). The publicly owned industrial wastewater treatment system is non functional, while the privately managed facility functions, though not sufficiently efficient to bring wastewater effluent parameters to regulatory standards. Research into the technical feasibility and economic cost-benefit analysis of such a system may give useful insights into the prospects of applying such technology for industrial wastewater pollution control in Nigeria.

It would also be interesting to apply the analytical framework developed in this study to other developing country case studies. This will make international comparison of the findings possible. It could also result in overcoming one of the limitations of this study by creating opportunity for international comparison that may lead to some generalisations or 'stylised facts' based on the findings. In addition, our framework could also be applied for the analysis of firms' adoption of technologies for the control of other forms of pollution, apart from water pollution. 


\section{REFERENCES}

Abdullahi, Hamza (1988). Policy Issues and Institutional Arrangement in National Environmental Programmes, in P.O. Sada and F.O. Odemerho (eds.), Environmental Issues and Management in Nigerian Development, Evans Brothers Publishers Limited, Ibadan, Nigeria.

Adeboye, Titus (1995). Diffusion of Pre-commercial Inventions from Government Funded Research Institutions in Nigeria, in O.M. Ogbu, B.O. Oyeyinka, and H.M. Mlawa (eds.), Technology Policy and Practice in Africa, International Development Research Centre, Ottawa, Canada.

Aden, Jean, A. Kyu-hong and M.T. Rock (1999). What is Driving the Pollution Abatement Expenditure Behaviour of Manufacturing Plants in Korea? World Development, Vol. 27, No.7, pp. 1203-1214.

Adeoti, John O. (2000). Sustainable Development and Small Enterprise Promotion: An Attempt at Integration, Journal of Developmental Entrepreneurship, Vol.5, No.1, pp.57-71.

Adjebend-Asem, A. (1995). Translating Technological Innovation into Entrepreneurship in Nigeria: Social and Policy Implications, in O.M. Ogbu, B.O. Oyeyinka, and H.M. Mlawa (eds.), Technology Policy and Practice in Africa, International Development Research Centre, Ottawa, Canada.

Aina, E.O.A. and Adedipe, N.O. (eds.) (1992). Towards Industrial Pollution Abatement in Nigeria, FEPA's Monograph 2: Proceedings of the National Environmental Seminar on Industries and the Nigerian Environment, $21^{\text {st }}-23^{\text {rd }}$ May, 1990, FEPA, Lagos / Ibadan University Press, Ibadan, Nigeria.

Akinbinu, Ajibayo F. (1997). Textile Industry Development, in A.O. Phillips, S. Titilola (eds.), Nigeria in 2010, NISER, Ibadan, Nigeria.

Aldrich, John H. and F.D. Nelson (1984). Linear Probability, Logit, and Probit Models, Sage Publications Ltd, Series No. 07-045, London.

Andersen, Mikael S. (1994). Governance by Green Taxes: Making Pollution Prevention Pay, Manchester University Press, Manchester.

Arrow, K.J. (1962). Economic Implications of Learning by Doing, Review of Economic Studies, Vol. 29, pp.155-173.

Ashford, Nicholas A. (1993). Understanding Technological Responses of Industrial Firms to Environmental Problems: Implications for Government Policy, in K. Fischer 
and J. Schot (eds.), Environmental Strategies for Industry: International Perspectives on Research Needs and Policy Implications, Island Press, Washington, D.C.

Bartzokas, Anthony and M. Yarime (1997). Technology Trends in Pollution Intensive Industries: A Review of Sectoral Trends, UNU-INTECH Discussion Paper No.9706, Maastricht.

Bass, Frank, M. (1969). A New Product Growth Model for Consumer Durables, Management Science, Vol.15, No.5, pp.215-227.

Baumol, William J. and W.E. Oates (1988). The Theory of Environmental Policy, Cambridge University Press, New York.

Bevan, David, P. Collier, and J.W. Gunning (1999). The Political Economy of Poverty, Equity, and Growth: Nigeria and Indonesia, A World Bank Comparative Study, Oxford University Press, Oxford.

Biemans, Wim G. (1992). Managing Innovation Within Networks, Routledge, London.

Biersteker, Thomas J. (1987). Multinationals, the State, and Control of the Nigerian Economy, Princeton University Press, Princeton, New Jersey.

Blackman, A. and G.J. Bannister (1998). Pollution Control in the Informal Sector: The Ciudad Juárez Brickmakers' Project. Discussion Paper 98-15, Resource for the Future, Washington, D.C.

Boahene, Kwasi (1995). Innovation Adoption as a Socio-economic Process: the Case of the Ghanaian Cocoa Industry, Thesis Publishers, Amsterdam.

Bongaerts, Jan and R.A. Kraemer (1989). Permits and Effluent Charges in the Water Pollution Control Policies of France, West Germany and the Netherlands, Environmental Monitoring and Assessment, Vol.12, pp. 127-147.

Bonifant, B.C., M.B. Arnold, and F.J. Long (1995). Gaining Competitive Advantage Through Environmental Investments, Business Horizons, Vol.38, No.4, pp.37-47.

Brautigam, D. (1992). Regional Industrialisation in Nigeria, AF4CO, African Region, The World Bank, Washington D.C.

Brezis, E.S., P.R. Krugman, and D. Tsiddon (1993). Leapfrogging in International Competition: A Theory of Cycles in National Technological Leadership, The American Economic Review, Vol.83, No.5, pp.1211-1219.

Chamarik, S. and S. Goonatilake (eds.) (1994). Technological Independence: The Asian Experience, United Nations University Press, Tokyo. 
Chokor, B.A. (1988). Environmental Awareness and Effective Environmental and Pollution Control, in P.O. Sada and F.O. Odemerho (eds.), Environmental Issues and Management in Nigerian Development, Evans Brothers Publishers Limited, Ibadan, Nigeria.

Clark, Peter and N. Staunton (1989). Innovation in Technology and Organization, Routledge, London.

Clift, Roland and A.J. Longley (1995). Introduction to Clean Technology, in R.C. Kirkwood and A.J. Longley (eds.), Clean Technology and the Environment, Chapman and Hill, London.

Cramer, J., J. Schot, F. van den Akker and G.M. Geesteranus (1990). UNEP Industry and Environment, Vol.13, pp.46-53.

Cropper, Maureen L and W.E. Oates (1992). Environmental Economics: A Survey, Journal of Economic Literature, Vol. 30, pp.675-740.

Dasgupta, S., M. Huq, D. Wheeler and C. Zhang (1996). Water Pollution Abatement by Chinese Industry: Cost Estimates and Policy Implications, Environment, Infrastructure and Agricultural Division, World Bank.

Dasgupta, S., R.E.B. Lucas and D. Wheeler (1998). Small Plants, Pollution and Poverty: New Evidence from Brazil and Mexico, DECRG, Infrastructure/Environment Group, World Bank.

Dasgupta, Nandini (2000). Environmental Enforcement and Small Industries in India: Reworking the Problem in Poverty Context, World Development, Vol. 28, No.5, pp.945-967.

David, Paul (1969). A Contribution to the Theory of Diffusion, Stanford Centre for Research in Economic Growth, Memorandum No. 71.

David, Reed (ed.) (1992). Structural Adjustment and the Environment, Earthscan Publications Ltd., London.

Davies, Stephen (1979). The Diffusion of Process Innovations, Cambridge University Press, Cambridge.

de Sitter, L.U., B. Dankbaar and J.F. den Hertog (1994). Designing Simple Organisations and Complex Jobs, MERIT Research Memoranda, MERIT RM 2/94012. 
Dijken, K. van, M. Frey, O. Hansen, E. Lopes, S. Sandra and T. Wolters (1998). The Adoption of Innovations by small and Medium Sized Enterprises, Final Report on the ENVIS Project, European Commission DGXII, Brussels.

Dosi., Giovanni, C. Freeman, R. Nelson., G. Silverberg, and L. Soete (eds.) (1988). Technical Change and Economic Theory, Pinter Publishers, London.

Downing, Paul B. and L.J. White (1986). Innovation in Pollution Control, Journal of Environmental Economics and Management, Vol.13, pp.18-29.

Dunning, John H. (1995). The Globalization of Business, Routledge, London.

Economic Commission for Europe (1984). Strategies, Technologies and Economics of Wastewater Management in ECE Countries: A Report on Prevailing Practice and Recent Experience in Domestic Sewage Purification and Industrial Wastewater Treatment, United Nations, New York.

Enos, J.L. (1995). In Pursuit of Science and Technology in Sub-Saharan Africa: The Impact of Structural Adjustment Programmes, Routledge, London.

Ethier, Wilfred J. and J.R. Markusen (1991). Multinational Firms, Technology Diffusion and Trade, NBER Working Paper No.3825, Cambridge MA.

European Commission (1996). Wastewater Charge Schemes in the European Union, Office of the Official Publications of the European Communities, Luxembourg.

European Commission (1997). The Implementation of Cleaner Technology, Socioeconomic Determinant of Adoption and Diffusion - A Cross-regional Comparison, Final Project Report, EC Environmental Research Programme, Brussels, Belgium.

Fair, G.M., J.C. Geyer and D.A. Okun (1981). Water and Wastewater Engineering, Volume 2: Water Purification and Wastewater Treatment and Disposal, John Wiley and Sons Inc., New York.

FEPA (1991a). National Guidelines and Standards for Environmental Pollution Control in Nigeria, Federal Government Press, Lagos, Nigeria.

FEPA (1991b). National Effluent Limitation Regulation, Federal Government Press, Lagos, Nigeria.

Federal Environmental Protection Agency (1995). The Corporate Profile of Federal Environmental Protection Agency; FEPA Publications, Abuja, Nigeria.

Federal Office of Statistics (1998). Report of the annual Survey of Manufacturing Industries (1991-1992), FOS, Abuja, Nigeria. 
Fischer, Kurt and J. Schot (eds.) (1993). Environmental Strategies for Industry: International Perspectives on Research Needs and Policy Implications, Island Press, Washington, D.C.

FMI (1988). Industrial Policy of Nigeria: Policies, Incentives, Guidelines and Institutional Frameworks, Federal Ministry of Industries (FMI), Federal Secretariat, Abuja, Nigeria.

FMST (1986). National Policy on Science and Technology; Federal Republic of Nigeria, Federal Ministry of Science and Technology (FMST)/Directorate of Social Mobilisation, Abuja, Nigeria.

Forrest, Tom (1994). The advance of African Capital: The Growth of Nigerian Private Enterprise, Edinburgh University Press, Edinburgh.

Freeman, C. and Soete, L. (1997). Economics of Industrial Innovation, Pinter, London.

Geffen, Charlette A. (1995). Radical Innovation in Environmental Technologies: the Influence of Federal Policy, Science and Public Policy, Vol.22, No.5, pp.313-323.

Geiser, Kenneth and M. Crul (1996). Greening of Small and Medium-sized Firms: Government, Industry and NGO Initiatives, in P. Groenewegen, K. Fischer, E.G. Jenkins and J. Schot (eds.), The Greening of Industry Resource Guide and Bibliography, Island Press, Washington, D.C.

Gobin, A.M.L., P. Campling, J. Feyen, and F.I. Idike (1996). The Role of Rainwater Harvesting for Rural Water Supply in Enugu State in South-eastern Nigeria, Science, Technology \& Development, Vol.14, No.3, pp.88-106.

Gold, Bela (1980). On the Adoption of Technological Innovations in Industry: Superficial Models and Complex Decision Processes, Journal of Management Science, Vol.8, pp.505-516.

Gold, Bela (1981). Technological Diffusion in Industry: Research Needs and Shortcomings, Journal of Industrial Economics, Vol.29, No.3, pp.247-269.

Griliches, Zvi (1957). Hybrid Corn: An Exploration in the Economics of Technological Change, Econometrica, Vol.25, No.4, pp.501-522.

Griliches, Zvi (1980). Hybrid Corn Revisited, Econometrica, Vol.48, No.6, pp.14631465.

Hamilton, Lawrence C (1992). Regression with Graphics, Brooks/Cole Publishing Company, Pacific Grove, California, USA. 
Hammer, Mark J. (1986). Water and Wastewater Technology, SI Version, John Wiley and Sons, New York.

Hart, Stuart L. and G. Ahuja (1996). Does It Pay to be Green? An Empirical Examination of the Relationship Between Emission Reduction and Firm Performance, Business Strategy and the Environment, Vol.5, pp.30-37.

Hartje, Volkmar J. (1984). The State of Economic Research in Innovation and Environmental Protection, IIUG DP 84-8, Wissenschaftszentrum, Berlin.

Hartje, V.J. and R.L. Lurie (1984). Adopting Rules for Pollution Control Innovations: End-of-pie Versus Integrated Process Technology, IIUG DP 84-6, Wissenschaftszentrum, Berlin.

Hartje, V.J. and R.L. Lurie (1985). Research and Development Incentives for Pollution Control Technologies, IIUG DP 85-3, Wissenschaftszentrum, Berlin.

Helmsing, A.H.J. (1993). Small Enterprise and Industrialisation Policies in Africa: Some Notes, in A.H.J. Helmsing and Th. Kolstee (eds), Small Enterprises and Changing Policies, IT Publications, London.

Hemmelskamp, Jens (1999). Umweltpolitik und Technischer Fortschritt, Schriftenreihe des Zentrums für Europäsche Wirtschaftsforschung, Mannheim, Physica-Verlag, Heidelberg, Germany.

Herbert-Copley, Brent (1998). Innovation, Regulation and Environmental Management in the Chilean and Canadian Pulp and Paper Industries, $\mathrm{PhD}$ Thesis, Carleton University, Ottawa, Canada.

Hesselberg, Jan and H.M. Knutsen (1994). Location of Pollution Intensive Industry in a North/South Perspective: Review of Literature, F.I.L. Working Papers No.1, University of Oslo, Norway.

Hettige, Hemamala, M. Huq, S. Pargal and D. Wheeler (1996). Determinants of Pollution Abatement in Developing Countries: Evidence from South and Southeast Asia, World Development, Vol.24, No.12, pp.1891-1904.

Hettige, Hamamala, M. Mani and D. Wheeler (2000). Industrial Pollution in Economic Development: The Environmental Kurznets Curve Revisited, Journal of Development Economics, Vol.62, pp.445-476.

Hoogvelt, Ankie (1979). Indigenisation and Foreign Capital: Industrialisation in Nigeria, Review of African Political Economy, Vol. 14, pp.56-68.

Hosmer, Jr, David W. and S. Lemeshow (1989). Applied Logistic Regression, John Wiley \& Sons, New York. 
Howes, R., J. Skea and B. Whelan (1997). Clean and Competitive? - Motivating Environmental Performance in Industry, Earthscan Publications Ltd., London.

Ihonvbere, Julius O. (1993). Economic Crisis, Structural Adjustment and Social Crisis in Nigeria, World Development, Vol.21, No.1, pp.141-153.

Irwin, Alan and P.D. Hooper (1992). Clean Technology, Successful Innovation and the Greening of Industry: A Case Study Analysis, Business Strategy and the Environment, Vol.2, pp.13-24.

Jaffe, A.B. and K. Palmer (1996). Environmental Regulation and Innovation: A Panel Data Study, NBER WP 5545, Cambridge MA.

Jaffe, A.B., S.R. Peterson, P.R. Portney, and R.N. Stavins, (1995). Environmental Regulation and the Competitiveness of U.S. Manufacturing: What does the evidence tell us? Journal of Economic Literature, Vol.33, pp.132-163.

Jalilian, H. and J. Weiss (2000). De-industrialisation in Sub-Saharan Africa: Myth or Crisis, Journal of African Economies, Vol.9, No.1, pp.24-43.

Jalilian, H., M. Tribe and J. Weiss (eds.) (2000). Industrial Development and Policy in Africa: Issues of De-industrialisation and Development Strategy, Edward Elgar, Cheltenham, UK.

JAMB (1999a). Joint Admissions and Matriculation Board, Brochure on Guidelines for Admissions to First Degree Courses in Nigerian Universities, 2000/2001 Session, Office of the Registrar, JAMB, Lagos, Nigeria.

JAMB (1999b). Joint Admissions and Matriculation Board, Brochure on Guidelines for Admissions to Programmes in Polytechnics and Courses in Colleges of Education, Office of the Registrar, JAMB, Lagos, Nigeria.

Jung, Chulho, K. Krutilla and R. Boyd (1996). Incentives for Advanced Pollution Abatement Technology at the Industry Level: An Evaluation of Policy Alternatives, Journal of Environmental Economics and Management, Vol.30, pp.95-111.

Kamien, Morton and N.L. Schwartz (1989). Market Structure and Innovation, Cambridge University Press, Cambridge CB2 IRP, New York.

Kanter, Rosabeth, M., B.A. Stein, T.D. Jick (1992). The Challenge of Organisational Change: How Companies Experience It and Leaders Guide It, The Free Press / Macmillan Inc. International, New York. 
Karshenas, Massoud and P. Stoneman (1992). A Flexible Model of Technological Diffusion Incorporating Economic Factors with an Application to the Spread of Colour Television Ownership in the UK, Journal of Forecasting, Vol.11, pp.577-601.

Karshenas, Massoud and P. Stoneman (1993). Rank, Stock, Order, and Epidemic Effects in the Diffusion of New Process Technologies: An Empirical Model, Rand Journal of Economics, Vol.24, No.4, pp.503-529.

Kemp, René and L. Soete (1992). The Greening of Technological Progress: An Evolutionary Perspective, Futures, Vol.24, No.5, pp.437-457.

Kemp, René (1997). Environmental Policy and Technical Change: A Comparison of the Technological Impact of Policy Instruments, Edward Eglar Publishing Co., Cheltenham, UK.

Kemp, René (1998). The Diffusion of Biological Wastewater Treatment Plants in the Dutch Food and Beverage Industry, Environmental and Resource Economics, Vol.12, pp.113-136.

Kemp, René (2000). Governance of Environment-enhancing Technical Change: Past Experiences and Suggestions for Improvement, MERIT Research Memorandum 20013, Maastricht University, The Netherlands.

Kemp, René and A. Smith (2000). TEP Synthesis Report for Urban Wastewater Treatment Directive, Unpublished TEP Project Report, MERIT, Maastricht University, The Netherlands.

Kessler, Peter (1998). Economic Instruments for Water Pollution, Unpublished Comments, Hessischen Ministerium für Umwelt, Energie, Jugend, Familie und Gesundheit, Wiesbaden.

Kim, Linsu (1997). Imitation to Innovation: The Dynamics of Korea's Technological Learning, Harvard University Press, Boston, MA.

Kim, Sun G. (2000). Is Government Investment in R\&D and Market Environment Needed for Indigenous Private R\&D in Less Developed Countries?: Evidence from Korea, Science and Public Policy, Vol.27, No.1, pp.13-22.

Knödgen, Gabriele (1979). Environment and Industrial Siting: Results of an Empirical Survey of Investment by West German Industry in Developing Countries. Zeitschrift für Umweltpolitik, Vol.4, pp.407-434.

Kraemer, R. Andreas (1995). The Effectiveness and Efficiency of Water Effluent Charge Systems - Case of Germany; OECD, Paris. 
Kraemer, R. Andreas and F. Jäger (1997). Landesbericht - Deutschland, in F.N. Correia and R.A. Kraemer (eds.), Eurowater I: Institutionen der Wasserwirtschaft in Europa, Länderberichte, Länderarbeitsgemeinschaft Wasser (LAWA), Berlin, Springer Verlag, Berlin.

Kumuyi, A.J. and B.U.N. Igwe (1987). 'Commercialisation of Technological Research and Development Results in Nigeria', Conference Proceedings, 'Developing National Economy Through Appropriate Technology Policy and Planning', Obafemi Awolowo University, Ile-Ife, Nigeria.

Laditan, G.O.A. (1998). Technology Acquisition and its Implications for the Environment in Nigeria, Research Report, No.7, Development Policy Centre, Ibadan, Nigeria.

Lall, Sanjaya (1987). Learning to Industrialise: The Acquisition of Technological Capability by India, Macmillan Press, London.

Lall, Sanjaya (1992). Technological Capability and Industrialisation, World Development, Vol.20, No.2, pp.165-186.

Lall, Sanjaya, G.B. Navaretti, S. Teitel, and G. Wignaraja (1994). Technology and Enterprise Development: Ghana Under Structural Adjustment, Macmillan Press Ltd., London.

Lall, Sanjaya (1997). Policies for Industrial Competitiveness in Developing Countries: Learning from Asia, A Paper for the Commonwealth Secretariat, Queen Elizabeth House, Oxford.

Lall, Sanjaya (1997). Investment, Technology and International Competitiveness, in: J.H. Dunning and K.A. Hamdani (eds.), The New Globalism and Developing Countries, United Nations University Press, Tokyo.

Lall, Sanjaya (ed.) (1999a). The Technological Response to Import Liberalisation in sub-Saharan Africa, Macmillan Press Ltd., London.

Lall, Sanjaya (1999b). Introduction and Setting, in S. Lall (ed.), The Technological Response to Import Liberalisation in sub-Saharan Africa, Macmillan Press Ltd., London.

LASEPA (1999). Lagos State Government Policy on the Environment, The Lagos Environment, Vol.1, No.1, pp.16-17.

Laudise, Robert A. and T.E. Graedel (1998). Manufacturing, in D.J. Richards and G. Pearson (eds.), The Ecology of Industry: Sectors and Linkages, National Academy Press, Washington, D.C. 
Leonard-Barton, Dorothy (1988). Implementation as Mutual Adaptation of Technology and Organisation, Research Policy, Vol.17, pp.251-267.

Lewis, Peter M. (1994). Economic Statism, Private Capital, and the Dilemmas of Accumulation in Nigeria, World Development, Vol.22, No.3, pp.437-451.

Liao, Tim F. (1994). Interpreting Probability Models: Logit, Probit, and Other Generalized Linear Models, Sage Publications, Series No. 07-101, International Educational and Professional Publishers, London.

Liedholm, Carl (1992). Small Scale Industry in Africa: Dynamic Issues and the Role of Policy, in F. Stewart, S. Lall and S. Wangwe (eds.), Alternative Development Strategies in Sub-Saharan Africa, Macmillan, London.

Lubeck, Paul M. (1992). Restructuring Nigeria's Urban-Industrial Sector Within the West African Region: the Interplay of Crisis, Linkages and Popular Resistance, International Journal of Urban and Regional Research, Vol.16, No.1, pp.6-23.

Lundan, Sarianna M. (1996). Internationalisation and Environmental Strategy in the Pulp and Paper Industry, PhD Dissertation, The State University of New Jersey, Newark, New Jersey.

Lundvall, Karl and G.E. Battese (2000). Firm size, Age and Efficiency: Evidence from Kenyan Manufacturing, The Journal of Development Studies, Vol.36, No.3, pp.146-163.

Maddala, G.S. (1983). Limited Dependent and Qualitative Variables in Econometrics, Cambridge University Press, Cambridge.

Maddala, G.S. (1992). Introduction to Econometrics, Macmillan Publishing Company, New York.

MAN (1994). Manufacturing Association of Nigeria: Industrial Directory, Manufacturing Association of Nigeria, Lagos, Nigeria.

MAN (2000). Manufacturing Association of Nigeria: Half Yearly Report, Manufacturing Association of Nigeria, Lagos, Nigeria.

Mansfield, Edwin (1961). Technical Change and the Rate of Imitation, Econometrica, Vol.29, No.4, pp.741-766.

Mansfield, Edwin (1968). Industrial Research and Technological Innovation: An Econometric Analysis, W.W. Norton \& Company, Inc., New York.

Mckibbin, Warwick J. and P.J. Wilcoxen, (1999). Permit Trading under the Kyoto Protocol and Beyond, in F. Lo, K. Matsushita and H. Takagi, Proceedings of the 
International Conference on Sustainable Future of the Global System, UNU/IAS and IGES, Tokyo, Japan.

Mcwilliams, Bruce and D. Zilberman (1996). Time of Technology Adoption and Learning by Using, Econ. Innov. New Techn., Vol.4, pp.139-154.

Megat, Wesley A. and W.K. Viscusi (1990). Effectiveness of the EPA's Regulatory Enforcement: The Case of Industrial Effluent Standards, Journal of Law and Economics, Vol. 33, pp.331-360.

Metcalfe, J.S. (1981). Impulse and Diffusion in the Study of Technological Change, Futures, Vol.5, pp.347-359.

Metcalfe, J.S. (1988). The Diffusion of Innovation: An Interpretative Survey, in: G. Dosi., C. Freeman, R. Nelson., G. Silverberg, and L. Soete (eds.), Technical Change and Economic Theory, Pinter Publishers, London.

Meijers, Huub (1994). On the Diffusion of Technologies in a Vintage Framework: Theoretical Considerations and empirical Results, Ph.D. Dissertation No. 94-22, Faculty of economics and Business Administration, University of Maastricht, The Netherlands.

Millette, Emru D. (1991). Industrial Wastewater Monitoring at a Cane Sugar Factory, Industry and Environment, Vol.14, pp.30-34.

Milliman, Scott R. and R. Prince (1989). Firm Incentive to Promote Technological Change in Pollution Control, Journal of Environmental Economics and Management, Vol.17, pp.247-265.

Moser, Gary, S. Rogers and R. van Till (1997). Nigeria: Experience With Structural Adjustment, Occasional Paper No.148, International Monetary Fund, Washington D.C.

Mosley, P. (1992). Policy Making Without Facts: A Note on the Structural Adjustment Policies in Nigeria, 1985-1990, African Affairs, Vol.91, pp.227-240.

Mowery, David C. and N. Rosenberg (1989). Technology and the Pursuit of Economic Growth, Cambridge University Press, Cambridge.

Murphy, Joseph and A. Gouldson (1997). Environmental Policy and Industrial Competitiveness: Searching for Synergy, Memeo, Department of Geography, University of Hull, UK.

Mukherjee, Chandan, H. White, and M. Wuyts (1998). Econometrics and Data Analysis for Developing Countries, Routledge, London. 
Myers, Stephen D. (ed.) (1998). Urban Wastewater Projects - A Layperson's Guide, European Environment Agency, Copenhagen, Denmark / The European Water Pollution Control Association e.V, Hennef, Germany.

Mytelka, Lynn K. (1985). Stimulating Effective Technology Transfer: The Case of Textiles in Africa, in N. Rosenberg and C. Frischtak (eds.), International Technology Transfer, Praeger, New York.

Nabseth, L. and G.F. Ray (eds.) (1974). Diffusion of New Industrial Process: An International Study, Cambridge University Press, London.

Nabseth (1974). Summary and Conclusions, in: L. Nabseth and G.F. Ray (eds.), Diffusion of New Industrial Process: An International Study, Cambridge University Press, London.

Nambudiri, C.N.S. (1983). Third World Multinationals: Technology Choice and Employment Generation in Nigeria, ILO Working Paper No.25, International Labour Office, Geneva.

Narayanan, Suresh and L.Y. Wah (2000). Technological Maturity and Development without Research: The Challenge for Malaysian Manufacturing, Development and Change, Vol.31, pp.435-457.

Narula, Rajneesh (1997). The Role of Developing Country Multinationals in Acquisition of Industrial Technology in Nigeria: A Pilot Study, Science, Technology and Development, Vol. 15. No.1, pp.140-161.

Nelson, Richard (1995). Recent Evolutionary Theorising About Economic Change, Journal of Economic Literature, Vol.33, No.1, pp.48-90.

Nelson, R.R. and S.G. Winter (1982). An Evolutionary Theory of Economic Change, The Belknap Press of Harvard University Press, Cambridge, MA.

NISER (2000). Nigerian Institute of Social and Economic Research, $50^{\text {th }}$ Anniversary Diary, NISER, Ibadan, Nigeria.

Norusis, Marija J. (1999). SPSS Regression Models 10.0, SPSS Inc., Chicago, USA.

O'Connor, David (1994). Managing the Environment With Rapid Industrialisation: Lessons From East Asian Experience, OECD, Paris.

OECD (1985). Environmental Policy and Technical Change, OECD, Paris.

OECD (1996). The Global Environmental Goods and Services Industry, OECD, Paris. 
OECD (1997). Evaluating Economic Instruments for Environmental Policy, OECD, Paris.

Ogun, Oluremi (1995). Country Studies: Nigeria, in S.M. Wangwe, Exporting Africa: Technology, Trade and Industrialisation in Sub-Saharan Africa, UNU/INTECH Studies in New Technology and Development, Routledge, London.

Ohagi S.M.O. (1988). The Effects of Brewery Effluent Discharge on Ikpoba River Water Quality, Benin City, in P.O. Sada and F.O. Odemerho (eds.), Environmental Issues and Management in Nigerian Development, Evans Brothers Publishers Limited, Ibadan, Nigeria.

Ohiorhenuan, John F.E. (1990). The Industrialisation of Very Late Starters: Historical Experience, Prospects and Strategic Options for Nigeria, Institute of Development Studies, University of Sussex, Brighton, UK.

Okejiri, Ephraim (2000). Foreign Technology and Development of Indigenous Technological Capabilities in Nigerian Manufacturing Industry, Technology in Society, Vol.22, No.2, pp.189-199.

Okorodudu-Fubara, Margaret T. (1998). Law of Environmental Protection-Materials and Text, Caltop Publications Nigeria Limited, Ibadan, Nigeria.

Olokesusi, F. (1988). An Overview of Pollution in Nigeria and the Impact of Legislated Standards on its Abatement, The Environmentalist, Vol.8, No.1, pp.31-38.

Olokesusi, F. (1990). An Assessment of Water Supply Situation in ECOWAS Countries and the Policy Implications, Water SRT-Aqua, Vol.39, No.3, pp.152-160.

Olokesusi, F., K. Akinpelu, A. Adekunjo and J. Ojo (1997). Technological Impact of Environmental Standards and Practice Relating to Pollution Control on Nigerian Industries, Technology Research Policy Brief, Vol.2, No.5, Technopol Publishers, Ibadan, Nigeria.

Osunbor, O. A. (1990). Performance Review of Nigeria's Institutions for Science and Technology Policy, in A.M. Goka, P.B. Mihyo and O.A. Osunbor, Performance Review of Institutions for Technology Policy in Ghana, Nigeria and Tanzania, Manuscript Report, IDRC-CRDI-CIID, Nairobi, Kenya.

Oyelaran-Oyeyinka, B., G.O.A. Laditan, and A.O. Esubiyi (1996). Industrial Innovation in Sub-Saharan Africa: the Manufacturing Sector in Nigeria, Research Policy, Vol.25, pp.1081-1096.

Oyelaran-Oyeyinka, B. (1997a). Nnewi: An Emergent Industrial Cluster in Nigeria, Technopole Publishers, Ibadan, Nigeria. 
Oyelaran-Oyeyinka, B. (1997b). Technological Learning in African Industry: A Study of Engineering Firms in Nigeria, Science and Public Policy, Vol 24, No.5, pp.309318.

Palmer, K, W.E. Oates, and P.R. Portney (1995). Environmental Standards: The Benefit-Cost or No-Cost Paradigm?, Journal of Economic Perspectives, Vol.9, No.4, pp.119-132.

Pargal, Sheoli and D. Wheeler (1996). Informal Regulation of Industrial Pollution in Developing Countries: Evidence from Indonesia, Journal of Political Economy, Vol. 104, No.6, pp.1314-1327.

Perez, Carlota and L. Soete (1988). Catching up in Technology: Entry Barriers and Windows of Opportunity, in G. Dosi., C. Freeman, R. Nelson., G. Silverberg, and L. Soete (eds.), Technical Change and Economic Theory, Pinter Publishers, London.

Pindyck R.S. and D.L. Rubinfeld (1998). Econometric Models and Economic Forecasts, Irwin McGraw-Hill, Boston.

Porter, M.E. and C. van der Linde (1995a). Towards a New Conception of the Environment-Competitiveness Relationship, Journal of Economic Perspectives, Vol.9, No.4, pp.97-118.

Porter, M.E. and C. van der Linde (1995b). Green and Competitive: Ending the Stalemate, Harvard Business Review, Vol. 73, No.5, pp.120-134.

Preece, David (1995). Organisations and Technical Change: Strategy, Objectives and Involvement, Routledge Series in the Management of Technology, Routledge, London.

Ray, G.F. (1974). Introduction, in: L. Nabseth and G.F. Ray (eds.), Diffusion of New Industrial Process: An International Study, Cambridge University Press, London.

Reinganum, Jennifer F. (1981). On the Diffusion of New Technology: A Game Theoretic Approach, Review of Economic Studies, Vol. 48, pp. 395-405.

Reinganum, Jennifer F. (1983). Technology Adoption under Imperfect Information, Bell Journal of Economics, Vol.14, pp.57-69.

Rennings, Klaus (ed.) (1999). Innovation durch Umweltpolitik, Schriftenreihe des ZEW, Band 36, Nomos Verlagsgesellschaft, Baden-Baden, Germany.

Repetto, Robert (1995). Jobs, Competitiveness and Environmental Regulation: What are the real issues?, WRI, Washington DC. 
RIVM/UNEP (1997), Bakkes, J.A. and J.W. van Woerden (eds.), The Future of the Global Environment: A Model-based Analysis Supporting UNEP's First Global Environment Outlook, RIVM 402001007 and UNEP/DEIA/TR.97-1.

Rogers, Everett M. (1983). Diffusion of Innovations, Third Edition, The Free Press, New York / Collier Macmillan Publishers, London.

Roome, Nigel (1994). Business Strategy, R\&D Management and Environmental Imperatives, $R \& D$ Management, Vol 24, No.1, pp.65-82.

Rosegger, Gerhard (1989). The Economics of Production and Innovation: An Industrial Perspective, Pergamon Press, Oxford.

Rosegrant, Mark W. (1999). Water Resources in the 21st Century: Increasing Scarcity, Declining Quality, and Implications for Action, in F. Lo, T. Morita and S. Shishido (eds.), The Sustainable Future of Global Systems: Issues, Models and Prospects, United Nations Institute of Advanced Studies, Tokyo.

Rosenberg, Nathan (1976). On Technological Expectations, The Economic Journal, Vol.86, pp.523-535.

Rosenberg, Nathan (1982). Inside the Black Box: Technology and Economics, Cambridge University Press, Cambridge.

Rothwell, Roy (1992). Industrial Innovation and Government Environmental Regulation: Some Lessons From the Past, Technovation, Vol.12, No.7, pp.447-458.

Rothwell, Roy (1994). Industrial Innovation: Success, Strategy, Trends, in M. Dodgson and R. Rothwell (eds.) The Handbook of Industrial Innovation, Edward Elgar, Cheltenham, UK.

Salau, Ademola T. (1990). Integrated Water Management: The Nigerian Experience, in B. Mitchell (ed.), Integrated Water Management: International Experiences and Perspectives, Belhaven Press, Pinter Publishers, London.

Sanni, L.O., J.O. Akingbala, A.O. Oguntade, Z.A. Bainbridge, A.J. Graffham and A. Westby (1998). Processing of 'Fufu' from Cassava in Nigeria: Problems and prospects for Development, Science, Technology and Development, Vol.16, No.1, pp.58-71.

Schumpeter, Joseph A. (1949). The Theory of Economic Development: An Inquiry into Profits, Capital, Credit, Interest, and the Business Cycle, Harvard University Press, Cambridge MA.

Shaaeldin, Elfatih (1992). New Industrial Strategies for Africa, in H.H. Bass et al (eds.), African Development Yearbook 1990/91, Industrialisation Based on Agricultural Development, Lit Verlag, Hamburg. 
Siebert, Horst (1987). Economics of the environment - Theory and policy; Springer Verlag, Berlin.

Singer, H.W. and S. Roy (1993). Economic Progress and Prospects in the Third World: Lessons of Development Experience Since 1945, Edward Elgar, Aldershot, Hants, England.

Smith, Adrian (1997). Integrated Pollution Control: Change and Continuity in the UK Industrial Pollution Policy Network, Avebury Press, Aldershot.

Smith, Stephen (1995). Green Taxes and Charges: Policy and practice in Britain and Germany, The Institute for fiscal studies, London.

Skea, Jim (1994). Environmental Issues and Innovation, in M. Dodgson and R. Rothwell (eds.) The Handbook of Industrial Innovation, Edward Elgar, Cheltenham, UK.

Skea, Jim (1995). Environmental Technology, in H.Folmer, H.L. Gabel and H. Opschoor (eds.) Principles of Environmental and Resource Economics, Edward Elgar, Aldershot, UK.

Stewart, F., S. Lall, and S. Wangwe (eds.) (1992). Alternative Development Strategies in sub-Saharan Africa, Macmillan Press Ltd., London.

Stewart, Richard B. (1981). Regulation, Innovation, and Administrative Law: A Conceptual Framework, California Law Review, Vol.69, No.5, pp.1259-1377.

Stoneman, Paul (1981). Intra-firm Diffusion, Bayesian Learning and Profitability, Economic Journal, Vol.91, pp.375-388.

Stoneman, Paul (1983). The Economic Analysis of Technical Change, Oxford University Press, Oxford.

Stoneman, Paul (1991). Technology Diffusion: The Viewpoint of Economic Theory, in: P. Mathias and J.A. Davis (eds.), Innovation and Technology in Europe, From the Eighteenth Century to the Present Day, Basil Blackwell Ltd, Oxford.

Stoneman, Paul and M.J. Kwon (1996). Technology Adoption and Firm Profitability, Economic Journal, Vol.106, pp.952-962.

TEP (1999). Technology and Environmental Policy Project: Technology Portfolio, Unpublished Manuscript; MERIT, Maastricht University, The Netherlands.

The Economist (1998). Dirty Poor: A Survey of Development and the Environment, March 21st Issue. 
The Nigerian Environment (1997). Federal Environmental Protection Agency Newsmagazine March/June, 1997, Abuja, Nigeria. Vol.9, Nos.1\&2, pp.6-9.

The Nigerian Environment (1998). Federal Environmental Protection Agency Newsmagazine April/May/June, 1998, Abuja, Nigeria. Vol.10., No.2, pp.2-4.

The Nigerian Environment (1998). Federal Environmental Protection Agency Newsmagazine July/August/September, 1998, Abuja, Nigeria. Vol.10., No.3, p.5.

The Nigerian Environment (1998). Federal Environmental Protection Agency Newsmagazine October/December, 1998, Abuja, Nigeria. Vol.10., No.4, p.9.

The World of Learning (1998). $48^{\text {th }}$ Edition, Europa Publications Limited, London.

Thirtle, Colin G. and V.W. Ruttan (1987). The Role of Demand and supply in the Generation and Diffusion of Technical Change, Harwood Academic Publishers, London.

Thoburn, John T. (2000). Developing African Exports: The Case of Nigeria, in H. Jalilian, M. Tribe and J. Weiss (eds.), Industrial Development and Policy in Africa: Issues of De-industrialisation and Development Strategy, Edward Elgar, Cheltenham, UK.

Tidd, Joe, J. Bessant and K. Pavitt (1997). Managing Innovation: Integrating Technological, Market and Organizational Change, John Wiley and Sons, New York.

Tybout, James R. (2000). Manufacturing in Developing Countries: How Well Do They Do, and Why? Journal of Economic Literature, Vol. 38, pp.11-44.

UNEP (1993). The Textile Industry and the Environment, Technical Report No.16, United Nations Environment Programme: Industry and Environment, Paris.

UNEP (1994). Cleaner Production in the Asia Pacific Region, United Nations Environment Programme: Industry and Environment, Cleaner Production Programme, Paris.

UNEP (1997). Global Environment Outlook, United Nations Environment Programme / Oxford University Press, Oxford.

UNIDO (1995). Food Processing Industry: Output of a Seminar on Energy Conservation in Food Processing Industry, Handy Manual, UNIDO/Ministry of International Trade and Industry (MITI), Japan.

UNIDO (1996). Industrial Development: Global Report 1996, Oxford University Press, Oxford. 
UNIDO (1997). Industrial Development: Global Report 1997, Oxford University Press, Oxford.

UNIDO (1998). Sustainable Industrial Development: UNIDO Position, UNIDO, Vienna.

Vernon, Jan and R. Johnson (1984). Environmentally Sound Technology for Industry, UNEP Industry and Environment, April/May/June, pp.20-24.

Wang, Hua and D. Wheeler (2000). Endogenous Enforcement and Effectiveness of China's Pollution Levy System, World Bank Policy Working Paper No. 2336, Development Research Group, The World Bank, Washington, D.C.

Winston, Gordon C. (1981). Increasing Manufacturing Employment Through Fuller Utilisation of Capacity in Nigeria, in N. Phan-Thuy, R.R. Betancourt, G.C. Winston and M. Kabaj (eds), Industrial Capacity and Employment Promotion: Case Studies of Sri Lanka, Nigeria, Morocco and Over-all Survey of Other Developing Countries, ILO and Gower Publishing Company Limited, Westmead, England.

World Bank (1978). World Development Report, The World Bank, Washington D.C.

World Bank (1992). World Development Report, Oxford University Press, Oxford.

World Bank (1995). World Development Report, Oxford University Press, Oxford.

World Bank (1997). World Development Report, Oxford University Press, Oxford.

World Bank (1998a). World Development Indicators: Water Pollution, CD-ROM, The World Bank, Washington D.C.

World Bank (1998b). World Development Report: Knowledge for Development, Oxford University Press, New York.

World Bank (1999). Pollution Prevention and Abatement Handbook 1998: Towards Cleaner Production, The World Bank Group, Washington D.C.

World Bank (2000). World Development Indicators: Water Pollution, CD-ROM, The World Bank.

World Bank (2001). World Development Report: Attacking Poverty, Oxford University Press, New York. 


\section{QUESTIONNAIRES}




\section{JPTQ1 : QUESTIONNAIRE FOR NIGERIAN MANUFACTURING FIRMS .}

\section{GUIDELINES}

Please, in case your firm is part of a large corporation or multinational, answer the questions with respect to your plant. You are requested to focus on your own manufacturing firm or business unit.

\section{Section 1: BASIC INFORMATION ON YOUR FIRM}

1.1. Please, list your main products in order of importance with respect to production volume in 1998, starting with the most important.

i)

ii)

iii).

1.2. What was your firm's sales turn over in 1998 ?

1.3. Is your firm a subsidiary or an affiliate of a multinational enterprise? $\square$ YES $\square$ NO If yes, please give the country of your parent company:

1.4. Ownership structure of your firm:

My firm is ......... \% Nigerian owned [please, give the percentage of domestic equity in the firm].

1.5. The highest educational qualification of the plant manager is : [tick the most appropriate below]

$\square$ Degree or Higher diploma $\square$ Professional $\square$ Secondary technical certificate school certificate

1.6. Year firm was established :

1.7. Current capacity utilisation : $\%$

1.8. Total number of persons currently employed by your firm :

1.9. Total number of Nigerian engineers/technicians and scientists (e.g. chemists, microbiologists, etc.) currently employed by your firm :

1.10. Total number of foreign (i.e. non-Nigerian) engineers/technicians and scientists (e.g. chemists, microbiologists, etc.) currently employed by your firm :

1.11. Please, give the proportion of your firm's employees with primary, secondary and higher education: Primary education: $\%$

Secondary education: $\%$

Higher education: \% 


\section{Section 2: TECHNOLOGY ADOPTION FOR WATER POLLUTION CONTROL}

2.1. Are the following pollution issues important to your firm?

\begin{tabular}{|l|l|l|}
\hline A. Wastewater & YES \\
\hline B. Air pollution $\left(\mathrm{CO}_{2}, \mathrm{SO}_{2}\right.$, particulates, etc.)
\end{tabular}

Which is the most important?

[fill in letter]

2.2. Please, briefly mention the types of liquid waste produced by your firm

2.3. Has your firm introduced any of the following measures or technologies to reduce water pollution before or after January, 1995? [Please, tick all that apply]

\section{Water pollution control measure/method}

A. Primary wastewater treatment

B. Secondary or biological wastewater treatment

C. Advanced wastewater treatment

D. Water or/and wastewater re-use or recycling

E. Raw material re-use or recycling

F. Change in one or more raw material inputs

G.Integrated physical device in the production line

H. Others (pls., specify):

From the experiences of your firm, which of the measures do you consider the most effective in achieving less water pollution? [fill in letter]

\section{If your firm has never adopted any of the water pollution control measures mentioned in question 2.3, then go to question 3.1.}

2.4. If your firm has adopted wastewater treatment, where is the source of the wastewater treatment technology mentioned in question 2.3 ? [Please, tick only the option that apply]

Locally built or fabricated equipment

Combination of locally built and foreign equipment

Completely foreign technology equipment

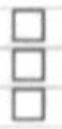

Please, state the country of origin of the foreign equipment component:

Give the year in which the wastewater treatment plant was built or adopted by your firm:

2.5. Did your firm invest in wastewater treatment technology for any of the following reasons?

\begin{tabular}{|l|}
\hline A. To pacify non-governmental organisations complaining about pollution \\
\hline B. To pacify the local community around your production plant \\
\hline C. To prevent environmental incidents \\
\hline D. To comply with Nigerian (FEPA) environmental regulation \\
\hline E. To comply with the international norm of your parent company \\
\hline F. To improve the environmental image of your company \\
\hline G. To make your products acceptable on international market \\
\hline H. Other reasons (pls., specify):
\end{tabular}

Which of the reasons above do you consider the most important reason?

[ fill in letter]

Which of the reasons above do you consider the second most important reason? 
2.6. Was the adoption of the wastewater treatment expected to reduce total production costs, perhaps through savings on environmental regulation related expenses?

$\square$ YES $\square$ NO $\square$ I can't say

2.7. Why did your firm adopt the wastewater reduction measures/methods given in the table below? [Please, tick all that apply]

\section{Measures for achieving wastewater reduction}

A. Water or/and wastewater re-use or recycling

B. Raw material re-use or recycling

C. Change in one or more raw material inputs

D. Integrated physical device in the production line

E. Others (pls., specify):

Has the effect of the adoption of wastewater reduction measures led to a net economic gain for your firm? $\square$ YES $\square$ NO $\square$ I can't say

2.8. Which of the following sources are used by your firm to solve technical problems with your wastewater treatment system or wastewater reduction measures? [Tick all that apply]
A. The technology supplier
B. Your firm's in-house technical staff
C. Your firm's foreign technical partners
D. Your firm's parent company
E. Nigerian engineering maintenance firms

Which of these five sources of technical support is the most important to your firm?

[ fill in letter]

2.9. How successful do you consider your firm's technical capability to operate or use wastewater treatment technology or the wastewater reduction measure that your firm has adopted?

$\begin{array}{llll} & \text { Very low } \\ \text { Wastewater treatment technology } & \text { Low moderate } \\ \text { Wastewater reduction measure } & \square & \square\end{array}$

2.10. Has your firm's investment in water pollution control measures led to increase, no difference or decrease in the factors listed in the table below?

\begin{tabular}{|l|l|}
\hline A. Raw materials use per unit of output \\
\hline B. Costs of wastewater treatment \\
\hline C. Costs of sludge disposal \\
\hline D. Total production costs \\
\hline E. Product quality \\
\hline F. New product development efforts \\
\hline G. First-mover advantage for export
\end{tabular}

Overall, have the effects of the adoption of water pollution control measures led to a net economic gain for your firm? $\square$ YES $\square$ NO $\square$ I can't say 
2.11. What is the current level of BOD removal from wastewater achieved by your plant's pollution control measures or technology? $\%$ BOD removal.

\section{Section 3: OBSTACLES TO ADOPTING WATER POLLUTION CONTROL TECHNOLOGY}

3.1. Before adopting technologies or measures that could reduce water pollution by your firm, was any of the following factors an important obstacle to your adoption? Alternatively, in case your firm has not adopted any water pollution control measure or technology, is any of the following factors an important obstacle to your adopting measures that could help your firm in reducing water pollution?

A. Lack of information about water pollution control technologies
B. High cost of installing and operating wastewater treatment plant
C. Lack of technical capability to use wastewater treatment plant in my firm
D. High cost of process integrated techniques that reduce wastewater generation
E. Lack of capability to carry out process integrated technical innovations in my firm
F. Poor technical feasibility of process integrated innovation that reduce wastewater
G. Uncertainty about the impact of water pollution control technologies on firm's
competitiveness
H. Lack of credit to invest in water pollution control technologies
I. There was no compelling reason to invest in water pollution control

Which of the obstacles do you consider the most importan? [fill in letter]

Which of the obstacles do you consider the second most importan? [fill in letter]

3.2. Does your firm plan to invest in the following technologies in the next three years?

[Please, tick all that apply]

Wastewater treatment technology

Production technology that will reduce water pollution

\section{Section 4: PRODUCTION PROCESS}

4.1. Where is the source of the main production equipment currently used by your firm?

\begin{tabular}{l|l|}
\hline Locally fabricated equipment \\
Combination of local and foreign equipment \\
\hline Completely foreign technology equipment
\end{tabular}

Please state the main country of origin of the foreign equipment component:

Mode of foreign equipment (technology) acquisition:

$\square$ Licensing 
4.2. How old is the main production equipment?

4.3. What is the current replacement cost of your main production equipment?

4.4. Are you using any of the following organisations or institutions as source(s) of general technological knowledge or innovation?

\begin{tabular}{|l|}
\hline A. Supplier(s) of the main production technology \\
\hline B. Supplier(s) of environmental technology \\
\hline C. Local research institute(s) in Nigeria \\
\hline D. International research institute(s) \\
\hline E. Nigerian higher institutions (universities, polytechnics, etc.). \\
\hline F. Your firm's in-house R\&D \\
\hline G. Your firm's parent company \\
\hline H. Your firm's foreign technical partners \\
\hline I. Other firm(s) in your manufacturing industry
\end{tabular}

Which is the most important source of technological knowledge or innovation?.

Which is the most important source of technical solutions to water pollution problems?

[fill in letter]

\section{Section 5: ENVIRONMENTAL REGULATION AND MANAGEMENT}

5.1. Which of the following best describes the current attitude of your firm's top management to environmental issues? [Please, tick only one option]

No commitment or environmental management is seen to be unnecessary

Somewhat committed or environmental concerns should only be addressed when necessary

Fairly actively involved, environmental management is regarded as useful

Environmental concerns are important

Environmental concerns are a top priority

5.2. FEPA's national effluent limitation regulation came into effect in January, 1995. How would you rate the commitment of your firm to environmental management before and after January, 1995?

\begin{tabular}{|c|c|c|c|c|c|}
\hline & Very low & Low & Moderate & High & Very High \\
\hline Before Jan., 1995 & $\square$ & $\square$ & $\square$ & $\square$ & $\square$ \\
\hline After Jan., 1995 & $\square$ & $\square$ & $\square$ & $\square$ & $\square$ \\
\hline
\end{tabular}

5.3. If your firm is a subsidiary or an affiliate of a multinational, how do you view the standard of environmental management in your firm in comparison to that of the parent company?

The standard of environmental management in my firm is :

lower than that of the parent company.

same as that of the parent company.

higher than that of the parent company. 
5.4. Do you discuss technical options for solving identified pollution problems with the government compliance monitoring officials?

$\square$ YES

$\square$ NO.

If yes, how useful are the technical suggestions of the government compliance monitoring officials?

\begin{tabular}{|l|}
\hline Very useful \\
\hline Useful \\
\hline Sometimes useful \\
\hline Not useful \\
\hline Usually they have no technical suggestion, they are only interested in forcing compliance \\
\hline
\end{tabular}

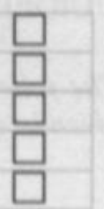

5.5. Is the attitude of the government compliance monitoring officials co-operative or confrontational to your firm?

$\square$ co-operative $\square$ confrontational

5.6. Was there ever a disagreement between your company and the environmental authority about the most appropriate compliance technology or method for water pollution control?

$\square$ YES $\square$ NO

If yes, was your firm forced to invest in the technology or measure favoured by the environmental authority? $\square$ YES $\square$ NO

5.7. How has environmental regulation in Nigeria affected your firm with respect to the following factors in the last four years?

\begin{tabular}{|l|l|}
\hline A. Total production costs \\
B. Product quality \\
\hline C. New product development efforts \\
\hline D. First-mover advantage for export \\
\hline E. Others (pls., specify): .....................................
\end{tabular}

Which of the above factors do you consider the most important impact of environmental regulation on your firm? [fill in letter]

5.8. Has your company been able to enter the export market? $\square$ YES $\square$ NO

If yes, to where do you export your products? [Please, tick all that apply].

West Africa $\square$ Other Africa $\square$ Others (pls., specify):

Which is the most important export destination for your products?

\section{THANK YOU！}

If you are interested in getting a report on the main findings of this research project, please complete the section below:

Name of respondent: Position:

Name of firm

Address:

Tel:

E-mail:

Fax: 


\section{JPTQ2 : QUESTIONNAIRE FOR NIGERIAN MANUFACTURING FIRMS \\ (SUPPLEMENT TO JPTQ1)}

\section{GUIDELINE}

The following questions are to be used to gather additional information to supplement the responses given in questionnaire JPTQ1, and as guides for detailed case study interview.

\section{SECTION 1 : INPUT RESOURCES AND TREND OF OUTPUT STRUCTURE}

1.1. List some of the raw materials you use in order of importance and state whether they are imported ('IMP'), locally sourced from other firms (' $L F$ ') or cultivated by your firm (' $C$ ').

\begin{tabular}{|l|l|}
\hline Name of raw material & Sources: 'IMP', ' $L F$ ' or ' $C$ ' \\
\hline & \\
\hline & \\
\hline & \\
\hline
\end{tabular}

1.2. When raw materials are sourced from Nigerian firms, is environmental performance (e.g. pollution control activities) of the firms considered?

$\square$ YES $\square$ NO

1.3. In the following table, please give your firm's annual turn-over and profit before tax in 1991, 1995, 1998 (or the nearest years for which information is available)?

\begin{tabular}{|c|c|c|}
\hline Year & annual sales turn-over & profit before tax \\
\hline 1991 & & \\
\hline 1995 & & \\
\hline 1998 & & \\
\hline
\end{tabular}

1.4. Are your outputs used as inputs by other Nigerian firms? $\square$ YES $\square$ NO If yes, in which sector(s)? 


\section{Section 2: TECHNOLOGY ADOPTION FOR WATER POLLUTION CONTROL}

2.1. Do you monitor the amount of wastewater generated by your plant?

If $y e s$, what is the average quantity? $\mathrm{m}^{3} /$

2.2. What is the BOD concentration of the wastewater before treatment? $\%$

2.3. What is the BOD concentration of the wastewater after treatment? $\%$

2.4. Do you share the wastewater treatment plant with other firms?

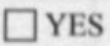

$\square$ NO If yes, how many firms?

To which industrial subsectors belong the firms with which you share the use of wastewater treatment plant?

2.5. What have been the most important source(s) of water pollution in your production process?

2.6. How do you see the future of your firm's investment in technologies that can reduce or prevent water pollution? Investment will

\begin{tabular}{|c|c|c|c|}
\hline$\square$ increase & $\square$ increase & $\square$ remain & $\begin{array}{l}\square \text { decrease } \\
\text { moderately }\end{array}$ \\
\hline
\end{tabular}

2.7. Are you aware of any subsidy or tax policy that could help you in acquiring water pollution control technologies?

YES

$\square$ NO

If $y e s$, which and has it been helpful?

2.8. What is the quantity of water required by your plant per month?

2.9. How do you source the water? [Please, rank the following water sources in order of their importance to your firm by ascribing 1 to the most important, 2 to the next important, etc.]

\begin{tabular}{|l|l|}
\hline Public water supply system & $\square$ \\
\hline Own bore hole & $\square$ \\
\hline Tanker service & $\square$ \\
\hline Others (pls., specify): & $\square$ \\
\hline
\end{tabular}




\section{Section 3: PRODUCTION PROCESS, R\&D AND INNOVATION}

3.1. Does your company have a foreign technical agreement with the supplier of your production technology?

$\square$ YES

$\square$ NO

If yes, what is the nature of the agreement? [Please, tick all the options applicable to your firm]

Turn-key agreement which expired with the installation and test running of the plant

Technical agreement for regular maintenance of the plant

Technical agreement for occasional problem beyond the capability of local staff

Others (pls., specify):

3.2. How does the production technology in the firm compare with the best available technology (BAT) currently in use? [Please, tick only the option applicable to your firm]

Comparable with current BAT any where in the world

BAT of between 2-5 yrs. ago

BAT of between 6-10 yrs. ago

BAT of between 11-20 yrs. ago

BAT of over 20 yrs. ago

Not comparable to any internationally used technology

$\square$
$\square$
$\square$
$\square$
$\square$
$\square$

3.3. Does your firm have an R\&D department?

YES

$\square$ NO

If yes, which of the following are important aspects of your in-house R\&D?

A. Maintenance and efficient operation of current production technology

B. Improvement of technical performance of current production technology

C. Improvement of environmental performance of current production technology

D. Minor product design and development

E. Major product design and development

F. Others (pls., specify):

Which is the most important?

Which is the second most important? 


\section{Section 4: ENVIRONMENTAL REGULATION AND MANAGEMENT}

4.1. What are the environmental regulations and norms that your firm has to comply with?

4.2. During which year(s) did environmental management become an important issue in your firm?

$\square$ Before $1991 \square$ 1991-94 $\square$ After $1994 \quad \square$ not yet important

4.3. Does your firm embark on environmental management for any of the following reasons?

\begin{tabular}{|c|c|c|}
\hline & YES & NO \\
\hline A. Compliance with FEPA's National effluent limitation regulation & $\square$ & \\
\hline B. Prevention of environmental incidents & $\square$ & \\
\hline C. Enhancement of the positive image of the firm & $\square$ & $\square$ \\
\hline D. Integrating environmental issues into the overall firm strategy & $\square$ & L \\
\hline E. Realising new market opportunities abroad & $\square$ & $\square$ \\
\hline F. Realising new market opportunities in Nigeria & $\square$ & $\square$ \\
\hline G. Pressure from local communities & $\square$ & $\square$ \\
\hline H. Pressure from non-governmental organisations & $\square$ & $\square$ \\
\hline I. Other reasons (pls., specify): & $\square$ & $\square$ \\
\hline
\end{tabular}

4.4. Does your firm practice TQM or a formal Environmental Management System (EMS)?

$\square$ YES $\square$ NO

If yes, since when and what type of EMS?

4.5. Does your firm perform eco-auditing or life-cycle analysis? $\quad \square$ YES $\square$ NO If yes, since when?

4.6. Has your firm obtained any ISO certification? $\square$ YES $\square$ NO If yes, which and when?

4.7. Does your firm have an environmental statement and/or environmental report? $\square$ YES If $y e s$, when was it produced?

The environmental statement includes 'a commitment to.

[Please, tick all the options below that are relevant to your firm]

work towards sustainable development
comply with national environmental laws and regulations
continual improvement in environmental performance
reduce waste and resource consumption through recycling, as opposed to disposal where feasible
development of own Environmental Management Systems (EMS)
evaluate the environmental impact of new activities and products
environmental education and training
encourage sound environmental practices amongst suppliers and contractors
involvement of and communication with local communities


4.8. Has your firm set specific environmental targets?

If yes, are the following targets applicable to your firm?

\begin{tabular}{|l|c|c|}
\hline A. Reductions in waste water produced by plant & YES & NO \\
\hline B. Reductions in solid waste & $\square$ & \\
\hline C. Reductions in atmospheric emissions & & \\
D. Increased energy efficiency & $\square$ & \\
E. Others (pls., specify): & $\square$ & \\
\hline
\end{tabular}

Which is the most important target?

4.9. Are the following means of environmental regulation compliance monitoring applicable to your firm?

A. Internal self monitoring only

B. External monitoring by parent company

C. Monitoring by officials of federal or state environmental protection agencies

D. Others (pls., specify):

Which is the most important?

4.10. How regular is monitoring by officials of federal or state environmental protection agencies? [Please, tick only the correct or most appropriate option]

Only once in a while

Only when there is major pollution problem

Regularly but not frequent enough to ensure adequate compliance

Regularly and effective

4.11. Do you think the compliance monitoring officials have adequate technical and scientific knowledge required for monitoring your firm's environmental performance? $\square$ YES $\square$ NO

4.12. Has any industrial association (national or international) important influence on your firm's attitude to environmental issues? $\square$ YES $\square$ NO

If yes, give name of such associations /organisations and the kind of influence

4.13. Has your firm been penalised for non-compliance with environmental regulation in the past?

$\square$ YES $\square$ NO

If yes, what was the penalty imposed? 
4.14. Does your firm have environmental activities linked with the local community and/or municipality? $\square$ YES

If yes, what is the nature?

4.15. Do you expect stricter environmental regulations in future?
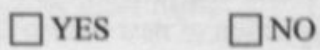

4.16. Do you think wastewater charges (tax) as an instrument of environmental regulation will make firms in your manufacturing subsector more responsive to the need to control industrial wastewater pollution?
$\square$ YES
$\square$ NO

4.17. Will you favour introduction of wastewater effluent charge (tax) as an instrument of water pollution control? $\square$ YES $\square$ NO

Why?

4.18. How do you respond to the economic argument that environmental regulation could create a "winwin" situation, in that while the quality of the environment is improved, firms can also gain competitive advantage through regulation-induced innovation?

4.19. What kinds of policy do you think necessary to enable your firm to be responsive to environmental issues without impinging on competitiveness?

4.20. What is your firm's long-term strategy of balancing competitiveness and 'greening'? 
1. What type of monitoring activity do you implement with regard to environmental pollution by manufacturing firms?

\begin{tabular}{|l|c|}
\hline A. General inspection of new industrial facilities & YES \\
\hline $\begin{array}{l}\text { B. Inspection of new industrial facilities with specific reference to pollution } \\
\text { control equipment }\end{array}$ & $\square$ \\
\hline C. General inspection of existing industrial facilities & $\square$ \\
\hline $\begin{array}{l}\text { D. Inspection of existing industrial facilities with specific reference to } \\
\text { pollution control equipment }\end{array}$ & $\square$ \\
\hline E. Inspection of effluent quality & $\square$ \\
\hline F. Evaluation of eco-audit reports from firms & $\square$ \\
\hline G. Others (pls., specify): & $\square$ \\
\hline
\end{tabular}

2. What is the attitude of firms to compliance monitoring?

\begin{tabular}{l|l|} 
Most firms co-operate & $\square$ \\
\hline Only some firms co-operate & $\square$ \\
\hline Most firms don't co-operate & $\square$
\end{tabular}

3. Do firms co-operate with monitoring officials in the inspection of the performance of the pollution control equipment?
Most firms co-operate
Only some firms co-operate
Most firms don't co-operate

4. Does your agency have a pollution control/monitoring laboratory? $\square$ YES $\square$ NO If yes, how do you rate the laboratory facility?

Very good, with modern apparatus

Satisfactory, suitable only for most urgent needs

Unsatisfactory, obsolete facility

5. Has your agency been involved in disputes with firms not complying with existing environmental regulation?

$\square$ YES $\square$ NO

If yes, which of the following have been employed in resolving the disputes?
A. Issue of warnings
B. Court action
C. Fine
D. Temporary ceiling/closure of the erring firm
E. Dialogue and persuasion that result in compliance
F. Others (pls., specify):

Which has been mostly used? 
6. What in your opinion are the obstacles to firms' compliance with the national effluent limitation regulation?

A. Lack of technical information on relevant technologies for compliance
B. Firms are incapable of operating pollution abatement technologies such as
wastewater treatment plants
C. Firms are incapable of technical solutions that reduce pollution at source
D. The costs of installing pollution control facilities are prohibitive for most firms
E. Inadequate monitoring of compliance
F. Inadequate market incentive for firms to comply
G. The national effluent limits are too stringent
H. Other obstacles (pls., specify):

Which do you consider the most important obstacle?

Which do you consider the second most important obstacle?

7. Where compliance has been observed, what in your opinion have been the factors that favoured firms compliance with the national effluent limitation regulation?

\begin{tabular}{|l|}
\hline A. Regular and effective monitoring of compliance by government officials \\
B. Firm's proactive attitude towards environmental management \\
C. Firm's own technical capability in pollution control \\
\hline D. Firm's contacts with foreign partners on technology for pollution control \\
E. Environmental policy of the parent company \\
F. Community pressure on firms \\
G. Other reasons (pls., specify):
\end{tabular}

Which do you consider the most important factor?

Which do you consider the second most important factor?

8. Are you of the opinion that necessary technical measures are being employed by firms in the FOOD AND BEVERAGES industry to prevent or abate water pollution?

$\square$ YES

If yes, from your monitoring experiences, which of the following is being used by firms in the FOOD AND BEVERAGES industry?

A. Primary wastewater treatment plant
B. Secondary or biological wastewater treatment plant
C. Advanced wastewater treatment plant
D. Water or/and wastewater re-use or recycling
E. Raw material re-use or recycling
F. Change in one or more raw material inputs
G. Integrated physical device in the production line
H. Others (pls., specify):

Which do you consider mostly in use?

Which do you consider second mostly in use? 
9. Do you think firms in Nigerian FOOD AND BEVERAGES industry have enough technical capability to significantly improve on current levels of pollution abatement?
$\square$ YES
$\square$ NO
$\square$ I can't say

10. How would you rate the FOOD AND BEVERAGES industry's compliance with the national effluent limitation regulation?
$\square$ Very good
$\square$ Good
$\square$ Fair
$\square$ Poor $\square$ Very poor

11. Are you of the opinion that necessary technical measures are being employed by firms in the TEXTILE industry to prevent or abate water pollution?

$\square$ YES $\square$ NO.

If yes, from your monitoring experiences, which of the following is being used by firms in the TEXTILE industry?

\begin{tabular}{|l|}
\hline A. Primary wastewater treatment plant \\
B. Secondary or biological wastewater treatment plant \\
\hline C. Advanced wastewater treatment plant \\
D. Water or/and wastewater re-use or recycling \\
E. Raw material re-use or recycling \\
\hline F. Change in one or more raw material inputs \\
\hline G. Integrated physical device in the production line \\
\hline H. Others (pls., specify):
\end{tabular}

Which do you consider mostly in use?

Which do you consider second mostly in use?

12. Do you think firms in Nigerian TEXTILE industry have enough technical capability to significantly improve on current levels of pollution abatement?

$\square$ YES

$\square$ NO $\square$ I can't say

13. How would you rate the TEXTILE industry's compliance with the national effluent limitation regulation?
$\square$ Very good
$\square$ Good
$\square$ Fair
$\square$ Poor
Very poor

14. How would you generally rate the current level of Nigerian manufacturing industry's compliance with the national effluent limitation regulation?
$\square$ Very good
$\square$ Good
$\square$ Fair $\square$ Poor
$\square$ Very poor

15. Do you favour introduction of wastewater effluent charge (tax) on effluents as a means of controlling pollution?

$\square$ YES $\square$ NO

If yes, why? 
16. What effect do you think wastewater effluent charge (tax) will have on firms' adoption of technologies for pollution control?

Why?

17. What are the important obstacles to effective monitoring of industrial water pollution in Nigeria?

A. Number of monitoring officials not sufficient

B. Monitoring officials have no adequate training to monitor industrial pollution

C. Inspection is constrained by lack of vehicles to carry out inspection visits

D. Firms are averse (antagonise) to inspection visits

E. Poor laboratory facilities for pollution monitoring

F. The process of granting pollution permit to firms is too cumbersome

G. The process of indicting erring firms is too cumbersome

H. Other obstacles (pls., specify):

Which do you consider the most important obstacle?

Which do you consider the second most important obstacle?

18. Are there areas of conflict between FEPA and SEPA officials with respect to monitoring industrial pollution?

$\square$ YES $\quad \square$ NO

If yes, please give examples.

19. Total number of employees in your environmental protection agency:

No. with first degree or higher national diploma:

No. with postgraduate degree:

No. with training in environmental sciences/technology:

20. Rank or grade level of officer completing the questionnaire:

Name of officer completing the questionnaire (optional):

Name of environmental regulatory agency: 
APPENDICES 


\section{APPENDIX 1: Instruments of Environmental Regulation in Nigeria}

This appendix provides briefs on environmental policy in Nigeria, especially part of the efforts of the Federal Environmental Protection Agency that has relevance for industrial pollution control.

1. National Policy on the Environment (November, 1989)

The document describes guidelines and strategies for achieving the policy goal of sustainable development by:

- Securing for all Nigerians a quality of environment adequate for their health and well-being;

- Conserving and using the natural resources for the benefit of present and future generations;

- Restoring, maintaining and enhancing the ecosystem and ecological processes essential for the preservation of biological diversity;

- Raising public awareness and promoting understanding of the essential linkages between environment and development; and,

- Co-operating with other countries and international organisations and agencies to achieve the above.

\section{National Guidelines and Standards for Environmental Pollution Control in Nigeria} (March, 1991)

This is the basic instrument for monitoring and controlling industrial and urban pollution.

\section{National Effluent Limitation Regulation (S.I.8 of 1991)}

This makes it mandatory for industrial facilities to install anti-pollution equipment, makes provision for effluent treatment and prescribes maximum limits of effluent parameters allowed for contravention.

4. Pollution Abatement in Industries and Facilities Generating Wastes Regulation (S.I.9 of 1991) Among other things, this imposes restrictions on the release of toxic substances and stipulates requirements for monitoring of pollution to ensure that permissible limits are not exceeded while unusual and accidental discharge's contingency plans, generator's liability and strategies for waste reduction and the safety of workers are put in place.

\section{Waste Management Regulations (S.I.15 of 1991)}

This regulates the collection, treatment and disposal of solid and hazardous wastes from municipal and industrial sources and gives the comprehensive list of chemicals and chemical wastes by toxicity categories.

\section{Environmental Impact Assessment (EIA) Decree No.86 of 1992.}

This law makes EIA mandatory for any major development project likely to have adverse impacts on the environment, and prescribes the procedure for conducting and reporting EIAs.

\section{Sectorial Guidelines for EIA}

These prescribe the detailed guidelines for conducting EIA for projects on sectoral basis.

\section{Natural Resources Conservation Action Plan.}

This spells out sectoral strategies for the conservation of Nigeria's natural resources (fauna, flora, soil, aquatic ecosystems) towards sustainable development. 
APPENDIX 2 : Effluent limitation guidelines in Nigeria for all categories of industries; units in milligram per litre ( $\mathrm{mg} / \mathrm{l})$ unless otherwise stated.

\begin{tabular}{|c|c|c|}
\hline Parameters & $\begin{array}{l}\text { Limit for discharge into } \\
\text { surface waters }\end{array}$ & Limit for land application \\
\hline Temperature & $\begin{array}{l}\text { less than } 40^{\circ} \mathrm{C} \text { within } 15 \mathrm{~m} \text { of } \\
\text { outfall }\end{array}$ & less than $40^{\circ} \mathrm{C}$ \\
\hline Colour (Lovibond Units) & 7 & - \\
\hline $\mathrm{pH}$ & $6-9$ & $6-9$ \\
\hline BOD 5 at $20^{\circ} \mathrm{C}$ & 30 & 50 \\
\hline Total suspended solids & 30 & - \\
\hline Total dissolved solids & 2,000 & 2,000 \\
\hline Chloride (as Cl) & 600 & 600 \\
\hline Sulphate (as $\mathrm{SO}_{4}{ }^{2}$ ) & 500 & 1,000 \\
\hline Sulphide (as $\mathrm{S}^{2}$ ) & 0.2 & - \\
\hline Cyanide (as $\mathrm{CN}$ ) & 0.1 & - \\
\hline $\begin{array}{l}\text { Detergents (Linear alkylate } \\
\text { sulphonate as methylene blue } \\
\text { active substance) }\end{array}$ & 15 & 15 \\
\hline Oil and grease & 10 & 20 \\
\hline Nitrate (as $\mathrm{NO}_{3}{ }^{2}$ ) & 20 & - \\
\hline Phosphate (as $\mathrm{PO}_{4}{ }^{3}$ ) & 5 & 10 \\
\hline Arsenic (as As) & 0.1 & 5 \\
\hline Barium (as Ba) & 5 & 10 \\
\hline Tin (as Sn) & 10 & - \\
\hline Iron (as Fe) & 20 & - \\
\hline Manganese (as Mn) & 5 & - \\
\hline $\begin{array}{l}\text { Phenolic compounds (as } \\
\text { phenol) }\end{array}$ & 0.2 & - \\
\hline Chlorine (free) & 1.0 & - \\
\hline Cadmium, Cd & less than 1 & - \\
\hline $\begin{array}{l}\text { Chromium (trivalent and } \\
\text { hexavalent) }\end{array}$ & less than 1 & - \\
\hline Copper & less than 1 & - \\
\hline Lead & less than 1 & - \\
\hline Mercury & 0.05 & - \\
\hline Nickel & less than 1 & - \\
\hline Selenium & less than 1 & - \\
\hline Silver & 0.1 & - \\
\hline Zinc & less than 1 & - \\
\hline Total metals & 3 & - \\
\hline Calcium (as $\mathrm{Ca}^{2}$ ) & 200 & \\
\hline Magnesium (as $\mathrm{Mg}^{2+}$ ) & 200 & - \\
\hline Boron (as B) & 5 & 5 \\
\hline Alkyl mercury compounds & Not detectable & Not detectable \\
\hline $\begin{array}{l}\text { Polychlorinated Biphenyl } \\
\text { (PCBs) }\end{array}$ & 0.003 & 0.003 \\
\hline Pesticides (total) & less than 0.01 & less than 0.01 \\
\hline Alpha emitters, $\mathrm{u} / \mathrm{ml}$ & $10^{-7}$ & - \\
\hline Beta emitters, uc/ml & $10^{-6}$ & - \\
\hline Coliform (daily average) & $400 \mathrm{MPN} / 100 \mathrm{ml}$ & $500 \mathrm{MPN} / 100 \mathrm{ml}$ \\
\hline
\end{tabular}

Source: FEPA (1991a). 
APPENDIX 3 : Additional effluent limitation for wastewater discharge for food \& beverages and textile sectors in Nigeria; units in milligram per litre $(\mathrm{mg} /)$ unless otherwise stated.

\begin{tabular}{|l|l|lc|}
\hline \multicolumn{1}{|c|}{$\begin{array}{c}\text { Industry } \\
\text { sector/subsector }\end{array}$} & \multicolumn{1}{|c|}{ Problems } & \multicolumn{2}{l|}{$\begin{array}{l}\text { Guidelines for maximum } \\
\text { concentration allowed for discharge } \\
\text { into inland waters }\end{array}$} \\
\hline Brewing & Alkaline effluent & Suspended solids & 15 \\
& High suspended solids & BOD & 30 \\
& High BOD & pH & $6-9$ \\
& High COD & COD & 80 \\
\hline Sugar processing & High BOD & BOD & 30 \\
& & Suspended solids & 5 \\
& & pH & $6-9$ \\
\hline Other food processing & High BOD & BOD & 15 \\
& Oil and grease & Oil and grease & 15 \\
& High suspended solids & Suspended solids & 15 \\
\hline & & & $6-9$ \\
& High BOD & pH & 20 \\
& High suspended solids & BOD & 8 \\
& Colour & COD & 15 \\
& & Suspended solids & $<0.10$ \\
& & Chromium (vi) & 0.01 \\
& & Phenols & 0.20 \\
& & Sulphide & None \\
& & Coliform & None \\
\hline & & Colour & Odour \\
& & &
\end{tabular}

Note: For wastewater discharge into small streams more stringent parameters could be applied. Source: FEPA (1991a). 


\section{APPENDIX 4: Glossary of Wastewater Treatment Plants}

The description of wastewater treatment technology and processes presented below is largely based on a literature survey of wastewater treatment practices reported under the Technology and Environmental Policy (TEP) research project ${ }^{1}$ (TEP, 1999), and a report by Economic Commission for Europe (ECE) on strategies, technologies and economics of wastewater management (ECE, 1984). It should however be noted that the listing is not exhaustive because wastewater treatment technology is diverse and innovation activities have introduced considerable sophistication into industrial wastewater treatment. What is presented in this glossary is more of a basic and general overview of wastewater treatment technology and processes.

\section{PRIMARY WASTEWATER TREATMENT}

In industry, primary treatment is usually the first stage of the wastewater treatment process. It will normally be followed by secondary treatment and /or advanced wastewater treatment.

\subsection{Septic tank}

A septic tank is a continuous-flow horizontal settlement basin for the treatment of domestic wastewater. This could only be used in industry exclusively for nonproduction related wastewater such as wastes from canteens.

\subsection{Imhoff tank}

Imhoff tank consists of a two-story tank in which sedimentation is accomplished in the upper compartment and digestion in the lower one. It is similar in use and operation to the septic tank.

\subsection{Floatation}

The floatation process separates solids or liquid particles from the liquid phase, and it is usually carried out as preliminary treatment before primary sedimentation. Separation is brought about by introducing fine gas or air bubbles into the liquid phase. The bubbles attach to the particles matter and both rise to the surface. Particles that have a higher density than the liquid can thus be made to rise and removal facilitated. Floatation may be enhanced by the use of chemical additives.

\subsection{Screening}

This is a process of removing solids by interception. There are two types of screens, bar racks (bar screens) and drum screens, which could be static (i.e. fixed) or rotary type. In the case of bar racks, debris collects on the screens and is removed by mechanical devices on a regular basis. Drum screens have fine mesh, which traps the debris, and thus sieve them out of the wastewater.

\footnotetext{
The TEP project assesses the technological impact of three EU environmental directives among which is the European Union Directive 91/271/EEC concerning urban wastewater treatment (Kemp and Smith, 2000).
} 


\subsection{Grit chambers}

These are locations or parts of the primary wastewater treatment system where special channels or separators are used to remove grit sands and gravel while settleable solids are retained in suspension.

\subsection{Oil traps/schemers}

These are interceptor tanks that may include mechanical oil separators to aid the removal of waste oils and greasy substances from wastewater. The process of trapping grease may include cooling and floatation, and oils by floatation.

\subsection{Primary sedimentation tanks}

This is a primary reservoir, which may include some chemical coagulation to remove settleable solids and reduce suspended solids content from wastewater. It may also include screens for floating solids removal if not preceded by a grit chamber. Primary sedimentation tanks could also be used as stormwater retention tanks. They may provide substantial degree of wastewater treatment, or they may be used as a preliminary step in the further processing of wastewater. When they serve as the main wastewater treatment facility, they are generally effective in removing settleable solids, a portion of the organic load, free oil and grease, and other floating materials. According to Myers (1998, p.80), the settlement process usually removes between 50 and $70 \%$ of the suspended solids and achieve only 20 to $35 \%$ reduction of BOD.

\subsection{Lamella plate separators}

Lamella plate separators could be introduced into primary sedimentation tanks in order to save space. Wastewater is allowed to flow down through a system of inclined Lamella plates in the sedimentation tank. The pattern of flow promotes flocculation of solids particles, which coalesce and settle to the bottom of the tank. The plate separators may reduce volume demand by sedimentation tanks by $60-90 \%$ but may markedly increase the capital costs of settlement tanks.

\section{BIOLOGICAL/SECONDARY WASTEWATER TREATMENT}

Biological or secondary wastewater treatment is a combination of processes customarily used for the removal of biodegradable organic and suspended solids. It generally includes biological treatment by the activated sludge process, fixed-film reactors, and anaerobic systems. According to Myers (1998, p.116), secondary treatment is generally expected to produce a removal efficiency of up to $85 \%$ for BOD and suspended solids.

\subsection{Activated sludge process}

TEP (1999) presents a concise description of the activated sludge process. The activated sludge treatment process has wide applications and variants. The basic process involves the mixing of wastewater that has undergone primary sedimentation 
with micro-organisms, mainly bacteria, known as activated sludge. The microbes feed on the polluting matter that is suspended or dissolved in the wastewater. The treatment is performed in a tank normally $2-4 \mathrm{~m}$ deep to which oxygen is supplied to drive the metabolism of the micro-organisms. The microbes need oxygen to respire and grow using as their source of food the carbonaceous and other nutrients in the wastewater. The sludge is separated from the treated effluent in secondary sedimentation or settlement tank, from where a clear supernatant is removed while part of the sludge is recycled to the start of the process. Below is the list of the common activated sludge systems.
a) Plug-flow
b) Complete-mix
c) High rate and extended aeration
d) Step aeration
e) Tapered aeration
f) Pure oxygen
g) Sequencing batch reactors (SBR)
h) Contact stabilisation
i) Oxidation/Pasveer ditches
j) Carrousel
k) Deep shaft

The conventional and more used variations are the plug-flow and complete-mix activated sludge systems.

\subsection{Trickling filter process}

According to TEP (1999), this is one of the oldest forms of biological wastewater treatment, and has been used for nearly 100 years. Trickling filters consist of a bed of a highly permeable medium (small piece of stone or plastic) to which microorganisms are attached and through which wastewater is percolated. They can have circular or rectangular designs. Wastewater is applied to the surface on the top of the bed by a distributor or an electric motor or turbine driven by the wastewater flow. Filters are constructed with an underdrain system for collecting the treated wastewater and any biological solids that have became detached from the media. This underdrain system is important both as a collection unit and as a porous structure through which air can circulate. The organic material present in the wastewater is degraded by a population of micro-organisms attached to the filter media. Organic material from the liquid is absorbed onto the biological film. In the outer area of the biological film the organic material is degraded by aerobic micro-organisms. As the thickness of the film increases the diffused oxygen is consumed before it can penetrate the full depth of the film so that an anaerobic environment is established. As the biological film increases in thickness, the adsorbed organic matter is metabolised before it can reach the microorganisms near the media face. As a result of having no external organic source available for cell carbon, the micro-organisms near the media face enter into an endogenous phase of growth and loose their ability to be attached to the media. The water then washes the biological film and a new layer starts to grow. 
Trickling filters are classified by loading rates as high rate, medium rate and low rate. Frequently, two stage filters are used, in which two trickling filters are connected in series.

\subsection{Anaerobic biological wastewater treatment}

Anaerobic wastewater treatment processes are almost exclusively used for high strength wastewater and for denitrification. There are two main types of anaerobic treatment processes: anaerobic suspended-growth treatment processes, and anaerobic attached-growth treatment processes.

\subsubsection{Anaerobic suspended-growth wastewater treatment}

Though several different anaerobic suspended-growth treatment processes have been developed in the past few years, the most common one is the complete-mix anaerobic digestion process.

In the complete-mix anaerobic digestion process, the organic material in mixtures of primary settled and biological sludge is converted biologically, under anaerobic conditions, to a variety of end products including methane $\left(\mathrm{CH}_{4}\right)$ and carbon dioxide $\left(\mathrm{CO}_{2}\right)$. The process is carried out in an airtight reactor. Sludge, introduced continuously or intermittently, is retained in the reactor for varying periods of time.

There are two types of anaerobic digesters:

a) Standard-rate reactor: This is usually an unheated and unmixed process. Detention times vary from 30 to 60 days.

b) High-rate reactor: This is a heated and mixed process, and therefore the detention times are shorter ( 15 days or less).

A combination of these two basic processes is known as the "two-stage process". The primary function of the second stage is to separate the digested solids from the supernatant liquor. Additional digestion and gas production may however occur.

Other types of anaerobic suspended-growth processes include the Upflow Anaerobic Sludge Blanket System (UABS) and the Anaerobic Contact Process (ACP).

The UABS is one of the major processes, which have been developed for treating high strength wastewater. It requires pre and post treatment stages before and after the main part of the process. Pre-treatment consists of an acidification stage at $30-35^{\circ} \mathrm{C}$. The wastewater is then pumped to the bottom of an anaerobic reactor containing a bed of sludge about $2 \mathrm{~m}$ in depth. There the carbonaceous matter is converted, in the absence of oxygen, in two successive biological processes to carbon dioxide and methane. Finally a post treatment stage is necessary to remove hydrogen sulphide formed during the anaerobic process, which is absorbed in a peat bed filter. The overall process can remove up to $90 \%$ of the carbonaceous matter from the wastewater.

In the anaerobic contact process (ACP), untreated wastes are mixed with recycled sludge solids and then digested in a reactor sealed off from the entry of air. The 
contents of the digester are mixed completely. After digestion, the mixture is separated in a clarifier or vacuum flotation unit, and the supernatant is discharged as effluent, usually for further treatment. Settled anaerobic sludge is then recycled to seed the incoming wastewater. Because of the low synthesis rate of anaerobic microorganisms, the excess sludge that must be disposed of is minimal. Some industrial wastes that are high in BOD can be stabilised very efficiently by ACP. This process has been used successfully for the stabilisation of meatpacking and other high-strength soluble wastes.

\subsubsection{Anaerobic attached-growth treatment processes}

Anaerobic processes can also be conducted in biofilm configurations, although this is not very common. The two most common anaerobic attached-growth treatment processes are the anaerobic filter and the expanded-bed processes.

a) Anaerobic filter process: This is a column filled with several types of solid media used for the treatment of the carbonaceous organic matter in wastewater. The waste flows upward through the column, containing the media on which anaerobic bacteria grow and are retained. Because the bacteria are retained on the media and not washed off in the effluent, mean cell-residence times on the order of 100 days can be obtained. The anaerobic filter can be used for the treatment of low-strength wastes at ambient temperature.

b) Expanded-bed process: In this process, wastewater is pumped upward through a bed of sand, coal or expanded aggregate on which the biofilm grows. Effluent is recycled to dilute the incoming waste and to provide an adequate flow to maintain the bed in an expanded condition. Since a large biomass can be maintained, the expanded-bed process can also be used for the treatment of municipal wastewater at very short hydraulic detention times. When treating municipal wastewater, the presence of sulphate can lead to the formation of hydrogen sulphide. The expanded-bed process has the advantage of producing considerably less quantity of sludge than that produced in aerobic systems, such as the activated-sludge process.

\subsection{Lagoons and stabilisation ponds}

These are artificial lakes or basins primarily designed and built to treat wastewater. They usually have depths of 0.8 to $2.5 \mathrm{~m}$ (Myers, 1998, p.85). For industrial purposes lagoons and ponds will normally be accompanied by unit processes (e.g. filtration, airflotation, micro-staining, mechanical aeration, etc.) to upgrade the quality of effluent from the lagoons/ponds. Lagoons/ponds may be aerobic, anaerobic or facultative (i.e., surface aerobic, subsurface anaerobic). In hot climates, lagoons may not only provide settlement of solids, but also biological treatment, and micro-organisms can be destroyed by the action of ultraviolet rays in sunlight.

\subsection{Flow equalisation}

Flow equalisation is a process of damping of flowrate variations so that a constant or nearly constant flowrate is achieved. This is used to overcome operational problems caused by flowrate variations especially in biological treatment processes. 


\subsection{Chemical precipitation}

Chemical precipitation involves the addition of chemicals to alter the physical state of dissolved and suspended solids in order to facilitate their removal by sedimentation. Chemical processes in conjunction with various physical operations have been developed for the complete secondary treatment of wastewater including removal of nutrients.

\subsection{Neutralisation}

Neutralisation involves the addition of chemicals (e.g. lime or calcium hydroxide solution, hydrochloric or sulphuric acid) to correct the $\mathrm{pH}$ (acidity or alkalinity) of wastewater.

\subsection{Disinfection}

Disinfection refers to the selective destruction of micro-organisms that may cause diseases. It is different from sterilisation. Sterilisation is the destruction of all organisms while all the organisms are not destroyed in the disinfection process. Several chemical compounds have been used as disinfectant. Examples include chlorine and its compounds, bromine, iodine, ozone, phenol and phenolic compounds, alcohols, heavy metals and related compounds, soaps and synthetic detergents, quaternary ammonium compounds, hydrogen peroxide and various alkalis and acids. Chlorine is the most used disinfectant in the world. The most common chlorine compounds used in wastewater treatment plants are Chlorine gas $\left(\mathrm{Cl}_{2}\right)$, Calcium hypochlorite $\mathrm{Ca}(\mathrm{OCl})_{2}$, Sodium hypochlorite $(\mathrm{NaOCl})$, and Chlorine dioxide $\left(\mathrm{ClO}_{2}\right)$.

Calcium and Sodium hypochlorite are most often used in treatment plants due to their simplicity and safety. Chlorine dioxide has proved to be more efficient in achieving inactivation of viruses than chlorine. However, chlorine dioxide is an unstable and explosive gas; and for this reason, it is usually generated on site when needed.

\section{ADVANCED/TERTIARY WASTEWATER TREATMENT}

Advanced wastewater treatment is usually an improvement on the secondary treatment by employing relatively sophisticated or complex physico-chemical processes that would not be normally applied in the course of the conventional biological/secondary treatment. The advanced physico-chemical processes are used to remove suspended matter that cannot be stabilised easily (e.g. nitrogen, chromium, phenols, etc.). Examples of such processes include chemically assisted sedimentation, mixed media filtration, adsorption, and ozonation. Physico-chemical processes may be preceded by biological treatment to enhance their effectiveness or may be used after biological treatment to meet specific discharge limits (UNEP, 1993, p.59). Advanced wastewater treatment process may also include granular-medium filtration, microscreening and membrane processes such as microfiltration, ultrafiltration, nanofiltration, reverse osmosis and electrodialysis. 
Principal physical and chemical processes for nitrogen removal are air stripping, breakpoint chlorination and selective ion exchange. The addition of certain chemicals to wastewater produces insoluble or low-solubility salts when combined with phosphate. The principal chemicals used for this purpose are alum, sodium aluminate, ferric chloride or sulphate and lime. Ferrous sulphate and ferrous chloride, available as by-products of steel-making operations (pickle liquor), are also used. Besides, polymers have been used effectively in conjunction with alum and lime as flocculant aids. 


\section{SAMENVATTING}

De relatie tussen technologie en milieu is onderwerp geweest van vele studies over technologie als bron van en oplossing voor milieuproblemen. De bestaande theorie en empirische studies op dit gebied zijn grotendeels gebaseerd op scenario's en case studies in ontwikkelde landen. Systematische studies in, vooral Afrikaanse, ontwikkelingslanden zelf zijn zeldzaam. Deze studie draagt ertoe bij deze kenniskloof te overbruggen aan de hand van een analyse van productiebedrijven in Nigeria. In dit proefschrift probeer ik antwoord te geven op twee belangrijke vragen:

1) Wat zet bedrijven in ontwikkelingslanden, en dan voornamelijk die in Nigeria, ertoe aan milieuvriendelijke technologieën toe te passen?

2) Welke implicaties hebben de factoren die van invloed zijn op de toepassing van milieuvriendelijke technologiee̊n voor het beleid met betrekking tot duurzame industriële ontwikkeling, en met name tot de vermindering van watervervuiling?

In dit proefschrift wordt met 'milieutechnologieën' bedoeld die technologische artefacten, maatregelen en kennis, die bijdragen aan de vermindering of eliminatie van negatieve externaliteiten van productiebedrijven. We hebben ons daarbij echter beperkt tot de bestudering van industrieel afvalwatervervuiling om het onderzoek beheersbaar te houden. Bovendien is dit een gebied waar ontwikkelingslanden eerst ervaring opdoen met de milieureguleringen en -management voordat zij overgaan tot de effectieve aanpak van andere soorten industriële vervuiling (zie Dasgupta et al, 1998 , p. 3; Hettige et al, 2000, p. 455). Dit is begrijpelijk omdat vervuiling door industrieel afvalwater in veel ontwikkelingslanden een directe bedreiging vormt voor de volksgezondheid (zie The Economist, 21 maart 1998; Rosegrant, 1999).

Wij hebben daartoe de voedingsmiddelen- en de textielsector nader onder de loep genomen. Voor deze twee sectoren is gekozen omdat ze algemeen worden beschouwd als sectoren die in grote mate watervervuiling veroorzaken. Daarnaast gaat het in deze sectoren om grotendeels van oudsher laagwaardige bedrijven waar ontwikkelingslanden aanzienlijke technologische vaardigheden in bezitten. Bovendien dragen deze twee sectoren significant bij aan de productie in Afrika landen ten zuiden van de Sahara; voor ten minste tweevijfde van de industriële toegevoegde waarde in de meeste landen waar zij in aanzienlijke aantallen voorkomen.

De theoretische onderbouwing van dit proefschrift stoelt op vier wetenschapsgebieden binnen de economie. Ten eerste de studie van de diffusie en toepassing van normale technologische bedrijfsinnovaties, waarin uiteengezet wordt waarom bedrijven overgaan tot de toepassing van technologieën. Ten tweede, het 'mainstream' economisch denken met betrekking tot de afweging van bedrijven tussen de bedrijfskosten van het naleven van milieureguleringen en de maatschappelijke kosten die voortkomen uit productieactiviteiten van bedrijven. Ten derde, de inzichten in de bedrijfseconomie dat de kosten als gevolg van milieuregulering worden gemitigeerd 
door zogenoemde 'innovation effects', dat wil zeggen technologische innovaties die een compensatie vormen voor de bedrijfskosten van het naleven van de reguleringen. Ten vierde de evolutionaire kijk op de economie van technologische innovatie met betrekking tot de relatie tussen technologische competenties op bedrijfsniveau en de toepassing van technologieën. Op basis van de inzichten die zijn opgedaan aan de hand van deze groepen in de literatuur, hebben wij een theoretisch kader ontwikkeld voor de empirische analyse. In het model worden twee drijfveercategorieën voor milieuvriendelijke technologieën gedefinieerd. De eerste is het milieubeleidregime waaronder bedrijven opereren; dit wordt in dit proefschrift de primaire drijfveer voor milieutechnologieën genoemd. De tweede categorie omvat factoren die betrekking hebben op technologische competenties op bedrijfsniveau, bedrijfskenmerken, en de implementatie van reguleringen. We verwijzen hiernaar met de term secundaire drijfveren voor de toepassing van milieutechnologieën. Ook hebben we onderscheid gemaakt in de wijze waarop bedrijven in technologische zin reageren op de primaire of secundaire drijfveer(-veren): doen zij dit met als doel de vervuiling te verminderen ('technology response for pollution abatement', afgekort tot TPA) of door de vervuiling te voorkomen ('technology response for pollution prevention' of TPP)? De centrale hypothese in het analytische kader, ofwel de 'primaire versus secundaire drijfveer'-hypothese luidt dat 'in ontwikkelingslanden waar het milieubeleid algemeen als relatief zwak wordt beschouwd, de secundaire drijfveren voor de toepassing van milieutechnologieën in de productieindustrie als stimuli voor milieubeleid even belangrijk zijn als (of zelfs belangrijker dan) stimuli voor milieutechnologische veranderingen.'

Om de validiteit van deze hypothese empirisch te testen, zijn vervolgens negen subhypotheses ontwikkeld. Twee hiervan hebben betrekking op milieubeleid als primaire drijfveer voor de toepassing van milieutechnologieën, de overige zeven op de secundaire drijfveren. De data voor de empirische analyses zijn voor het grootste deel verkregen uit een survey van bedrijven in de twee genoemde sectoren, bedrijfsinterviews, een survey van Nigeriaanse milieureguleringen, interviews met directeuren van de Nigeriaanse milieubeschermingsbureaus, en secundaire informatie van het Nigeriaanse ministerie van milieu, milieubeschermingsbureaus van de staat, het bureau voor de statistiek, en de vereniging van productiebedrijven, alle in Nigeria.

De resultaten van deze studie leveren in twee opzichten een belangrijke bijdrage aan kennis. In de eerste plaats wordt in het theoretische kader dat werd ontwikkeld een grensverleggend milieubeleid voorgesteld als stimulus voor milieutechnologische veranderingen die de negatieve milieuexternaliteiten van productiebedrijven verminderen of elimineren. Hoewel ons model vasthoudt aan milieubeleid als een belangrijke determinant van de investering van bedrijven in milieutechnologieën, toont het aan dat ook niet-milieuregulerende factoren in belangrijke mate investeringen in milieutechnologieën kunnen stimuleren, vooral in ontwikkelingslanden waar sprake is van relatief zwakke regulerende maatregelen. In de tweede plaats zijn in dit proefschrift de resultaten neergelegd van een baanbrekend onderzoek naar de technologische antwoorden op milieuregulaties door productiebedrijven in Afrikaanse landen ten zuiden van de Sahara. Met dit onderzoek 
is aangetoond dat bedrijven in Afrika in staat zijn zich bezighouden met technologische innovaties ter vermindering van industriële vervuiling, en deze ook daadwerkelijk toepassen.

Dit proefschrift toont aan dat Nigeria beschikt over een goedgestructureerd systeem voor de aanpak van industriële vervuiling. Het is echter gebleken dat de institutionele capaciteit voor milieureguleringen deficiènt is als het gaat om mankracht en infrastructuur om effectief te kunnen controleren of bedrijven zich ook aan de reguleringen houden. Afgezien van de relatief goed-geoutilleerde laboratoria voor industrieel afvalwateranalyses, wordt de handhaving beperkt door een onvoldoende aantal beschikbare ambtenaren en onvoldoende technische opleidingsprogramma's gericht op de vermindering van industriële vervuiling. Bovendien wordt het gebrek aan motorvoertuigen ten behoeve van de controle gezien als de belangrijkste infrastructurele beperking voor de handhaving van milieuregels.

Dit onderzoek toont aan dat Nigeriaanse bedrijven actief gebruiken maken van conventionele end-of-pipe technologieën, d.w.z. zuiveringsinstallaties voor industrieel afvalwater, om de negatieve externaliteiten van industrieel afvalwater te verminderen. Ook is bewezen dat de bedrijven procesgerelateerde of -geïntegreerde technieken gebruiken om afvalwater bij de bron te verminderen. Onze analyses laten zien dat het grotendeel van de secundaire en tertiaire afvalwaterzuiveringsinstallaties in gebruik werden gesteld na het driejarig moratorium om te voldoen aan de Nigeriaanse milieureguleringwet, S.I.8/S.I.9, die in augustus 1991 werd ingesteld. Met andere woorden, deze wet heeft effectief geleid tot de toepassing van milieutechnologieën met betrekking tot de vermindering van de vervuiling door industrieel afvalwater. Helaas zijn dergelijke positieve effecten niet direct waargenomen voor de toepassing van technologieën die vervuiling door industrieel afvalwater aan de bron aanpakken, vooral onder de textielbedrijven. Ook is vastgesteld dat beslissingen van multinationals (MNEs) om over te gaan op milieutechnologieën niet significant beïnvloed werden door de S.I.8/S.I.9-wet. De resultaten van de casestudie geven aan dat de internationale norm of het milieubeleid van de moederbedrijven een belangrijke rol hebben gespeeld bij de beslissing van de dochterbedrijven om in milieutechnologieën te investeren.

Ook is uit de resultaten gebleken dat de belangrijkste belemmering voor bedrijven om over te gaan tot de toepassing van schone technologieën is gelegen in de hoge kosten ervan. In het algemeen zijn het gebrek aan informatie over schone technologieën, het gebrek aan technische capaciteit, onzekerheid over de invloed van de toepassing van milieuvriendelijke technologieën op het competitief vermogen, en het gebrek aan liquide middelen voor investeringen in technologie geen belangrijke hindernissen voor toepassing voor bedrijven. Bedrijven in de textielsector blijken echter het gebrek aan informatie over milieutechnologieën en het gebrek aan geldmiddelen wel als belangrijke hindernissen voor toepassing te zien. We vermoeden dat dit samenhangt met de relatief strengere technologievereisten vanuit milieuoogpunt voor de textielindustrie, en de daarmee gepaard gaande hogere kosten voor het installeren en in bedrijf houden van technologieën ter vermindering van vervuiling. 
We hebben een logit-regressieanalyse uitgevoerd om de onderzoekshypothesen te testen. De regressieresultaten tonen dat wanneer we kijken naar EBT (alle milieusparende oplossingen samen), milieubeleid een significante primaire drijfveer voor toepassing blijkt te zijn. Hoewel secundaire drijfveervariabelen zoals de eigendomstructuur, bedrijfsgrootte, en de beleidsimplementatiestrategie evenzeer significant blijken te zijn, is de significantie van milieubeleid het grootst. $\mathrm{Na}$ het isoleren van de invloed van de primaire en secundaire drijfveren op TPA, bleek dat de milieubeleidvariabele een significante invloed heeft op de toepassing van TPA, maar niet voldoende invloed om de rol van primaire drijfveer voor de toepassing van TPA toebedeeld te krijgen. Gebleken is dat secundaire drijfveren zoals eigendomstructuur van het bedrijf, bedrijfsgrootte, en het menselijk kapitaal van interne capaciteit voor innovatie (het percentage van het personeel dat een hogere opleiding genoten heeft), en beleidsimplementatiestrategie belangrijker zijn dan milieubeleid als stimuli voor de toepassing van TPA als we kijken naar de statistische significantie. Zo is ook gebleken dat, wanneer de invloed van de belangrijkste en secundaire drijfveren m.b.t. de toepassing van TPP werd geïsoleerd, milieubeleid geen primaire drijfveer voor de toepassing van TPP is. Hoewel milieubeleid significant is als determinant voor TPPtoepassing, blijken secundaire drijfveervariabelen zoals bedrijfsgrootte, het menselijk kapitaalaspect van de interne capaciteit voor innovatie (het percentage van het personeel dat een hogere opleiding genoten heeft), en de eigendomsstructuur van een bedrijf significanter te zijn. Uit deze resultaten blijkt dat analyses gericht op milieutechnologieën zonder onderscheid te maken in het type technologie, de verkeerde indruk geven dat milieubeleid de primaire drijfveer voor de toepassing van ETB is. Zoals echter voor alle beleidsbeslissingen geldt, moet hier benadrukt worden dat het onderscheiden van technologietypes (TPA of TPP) voor vervuilingsvermindering heeft aangetoond dat de secundaire drijfveren een veelheid van factoren kunnen vormen die de toepassing door bedrijven van EBT redelijkerwijs meer verbeteren dan milieubeleid zou doen.

Een aantal belangrijke beleidsimplicaties zijn uit deze studie naar voren gekomen. Door beleidsmaatregelen gericht op het stimuleren van multinationale investeringen in productie, zoals foreign direct investment (FDI)-beleid of divestment die het buitenlands eigendomaandeel in productiebedrijven kunnen vergroten, zullen investeringen in milieutechnologieën toenemen. Hoe groter het bedrijf, hoe groter de kans dat het bedrijf betere milieumaatregelen neemt. Zo kunnen ook beleidsmaatregelen die grootschalige greenfield productieinvesteringen stimuleren, of de groei van bestaande kleine en middelgrote bedrijven in grootschalige productiebedrijven de toepassing van EBT bevorderen. De resultaten wijzen er verder op dat technologiebeleid ter bevordering van interne technische competenties in productiebedrijven, bedrijven onbedoeld ook stimuleren te investeren in milieutechnologie. In dit opzicht zou technologiebeleid gericht moeten zijn op het bevorderen van de beschikbaarheid van hoogopgeleid technisch personeel voor productiebedrijven. In het geval van Nigeria is aangetoond dat het personeel van bedrijven (met inbegrip van dochterbedrijven van multinationals) grotendeels afkomstig is van de lokale gemeenschap. De resultaten geven ook aan dat 
implementatiestrategie van milieubeleid een bepalende factor is voor bedrijven om over te gaan tot de toepassing van EBT. Wat betreft Nigeria is gebleken dat wanneer handhavers een coöperatieve strategie toepassen met betrekking tot milieuwetten, bedrijven deze eerder zullen naleven, vooral waar het gaat om TPA (zuiveringstechnologieën voor industrieel afvalwater). Dit is vooral van belang voor landen met een relatief moeilijke economische omgeving zoals Nigeria. Regulerende overheden die hiervoor begrip tonen, zouden eerder een stimulerende dan een afschrikkende rol kunnen spelen bij de toepassing van EBT.

Verder blijkt uit de resultaten van de case studie dat zuiveringsinstallaties voor industrieel afvalwater die voldoen aan de regulerende vereisten voor de kwaliteit van afvalwater geïmporteerde technologieën zijn. Ook de chemicaliën voor de zuivering van afvalwater zijn grotendeels geïmporteerd. Het R\&D-beleid met betrekking tot technologie voor de vermindering van vervuiling door industrieel afvalwater in Nigeria zou zich vooral moeten richten op de verbetering van de technische doelmatigheid van lokaal ontworpen (en gebouwde) zuiveringsinstallaties voor industrieel afvalwater en de ontwikkeling van lokale (of minder dure) vervangende chemicaliën voor de zuivering van afvalwater. Daarnaast laten de case studies zien, met mogelijke uitzondering van één van de twaalf bedrijven, dat er over het algemeen gebrek is aan goed uitgesponnen programma van schonere productie binnen Nigeriaanse bedrijven. Het huidige Nigeriaanse milieubeleid legt de nadruk op TPA (end-of-pipe)-oplossingen voor problemen veroorzaakt door industrieel afvalwater, en in het Nigeriaanse industrie-technologiebeleid (o.a. FMST, 1986; FMI, 1988) is tot nu toe geen melding gemaakt van schonere productie als onderdeel van het technologiebeleid. Dit proefschrift heeft echter bewezen dat ten minste een deel van de bedrijven toch overgaat tot de toepassing van TPP; de vooruitzichten voor programma's gericht op schonere productie in de Nigeriaanse productieindustrie zijn dan ook goed te noemen. Zowel het milieu- als het technologiebeleid zou zich moeten richten op milieutechnologische veranderingen die leiden tot een regime van schonere productie in Nigeriaanse bedrijven. Deze inzichten volgen uit de studie, die in theoretische zin bovendien een bijdrage levert aan de innovatie-effecten van milieubeleid. 


\section{Curriculum Vitae}

John Adeoti was born on 19 October 1962 in Omu-Aran, Nigeria and had his secondary school education at Barewa College, Zaria, Nigeria. Thereafter, he proceeded to the University of Ife (now Obafemi Awolowo University), Nigeria, where he obtained his B.Sc. degree in civil engineering in 1985. In 1991, he completed his M.Sc. degree programme in industrial engineering at the University of Ibadan, Nigeria. He also obtained an M.A. in development studies at the University of Bremen, Germany in 1995. John worked briefly on maintenance of civil engineering facilities at a Nigerian military barrack before joining the Nigerian National Directorate of Employment (NDE) as a pioneering project officer in June 1987. For more than ten years, he was involved in the execution and management of small and medium-scale enterprise (SME) development projects in Nigeria. He was at various times head of department of vocational skills development department and the inspectorate department at the Oyo State office of the NDE, Ibadan, Nigeria. Since 1992, he has also studied and researched into SME development problems in subSaharan Africa. 

